\title{
The adolescent girls vulnerability index: Guiding strategic investment in Uganda
}

\author{
Sajeda Amin \\ Population Council \\ Karen Austrian \\ Population Council \\ Michelle Chau \\ Population Council \\ Kimberly Glazer \\ Population Council \\ Eric P. Green
}

See next page for additional authors

Follow this and additional works at: https://knowledgecommons.popcouncil.org/departments_sbsr-pgy

Part of the Demography, Population, and Ecology Commons, Family, Life Course, and Society

Commons, Gender and Sexuality Commons, International Public Health Commons, and the Medicine and

Health Commons

How does access to this work benefit you? Let us know!

\section{Recommended Citation}

Amin, Sajeda, Karen Austrian, Michelle Chau, Kimberly Glazer, Eric P. Green, David Stewart, and Marie Stoner. 2013. "The adolescent girls vulnerability index: Guiding strategic investment in Uganda." New York: Population Council. 


\section{Authors}

Sajeda Amin, Karen Austrian, Michelle Chau, Kimberly Glazer, Eric P. Green, David Stewart, and Marie Stoner

This report is available at Knowledge Commons: https://knowledgecommons.popcouncil.org/departments_sbsr-pgy/ 


\section{THE ADOLESCENT GIRLS VULNERABILITY INDEX GUIDING STRATEGIC INVESTMENT IN UGANDA}
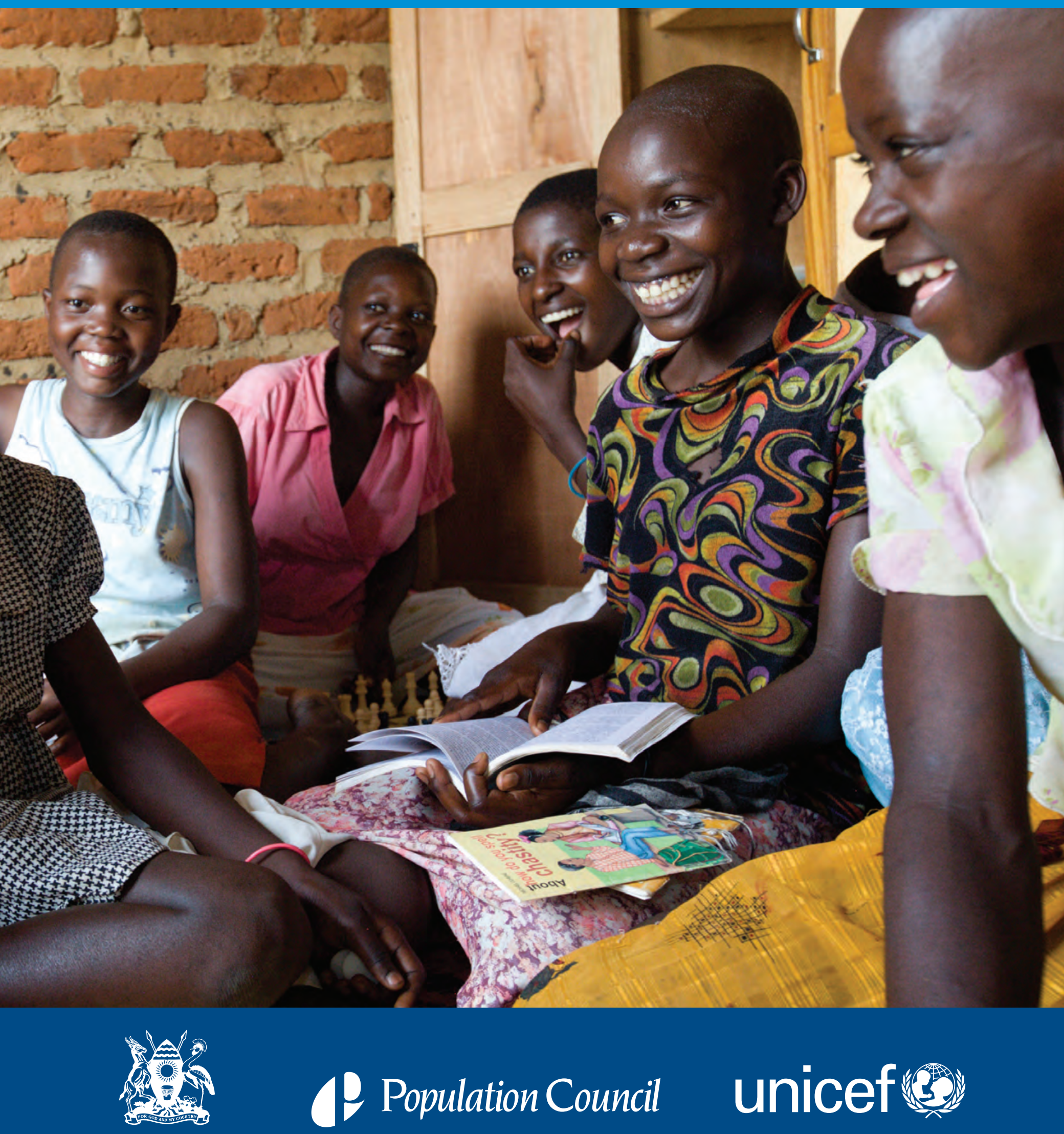



\section{THE ADOLESCENT GIRLS VULNERABILITY INDEX GUIDING STRATEGIC INVESTMENT IN UGANDA}




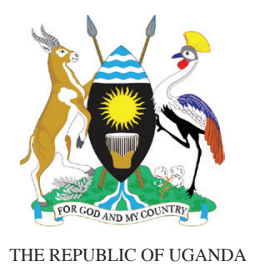

The Ministry of Gender, Labour and Social Development is the Government of Uganda's leading and coordinating agency for the Social Development Sector. The Ministry is responsible for community empowerment, protection and promotion of the rights of vulnerable groups in society and gender responsive development. The Ministry's mandate is to empower communities to harness their potential through cultural growth, skills development and labour productivity for sustainable and gender responsive development.

\section{unicef}

UNICEF is mandated by the United Nations General Assembly to advocate for the protection of children's rights, to help meet their basic needs and to expand their opportunities to reach their full potential. We are guided by the Convention on the Rights of the Child and strive to establish children's rights as enduring ethical principles and international standards of behaviour towards children. Through our country programmes, we work to promote the equal rights of women and girls and to support their full participation in the political, social, and economic development of their communities.

\section{(P) Population Council}

The Population Council confronts critical health and development issues-from stopping the spread of HIV to improving reproductive health and ensuring that young people lead full and productive lives. Through biomedical, social science, and public health research in 50 countries, we work with our partners to deliver solutions that lead to more effective policies, programs, and technologies that improve lives around the world. Established in 1952 and headquartered in New York, the Council is a nongovernmental, nonprofit organization governed by an international board of trustees.

Suggested citation: Amin, S., Austrian, K., Chau, M., Glazer, K., Green, E., Stewart, D., and Stoner, M. (2013). Adolescent Girls Vulnerability Index: Guiding Strategic Investment in Uganda. New York: Population Council.

(c) 2013 The Population Council, Inc.

Population Council

One Dag Hammarskjold Plaza

New York, NY 10017 USA

http://www.popcouncil.org

Cover photo: BRAC/Jake Lyell.

Any part of this publication may be copied or adapted to meet local needs without permission, provided that the parts copied are distributed free or at cost (not for profit) and that the source is identified. We would appreciate receiving a copy of any materials in which the text is used. 


\section{Contents}

List of tables

List of figures

List of acronyms

Acknowledgements

Foreword

Executive summary

\section{Introduction}

1.1. Demographics: Adolescents, population projections, and benefiting from the youth bulge

1.2 Why adolescent girls?

1.3. The vulnerabilities of adolescent girls in East and Southern Africa

1.4. Conclusion

2. Developing an Adolescent Girls Index

2.1 Putting the AGI in context

2.2 Creating the index

\section{Index results}

3.1 Uganda

3.2 Regional index results

3.3 Limitations

3.4 Conclusions

\section{Program analysis}

4.1 What is a coverage exercise?

$\begin{array}{ll}4.2 \text { Results } & 69\end{array}$

4.3 Discussion 74

$\begin{array}{ll}\text { 5. Policy analysis } & \mathbf{7 5}\end{array}$

5.1 Introduction 76

5.2 Methods 76

5.3 Policy review $\quad 76$

5.4 Policy areas in the context of the Adolescent Girls Multilevel Vulnerability Index 81

5.5 Review of policy areas not covered by the AGI 87

5.6 Barriers to policy implementation

5.7 Policy analysis: Regional assessment $\quad 94$

5.8 A note on national youth policies 98

\section{Conclusions 103}

6.1 Program and policy recommendations in the context of the AGI 104

6.2 Investing in girls and the role of the AGI $\quad 112$

$\begin{array}{ll}\text { 7. References } & 113\end{array}$

$\begin{array}{ll}\text { 8. Appendices } & 121\end{array}$

Appendix I. Participatory assessment $\quad 122$

$\begin{array}{ll}\text { Appendix II. Suggestions for additional survey topics } & 128\end{array}$

$\begin{array}{ll}\text { Appendix III. Forms } & 129\end{array}$ 
1 Percentage of adolescents aged 10-19 living in the two poorest wealth quintiles, East and Southern Africa

2 Ratio of girls to boys who report attending school at any time during current year, by age group, in East and Southern Africa

3 Percentage of adolescent girls who attended school at any time during current year, in Uganda, by age and region, 2006 and 2011

4 Percentage of adolescent girls, by school categories and age groups, East and Southern Africa

5 Percentage of adolescent girls aged 10-14, by schooling categories and region, Uganda, 2006 and 2011

6 Percentage of adolescent girls aged 15-19, by schooling categories and region, Uganda, 2006 and 2011

7 Distribution of characteristics within school categories of adolescent girls, Uganda, 201

8 Literacy rates among adolescents aged 15-19 and ratio of literate girls to boys, East and Southern Africa

9 Literacy rates of adolescent girls aged 15-19 by educational categories, Uganda, 2011

10 Percentage of adolescent boys and girls aged 15-19 by school and employment status, East and Southern Africa

11 Percentage of adolescent boys and girls aged 15-19 by school and employment status, Uganda, 2011

12 Percentage of adolescents aged 15-19 who have ever had sex, East and Southern Africa

13 Percentage of adolescent girls in Uganda aged 15-19 who have ever had sex, are sexually active, and have had high-risk sex, by characteristics, 2011

14 Sexual behaviors among adolescents in Uganda, by percent and region, 2011

15 Contraceptive use among adolescents aged 15-19 who have ever had sex, Uganda

16 Percentage of female and male adolescents in Uganda aged 15-24 who are HIV-positive, 2005 and 2011

17 Percentage of female and male adolescents in Uganda aged 15-24 who are HIV-positive, by region

18 Percentage of adolescents aged 15-19 who know the following HIV prevention methods, East and Southern Africa

19 Percentage of adolescents aged 15-24 with comprehensive knowledge of HIV/AIDS in Uganda

20 Percentage of adolescent girls in Uganda aged 15-19 who are currently married, by region, educational attainment, and wealth quintile, 2006 and 2011

21 Percentage of adolescent girls in Uganda aged 15-19 who are currently pregnant or have ever given birth, by region, marital status, and educational attainment, 2006 and 2011

22 Vulnerability indices

23 Indicator topics available for inclusion in the Adolescent Girls Multilevel Vulnerability Index

24 Complete list of individual indicators considered for inclusion in the $\mathrm{AGI}$

25 Complete list of household indicators considered for inclusion in the AGI
26 Adolescent Girls Multilevel Vulnerability Index: Levels and indicators

27 Comparisons of $A G I$ rankings to other wealth and development indices, by country

28 Percentage of adolescent girls aged 10-19 with multilevel vulnerability and percentage who are vulnerable at each level, East and Southern Africa

29 Percentage of adolescent girls aged 10-19 with multilevel vulnerability and percentage who are vulnerable at each level, by region, Uganda

30 Percentage of adolescent girls aged 10-14 and 15-19 with multilevel vulnerability and percentage who are vulnerable at each level, by region, Uganda

31 Household-level results for girls aged 10-19 by wealth quintile within Kampala, Uganda

32 AGI community-level results for adolescent girls aged 10-19, Uganda

33 AGI results for East and Southern Africa, by age group

34 AGI community-level results for adolescent girls aged 10-19, East and Southern Africa

35 Sample size

36 First-stage selection district allocation

37 Ladder questions asked of subcounty officials

38 Average number of eligible programs for adolescents per subcounty, by region, Uganda

39 Total number of adolescent programs, by region, Uganda

40 Subcounty officials' comparisons of program quality to other subcounties in the district and nation, Uganda

41 Distribution of program type and content

42 Average percentage of program participants, by sex and region, Uganda

43 Average percentage of program participants, by age group and region, Uganda

44 Percentage of programs that are co-ed, girls-only, or boys-only, by region

45 Descriptive statistics and comparisons to Uganda DHS 2011

46 Weighted and unweighted participants and encounters, by age and sex

47 Predictors of days attended (encounters) and attendance rate

50 List of policies by AGI indicators

51 Additional policies reviewed: Gender-based violence and sexual exploitation, participation, employment and entrepreneurship, and property rights

52 List of policies by country

A1 Location, number and type of each discussion group

A2 Frequency of the top nine issues, by age group, all groups 


\section{LIST OF FIGURES}

1 The changing context of development-The second decade of life is becoming more important

2 Percentage of population who are adolescents (aged 10-19), East and Southern Africa

3 Uganda: Alternative population projections for 2005-2050 and population growth components

4 Percentage of population who are working age (15-64): Estimates and projections in Uganda, sub-Saharan Africa, less developed world, and the world, 1950-2100

5 Multilevel model for vulnerability

6 Proportion of adolescents aged 10-19 by region, Uganda, 2011

7 Percent of adolescents aged 10-19 living in households with no improved or with shared sanitation, East and Southern Africa

8 Percent of adolescents aged 10-19 living in households with no improved water source, East and Southern Africa

9 Percent of adolescents aged 10-19 living in households without access to improved water and without access to improved or with shared sanitation, in Uganda, by region, 2006 and 2011

10 Percentage of adolescents aged 10-19 living in each wealth quintile, Uganda, 2011

11 Percentage of adolescents aged 10-19 living with a household head with no education, East and Southern Africa

12 Percentage of adolescents aged 10-19 living in households where the head of household has no education, Uganda, 2006 and 2011

13 Percentage of adolescents aged 10-14 living without either biological parent in the household, East and Southern Africa

14 Percentage of adolescents in Uganda aged 10-14 living without either biological parent in the household, by region, 2006 and 2011

15 Percentage of adolescent girls and boys aged 10-14 who reported attending school any time during current year, East and Southern Africa

16 Percentage of adolescent girls and boys aged 15-19 who reported attending school any time during current year, East and Southern Africa

17 Percentage of adolescent girls aged 15-19 who have not attended any secondary school, East and Southern Africa

18 Percentage of adolescent girls in Uganda aged 15-19 who have not attended any secondary school, by region, 2006 and 2011

19 Percentage of adolescent girls aged 15-19 who are literate by percentage who report attending school at any time during the current school year, East and Southern Africa

20 Percentage of adolescent girls in Uganda living in communities where women aged 20-49 have literacy rates below the mean for women in that age group

21 Percentage of adolescent girls in Uganda aged 15-19 who are literate, by region, 2011

22 Percentage of adolescent girls in Uganda aged 15-19 who are neither in school nor employed, by region, 2006 and 2011
23 Percentage of adults 15-49 who are HIV-positive, East and Southern Africa

24 Percentage of female and male adolescents in Uganda aged 15-24 who are HIV-positive, by age group

25 Percentage of females and males aged 20-24 who were married by age 18, East and Southern Africa

26 Percentage of adolescent girls aged 10-14 and 15-19 living in communities where rates of child marriage among women aged 20-49 exceed the national average, Uganda

27 Percentage of adolescent girls aged 15-19 who are ever-married, East and Southern Africa

28 Percentage of adolescent girls aged 15-19 who have ever given birth, Eastern and Southern Africa

29 Indicators at each level

30 Cutoffs at each level

31 Percentage of adolescent girls aged 10-19 vulnerable at each AGI level, by region, Uganda

32 Percentage of adolescent girls aged 10-19 vulnerable at each AGI level, Uganda, 2006 and 2011

33 Percentage of vulnerable adolescent girls aged 10-19, by region, Uganda, 2006 and 2011

34 AGI multilevel vulnerability (3-levels) results for adolescent girls aged 10-19, Uganda

35 AGI results for girls aged $10-19$ by wealth quintile within Kampala, Uganda

36 Percentage of adolescent girls aged 10-14 and 15-19 who are extremely vulnerable, by region, Uganda

37 AGI individual-level results for adolescent girls aged 10-14, Uganda

38 AGI individual-level results for girls aged 15-19, Uganda

39 AGI household-level results for girls aged 10-19, Uganda

40 Percentage of adolescent girls aged 10-19 who are extremely vulnerable, East and Southern Africa

41 AGI individual-level results for girls aged 10-14, East and Southern Africa

42 AGI individual-level results for adolescent girls aged 15-19, East and Southern Africa

43 AGI household-level results for adolescent girls aged 10-19, East and Southern Africa

44 Data that inform policies and programs for adolescents

45 Random selection of districts in Uganda, and subcounties within districts

46 Self-reported program demographics

47 Total days attended (encounters) and mean attendance rate, by age

48 Map of catchment areas around a subset of participating programs

49 Exclusion of the most disadvantaged girls from community services and resources

50 Connecting sub-groups of girls to community resources

A1 Frequency of all issues, by age group, all groups

A2 Frequency of school dropout, pregnancy, and marriage, by age group, all groups

A3 Frequency of the top nine issues by age group, all groups 


\begin{tabular}{|c|c|c|c|}
\hline AGI & Adolescent Girls Multilevel Vulnerability Index & MICS & Multiple Indicator Cluster Surveys \\
\hline AIDS & Acquired Immune Deficiency Syndrome & MPI & Multidimensional Poverty Index \\
\hline BMI & Body Mass Index & NAADS & National Agricultural Advisory Services \\
\hline BTVET & $\begin{array}{l}\text { Business, Technical, Vocational Educational } \\
\text { Training }\end{array}$ & NCC & National Council for Children \\
\hline & & NPA & National Planning Authority \\
\hline CE & Coverage Exercise & OECD & Organisation for Economic Co-operation and \\
\hline CPDI & Child Poverty and Deprivations Index & & Development \\
\hline CRC & Convention on the Rights of the Child & OVC & Orphans and Other Vulnerable Children \\
\hline CSI & Child Status Index & OVC-MIS & $\begin{array}{l}\text { Management Information System for Orphans } \\
\text { and Other Vulnerable Children }\end{array}$ \\
\hline CSO & Community Service Organization & & \\
\hline CWI & Child and Youth Wellbeing Index & OVC-NIU & $\begin{array}{l}\text { Orphans and Other Vulnerable Children } \\
\text { National Implementation Unit }\end{array}$ \\
\hline DFCU & Development Finance Company of Uganda & PASDEP & $\begin{array}{l}\text { Plan for Accelerated and Sustainable } \\
\text { Development to End Poverty }\end{array}$ \\
\hline DHS & Demograpnic ana Heaitn surveys & PCA & Principal Components Analysis \\
\hline FDRE & $\begin{array}{l}\text { Disorganized Poverty } \\
\text { Federal Democratic Republic of Ethiopia }\end{array}$ & PQLI & Physical Quality of Life Index \\
\hline FGM/C & Female Genital Mutilation/Cutting & PPP & Purchasing Power Parity \\
\hline FOWODE & Forum for Women in Democracy & SGBV & Sexual and Gender-based Violence \\
\hline FY & Fiscal Year & STI & Sexually Transmitted Infections \\
\hline GBS & Go to school, Back to school, Stay in school & TAAAC & Tisundge Ana Akazi Coalition \\
\hline GBV & Gender-Based Violence & U5MR & Under-Five Mortality Rate \\
\hline GDP & Gross Domestic Product & UN & United Nations \\
\hline GEM & Girls Education Movement & UNDP & United Nations Development Programme \\
\hline GFA & Grade for Age & UNGEI & United Nations Girls' Education Initiative \\
\hline GNP & Gross National Product & UNRISD & $\begin{array}{l}\text { United Nations Research Institute for } \\
\text { Development }\end{array}$ \\
\hline HDI & Human Development Index & UPE & Universal Primary Education \\
\hline HIV & Human Immunodeficiency Virus & USAID & U.S. Agency for International Development \\
\hline HSSP & Health Sector Strategic Plan & USD & U.S. Dollar \\
\hline IEC & Information, Education, and Communication & VCT & Voluntary Counseling and Testing \\
\hline LC1 & Local Council Court & WHO & World Health Organization \\
\hline MDG & Millennium Development Goal & YFS & $\begin{array}{l}\text { Youth-Friendly Sexual and Reproductive } \\
\text { Health Services }\end{array}$ \\
\hline
\end{tabular}




\section{Acknowledgements}

The report was led by a Core Steering Committee chaired by Beatrice Ayikoru and Richard Ndiku of the Ministry of Gender, Labour and Social Development. The committee included Martin Kiiza, National Council for Children; Bylon Tumwesigye, Uganda Bureau of Statistics; and David Stewart, UNICEF.

The report benefited from the contributions of many individuals and institutions. The team thanks all those who provided their expertise and energy, in particular:

The National Advisory Committee: Ben Paul Mungyereza, Uganda Bureau of Statistics; Mondo Kyateka, Ministry of Gender, Labour and Social Development; James Kabagooza, Ministry of Gender, Labour and Social Development; Nathan Bwire, Ministry of Gender, Labour and Social Development; David Tumwesigye, Ministry of Gender, Labour and Social Development, Expanding Social Protection Programme; Rosemary Waya, Ministry of Education and Sports, Miriam Namugeere, Ministry of Health; Jacinta Sabiiti, Ministry of Health; David Wamai, Ministry of Finance, Planning and Economic Development; Fredrick Matyama, Ministry of Finance, Planning and Economic Development; Lucy Ladira, Justice, Law and Order Sector; Paul Gandeya, Justice, Law and Order Sector; Charles Zirarema, Population Secretariat; Seth Wambede, National Planning Authority; Lawrence Bategeka, Economic Policy Research Centre; Pierre de Galbert, USAID/International Youth Foundation Youth Map; Florence Kanyike, Girls Education Movement (GEM); Suzanne Ajok, Straight Talk Foundation; Miriam Mutabazi, USAID Straight Project; Dr. Florence Muhanguzi, School of Women and Gender Studies, MUK; Professor Grace Bantebya Kyomuhendo, School of Women and Gender Studies, MUK; Fred Matovu, Faculty of Economics and Management, Makerere University; Mattias Bryneson, Plan International Uganda; Natasha De Marken, US Agency for International Development; Barry Wojega, US Agency for International Development; Jessica Greenhalf, Restless Development (Uganda); Obert Pimhidzai, The World Bank; Alex Ouma, Uganda Investment Authority; Emmanuel Kitamirike, Uganda Youth
Network; Alex Warren, United Nations Development Programme; Brian Kironde, United Nations Population Fund; Teresa Del Ministro, Office of the UN Resident Coordinator, Uganda; Rachel Waterhouse, DFID Uganda; Carol Kego-Laker, Irish Aid in Uganda; Nicola Banks, BRAC Uganda; Munshi Sulaiman, BRAC Uganda; Diana Francisco, Save the Children in Uganda; and Daisy Muculezi, Save the Children in Uganda.

With special thanks for technical support on index construction: Sarah Kabaija, UNICEF; Bylon Tumwesigye, Uganda Bureau of Statistics; Ibrahim Kasirye, Economic Policy Research Centre; Frederick Mugisha, Ministry of Finance, Planning and Economic Development; Eria Hisali, Makerere University; Alex Warren-Rodriquez, United Nations Development Programme; Claudia Cappa, UNICEF NY; Martin Evans, UNICEF NY; Milorad S. Kovacevic, UNDP; and Nick Cooper, Harvard University.

A thanks to several international advisors who commented on earlier versions of the index and report: UNICEF: Claudia Cappa, Paula Claycomb, Judith Diers, Martin Evans, Claes Johannson, Marina Komarecki, Anju Malhotra, Mima Perisic, Eric Rodriguez. Human Development Report at UNDP: Eva Jespersen, Deputy Director; Milorad S. Kovacevic, Head of Unit, Statistical Unit; Harvard: Elizabeth Gibbons, Theresa Betancourt, Jennifer Leaning, Nick Cooper, Phuong Pham. International academic advisors: George Patton, University of Melbourne; and John Santelli, Columbia University.

Thanks to the ministry representatives and program staff from the following agencies who shared their knowledge of Ugandan adolescent policy and programming: Ministry of Gender, Labour and Social Development; Ministry of Education and Sports; Ministry of Health; Ministry of Finance, Planning and Economic Development; Justice, Law and Order Sector; Population Secretariat; National Planning Authority; Economic Policy Research Centre; USAID/International Youth Foundation Youth Map; Girls Education Movement; Straight Talk Foundation; USAID Straight Project; and UNICEF Uganda, Social Policy and Evaluation. A 
thanks to Jordan Levine for her assistance in the policy literature review.

A thanks to those who assisted in the program coverage exercise: Caesar Lubangakene, Pelegrino Turinawe, Julius Busiri, and Ruth Chebet.

A special thanks to those who contributed to the adolescent participatory assessment: the girls who shared their experiences and perspectives on adolescence in Uganda; Umbareen Kuddus, BRAC Uganda for coordinating the group sessions; Rashid Mwesigwa, Community Development Research Network; and research assistants, Brenda Nanyonga and Joan Ainembabazi.
A warm thanks to Population Council colleagues who made important contributions to the report: Judith Bruce for her critical insights on adolescent girls; Mark Montgomery for his technical advice on index construction; Christina Tse for coordinating the report production; Michael Vosika for design, layout and graphics; and Robert Heidel for copyediting.

Finally, a special thank you to UNICEF Uganda Representative, Sharad Sapra, who saw the importance of focusing on adolescents both for Uganda and UNICEF more generally, as well as the value of developing an Adolescent Girls Index to better understand their vulnerability.

\section{Authors:}

Sajeda Amin', Karen Austrian', Michelle Chau', Kimberly Glazer', Eric Green², David Stewart ${ }^{3}$, Marie Stoner

'Population Council 2Population Council (currently Duke Global Health Institute) ${ }^{3}$ UNICEF Uganda ${ }^{4}$ Population Council (currently University of North Carolina-Chapel Hill) 


\section{Foreword}

Adolescence (from the ages of 10 to 19) is a critical stage of human development during which children experience rapid social, physical, psychological, and emotional changes on the path from childhood to adulthood. The decisions that are made during this period of life affect not only the individual well-being of young people, but also the well-being of the entire society.

When household and community environments are positive, children will thrive during adolescence, move to adulthood with ease, and bring great benefits to the community. However, while adolescence is a time of having dreams and possibilities, it is also a time of confronting great risks, particularly for girls.

Girls face the possibilities of early childbirth and marriage, dropping out of school, and acquiring a variety of sexually transmitted infections, including HIV/AIDS. These consequences diminish the opportunities of adolescent girls and jeopardize their future.

It is evident from existing literature that ensuring that young people successfully navigate this stage of life can help break the cycle of poverty and produce great benefits for individuals, communities, and countries.

Therefore, investments to help young people make a smart and healthy transition into adulthood are directly related to achieving the Millennium Development Goals (MDGs), the National Development Plan (NDP) goals, and Vision 2040 goals. Helping young people complete their education can help to prevent unintended pregnancies and HIV/AIDS. At the same time, education allows them to accumulate skills that are relevant to the job market and starting an independent livelihood. In addition, investing in young people's sexual and reproductive health will help them make informed decisions about marriage and childbearing and prepare them to become the next generation of responsible parents.
The Adolescent Girls Vulnerability Index (AGI) has been developed based on a growing recognition of the need to channel resources to vital-and highly vulnerable and vastly underserved-populations of adolescent girls in Uganda specifically, and in East and Southern Africa in general.

The AGI aims to be a summary indicator that can serve as an advocacy tool to draw attention to adolescent girls. It is a tool that will inform policymaking and macro-level resource allocation and will be an instrument of planning and monitoring progress.

I do earnestly hope that you will find the Adolescent Girls Vulnerability Index Report useful in informing your strategic decisions as we work together for and with the adolescent girls of Uganda and other parts of the world.

\section{Moub.}

Mary Karooro Okurut

MINISTER OF GENDER, LABOUR AND SOCIAL DEVELOPMENT 



\section{Executive Summary}

\section{Increasing the Focus on Adolescent Girls}

The Adolescent Girls Multilevel Vulnerability Index (AGI) was developed based on a growing recognition of the need to channel resources to vital-yet highly vulnerable and vastly underserved-populations of adolescent girls in Uganda specifically, and the East and Southern Africa region in general. The AGI aims to be a summary indicator that can serve as an advocacy tool to draw attention to adolescent girls, a rigorous measure to inform decisions about policymaking and macro-level resource allocation, and an instrument for planning and monitoring progress. The project is a joint collaboration between the Government of Uganda, UNICEF, and the Population Council.

\section{A changing world where adolescents require increasing attention}

As outlined in The State of the World's Children 2011 , adolescence is a critical phase of human development during which the stage is set for later life. Adolescents (10-19 year olds) experience rapid social, physical, and emotional changes. Appropriate support structures and skills can lead to increased independence and development of positive and healthy behaviors with significant implications for society as a whole. However, without the skills to face these changes, adolescence can be a time of great risk. The introduction of complicating factors such as changes in family structure and unsafe sexual relations can threaten progress toward healthy development and achieving key milestones on the pathway to adulthood. Identifying and investing in those vulnerable to these risks will ensure adolescents emerge from this period with the economic and social assets necessary for the future.

The importance of investing in this group, however, has not always been reflected in policy and programming. Throughout developing countries, a focus on early to late childhood has led to reduced mortality rates, improved developmental outcomes, and increased access to schooling for young children. However, the world-and the East and Southern Africa Region specifically-is changing rapidly, and ignoring adolescents is becoming increasingly unsustainable. Already population age structures within East and Southern Africa are among the youngest in the world, with populations under the age 30 exceeding 60 percent. And as these countries transition from high to low fertility and mortality rates, populations of young people are expected to grow.

As the AGI and the rest of the data in the main report show, adolescents face wide ranging vulnerabilities, ranging from early dropout from school to early marriage, early childbearing and violence.

\section{Why adolescent girls?}

While all adolescents-both boys and girls-are entitled to decent livelihoods, girls face disproportionate risks and distinctive consequences from the vulnerabilities experienced and play a crucial role in breaking the intergenerational cycle of poverty and driving a country's development forward. Young girls are more likely than their male peers to drop out of school, to marry at an early age, and to bear the brunt of poor sexual and reproductive health outcomes.

Girls' and boys' needs and opportunities diverge during early adolescence, with girls entering puberty on average two years earlier than boys. For many girls in the developing world, this marks the beginning of a protracted risk period during which they have little or no control over critical social, health, and economic outcomes. Sexual maturation, mounting domestic burdens, migration for work, an increasing need for disposable income and pressure for marriage or other sexual relationships compound the challenges of adolescence for young girls.

There is clear and compelling evidence that investments in girls have broad and positive impacts. Through their labor force participation, fertility choices, and health, girls can play a pivotal role in breaking the intergenerational transmission of poverty and shaping a country's development. Investments in education and employment opportunities for girls lead to greater economic contributions from this largely untapped segment 
of the potential workforce. Girls with access to and control over economic resources are more likely to invest in their families.

Investments in girls' education and economic empowerment have also proven effective in improving health outcomes. The importance of girls' health has implications not only for themselves but for future generations. Girls with higher levels of education make better sexual and reproductive health decisions. Investments in delaying marriage and reducing childbearing have effects on reducing population growth, and increasing age at first birth reduces health risks (Bruce and Bongaarts 2009). Girls who are healthier and those with greater education are more likely to have fewer and healthier babies. Research has shown that children born to younger mothers have greater risks of mortality before the age of five and of being stunted or underweight (Temin and Levine 2009).

\section{Developing the Adolescent Girls Multilevel Vulnerability Index}

We followed a four-step process for developing the AGI that was based on the approach outlined in the Handbook on Constructing Composite Indicators (OECD 2008). The first step was the development of a theoretical framework that could serve as a basis for selecting and combining indicators into a composite score. We then matched our framework with the available data sources and indicators and prepared the data for index construction. Lastly, the validity and robustness of the index were tested through a sensitivity analysis.

\section{Developing the theoretical framework}

\section{Defining adolescence: Developing the AGI for 10-14 year-olds and 15-19 year-olds}

For the purpose of the index, we follow the United Nations definition of adolescence, which refers to individuals between the ages of 10 and 19 years (UNICEF 2011). Due to the different experiences, vulnerabilities and needs of girls in early and later adolescence, the AGI is designed to look at the whole age group (10-19) as well as subgroups of early adolescence (10-14) and later adolescence (15-19).

\section{The ecological approach, choosing dimensions and understanding multilevel vulnerability}

The conception of adolescent well-being draws heavily on Bronfenbrenner's Ecological Framework for Human Development, in which the development of a person involves individuals themselves, their environment and interactions between the two. Using this framework, the AGI measures vulnerability at three different levels-the individual, household and community level. This structure was selected as a way of measuring the theoretical concept that risk factors for adolescent girls are present at multiple levels from the individual level to familial, institutional and community levels, and a girl is defined as vulnerable if she experiences risks at all of these levels.

In creating a measure of adolescent vulnerability, the AGI hopes to identify areas with high percentages of extreme vulnerability and to encourage interventions that address these multiple levels of risk.

\section{Selecting the data and potential indicators}

All of the indicators that were selected for inclusion in the index are based on extensive research on adolescence. The indicators touch on common themes of poverty, household and family structures, regional and community characteristics, housing conditions, education, employment, sexual and reproductive health, HIV/AIDS and family formation (marriage and parenthood).

In order to create an index that could be used to compare across time and countries, we relied on Demographic Health Survey (DHS) and Multiple Indicator Cluster Survey (MICS) data. These surveys are appropriate sources of data because they are nationally representative, publicly available, and generated on a periodic basis. These surveys contain information on adolescent vulnerability and are implemented through standardized guidelines at the national level. The final indicators selected for the AGI can be found in Figure 29 (page 49). The complete data selection process is outlined in the full report.

\section{Constructing the index}

With the indicators selected, decisions need to be made about what constitutes 'vulnerable' in each dimension. We follow a cut-off method similar to the approach used by the Bristol Approach and the Multidimensional Poverty Index. Figure 30 (page 49) summarizes the vulnerability cut-offs. At the individual level girls (both 10-14 and 15-19) are considered vulnerable if deprived in any one dimension. At the household level girls are vulnerable if they experience 2 of 3 deprivations. At the community level, girls are considered vulnerable if they experience 1 of 3 deprivations. 
In constructing the overall AGI, a girl is considered vulnerable if deprived in all three dimensions-individual, household, community. As such the AGI is a measure of extreme vulnerability.

For the purposes of the AGI index, dimensions and indicators were not weighted.

\section{The Adolescent Girls Multilevel Vulnerability Index (AGI): Results}

\section{Overall, girls face the most extreme vulnerabilities in Karamoja and the fewest in the Western region, but significant challenges remain across the country}

Within Uganda, the AGI reveals that the most challenging region in which to be an adolescent girl is Karamoja, where over half of adolescent girls between 10 and 19 (53.6 percent) are vulnerable at all three levels-individual, household and community (Table 29, page 56). According to AGI findings, Karamoja has the highest percentages of vulnerable girls at the individual (91.9 percent), household (57.0 percent) and community levels (100 percent). West Nile, where around 1 in 4 adolescent girls (26 percent) experience extreme vulnerability, is the second most challenging region, followed by Central 1 which ranks third. Vulnerability is lowest in the Western region, where 12 percent of adolescent girls experience extreme vulnerability. Put another way, an adolescent girl is four times more likely to be vulnerable in Karamoja than in Western Uganda.

\section{Even regions with lower levels of extreme vulnerability face challenges}

The AGI is designed to measure extreme vulnerability. However, the AGI also allows analysis of less severe vulnerability which produces some interesting results. In Eastern Uganda, three out of four adolescent girls (74.9 percent) face vulnerabilities in two levels, driven by high levels of vulnerability at the individual and community levels. This places the Eastern region as one of significant vulnerability for adolescent girls. The bottom line is that even for parts of the country where relatively few girls experience extreme vulnerability, the AGI can highlight where significant challenges remain.

\section{Disaggregating the index, who needs to improve and where}

The AGI is designed to be deconstructed to look behind the overall numbers to understand the challenges that adolescent girls are facing at different levels and in different domains. The full report provides a detailed breakdown of the AGI. Some key conclusions at each of three levels suggest the following:

At the individual level, lack of education is driving much vulnerability, but with significant regional variation.

For adolescents across the age range, education is a driving factor behind vulnerability, but with some significant variation. In Karamoja almost 90 percent of 10-14 year old girls are two years behind in their education or have never been to school (Figure 37, page 59). Some regions such as Kampala and the central regions fare much better, with around half of girls fully 'on track' in education.

\section{URBAN VULNERABILITY}

The current version of the AGI is not effectively able to capture the vulnerability of adolescent girls living in Kampala. This is the case because girls living in Kampala are not classified as vulnerable at the community level as the women in these urban communities have below national average levels of deprivation when compared to other, rural parts of the country. However, results based on urban wealth quintiles show that adolescent girls aged 10 to 19 living in Kampala and in the poorest and second poorest quintiles have much higher levels of vulnerability at the individual and household level (Figure 35, page 57)

Part of the challenge is that DHS (and MICS) surveys do not collect detailed data for urban neighborhoods, and geographic identifiers used to classify regions do not correspond to slum versus non-slum areas. The inability of the AGI to capture vulnerabilities in Kampala points to a need for more information on what makes urban girls vulnerable and highlights urban vulnerabilities as a distinct and important point for further inquiry. 
For girls 15-19 a lack of secondary education is also a driving factor. In a number of regions 3 out of 4 girls or more do not have any secondary education (Figure 38, page 60). Vulnerabilities from having been married or pregnant range around 20 percent, with lower but still significant numbers of girls experiencing high-risk sexual activity.

\section{The household level is generally less of a driver of vulnerability than individual and community levels.}

However, lack of sanitation is a key factor in many regions. Analysis shows wide variation among regions in terms of household vulnerability with the highest percentages concentrated in no access to improved sanitation (Figure 39, page 60). Adolescents in Central 1 and the Southwest face relatively greater vulnerability at the household level, as they more frequently live in households without access to an improved water source. Again education is a major challenge in Karamoja, where the percentage of girls living with household heads having no education is at least two times as high as in other regions.

\section{Girls experience a wide range of community level vulnerabilities.}

The community-level variables capture girls who are vulnerable as a result of living in a vulnerable community environment, as measured by women aged 20-49 having greater than average deprivations in key areas (Table 32, page 60). Adolescent girls in the eastern parts of Uganda and the North live in areas with high prevalence of early marriages. Illiteracy is the dominating factor in Eastern and Karamoja, where all girls live in communities with higher than average illiteracy among women 2049. The HIV indicator captures vulnerability among girls living both in communities with high prevalence of HIV and with limited knowledge-with the vulnerabilities highest in Central 2, Western, and the Southwest regions.

Despite challenges, there are signs of significant improvement over time.

While challenges are significant, the AGI shows positive improvements in reducing the vulnerability of adolescent girls in Uganda over time, with the AGI falling from 32.7 percent in the 2006 to 20.6 percent in the 2011 DHS (Figure 32, page 55). This decrease in extreme vulnerability is concentrated in a decrease in household vulnerability and is due to a large improvement in access to improved water and sanitation. Changes in index rankings between 2006 and 2011 were most dramatic in the Western and West Nile regions. In both of these regions, there were reductions in vulnerabilities at all three levels.
The high levels of individual and community level vulnerabilities and lack of change in these areas suggest that investments are needed to reduce individual and community level vulnerabilities.

\section{The AGI: Uganda in the East and Southern Africa context}

The AGI was designed not only for analysis within Uganda, but analysis across the region. Figure 40 (page 61), presents results for the East African Community. Uganda falls in the middle of the ranking when compared to fellow members of the East African Community. Uganda performs significantly better than Burundi and Tanzania where 33.5 percent and 28.6 percent, respectively, of adolescent girls are vulnerable but significantly worse than Rwanda, where 8.5 percent are vulnerable and Kenya where fewer than 1 in 8 adolescent girls experiences extreme vulnerability. Strikingly in Uganda the highest levels of vulnerability are at the individual and community level, rather than the household level, highlighting the need to focus on these areas.

\section{Programming and policy for adolescent girls in the Ugandan context}

\section{Policy review}

The research behind the AGI Report included a substantial review of policy documents, in-depth interviews with stakeholders in Uganda, and discussions with adolescent girls themselves. The overall conclusions indicate that adolescent girls do not feature as a distinct priority population in Ugandan policy, with adolescent issues falling under the mandates of both youth- and child-serving initiatives, and the country has yet to see a critical mass of public and private stakeholders converge into an adolescent 'policy camp'.

\section{Policy implementation}

Uganda has, as one representative interviewed for this analysis reported, "one of the best legal environments on paper." However, weak implementation and enforcement limit the degree to which Ugandan policy affects vulnerable girls. Further, very young adolescent girls are largely left out of the "youth" conversation, and policies are not designed to intervene early and prevent negative outcomes before their onset. 


\section{Program scan: what options do} adolescent girls have?

As part of the AGI report, a nationally representative survey of adolescent-serving organizations was conducted. This involved completing a subcounty-level program scan and a 30-day coverage exercise with a sample of identified programs. A program scan answers the questions "How many?" and "What type?" A coverage exercise builds on this information to answer the question "Who is served?" Full details of the sampling approach can be found in the full report.

\section{Number of programs}

The average subcounty reported having 2.9 eligible programs for adolescents ages 10 to 19. The 95 percent confidence interval around this value ranges from 2.2 to 3.6, and the number of programs per subcounty is not associated with subcounty population sizes. Our estimate of the total number of adolescent programs in the country is 3,095 serving 8.2 million adolescents (excluding Kampala).

\section{Types of programs}

Most programs classified themselves as community-based organizations. More than half of the programs indicated that they address HIV, life skills, livelihoods, and other non-specified topics.

\section{Who is attending}

Program representatives reported that, on average, 58.8 percent of participants are boys. They indicated that adolescents ages 15 to 19 make up the greatest proportion of participants at 38.2 percent, followed by young adults age 19 and older (34.9).

\section{Recommendations}

The AGI shows that in Uganda there is a need to focus on individual- and community-level investments, particularly in some key areas.

While Uganda falls in the middle of cross-national rankings of multidimensional adolescent vulnerability, girls ages 10 to 19 have higher than average rankings of individual and community level vulnerability but lower rankings at the household level. In particular, reducing individual and community level vulnerabilities will be accelerated by:

1. increasing educational attainment and keeping girls in school;

2. strengthening HIV programming in the regions of Central 2, Western, North, Southwest, and East Central; and

3. targeting social values and cultural norms that promote child marriage and early childbearing.

\section{POLICY RECOMMENDATIONS}

Given the largely favorable policy frameworks, data on health and social outcomes for girls in this region identify lack of dissemination, enforcement, and coordination as barriers to improvement. The following recommendations are offered for improving policy implementation and potential for effectiveness in Uganda:

1 Create an inter-ministry committee at the national level to harmonize policy and coordinate government response for adolescent girls.

2 Design policies to reach very young adolescent girls with investments that can prevent negative outcomes before their onset.

3 Collect additional data that can be disaggregated below the regional level, for younger adolescents aged 10 to 14, and for material and psychosocial support at the household level.

4. Use data to locate investments and measure progress according to the internal diversity of adolescent populations in terms of age, gender, marital and schooling status, social status, economic class, living arrangements, and urban/rural residence.

5 Invest in replicable and scalable interventions in geographic areas with the highest concentrations of girls at risk of the worst outcomes.

6 Create district-level committees to monitor and address adolescent girls' issues.

7 Strengthen child protections and address social norms and cultural values that drive irremediable rights violations and mistreatment of girls at the household and community levels.

8 Prioritize interventions that improve educational quality to increase school retention and attainment.

9 Ensure that a strong program base exists that reaches vulnerable adolescent girls at ground level, puts assets directly in their hands, and creates an enabling environment in their communities. 


\section{PROGRAM RECOMMENDATIONS}

Closer examination of programs and populations served makes it clear that the existing base of programming is not reaching vulnerable adolescent girls. Experience has shown the following strategies to be effective in creating girl-centered programs:

\section{Incorporate key characteristics of successful girls programs}

Before deciding on the content of the intervention, a program must have the proper structure to ensure participation of vulnerable girls.

Core building blocks include ensuring there is a safe place in the community where a group of girls can meet regularly with peers, and that effective female mentors are incorporated into the program.

\section{Focus on asset building for adolescent girls}

Once the structure of a program has been developed to ensure the participation of vulnerable girls, the content and focus of the program can be decided. Providing a diverse range of social, health, and economic assets for girls has proven to be a successful approach.
Using the asset-building framework to design program content shifts the focus to a more preventive approach. The key question becomes "what do girls need?" and not "what problems do girls have?" Often, the answers to what girls need will help them in a range of areas in their lives, as opposed to focusing on a single problem that leads to a very narrow approach.

\section{Increase programming options}

Two approaches can be taken to expand programming options for adolescent girls at the community level. The first is to make changes to existing programs and institutions to allow for greater participation of adolescent girls. The second is the creation of new programs. Existing resources at the community level can be adjusted to incorporate programming elements for girls and to ensure that girls have access to the services they are entitled to on paper. These include programs at schools, churches/mosques, youth centers, and youth councils. In many cases, nothing exists at the community level in which girls can participate and new programs will need to be created. Often, a combination of making use of existing community resources and creating new programming will be necessary in order to reach vulnerable adolescent girls. 


\section{INTRODUCTION}

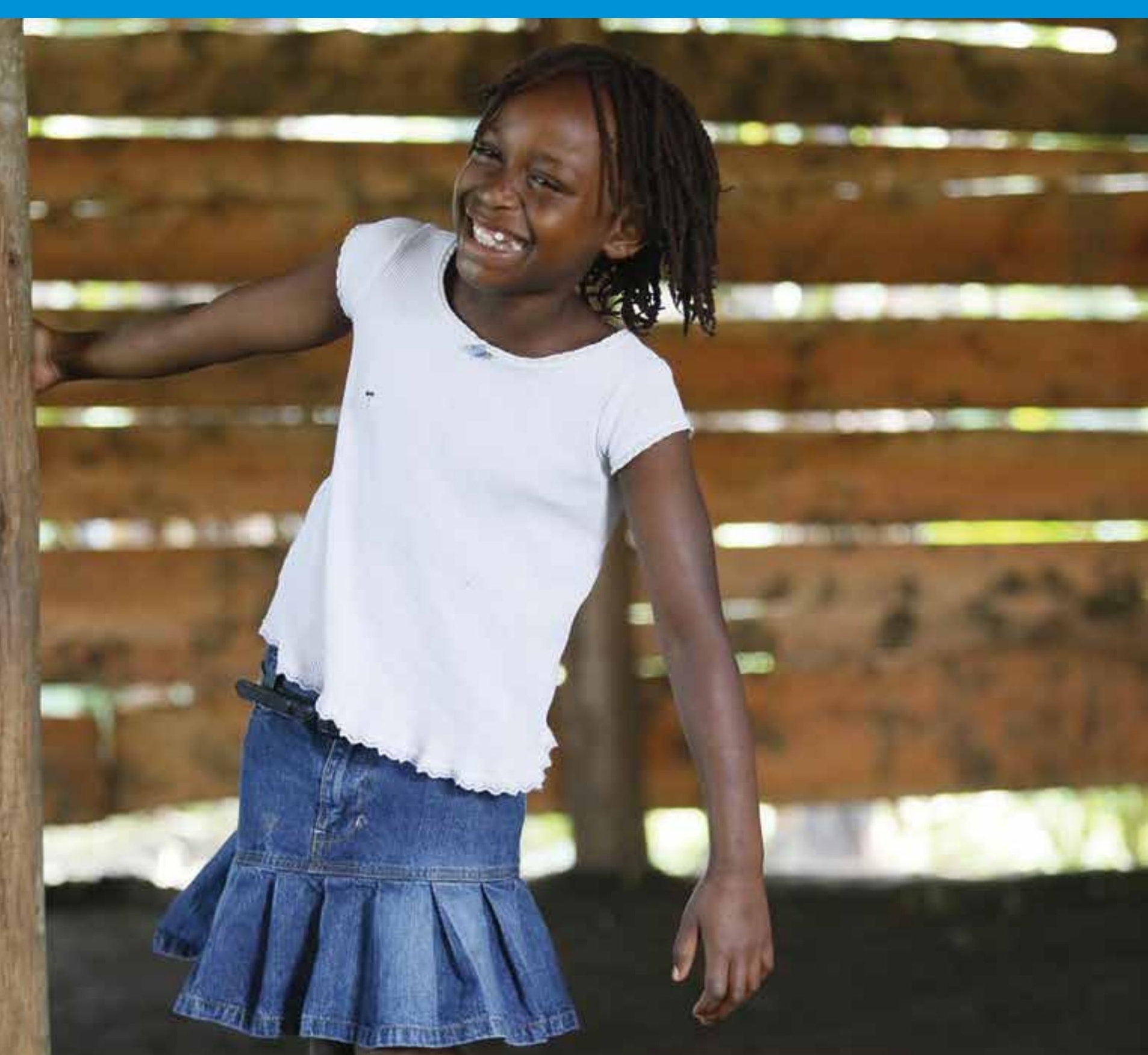


The Adolescent Girls Index project, a collaboration between the Government of Uganda, UNICEF and the Population Council, emerged from a growing recognition of the need to channel resources to vital-yet highly vulnerable and vastly underserved-populations of adolescent girls in the developing world. The aim was to develop a summary indicator that can serve as an advocacy tool to draw attention to adolescent girls, a rigorous measure to inform decisions about policymaking and macro-level resource allocation, and an instrument for planning and monitoring progress.

In the 2011 State of the World's Children Report and subsequent 2012 Progress for Children Report, UNICEF made the case that its own efforts must focus more on adolescents. This report briefly revisits these arguments in the context of East and Southern Africa, with a particular focus on Uganda.

\begin{abstract}
Adolescents constitute a substantial portion of developing-country populations. Investing in these young people, and specifically in adolescent girls, promises both immediate benefits and dividends for future generations. In addition to articulating this overarching argument, this report will examine the specific vulnerabilities that adolescent girls face in Uganda and East and Southern Africa more generally and make the case for focused policy and program intervention to maximize impact.
\end{abstract}

Many of the concepts discussed here are not new: the youth bulge in many countries and the vulnerabilities faced by adolescent girls and their role in the intergenerational transmission of poverty. Dramatic global reductions in under-five mortality rates and increases in primary school completion drive the need to shift focus to adolescents. As the youth bulge continues to dominate demographics, educated and employed adolescents will become an increasingly important group.

Relatively little is known about resource allocation to adolescent programming, and an important reason for this lack of knowledge is that data are not appropriately disaggregated. It is likely that governments are falling short of meeting the demands of these demographic and development realities. This report will underline that while policy frameworks are often in place and the importance of the issue is recognized, implementation is weak and programming is limited and underutilized by vulnerable adolescent girls.
A rigorously-constructed index can offer simplicity and visibility, and can be a powerful planning and monitoring tool. An index for adolescent girls can bridge the gap between priorities and action. While the index presented in this report is a first in the area of adolescents, it follows a long tradition of index construction as an effective tool for drawing attention to emerging and critical issues. The Human Development Index and the Corruption Perceptions Index are good examples.

This work coincides with a crucial period as the post Millennium Development Goal agenda is being formed. Adolescents received relatively little attention in the original MDGs, and in Uganda and in the East and Southern Africa region more generally, it is essential that this group (and adolescent girls in particular) be placed at the center of this agenda.

This report has six chapters:

Chapter 1 provides background on reasons to invest in adolescents-specifically adolescent girls. It includes a demographic exercise analyzing individual, household, and community level characteristics of adolescent girls in East and Southern Africa in general, and Uganda in particular;

Chapter 2 describes the conceptualization and construction of the Adolescent Girls Multilevel Vulnerability Index (AGI);

Chapter 3 presents Index results identifying regional and subnational areas of extreme adolescent vulnerability;

Chapter 4 includes an in-depth adolescent girl program review in the form of a coverage exercise in Uganda. It addresses both the number of programs and the populations of young people that these programs serve, with implications and recommendations for East and Southern Africa.

Chapter 5 contains a review and analysis of policies related to adolescent girls in Uganda and in East and South Africa; and

Chapter 6 identifies policy gaps and provides actionable items to improve policymaking and programming

Appendices include results of a participatory assessment with adolescent girls in Uganda, suggestions for additional survey topics to fill gaps in adolescent data, and forms used in data collection. 
This report argues that an index for adolescent girls will provide a signature indicator that can generate a sensitive measure of societal health, raise public awareness of the issue, and guide policymakers to improve the currently inadequate resources and programming that adolescent girls receive.

\subsection{Demographics:}

\section{Adolescents, population projections, and benefiting from the youth bulge}

\begin{abstract}
As outlined in The State of the World's Children 2011, adolescence is a critical phase of human development during which the stage is set for later life. Adolescents (10-19 year olds) experience rapid social, physical, and emotional changes. Appropriate support structures and skills can lead to increased independence and development of positive and healthy behaviors during this period of transition. But without these supports, adolescence can be a time of great risk. The introduction of complicating factors such as changes in family structure and unsafe sexual relations can threaten progress toward healthy development and achieving key milestones on the pathway to adulthood. Identifying and investing in those vulnerable to these risks will ensure adolescents emerge from this period with the economic and social assets necessary for the future.
\end{abstract}

Yet, the importance of investing in this group has not always been reflected in policy and programming. Throughout developing countries, a focus on early to late childhood has led to reduced mortality rates, improved developmental outcomes, and increased access to schooling for young children. The needs of adolescents, however, have not received the same attention, with limited focus in policy, programs and budgets.

The world-and the East and Southern Africa region specifically-is changing rapidly, and ignoring adolescents is becoming increasingly unsustainable. For example, extrapolating current trends suggests that by 2015 , only 69 countries will have under-five mortality rates (U5MR) above 30 per 1,000 live births (Figure 1), and in the East Africa region fewer than 10 countries are expected to have U5MR at this level by 2035. While much work needs to be done to ensure and accelerate this progress, as children continue to survive and thrive through their first decade, focusing on adolescents and the second decade of life is becoming increasingly important.
When compared to the immediacy of threats to survival during early childhood, the period of adolescence can appear to be a relatively healthy and risk-free time. The reality is that adolescents encounter significant vulnerabilities with consequences that only begin to manifest during adolescence. As the AGI and the rest of the data in the report will show, adolescents face numerous vulnerabilities, ranging from school dropout to early marriage and childbearing.

Population age structures within East and Southern Africa are among the youngest in the world, with proportions of the population under age 30 exceeding 60 percent. Countries with mature age structures, such as in Europe or the United States, have proportions under 30 of less than 45 percent. In Uganda, three-quarters of the population is under age 30 and one-quarter fall within the adolescent age range of 10 to 19 (see Figure 2). Throughout East and Southern Africa, adolescent proportions range from 22.5 to 27.5 percent. Similarly in other parts of the developing world, adolescent proportions are extremely high, at 23 percent in West Africa, 20 percent in the Middle East and North Africa, and 19 percent in Latin America and the Caribbean (UNICEF 2012).

\section{FIGURE 1}

THE CHANGING CONTEXT OF DEVELOPMENTTHE SECOND DECADE OF LIFE IS BECOMING MORE IMPORTANT

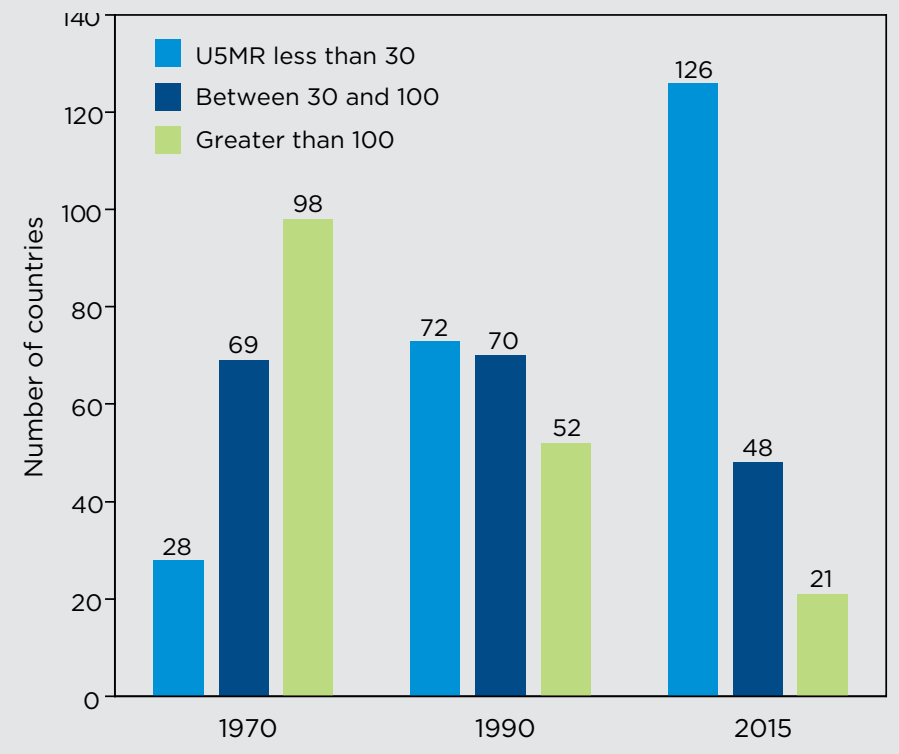

U5MR = Under-five mortality rate

Source: Authors' calculations, based on data from UNICEF 2013a. 


\section{FIGURE 2}

PERCENTAGE OF POPULATION WHO ARE ADOLESCENTS (AGED 10-19), EAST AND SOUTHERN AFRICA

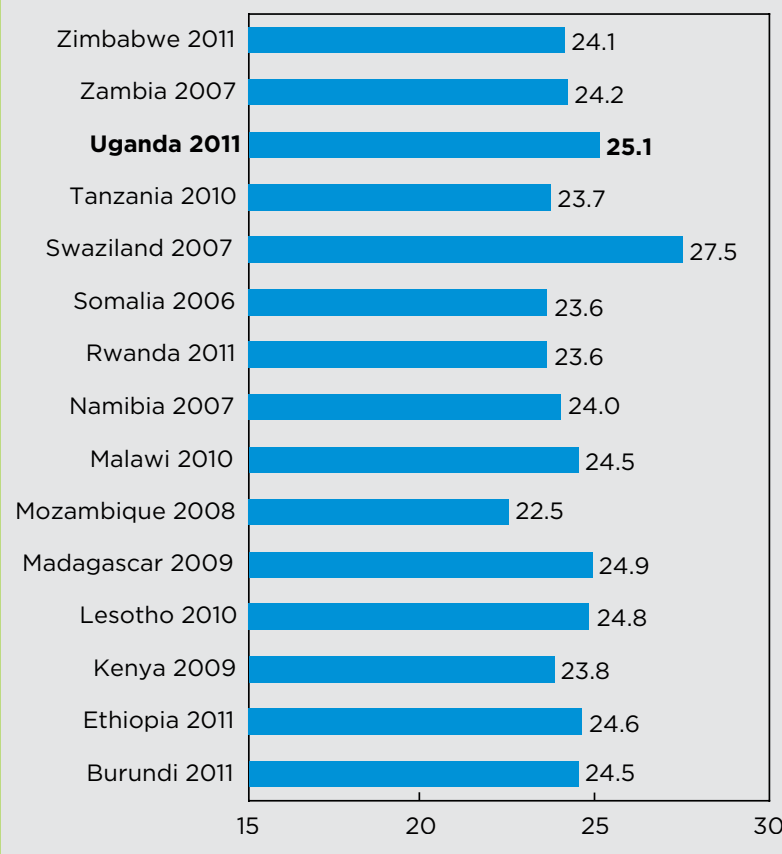

Source: DHS 2007-2011; MICS 2006-2008.

\section{FIGURE 3}

UGANDA: ALTERNATIVE POPULATION PROJECTIONS FOR 2005-2050 AND POPULATION GROWTH COMPONENTS

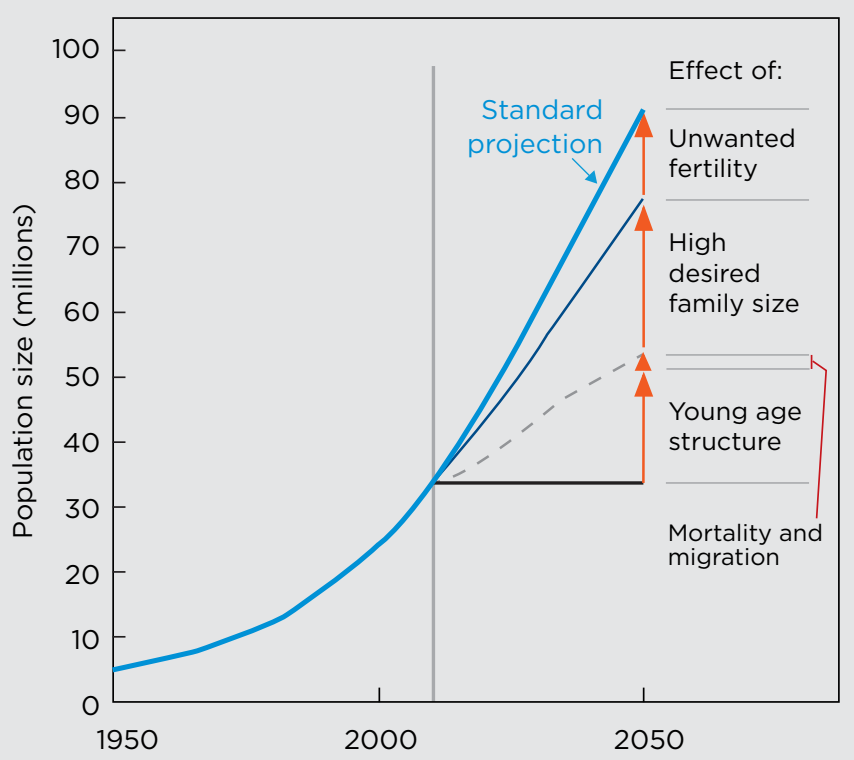

Source: Bongaarts 2012.

\section{FIGURE 4}

PERCENTAGE OF POPULATION WHO ARE WORKING AGE (15-64): ESTIMATES AND PROJECTIONS IN UGANDA, SUB-SAHARAN AFRICA, LESS DEVELOPED WORLD, AND THE WORLD, 1950-2100

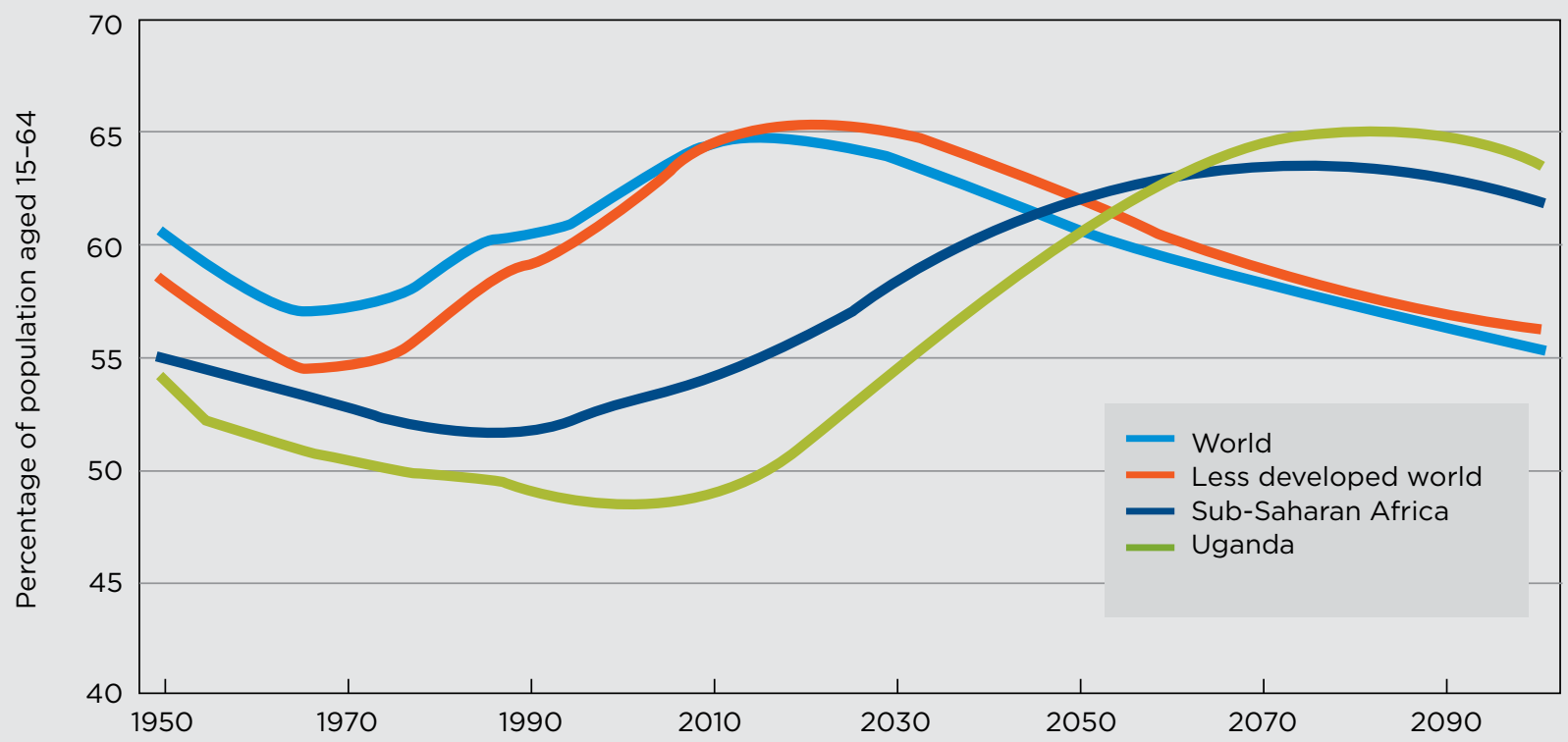

Source: United Nations, Department of Economic and Social Affairs, Population Division, 2011. 
As countries transition from high to low rates of fertility and mortality, populations of young people are only expected to grow. Between 1950 and 2010, the population of Uganda grew from 5.2 to 33.8 million, and by 2050 the total is expected to reach 91.3 million (United Nations, Department of Economic and Social Affairs 2011). The future growth expected for any population is attributable to several demographic factors (Bongaarts 1994; Bongaarts and Bulatao 1999): high fertility (above the replacement level of two surviving children per woman); population momentum (a young age structure that leads to high fertility); and other factors (namely declining mortality and migration). Figure 3 illustrates four population growth projections for Uganda that take into account variation in the contribution of each of these factors (Bongaarts 2012). Based on the baseline of 33.8 million in Uganda in 2010, the standard projection incorporating no change to current demographic factors projects a population of 91.3 million in 2050. Subsequent models successively remove contributing growth factors: 1) unwanted fertility; 2) wanted fertility is set at replacement level of two children per woman; and 3) mortality and migration are held constant, leaving the effects of young age structure (Bongaarts 1994; Bongaarts and Bulatao 1999). Changes to unwanted fertility and high desired family size may reduce population growth, but-at a minimum-a young age structure, which is not amenable to change, will add an estimated 17.5 million people to Uganda's population by 2050 .

As a result of this explosive growth, the proportion of the population who are working age-15 to 64will increase in Uganda. Figure 4 shows United Nations estimates and projections using the medium fertility variant for the percentage of the working age populations in Uganda, sub-Saharan Africa, and the world for 1950 to 2100. The world as a whole and the less developed world are currently experiencing peaks in working age populations with expected declines in the coming years. The trends for sub-Saharan Africa and Uganda are different. These regions are in the early stages of their demographic transitions and the working age populations are still growing with peaks expected within the next 70 years. By 2080, 65 percent of Uganda's population is projected to be working age.

Although a very young age structure can strain developing nations, a youthful population can offer a unique opportunity for economic growth. As a country progresses through the stages of the demographic transition, declines in birth and mortality rates cause shifts in the relative size of age groups. The share of the working-age population increases relative to children and the elderly, which reduces dependency ratios. If the working

\section{Investing appropriately in adolescents is not only vital for adolescents themselves, but is a vital investment for societies and economies as a whole, particularly those going through a demographic transition.}

age population is absorbed into productive employment, income per capita within a country will rise leading to a long period of sustained economic growth. This is referred to as the demographic dividend. This potential, however, is contingent upon nations investing in young, maturing populations to create a healthy and educated workforce. Population projections estimate that by 2030 working-age adults will outnumber children in most African countries (Ashford 2007). With this window of opportunity fast approaching, policies and programming to support the education, employment, and health of today's adolescents are increasingly important. Without investments in this population, no benefits will be reaped from these demographic changes.

\section{Investing in adolescents as part of the strategy to realize the demographic dividend}

Investing appropriately in adolescents is not only vital for adolescents themselves, but is a vital investment for societies and economies as a whole, particularly those going through a demographic transition. Investments in the health, education, and opportunities available to young people are necessary to realize any potential economic growth from population dynamics. Rapid population growth can offer large demographic dividends where there is strong investment in the human development of young people. In order to ensure today's youth are healthy, active, engaged, and gainfully employed citizens, policies, pro- 
grams and services must be put into place that focus on their well-being. For Uganda to quickly achieve its aim of becoming a prospering middle income country, investing in adolescents is essential. Preparing youth for adulthood requires strengthening capacities across multiple areas. Policy and programming should work toward addressing the following key domains of need among adolescents: 1) health; 2) education; 3 ) employment; and 4) civil rights and participation.

HEALTH: Promoting the health of adolescents ensures that they live longer and more productive lives. Safeguarding living standards, including access to improved water and sanitation, ensures that adolescents grow up in environments conducive to good health. Adequate nutrition and healthy eating habits also set adolescents on a path for healthier adult lives. Maintaining good sexual and reproductive health is a key goal for adolescents, as are avoiding risks associated with drug and alcohol abuse. Among the most vulnerable adolescents are those with disabilities who have special health needs. It is paramount that adolescents have access to information, programs, and services to understand potential health risks and ensure adoption of safe behaviors that minimize harm to their health.

EDUCATION: Increasing access to schooling and improving the quality of education will provide individuals with the knowledge and skills to become gainfully employed and make informed decisions about their livelihoods, health, and families.

EMPLOYMENT: Increasing educational attainment and improving job skills are necessary for improving livelihood potential among adolescents. However, improvements beyond the individual level need to occur as well. Human capital improvements will have little impact without sufficient opportunities for gainful employment. Unemployment rates are often highest in younger populations. Reducing barriers to work and increasing training/ apprenticeship programs will make the labor force more inclusive of young people who are ready to work.

CIVIL RIGHTS AND PARTICIPATION: Protection of rights will ensure adolescents have access to government services, have a sense of engagement, and are active citizens in their communities.
Countries that make investments in the education and training of young people experience stronger economic growth (UNESCO 2012). Adolescents equipped with a foundation of individual assets to reduce dependencies, know their rights, and access resources available within their communities can forge a better life for themselves and their communities. In the absence of government policies to support the needs of this group, successful adolescent programming has used livelihoods approaches that measure individual well-being beyond income and conventional assets by assessing factors such as social isolation, poor health, residential stability, and agency. This approach inventories individual capabilities, activities, and assets in the following four categories, which are required for gaining a means of living (Population Council 2005):

1. Social assets-relationships that support the psychological needs of girls and keep them connected to resources available within communities. These assets include social networks, group membership, and relationships of trust. Without such assets, meaningful access to wider institutions and resources can be difficult to achieve.

2. Human assets - the individual skills and knowledge that enhance health, ability to work, self-esteem, and autonomy. Essential skills such as literacy and numeracy can be developed through participation in formal education. A positive externality is increased confidence and self-efficacy related to increased capacities.

3. Physical assets - the goods and services needed for basic daily living and maintaining livelihoods. Food, clothing, and shelter are often the minimum physical assets. Beyond these essentials are goods such as transport and tools of production that can provide individuals with the means to support themselves.

4. Financial assets-items such as cash, savings, and entitlements that provide a source of monetary wealth. These assets support economic security by enabling individuals to purchase goods and services. Also included in this category is financial literacyan understanding of the use and management of these resources.

Supporting adolescents with effective, targeted government policies and programming ensures that adolescents can make successful transitions to adulthood through the acquisition of these important assets, and is a strategic approach to sustainable development. 


\subsection{Why adolescent girls?}

While all adolescents are entitled to decent livelihoods, girls face disproportionate risks and distinctive consequences related to the vulnerabilities experienced. Young girls are more likely than their male peers to drop out of school, to marry at an early age, and to bear the brunt of poor sexual and reproductive health outcomes. Adolescent girls confront distinct physical and social vulnerabilities that threaten their human rights and livelihoods.

Girls' and boys' needs and opportunities diverge during early adolescence, with girls entering puberty on average two years earlier than boys. For many girls in the developing world, this marks the beginning of a protracted risk period during which they have little or no control over critical social, health, and economic outcomes. Sexual maturation, mounting domestic burdens, migration for work, an increasing need for disposable income, pressure for marriage or other sexual relationships, and isolation from peers and mentors compound the challenges of adolescence for young girls.

As a result, girls are disproportionately vulnerable to gross and irreparable violations of their human rights, cut off from civic participation, and excluded from health, education, and other social services (Bruce 2007a). Girls are more likely than boys to drop out of school, engage in illegal or unsafe work, or be subjected to child marriage, transactional sex, and unsafe sexual relations inside or outside of marriage-all limiting realization of their full human potential (Bruce 2007a). Vulnerabilities lead to school dropout, and leaving school can further increase vulnerability among girls, who often do not return. As a result, girls are left socially isolated without sufficient knowledge and skills to effectively navigate life's challenges.

Gender norms further limit girls' mobility, selection of peer groups, and access to important social capital and financial assets (Bruce et al. 2006). Girls often have fewer social opportunities to meet friends and interact with mentors compared to boys. Research in Addis Ababa and KwaZulu-Natal found that boys reported having significantly more friends compared to girls; and girls in Addis Ababa were more likely to report having fewer people to turn to for assistance (Erulkar et al. 2004; Hallman and Diers 2004). Girls were also more likely to have migrated to urban areas and to be living without their parents and to feel less safe in their neighborhoods. Girls were more likely to feel discomfort in their communities, and to report being scared and to experience harassment (Erulkar et al. 2004). Strengthening social networks empowers girls and can reduce these risks (Austrian 2012).
These challenges stem not just from the particular vulnerabilities that girls face, but from chronic disinvestments that have resulted in less access to education, health, and employment opportunities compared to boys. Programmatic efforts focus on youth in general, often reaching boys and missing girls. Additionally, program efforts more often reach young children and, in some cases, older adolescents when deprivations have already occurred. An analysis of five youth centers in subSaharan Africa found youth programs were more likely to reach those in school, living with parents, and typically older, male youth (Bruce 2007a). Young adolescence is a period that is particularly ripe for intervention. Yet, many programs often overlook this key group-those aged 10 to 14 . Adolescents in this age group are less likely to be exposed to the risks that dominate older adolescence. This is an age before many key adverse events-dropping out of school, first sex, and pregnancy-occur. Reaching adolescents during this period is critical to avoiding these risks. Adolescents during this age are also better situated within reach of programming efforts as most are still connected to the institution of school. Preventive measures need to support adolescents in protecting themselves before negative outcomes can occur. By expanding individual and community resources available to girls, gender disparities in health, social, and economic outcomes can be reduced.

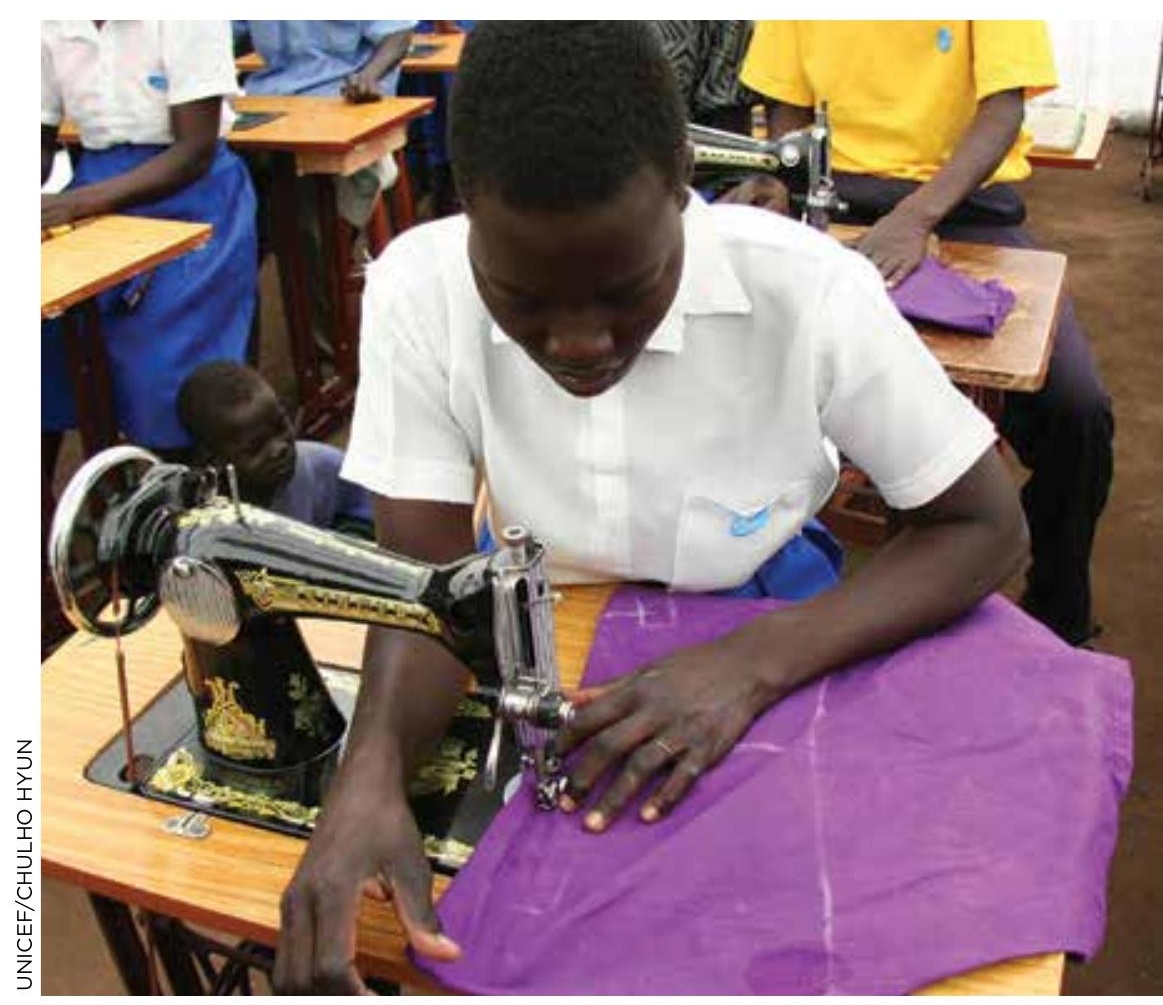

In Kitgum District, Uganda, orphans and other vulnerable children, including those formerly abducted by fighting forces, participate in tailoring and other vocational skills training programs. 
There is clear and compelling evidence that investments in girls have broad and positive impacts. Through their labor force participation, fertility choices, and health, girls can play a pivotal role in shaping a country's development. Investments in education and employment opportunities for girls can lead to greater economic contributions from this largely untapped segment of the potential workforce. Girls with access to and control over economic resources are more likely to invest in their families. A study of sub-Saharan Africa found that a large proportion of women are likely to experience single motherhood before the age of 45 (Clark and Hamplova 2013). For this reason, it is critical to equip girls with the tools to navigate challenges in their lives.

Investments in girls' education and economic empowerment have also proven effective in improving health outcomes. The importance of girls' health not only has implications for themselves but for future generations. Girls with higher levels of education make better sexual and reproductive health decisions (Levine et al. 2009). Investments in delaying marriage and reducing childbearing have effects on reducing population growth, and increasing age at first birth reduces health risks (Bruce and Bongaarts 2009). Girls who are healthier and those with greater education are more likely

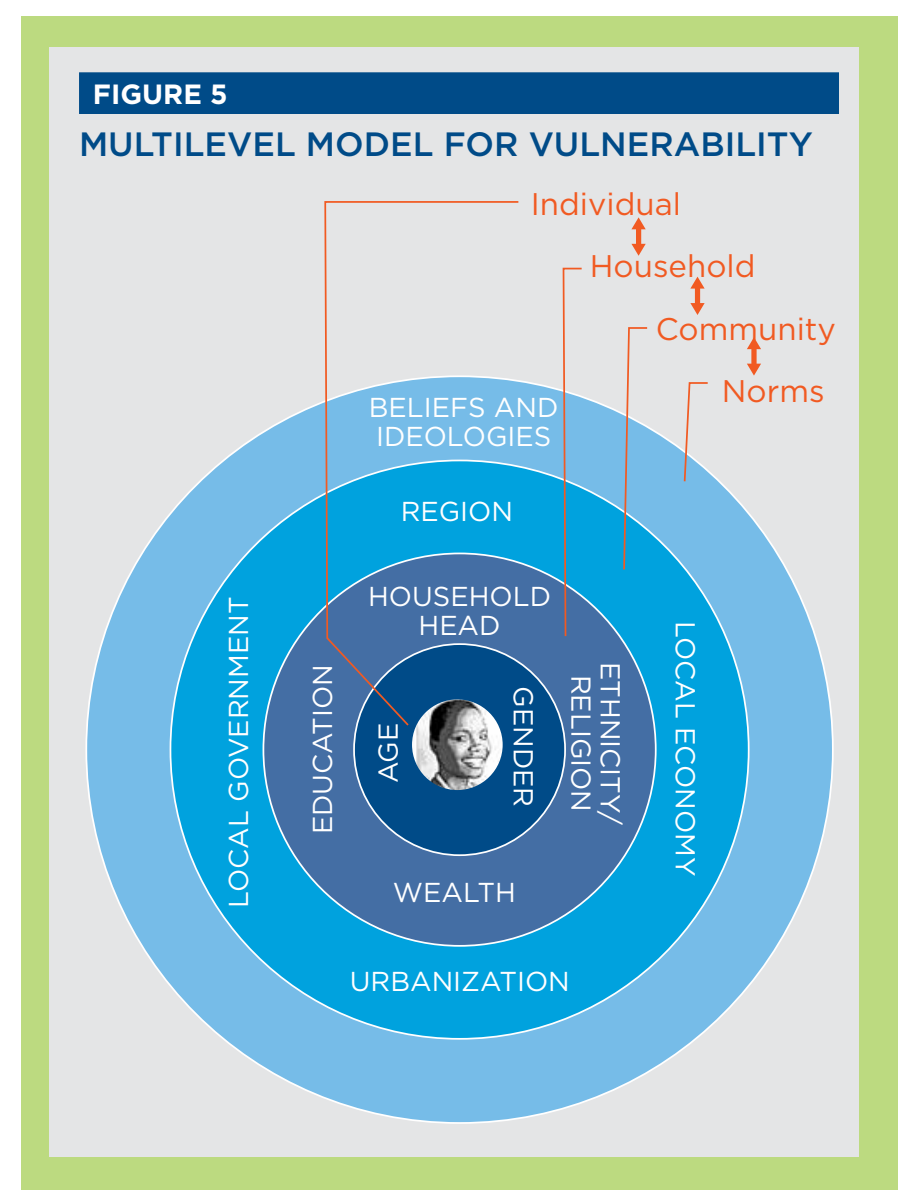

to have fewer and healthier babies. Research has shown that children born to younger mothers have greater risks of mortality before the age of five, and of being stunted or underweight (Temin and Levine 2009).

Investments in girls are also a vehicle for achieving the goals of international conventions. Through the Millennium Development Goals (MDGs) and international conventions, countries have pledged to protect human rights and ensure that all individuals lead healthy, productive, and fulfilling lives. Investing in the welfare of women and children is a primary focus in these agreements. The Convention on the Rights of the Child (CRC) clearly articulates how the rights of children are to be respected and calls for the provision of resources to ensure their survival and development. Additionally, the MDGs explicitly address gender equity, and the health, education, and empowerment of children and women. Countries can invest in adolescent girls to fulfill the promises made on these commitments (Bruce and Chong 2003).

Investments in adolescent girls are critical for achieving overarching health and development objectives. However, there is a gap in translating these global goals and strategies into effective policy formulation and implementation. Adolescents are often grouped into an overly large categorization of "youth," ignoring the biological and socio-cultural differences of gender. This approach inevitably leaves behind the marginalized girls most in need of services and support.

\subsection{The vulnerabilities of adolescent girls in East and Southern Africa}

To fully understand the need to invest in adolescents, we need to look beyond the demographic profile to the vulnerabilities they face in East and Southern Africa, and Uganda in particular. Given limited resources, it is necessary to identify which groups of adolescents have the greatest need for targeted programming and policy. This section outlines these vulnerabilities and provides the background to the areas and indicators considered for the development of the Adolescent Girls Multilevel Vulnerability Index.

\section{An ecological approach to examining adolescent well-being}

In conceptualizing vulnerability, this report uses an ecological model to show how community, household, and individual factors affect adolescent well-being (Figure 5). Research on child develop- 
ment has often focused on proximate relationships such as family as the primary influences on child well-being (Earls and Carlson 2001). However, the determinants of adolescent well-being exist and interact on multiple levels. Family members and household environments have the most direct interactions with and influence on children. But as members of communities, adolescents are affected by the larger social, political, and economic environments. For example, employment opportunities in the local economy may influence decisions to complete schooling. Moreover, community members who shape the norms and characteristics of the social contexts can indirectly affect adolescents. For instance, girls living in communities practicing female genital mutilation often conform to avoid risks to marriageability and to maintain social standing (UNICEF Innocenti 2010). As a result, comprehensive frameworks that reach beyond the individual are needed to fully understand the scope and dynamics of influences shaping vulnerability.

Our conception of adolescent well-being draws heavily on Bronfenbrenner's Ecological Framework for Human Development. According to Bronfenbrenner, the concept of the developing person involves the individual, his or her environment and the interactions between the two (Bronfenbrenner 1979). Human development is a life-long process that occurs within individuals and their changing environment that encompasses their immediate and larger surroundings. An individual's ecological environment is conceived of as a nested arrangement with successive levels of influence, each farther removed from the individual at the center (Bronfenbrenner 1979).

At the core of this theoretical framework are the relationships between the developing person and the environment in the immediate settings containing the person (Bronfenbrenner 1977). Common settings where developing individuals play particular roles and engage in activities include the household, school, religious institutions, social clubs, and neighborhoods. Interactions between and among individuals and those in their immediate environment at a particular time contribute to well-being. For example, for a 10-year-old girl, this system can include interactions between a girl and school but also the interactions between school and her family.

Formal structures and institutions of society as they operate on a concrete local level comprise the next level of the ecological framework. Individuals may not have direct interactions with these structures but they contain and/or affect and determine events in the immediate environment of the developing individual. These include neigh- borhoods, agencies of government, mass media, infrastructure, commerce, and social networks (Bronfenbrenner 1977).

At the highest levels are legal systems along with less tangible norms that "set the pattern for activities occurring at more concrete levels" (Bronfenbrenner 1977). Included are formal rules such as laws and regulations that govern society. Others, however, are informal such as ideologies and cultural customs that are not as explicitly evident. The places where children and their families fall within this system of ideas and norms affect their interactions and treatment within society.

\section{Determinants of health and well-being}

Using this ecological framework, our analysis examines individual, household, and community characteristics that potentially influence adolescent well-being. Individual-level characteristics such as age, sex, ethnicity, and religion can all play a role in experiences of vulnerability. At the household level, family structure and composition, along with the characteristics of household members, can be protective or potential risk factors. At the highest levels, community resources and social norms shape opportunities and behaviors within regions. Together, this multilevel approach provides a holistic assessment of characteristics affecting vulnerability.

In the following sections, we examine the factors associated with adolescent vulnerability across East and Southern Africa and within Uganda using the most recent country data from Demographic and Health Surveys (DHS) and Multiple Indicator Cluster Surveys (MICS). Data disaggregated by subgroup allow us to recognize the diversity among adolescents and to identify populations at greatest risk for vulnerability. Classifying adolescents by key social categories of risk and strength also helps us to identify those who are in potentially vulnerable conditions. Several characteristics by which vulnerability may affect subgroups differently include age, geography, wealth, and education. In later chapters, we use the Adolescent Girls Multilevel Vulnerability Index (AGI) to explore how these indicators at the community, household, and individual level work together to create distinct levels of vulnerability for an individual.

\section{Communities and regions}

According to the Uganda Bureau of Statistics, there are approximately 7.8 million adolescents aged 10-19 (2012). The communities in which these adolescents live can have a lasting impact on their development and well-being. Differences in the 
physical, social, political, and economic structures of a region can place residents at varying risks for vulnerability. Areas susceptible to violence or natural disaster pose clear threats to individuals. An individual's environment also affects his or her development and behavioral choices. Resources available in the physical and social environments create the contexts within which decisions are made about health, education, and employment. Political and social environments also dictate whether resources are accessible to all adolescents. An examination of the residential distribution of adolescents provides a baseline for comparing geographical patterns of vulnerability. Within Uganda, by type of residence, the majority of adolescents (87 percent) live in rural versus urban areas. Figure 6 shows the distribution of adolescents aged 10 to 19 living in Uganda. Regional distributions show Karamoja contains only four percent of the adolescent population. Kampala with a much denser population contains 4.6 percent of the population. The Eastern and Western regions contain the largest proportions of the adolescent population.

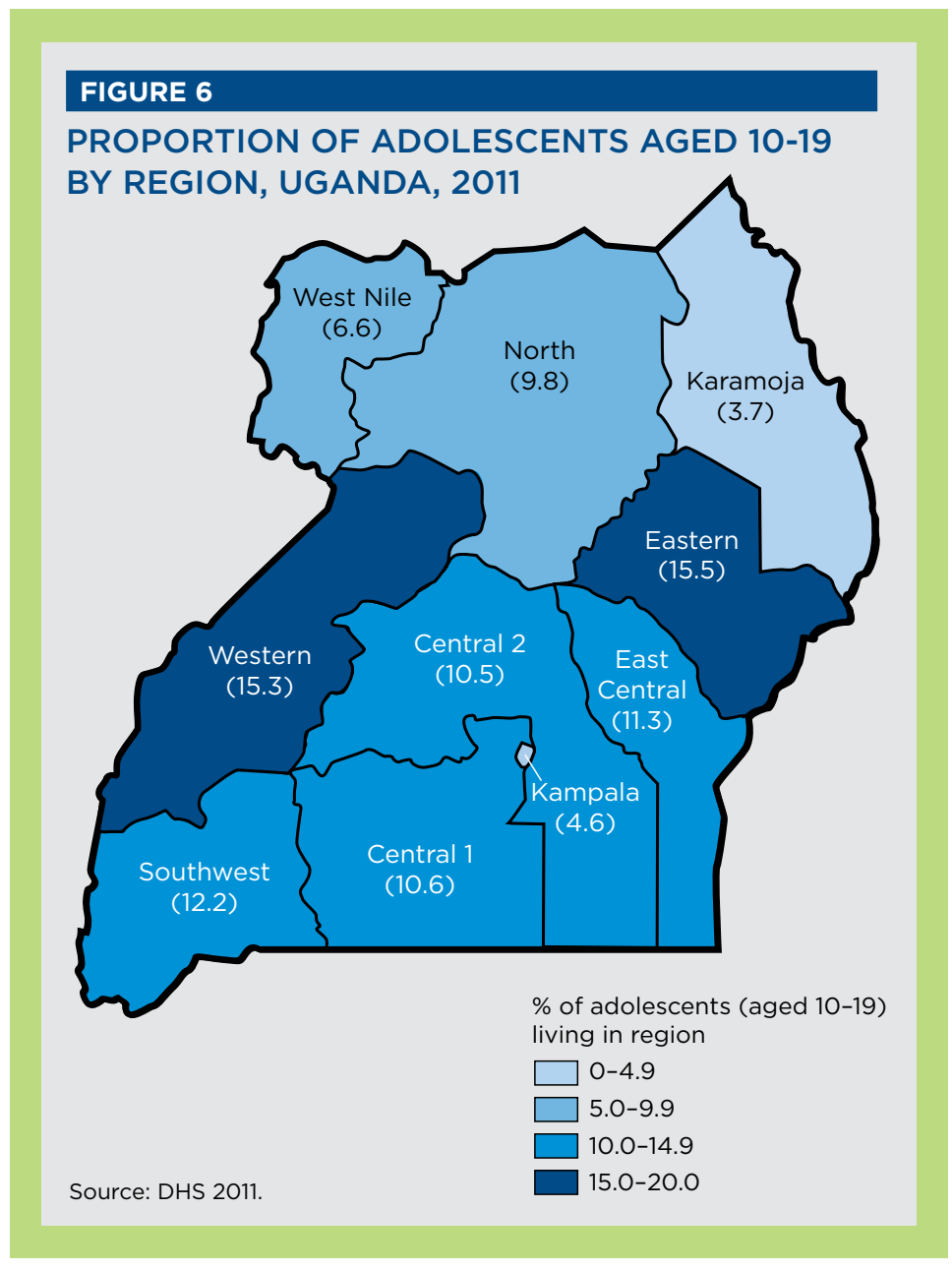

\section{Household factors influencing vulnerability}

Household-level factors have direct impacts on the well-being of adolescents. Households are the primary setting where adolescents live and engage in activities. For this reason, the household environment and the people who live there have significant impacts on the lives of adolescents. Physical conditions of the home influence the health of residents. Family structures and demographic characteristics of household members affect the knowledge, decisions, behaviors and interactions in the environment of the adolescent.

\section{Access to improved water sources and sanitation}

Unsafe water, inadequate sanitation, and poor hygiene are among the five leading risk factors responsible for one quarter of all deaths in the world (WHO 2009). Unsafe water supplies and inadequate sanitation in homes increase exposure to water-borne diseases and can cause diarrhea. Ensuring access to clean water sources and sanitation is key to maintaining hygiene and health. Improved water sources are those that either naturally protect water from contamination or are constructed to do so. These include piped water, public taps, standpipes, boreholes, tube wells, protected wells and springs, and rainwater collection. Improved sanitation includes constructs and systems that prevent fecal contamination. These include flush or pour toilets, ventilated pit latrines, pit latrines with slabs, and composting toilets (UNICEF 2013b).

Housing conditions across East and Southern Africa are largely in need of improvement, and lack of improved sanitation varies by country. In nearly all of East and Southern Africa, over half of adolescents either do not have improved sanitation or share facilities with other households. Conditions are worst in Madagascar and Mozambique where fewer than four percent of adolescents live in households with improved sanitation that is not shared (Figure 7). Rwanda has the lowest proportion of adolescents affected-35 percent-which is still unacceptably high. Lack of access to improved water sources affects lower proportions but is still a problem in the region. In five countries, fewer than half of adolescents have access to improved water sources (Figure 8). Water conditions are best in Namibia, where only 15 percent of adolescents have no access to improved water.

In Uganda, overall access to improved water and sanitation increased by a small but significant percentage between 2006 and 2011 (Figure 9). In 2006, 33 percent of adolescents had no access to improved water; in 2011, it is 30 percent. The proportion of adolescents without access to improved 


\section{FIGURE 7}

PERCENT OF ADOLESCENTS AGED 10-19

LIVING IN HOUSEHOLDS WITH NO

IMPROVED OR WITH SHARED SANITATION, EAST AND SOUTHERN AFRICA

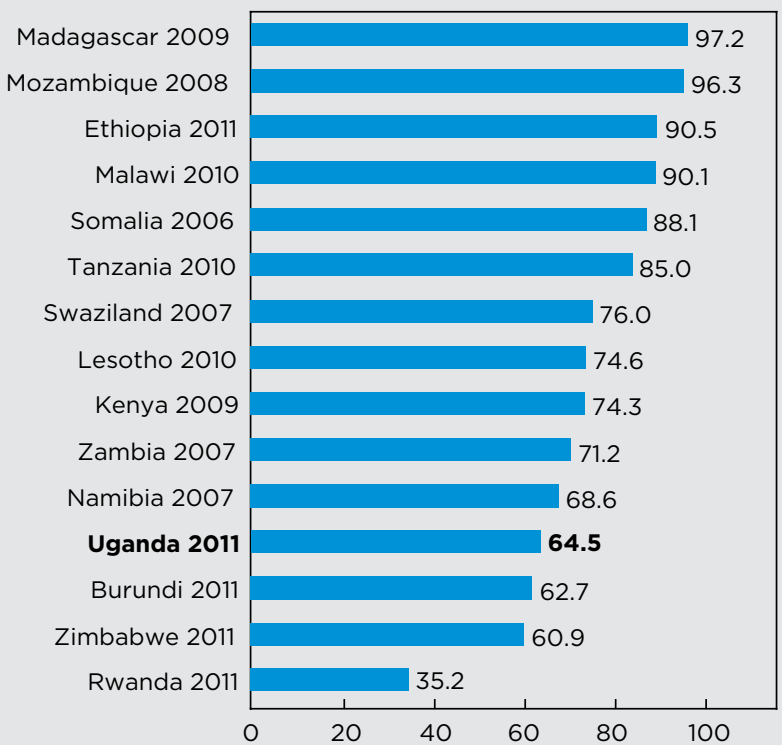

Source: DHS 2007-2011; MICS 2006-2008.

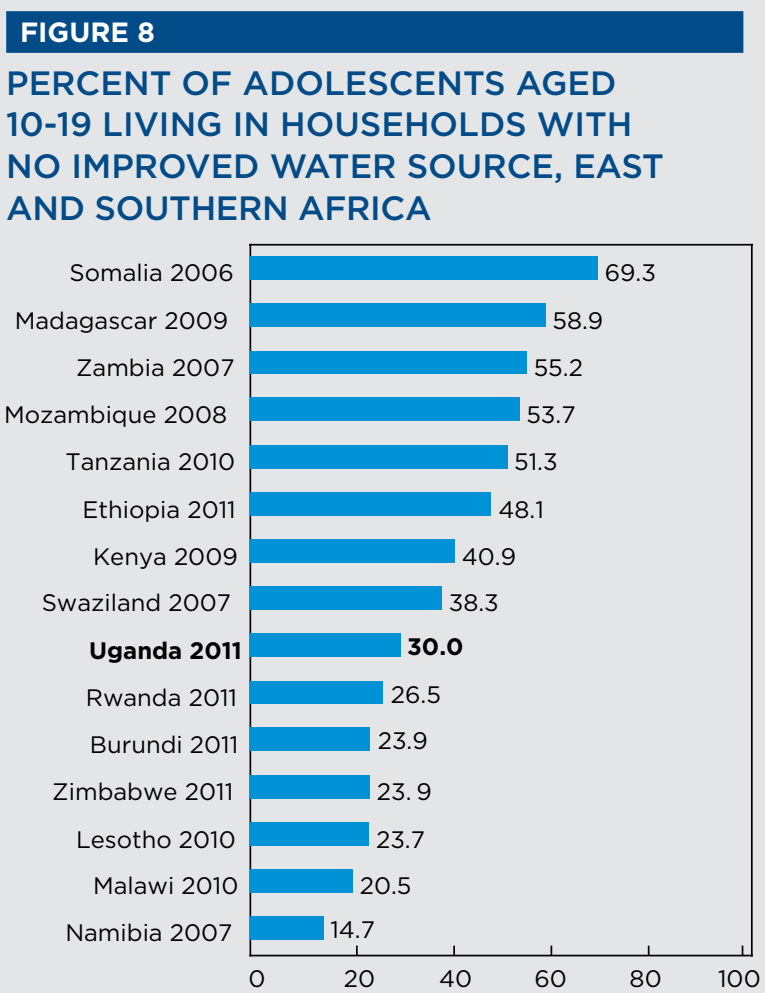

Source: DHS 2007-2011; MICS 2006-2008.

\section{FIGURE 9}

PERCENT OF ADOLESCENTS AGED 10-19 LIVING IN HOUSEHOLDS WITHOUT ACCESS TO IMPROVED WATER AND WITHOUT ACCESS TO IMPROVED OR WITH SHARED SANITATION, IN UGANDA, BY REGION, 2006 AND 2011

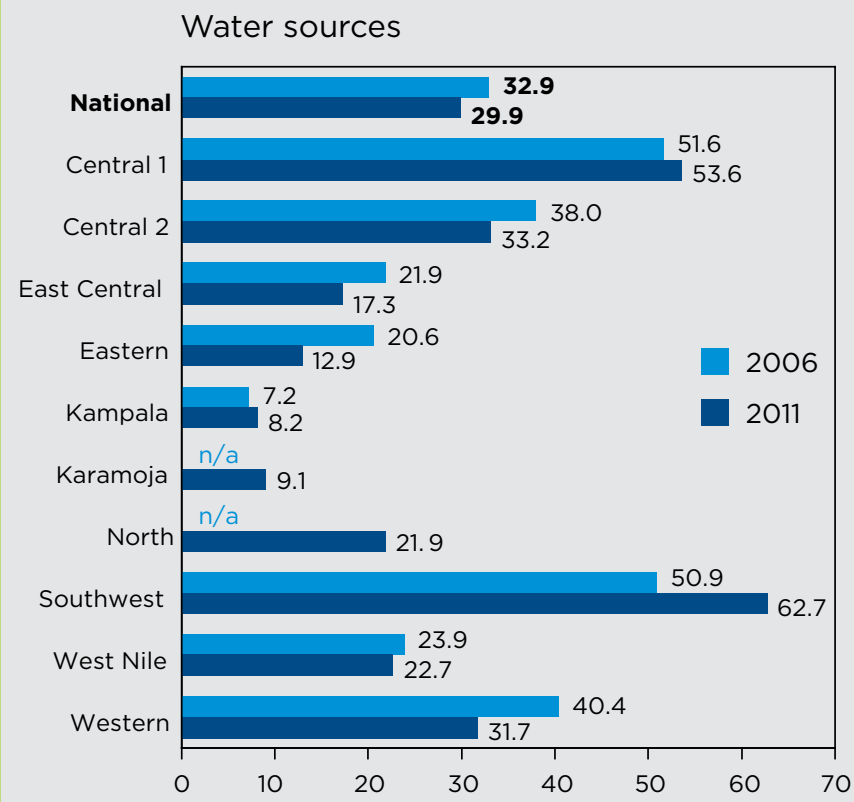

Sanitation or shared facilities

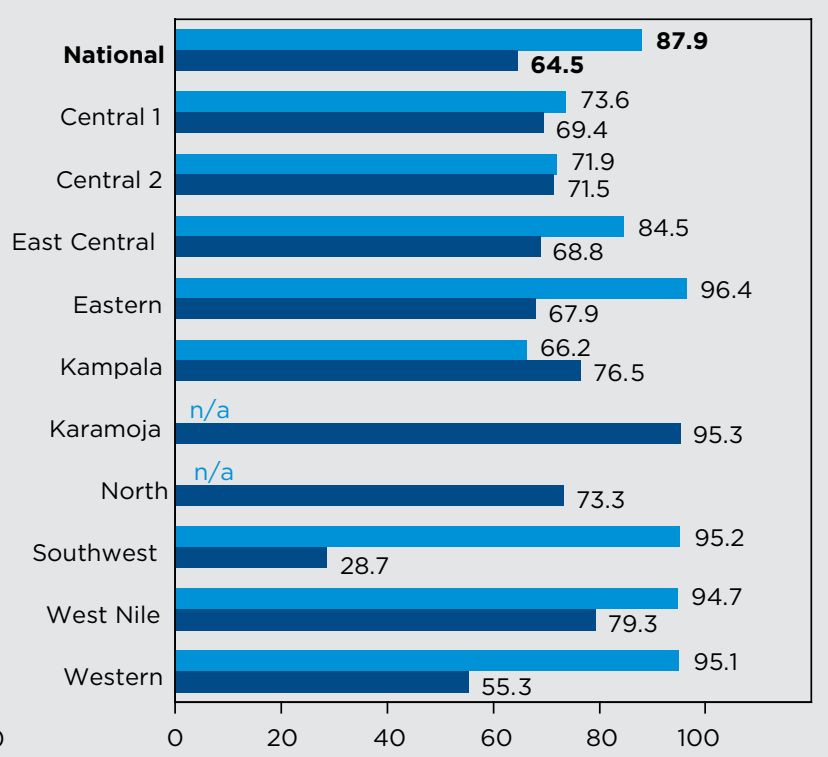

Source: DHS 2006 and 2011.

Note: Changes to the geographic boundaries were made to the North region in the 2011 DHS. The 2006 DHS North region is now divided into the North and Karamoja. For this reason, rates for 2006 are not shown for the North since it is not comparable and Karamoja was not identified in the previous survey. 
sanitation decreased significantly from 88 percent in 2006 to 65 percent in 2011. Although there have been improvements, both issues remain a problem. Access to improved sanitation is also a more prevalent problem compared to access to improved water sources. Sixty-five percent of adolescents do not have access to improved sanitation or share sanitation facilities, and 30 percent have no improved water sources. Conditions vary by region within the country. In 2011, between 28 and 95 percent of adolescents in various regions either do not have access to improved sanitation or share facilities. Although Karamoja has among the greatest access to improved water due to large proportions of boreholes, it has the least access to improved sanitation. Kampala shows similar patterns. The Southwest has the least access to improved water but is one of the better regions in the country for improved sanitation.

\section{Wealth}

Growing up in poverty is associated with negative outcomes across multiple areas of vulnerability. Wealth is an indicator of the ability to achieve and maintain adequate standards of living. At the most basic level this translates to providing shelter, food, and clothing. However, it is also associated with ability to access social and economic resources that improve well-being. With greater wealth comes increased access to schooling, with higher levels of income leading to greater investments in girls' schooling (Glick and Sahn 2000). Higher income also yields access to goods and services that promote overall well-being and health, including better nutrition, access to safe water, and access to higher quality health services (Bloom and Canning 2000).

Across East and Southern Africa, the proportion of adolescents living in the two poorest quintiles ranges from 36 to 45 percent (Table 1). In Uganda, approximately 38.5 percent of adolescents fall into the two poorest wealth quintiles. Large disparities in wealth are apparent by urban-rural distinctions across nations as well. In Uganda's urban areas, only 6 percent of 10 to 19 year olds are in the lowest two wealth quintiles compared to 39 percent overall in the nation. In rural areas, 43.3 percent of adolescents are in the poorest two quintiles. The regional rate for Kampala, Uganda's capital, shows no adolescents living in the two poorest quintiles (Figure 10). At the other extreme is Karamoja, a rural area that has suffered from poor climate, drought, and armed conflict and where 87 percent of adolescents are in the two poorest quintiles. This suggests that adolescents in rural areas are worse off than those in urban areas. Although the majority of urban dwellers are at a distinct relative wealth advantage, member- ship within the highest wealth quintile does not guarantee low risks for other indicators of vulnerability. Costs of living are often higher in urban compared to rural areas. The poor in urban areas also have lower access to resources and worse outcomes. Research suggests that the urban poor experience similar disadvantages to the rural poor in terms of health (Montgomery 2009). Other studies show that in urban slums children have low schooling enrollment levels similar to those in rural areas (Mugisha 2006). With urban populations in developing nations projected to grow significantly, investments in urban areas are as vital as those in rural areas.

\section{Education of the head of household}

Low levels of household education are consistently shown to be a risk factor for negative outcomes for adolescents and children. Within East and Southern Africa, the majority of countries have nearly a fifth to a quarter of adolescents living in households where the head has no education (Figure 11). Ethiopia and Burundi have the highest rates of adolescents aged 10-19 living with a household head who has no education, 59.5 and 57.5 percent respectively. Zambia has the lowest rate at 11 percent.

In Uganda, less than a fifth of adolescents aged 10 to 19 live with a household head with no education in 2011, with no significant change since 2006 (Figure 12). However, rates vary significantly by region across Uganda. Kampala has the lowest rates of adolescents living in households where the household head has no education. Karamoja has by far the highest levels of household heads with no education at 62 percent. Remaining regions fall in the middle with ranges from 12 to 24 percent.

\section{Living without parents in the household}

Adolescents living outside the protective structures of families may be at risk of deprivations for multiple reasons. Changes in household and family structures during adolescence have important consequences for familial and economic responsibilities. Adolescents living without parents, or living with a spouse, or with children may bear the burden of supporting themselves and additional family members. Adolescents in this situation may be forced to leave school early. Adolescents who are inadequately prepared to take on these roles may require additional economic, social, and emotional supports. Adolescents living without parents in a household may also face greater risks than those living with parents. Household situations for adolescents may not be safe. Adolescents may be exposed to or become victims of exploitation and 


\section{TABLE 1}

PERCENTAGE OF ADOLESCENTS AGED 10-19 LIVING IN THE TWO POOREST

WEALTH QUINTILES, EAST AND SOUTHERN AFRICA

\begin{tabular}{|lrrr|}
\hline & All & Urban & Rural \\
\hline Burundi 2011 & 38.4 & 6.8 & 41.8 \\
\hline Ethiopia 2011 & 37.5 & 3.9 & 45.3 \\
\hline Kenya 2009 & 43.7 & 3.3 & 50.3 \\
\hline Lesotho 2010 & 39.9 & 3.1 & 49.9 \\
\hline Madagascar 2009 & 37.9 & 2.6 & 43.7 \\
\hline Mozambique 2008 & 36.1 & 9.1 & 51.2 \\
\hline Malawi 2010 & 38.1 & 5.7 & 44.0 \\
\hline Namibia 2007 & 45.3 & 5.7 & 67.3 \\
\hline Rwanda 2011 & 38.0 & 18.7 & 40.8 \\
\hline Somalia 2006 & 38.3 & 1.8 & 64.2 \\
\hline Swaziland 2007 & 41.2 & 4.8 & 48.0 \\
\hline Tanzania 2010 & 38.0 & 5.5 & 47.8 \\
\hline Uganda 2011 & $\mathbf{3 8 . 5}$ & $\mathbf{5 . 7}$ & $\mathbf{4 3 . 3}$ \\
\hline Zambia 2007 & 35.8 & 0.5 & 59.3 \\
\hline Zimbabwe 2011 & 41.4 & 0.7 & 56.4 \\
\hline
\end{tabular}

Source: DHS 2007-2011; MICS 2006-2008.

\section{FIGURE 11}

PERCENTAGE OF ADOLESCENTS AGED 10-19 LIVING WITH A HOUSEHOLD HEAD WITH NO EDUCATION, EAST AND SOUTHERN AFRICA

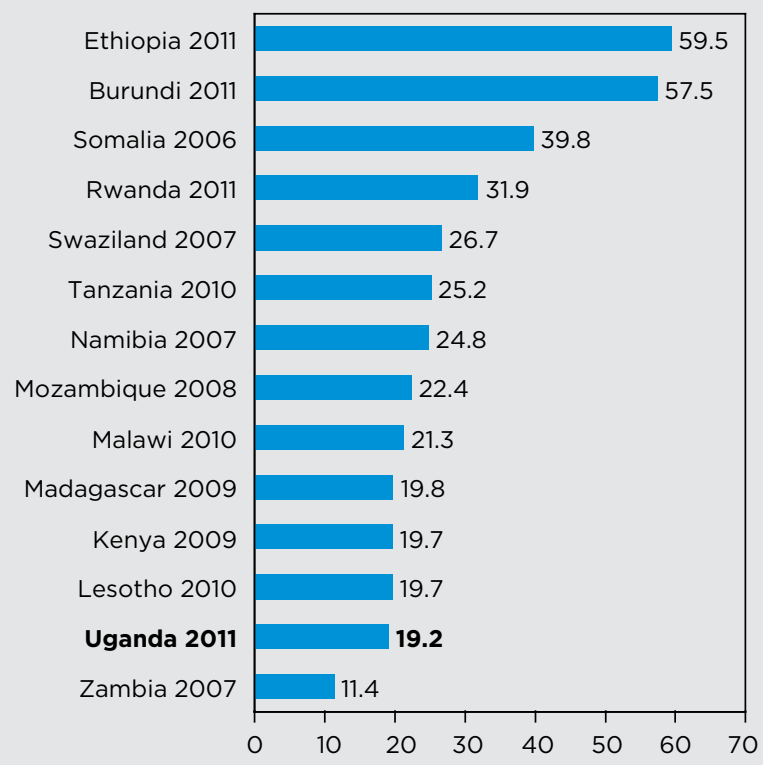

Source: DHS 2007-2011; MICS 2006-2008.

\section{FIGURE 10}

PERCENTAGE OF ADOLESCENTS AGED 10-19 LIVING IN EACH WEALTH QUINTILE, UGANDA, 2011

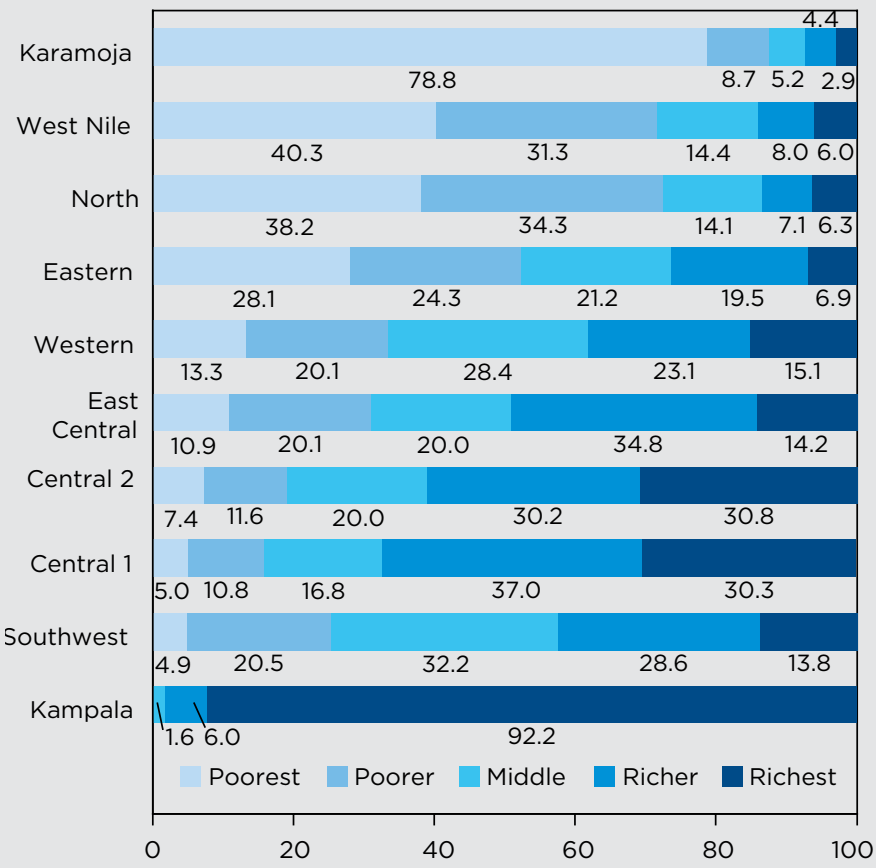

Source: DHS 2011

\section{FIGURE 12}

PERCENTAGE OF ADOLESCENTS AGED 10-19 LIVING IN HOUSEHOLDS WHERE THE HEAD OF HOUSEHOLD HAS NO EDUCATION, UGANDA, 2006 AND 2011

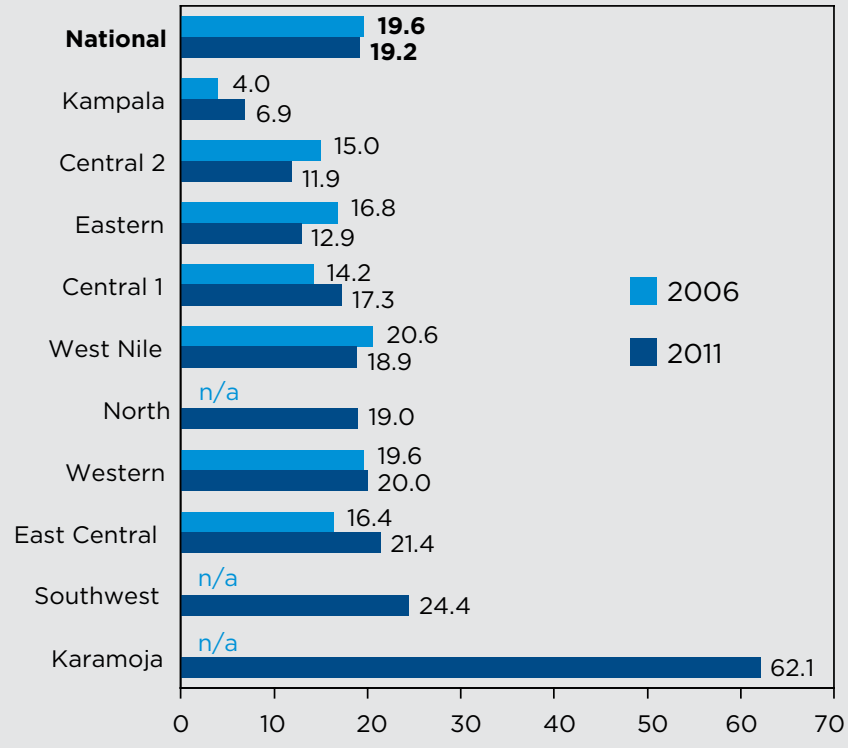

Source: DHS 2006 and 2011. 
violence. Within this group are adolescents whose parents have died, domestic workers, and children who have left home intentionally. However, in some cases, adolescents may be living without parents for beneficial reasons. For example, in many countries, fostering is common where children migrate to gain access to better schooling opportunities.

Across East and Southern Africa, proportions of adolescents by parental residence in the household vary by country (Figure 13). The proportion of adolescents living with neither biological parent ranges from nine percent in Somalia to over 44 percent in Namibia for adolescent boys and girls ages 10 to 14 . In Uganda 19.4 percent of adolescents lived without either biological parent in 2011. Uganda has seen improvements on this front with a significant decrease of 9 percentage points in the past five years (Figure 14). In 2006, 28 percent of adolescents in this age group lived in households without either parent. In 2006, the lowest percentage (21 percent) was found in the Western region while the highest percentage (38 percent) without parents was found in Central 1 region. The latest Demographic and Health Survey from 2011 shows that across nearly all regions in Uganda, fewer than a quarter of children are living without any parent. At 11 percent, Karamoja has the lowest rates of children living without any parent.

\section{Individual-level factors influencing vulnerability}

\section{Preparation for decent livelihoods}

At the individual level, adolescence is a time when boys and girls build human and social assets used for roles in the worlds of work, family, and society. Schooling is the major route through which adolescents gain skills and knowledge to be used throughout their lives. Literacy and numeracy are basic skills needed for gainful employment. Central to human capacity are health and well-being. The health behaviors learned in this stage of development have lasting implications for future health and productivity. Together these skills prepare adolescents for decent livelihoods and offer them a full range of life chances. Overall trends are positive for both boys and girls - the health and education of young people in low-resource settings is improving (Lloyd 2006), but progress has been uneven, particularly for the most vulnerable.

\section{Age}

Adolescents have different needs and vulnerabilities, and age is often a key determinant in identifying level of risk. There is wide variation even within the 10 to 19 year age group. Adolescents ages 10 to 14 are physically, psychologically, and socially different from those 15 to 19. Boys and girls differ in their age pattern of physiological development. Girls experience physical maturation and puberty earlier than boys. The onset of puberty often marks the beginning of sexual activity and with it, risks of becoming pregnant and increased risk of contracting sexually transmitted diseases. Adolescence also alters the ways in which families, communities, and social institutions treat girls. This can result in increased risk of experiencing sexual coercion or violence. A study in Uganda found 23 percent of girls aged 12-19 experienced forced sexual initiation (Moore et al. 2007). Intervening before the onset of puberty can lead to better health outcomes in later life. Key transitions in school, work, and family also take place within this period.

\section{Education}

Education is key to eliminating gender inequality, reducing poverty, and improving outcomes among girls. Schooling enhances human capital by increasing skills and knowledge used for gainful employment. Livelihoods education can lead to increased economic security and greater financial assets. Schooling also has implications for social well-being. Across income groups, girls are often more socially isolated than boys with smaller networks and fewer opportunities to meet friends (Bruce 2007b). Girls can increase their social networks and supports through school participation. Girls' attendance in formal schooling is also associated with delayed sexual initiation, marriage and childbearing; lower rates of HIV/AIDS; and engaging in fewer hours of domestic work. There are also spillover effects for the families of these girls. Improvements in schooling lead to improved health of women and their families. Higher maternal education is associated with safer health and hygiene practices, greater access to information used to enhance children's health, better nutrition, more equality in household relationships, and greater earnings and economic resources within families (Lloyd and Young 2009).

Educational trends in developing nations have improved with increased access to schooling, elimination of school fees, and the proliferation of universal primary education policies (Lloyd 2006). Within East and Southern Africa, rates of enrollment for adolescents ages 10-14 are relatively high, but enrollment is still not universal (Figure 15). A clear pattern emerges across the region, showing that older adolescents are at a disadvantage in schooling, particularly girls. Enrollment rates for both boys and girls ages 15 to 19 range from a low of 31 percent among girls in Madagascar and Somalia to 82 percent among boys in Kenya (Figure 16). In nearly every country examined, 


\section{FIGURE 13 \\ PERCENTAGE OF ADOLESCENTS AGED 10- 14 LIVING WITHOUT EITHER BIOLOGICAL PARENT IN THE HOUSEHOLD, EAST AND SOUTHERN AFRICA

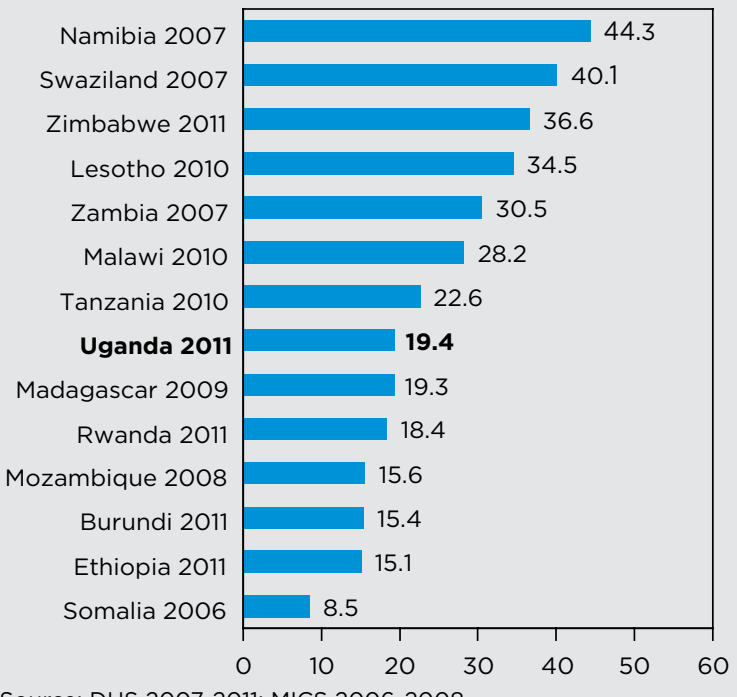 \\ Source: DHS 2007-2011; MICS 2006-2008.}

\section{FIGURE 15}

PERCENTAGE OF ADOLESCENT GIRLS AND BOYS AGED 10-14 WHO REPORTED ATTENDING SCHOOL ANY TIME DURING CURRENT YEAR, EAST AND SOUTHERN AFRICA

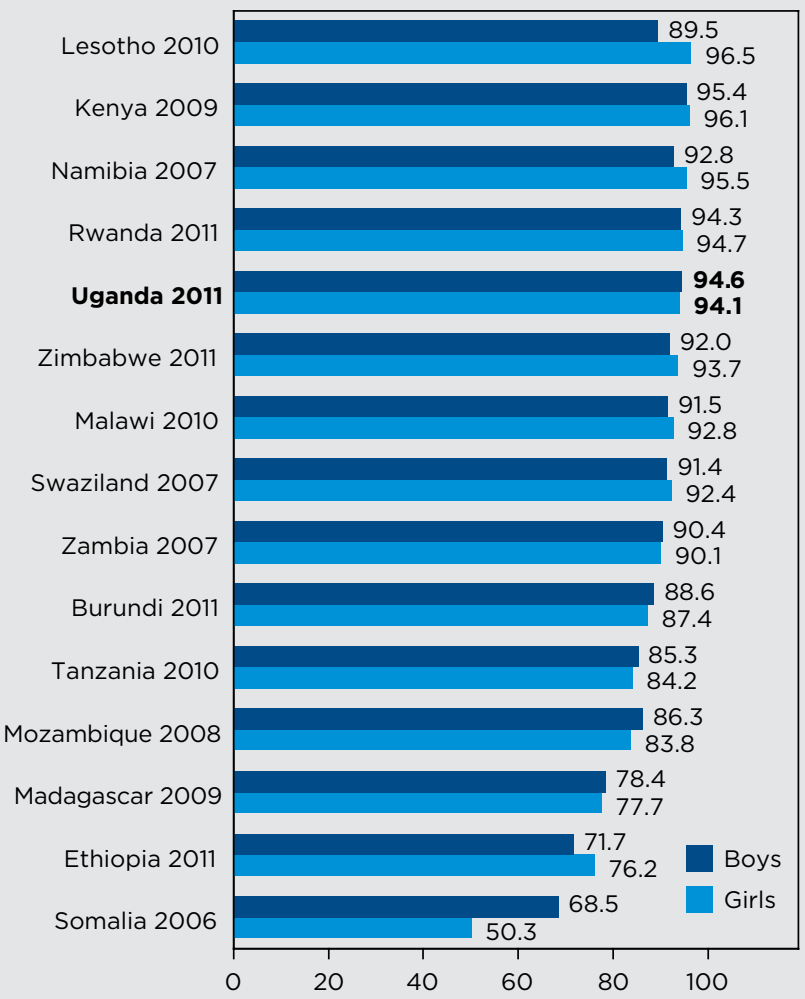

Source: DHS 2007-2011; MICS 2006-2008

\section{FIGURE 14}

PERCENTAGE OF ADOLESCENTS IN UGANDA

AGED 10-14 LIVING WITHOUT EITHER

BIOLOGICAL PARENT IN THE HOUSEHOLD, BY REGION, 2006 AND 2011

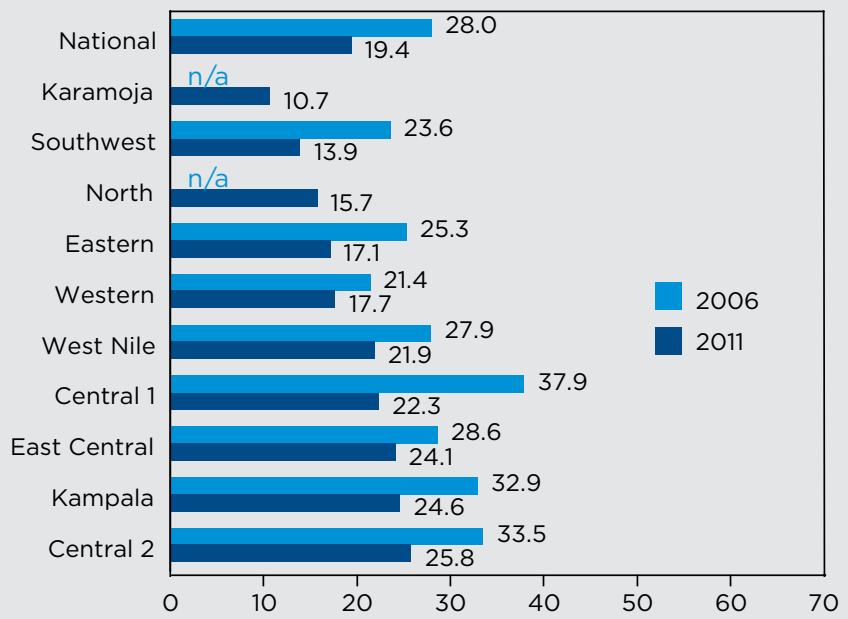

Source: DHS 2006 and 2011.

\section{FIGURE 16}

PERCENTAGE OF ADOLESCENT GIRLS AND BOYS AGED 15-19 WHO REPORTED ATTENDING SCHOOL ANY TIME DURING CURRENT YEAR, EAST AND SOUTHERN AFRICA

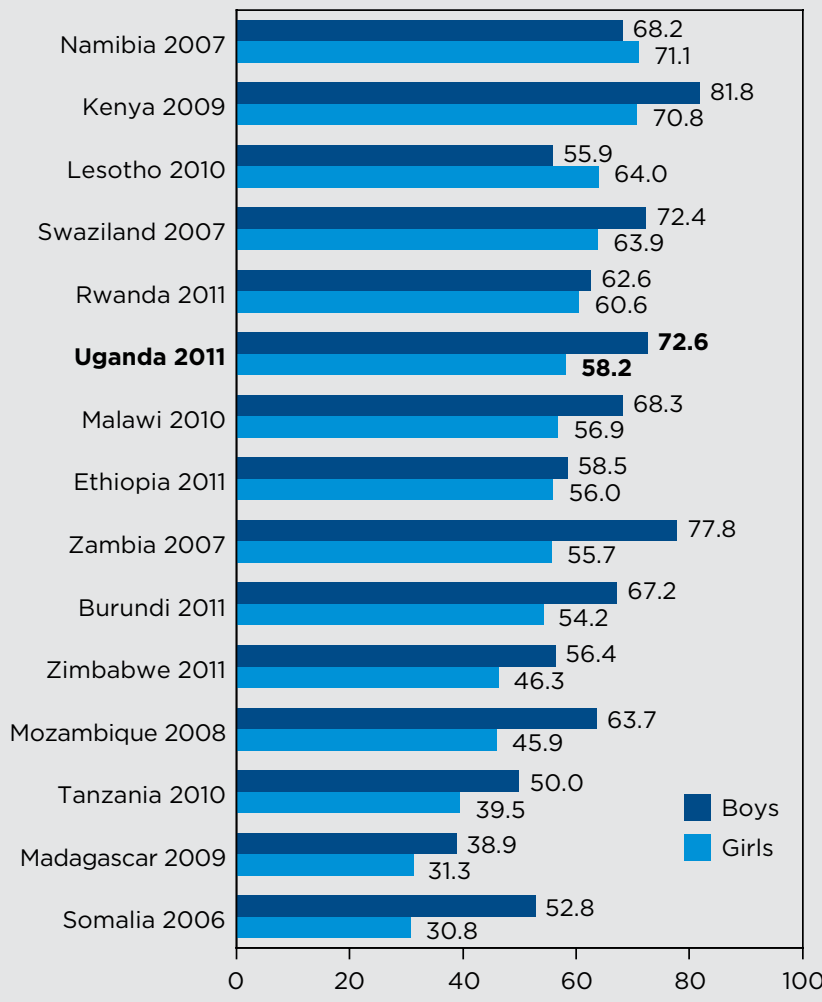

Source: DHS 2007-2011; MICS 2006-2008. 
adolescent girls aged 15 to 19 are enrolled in school at lower rates compared to boys. Only in Lesotho and Namibia is the ratio of boys to girls aged 15-19 who attended school during the current year at or greater than one (indicating girl advantage) (Table 2). These differences are greatest in Somalia where only 58 girls attend school for every 100 boys in the 15 to 19 year old age group.

Girls who are not in school experience threats to economic security and health, and often face pressures to marry (Bruce 2007b). Overall, the proportion of girls who are attending school in the 10 to 14 and the 15 to 19 year old age groups have not changed significantly since 2006 in Uganda (Table 3). In 2011, rates for younger adolescents are generally high for girls except in Karamoja where fewer than two-thirds are in school. In the 15 to 19 year old group, Kampala, the West Nile, and the Southwest showed statistically significant differences in rates of girls attending school between 2006 and 2011. In the Southwest, significantly more girls are attending school. In Kampala and the West Nile, proportions of girls aged 15-19 who are attending school have decreased.

Although girls may be attending school, many are behind in schooling. To examine which girls are potentially on- and off-track to achieving higher levels of education, we classify girls into categories based on current enrollment and grade for age-a measure of whether an adolescent is in the appropriate grade level for his or her age. The first category is girls who have never been to school.

The second is those who have been to school but are not currently enrolled. Next are the girls who are in school but not at grade for age-two or more years behind in grade. Finally, there are those who are in school and at grade for age.

Within East and Southern Africa, many adolescent girls lag behind in schooling (Table 4). Larger proportions of younger adolescent girls are on track in school compared to older girls. Many young adolescents are in school but not all of them are at grade for age. Zimbabwe has the best schooling outcomes with 87 percent of girls in school and at grade for age. In Somalia, 41 percent of girls aged 10 to 14 have never been to school and an additional 8.7 percent did not attend during the current school year.

In the older cohort, adolescent girls fall farther behind. Proportions who have never attended school are similar to younger groups. However, drop off rates worsen for older girls. In Zimbabwe, which has the highest proportion of girls in school and at grade for age within the 10 to 14 year old group,

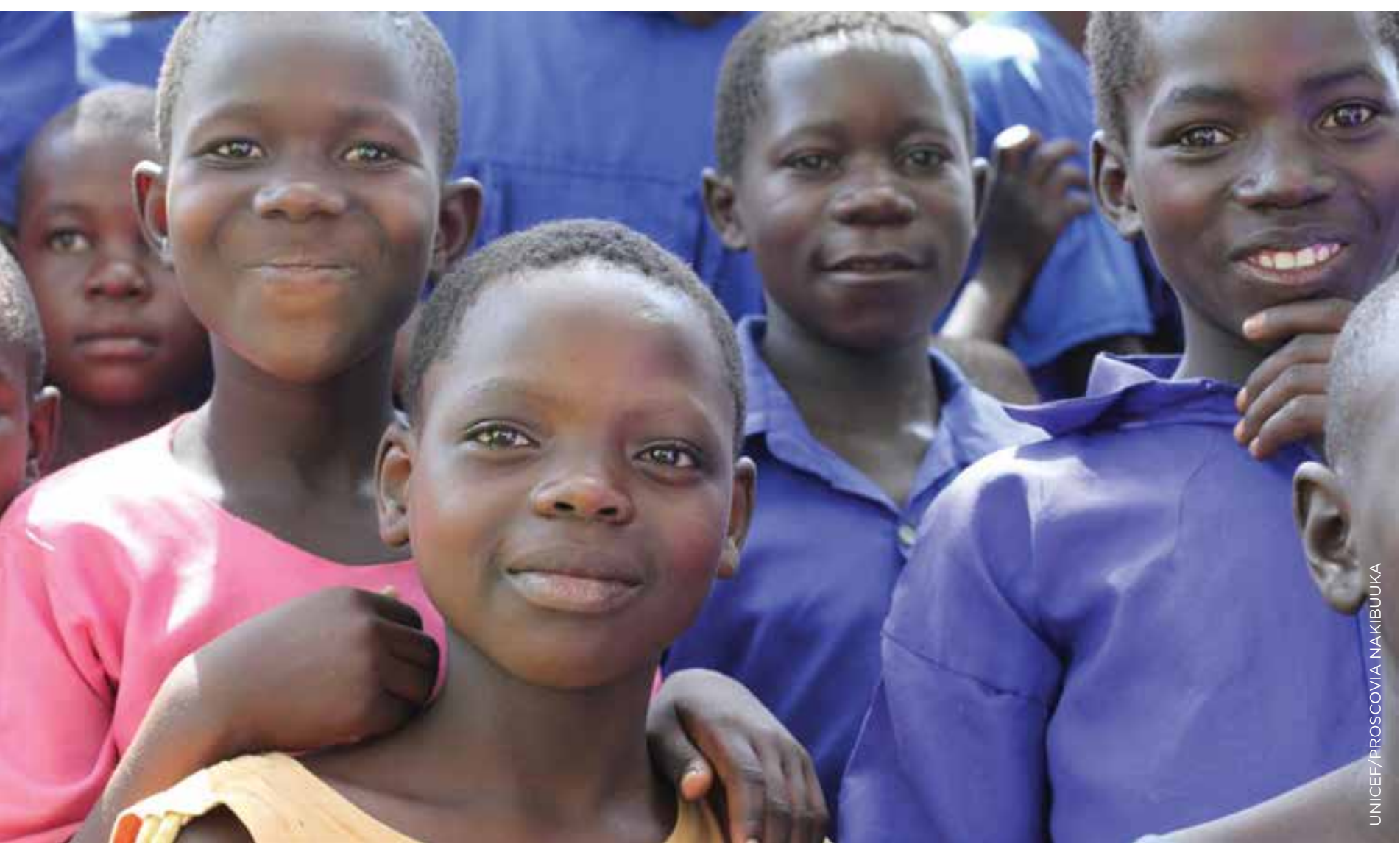

By attending school, girls can increase their social networks and supports. These girls from Nankoma Primary School in the Bugiri District of Uganda gather to attend a skills-building activity. 


\section{TABLE 2}

RATIO OF GIRLS TO BOYS WHO REPORT

ATTENDING SCHOOL AT ANY TIME DURING CURRENT YEAR, BY AGE GROUP, IN EAST AND SOUTHERN AFRICA

\begin{tabular}{|l|c|c|}
\hline & \multicolumn{2}{c|}{ Ratio of girls to boys } \\
\cline { 2 - 3 } & Aged 10-14 & Aged 15-19 \\
\hline Burundi 2011 & 0.99 & 0.81 \\
\hline Ethiopia 2011 & 1.06 & 0.96 \\
\hline Kenya 2009 & 1.01 & 0.87 \\
\hline Lesotho 2010 & 1.08 & 1.14 \\
\hline Madagascar 2009 & 0.99 & 0.81 \\
\hline Mozambique 2008 & 0.97 & 0.72 \\
\hline Malawi 2010 & 1.01 & 0.83 \\
\hline Namibia 2007 & 1.03 & 1.04 \\
\hline Rwanda 2011 & 1.00 & 0.97 \\
\hline Somalia 2006 & 0.73 & 0.58 \\
\hline Swaziland 2007 & 1.01 & 0.88 \\
\hline Tanzania 2010 & 0.99 & 0.79 \\
\hline Uganda 2011 & 0.99 & 0.80 \\
\hline Zambia 2007 & 1.00 & 0.72 \\
\hline Zimbabwe 2011 & 1.02 & 0.82 \\
\hline Note: White boxe
\end{tabular}

Note: White boxes highlight values less than 1.00

Source: DHS 2007-2011; MICS 2006-2008.

\section{TABLE 3}

PERCENTAGE OF ADOLESCENT GIRLS WHO ATTENDED SCHOOL AT ANY TIME DURING CURRENT YEAR, IN UGANDA, BY AGE AND REGION, 2006 AND 2011

\begin{tabular}{lrrrrrr} 
& \multicolumn{2}{c}{ Aged 10-14 } & & \multicolumn{2}{c}{ Aged 15-19 } \\
\cline { 2 - 3 } \cline { 6 - 6 } National & $\mathbf{2 0 0 6}$ & $\mathbf{2 0 1 1}$ & & $\mathbf{2 0 0 6}$ & $\mathbf{2 0 1 1}$ \\
\cline { 1 - 2 } Central 1 & $\mathbf{9 2 . 2}$ & $\mathbf{9 4 . 1}$ & & $\mathbf{5 4 . 2}$ & $\mathbf{5 8 . 2}$ \\
\hline Central 2 & 94.9 & 97.3 & & 58.3 & 64.7 \\
East Central & 97.2 & 98.5 & & 57.7 & 62.9 \\
\hline Eastern & 94.8 & 96.7 & & 63.3 & 63.2 \\
\hline Kampala & 96.5 & 96.8 & & 60.5 & 63.0 \\
\hline Karamoja & 90.3 & 89.9 & & 59.8 & 41.9 \\
\hline North & $\mathrm{n} / \mathrm{a}$ & 58.8 & & $\mathrm{n} / \mathrm{a}$ & 26.2 \\
\hline Southwest & 93.5 & 96.6 & & 49.4 & 63.0 \\
\hline West Nile & 91.6 & 88.6 & & 56.5 & 46.7 \\
\hline Western & 92.3 & 94.8 & & 50.3 & 59.5 \\
\hline
\end{tabular}

Source: DHS 2006 and 2011.

\section{TABLE 4}

PERCENTAGE OF ADOLESCENT GIRLS, BY SCHOOL CATEGORIES AND AGE GROUPS, EAST AND SOUTHERN AFRICA

\begin{tabular}{|c|c|c|c|c|c|c|c|c|}
\hline & \multicolumn{4}{|c|}{ Aged 10-14 } & \multicolumn{4}{|c|}{ Aged 15-19 } \\
\hline & $\begin{array}{r}\text { Never } \\
\text { been to } \\
\text { school }\end{array}$ & $\begin{array}{r}\text { Been to } \\
\text { school } \\
\text { but not } \\
\text { in school }\end{array}$ & $\begin{array}{r}\text { In school, } \\
\text { not grade } \\
\text { for age }\end{array}$ & $\begin{array}{l}\text { In school } \\
\text { and grade } \\
\text { for age }\end{array}$ & $\begin{array}{r}\text { Never } \\
\text { been to } \\
\text { school }\end{array}$ & $\begin{array}{r}\text { Been to } \\
\text { school } \\
\text { but not } \\
\text { in school }\end{array}$ & $\begin{array}{r}\text { In school, } \\
\text { not grade } \\
\text { for age }\end{array}$ & $\begin{array}{l}\text { In school } \\
\text { and grade } \\
\text { for age }\end{array}$ \\
\hline Burundi 2011 & 6.8 & 5.7 & 53.7 & 33.8 & 22.1 & 23.6 & 49.6 & 4.8 \\
\hline Ethiopia 2011 & 17.2 & 6.5 & 44.6 & 31.7 & 18.3 & 25.7 & 43.6 & 12.4 \\
\hline Kenya 2009 & 3.2 & 0.6 & 24.8 & 71.4 & 4.8 & 24.4 & 37.0 & 33.9 \\
\hline Lesotho 2010 & 0.6 & 2.9 & 21.7 & 74.8 & 0.8 & 35.1 & 32.7 & 31.5 \\
\hline Madagascar 2009 & 9.2 & 12.9 & 35.4 & 42.5 & 13.7 & 54.9 & 19.3 & 12.2 \\
\hline Mozambique 2008 & 9.3 & 6.9 & 59.9 & 24.0 & 11.4 & 42.7 & 41.2 & 4.6 \\
\hline Malawi 2010 & 2.5 & 4.4 & 41.2 & 52.0 & 3.6 & 39.5 & 35.1 & 21.9 \\
\hline Namibia 2007 & 2.8 & 1.4 & 17.6 & 78.2 & 2.9 & 25.7 & 27.8 & 43.6 \\
\hline Rwanda 2011 & 1.7 & 3.6 & 56.8 & 37.9 & 3.2 & 36.2 & 54.4 & 6.2 \\
\hline Somalia 2006 & 41.1 & 8.7 & 40.5 & 9.8 & 45.1 & 24.1 & 25.6 & 5.1 \\
\hline Swaziland 2007 & 2.3 & 5.0 & 23.7 & 68.9 & 2.8 & 33.2 & 31.1 & 33.0 \\
\hline Tanzania 2010 & 7.1 & 8.6 & 18.9 & 65.4 & 9.3 & 51.1 & 19.1 & 20.5 \\
\hline Uganda 2011 & 3.4 & 2.5 & 53.8 & 40.3 & 3.3 & 38.4 & 42.2 & 16.0 \\
\hline Zambia 2007 & 5.3 & 4.5 & 37.6 & 52.7 & 4.4 & 39.9 & 31.5 & 24.2 \\
\hline Zimbabwe 2011 & 1.0 & 5.3 & 6.6 & 87.1 & 1.1 & 52.5 & 4.5 & 41.8 \\
\hline
\end{tabular}

Source: DHS 2007-2011; MICS 2006-2008. 


\section{Adolescent girls'}

schooling in Uganda

falls behind levels in

several other countries

in the region. Among

10 to 14 year olds, 94

percent are in school

but only $\mathbf{4 0}$ percent are

in school and at grade

for age. over half of 15 to 19 year old girls are no longer in school. In Burundi, Mozambique, Rwanda, and Somalia, less than 7 percent of girls are in school and at grade for age. Namibia has the lowest proportion of adolescent girls who are not in school and the largest proportion that are in school and at grade for age (44 percent).

Adolescent girls' schooling in Uganda falls behind levels in several other countries in the region. Among 10 to 14 year olds, 94 percent are in school but only 40 percent are in school and at grade for age. For ages 15 to 19 , only 17 percent are at grade for age. In most regions, adolescent girls ages 10 to 14 are in school but not at grade for age (Table 5). Karamoja has the lowest proportions of girls on track in this age group. Estimates from 2006 and 2011 show significant changes in the West Nile and Western regions over those five years. For 15 to 19 year olds, across all regions, over 35 percent are not in school (Table 6). In 2011, Karamoja has the highest proportion of girls who are not in school and/or have never been to school (data not available for 2006). The North, West Nile, and Western regions have the lowest proportions of girls who are in school and at grade for age. Although Kampala has the highest proportion of girls who are in school and at grade for age, the majority of regions have greater proportions in school. Significant changes have occurred since 2006. In Kampala, fewer girls are in school and/or at grade for age in 2011 compared to 2006. The Southwest has a greater proportion of girls who are staying in school.
Table 7 shows the distribution of characteristics of adolescent girls within each category of school attendance and grade for age. In both age groups, the highest proportion of girls who have never been to school are from the poorest wealth quintiles. Seventy one percent of 10 to 14 year old girls and 64 percent of 15 to 19 year old girls who have never been to school are in the poorest quintile. Girls who are in school and at grade for age are more likely to be in the richest quintiles. In the lower quintiles including the middle, fewer than 10 percent of older girls are in school and at grade for age.

Marital status and having given birth appear to be correlated with schooling (Table 7). Among 15 to 19 year olds girls who are in school and at grade for age or behind, nearly all are not married and have never given birth. Among those who have never been to school or are no longer in school, 28 to 42 percent have given birth and over half are married. The order and timing of school dropout and marriage and childbirth are not apparent from this data. However, research suggests that pregnancy and marriage typically occur after school dropout rather than being the causes; most girls who leave school early do so for other reasons (Lloyd and Young 2009).

In terms of school advancement, a relatively low percentage of adolescent girls in East and Southern Africa ever attend secondary school. In 11 out of 15 countries examined, more than half of adolescent girls aged 15 to 19 have never attended secondary school (see Figure 17). In Zimbabwe, only 23 percent of adolescent girls aged 15-19 have never attended secondary school. Countries with the highest percentages of never attending are Ethiopia, Burundi, and Mozambique. And despite Uganda's universal secondary school policy, nearly 69 percent of older adolescent girls have not yet attended any secondary school (Figure 18). In Uganda the secondary school starting age is 13 . Within Uganda, regional rates of never attending secondary school range from a low of 41 percent in Kampala to a high of 89 percent in the North and West Nile regions. Since 2006, overall and in most regions, there have been no improvements or significant changes. The Western region of the country is the only area showing significant improvement in reducing the proportion of girls who do not attend secondary school.

Although access to primary schooling is increasing, literacy rates in many sub-Saharan countries continue to be subpar. Rates of literacy-measured as the ability to read a simple sentence-show that despite most boys and girls attending school until age 14, many adolescents are still unable to read. Among female adolescents aged 15 to 19, literacy rates are high in Lesotho, Swaziland, Zimbabwe, 


\section{TABLE 5}

PERCENTAGE OF ADOLESCENT GIRLS AGED 10-14, BY SCHOOLING CATEGORIES AND REGION, UGANDA, 2006 AND 2011

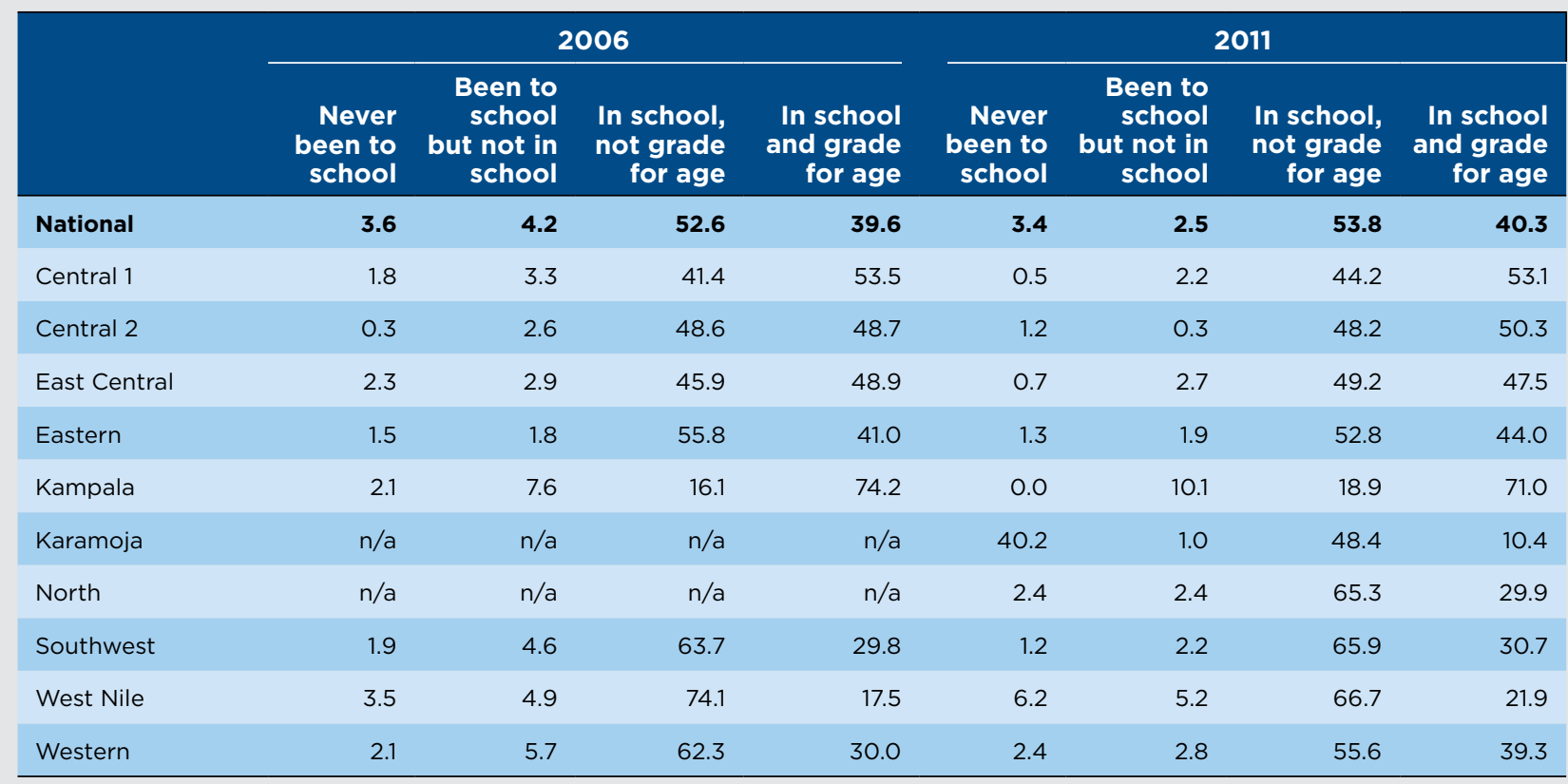

Source: DHS 2007-2011; MICS 2006-2008.

\section{TABLE 6}

PERCENTAGE OF ADOLESCENT GIRLS AGED 15-19, BY SCHOOLING CATEGORIES AND REGION, UGANDA, 2006 AND 2011

\begin{tabular}{|c|c|c|c|c|c|c|c|c|}
\hline & \multicolumn{4}{|c|}{2006} & \multicolumn{4}{|c|}{2011} \\
\hline & $\begin{array}{r}\text { Never } \\
\text { been to } \\
\text { school }\end{array}$ & $\begin{array}{r}\text { Been to } \\
\text { school } \\
\text { but not in } \\
\text { school }\end{array}$ & $\begin{array}{l}\text { In school, } \\
\text { not grade } \\
\text { for age }\end{array}$ & $\begin{array}{r}\text { In school } \\
\text { and grade } \\
\text { for age }\end{array}$ & $\begin{array}{r}\text { Never } \\
\text { been to } \\
\text { school }\end{array}$ & $\begin{array}{r}\text { Been to } \\
\text { school } \\
\text { but not in } \\
\text { school }\end{array}$ & $\begin{array}{r}\text { In school, } \\
\text { not grade } \\
\text { for age }\end{array}$ & $\begin{array}{l}\text { In school } \\
\text { and grade } \\
\text { for age }\end{array}$ \\
\hline National & 3.7 & 42.3 & 37.4 & 16.6 & 2.7 & 38.9 & 41.9 & 16.5 \\
\hline Central 1 & 0.3 & 40.9 & 25.0 & 33.8 & 1.9 & 35.4 & 30.7 & 32.1 \\
\hline Central 2 & 1.9 & 40.4 & 36.8 & 20.9 & 0.3 & 35.8 & 37.3 & 26.7 \\
\hline East Central & 1.6 & 36.2 & 43.6 & 18.6 & 0.0 & 38.7 & 44.3 & 17.0 \\
\hline Eastern & 1.4 & 38.4 & 47.4 & 12.7 & 0.7 & 36.8 & 52.0 & 10.5 \\
\hline Kampala & 1.3 & 38.2 & 15.0 & 45.5 & 1.1 & 58.5 & 6.4 & 34.0 \\
\hline Karamoja & $\mathrm{n} / \mathrm{a}$ & $\mathrm{n} / \mathrm{a}$ & $n / a$ & $\mathrm{n} / \mathrm{a}$ & 46.3 & 27.0 & 18.9 & 7.8 \\
\hline North & $\mathrm{n} / \mathrm{a}$ & $n / a$ & $\mathrm{n} / \mathrm{a}$ & $\mathrm{n} / \mathrm{a}$ & 1.1 & 40.0 & 55.2 & 3.7 \\
\hline Southwest & 3.6 & 46.2 & 38.1 & 12.2 & 0.5 & 34.6 & 51.9 & 13.1 \\
\hline West Nile & 4.5 & 40.3 & 52.5 & 2.7 & 3.5 & 46.1 & 46.4 & 4.0 \\
\hline Western & 4.4 & 47.2 & 42.6 & 5.9 & 2.3 & 37.2 & 49.4 & 11.1 \\
\hline
\end{tabular}

Source: DHS 2007-2011; MICS 2006-2008. 


\section{TABLE 7}

DISTRIBUTION OF CHARACTERISTICS WITHIN SCHOOL CATEGORIES OF ADOLESCENT GIRLS, UGANDA, 2011

\begin{tabular}{|c|c|c|c|c|c|c|c|c|}
\hline & \multicolumn{4}{|c|}{ Aged 10-14 } & \multicolumn{4}{|c|}{ Aged 15-19 } \\
\hline & $\begin{array}{r}\text { Never } \\
\text { been to } \\
\text { school }\end{array}$ & $\begin{array}{r}\text { Been to } \\
\text { school } \\
\text { but not in } \\
\text { school }\end{array}$ & $\begin{array}{r}\text { In school, } \\
\text { not grade } \\
\text { for age }\end{array}$ & $\begin{array}{r}\text { In school } \\
\text { and grade } \\
\text { for age }\end{array}$ & $\begin{array}{r}\text { Never } \\
\text { been to } \\
\text { school }\end{array}$ & $\begin{array}{r}\text { Been to } \\
\text { school } \\
\text { but not in } \\
\text { school }\end{array}$ & $\begin{array}{r}\text { In school, } \\
\text { not grade } \\
\text { for age }\end{array}$ & $\begin{array}{r}\text { In school } \\
\text { and grade } \\
\text { for age }\end{array}$ \\
\hline Poorest & 70.8 & 25.4 & 24.7 & 12.7 & 64.3 & 1.6 & 14.6 & 2.2 \\
\hline Poorer & 10.7 & 21.1 & 23.5 & 15.0 & 20.0 & 17.2 & 20.6 & 8.1 \\
\hline Middle & 10.8 & 17.9 & 21.2 & 19.3 & 0.9 & 17.4 & 23.3 & 8.1 \\
\hline Richer & 1.6 & 7.1 & 20.6 & 26.2 & 9.3 & 18.4 & 26.5 & 30.3 \\
\hline Richest & 6.1 & 28.6 & 10.0 & 26.8 & 5.4 & 28.4 & 15.0 & 51.3 \\
\hline Never married & - & - & - & - & 49.2 & 47.4 & 99.3 & 99.6 \\
\hline Ever married & - & - & - & - & 50.8 & 52.6 & 0.7 & 0.4 \\
\hline Never given birth & - & - & - & - & 71.8 & 58.5 & 99.4 & 99.0 \\
\hline Ever given birth & - & - & - & - & 28.2 & 41.5 & 0.6 & 1.0 \\
\hline
\end{tabular}

Source: DHS 2011.

\section{FIGURE 17}

PERCENTAGE OF ADOLESCENT GIRLS AGED 15-19 WHO HAVE NOT ATTENDED ANY SECONDARY SCHOOL, EAST AND SOUTHERN AFRICA

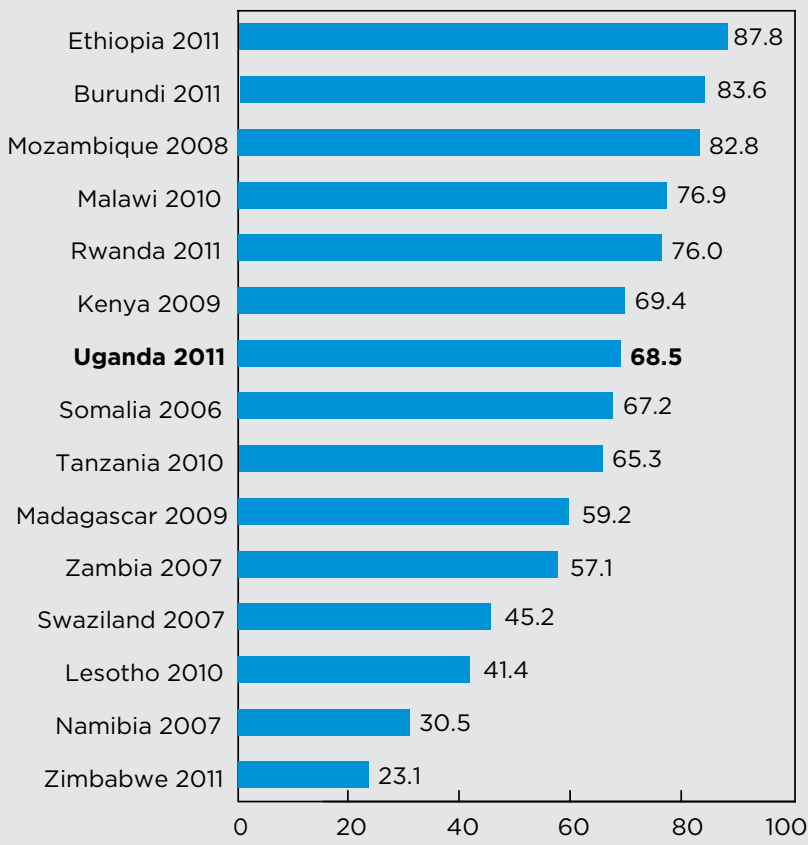

Source: DHS 2007-2011; MICS 2006-2008.

\section{FIGURE 18}

PERCENTAGE OF ADOLESCENT GIRLS IN UGANDA AGED 15-19 WHO HAVE NOT ATTENDED ANY SECONDARY SCHOOL, BY REGION, 2006 AND 2011

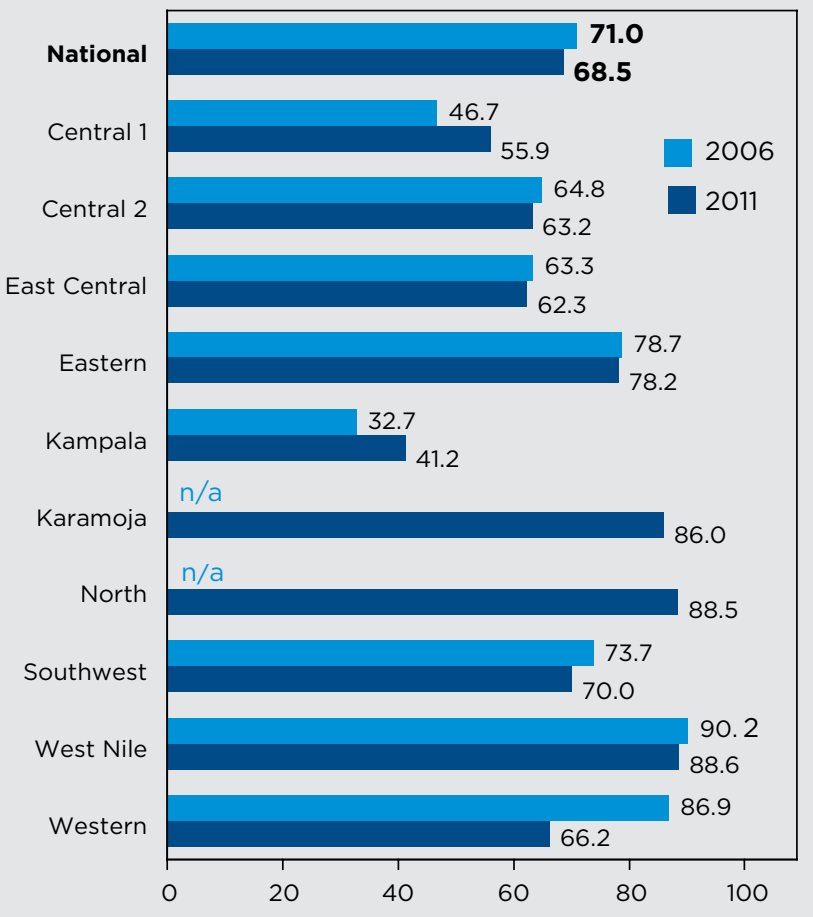

Source: DHS 2006 and 2011. 


\section{TABLE 8}

LITERACY RATES AMONG ADOLESCENTS AGED 15-19 AND RATIO OF LITERATE GIRLS TO BOYS, EAST AND SOUTHERN AFRICA

\begin{tabular}{|c|c|c|c|}
\hline & Girls & Boys & $\begin{array}{r}\text { Ratio of } \\
\text { girls to } \\
\text { boys }\end{array}$ \\
\hline Somalia 2006 & 34.9 & $\mathrm{n} / \mathrm{a}$ & $\mathrm{n} / \mathrm{a}$ \\
\hline Mozambique 2008 & 58.2 & $\mathrm{n} / \mathrm{a}$ & $\mathrm{n} / \mathrm{a}$ \\
\hline Ethiopia 2011 & 63.6 & 77.7 & 0.82 \\
\hline Burundi 2011 & 74.6 & 87.7 & 0.85 \\
\hline Zambia 2007 & 73.4 & 84.6 & 0.87 \\
\hline Kenya 2009 & 91.7 & 95.9 & 0.96 \\
\hline Uganda 2011 & 78.2 & 79.5 & 0.98 \\
\hline Madagascar 2009 & 80.3 & 82.1 & 0.98 \\
\hline Malawi 2010 & 80.7 & 82.6 & 0.98 \\
\hline Tanzania 2010 & 84.0 & 84.6 & 0.99 \\
\hline Zimbabwe 2011 & 96.5 & 94.4 & 1.02 \\
\hline Namibia 2007 & 95.0 & 92.5 & 1.03 \\
\hline Rwanda 2011 & 89.5 & 86.1 & 1.04 \\
\hline Swaziland 2007 & 95.9 & 91.1 & 1.05 \\
\hline Lesotho 2010 & 98.8 & 90.0 & 1.10 \\
\hline
\end{tabular}

Source: DHS 2007-2011; MICS 2006-2008.

Notes: White boxes highlight values less than 1.00. Male literacy data are not available for countries using MICS surveys because there is no Male questionnaire.

\section{FIGURE 20}

PERCENTAGE OF ADOLESCENT GIRLS IN UGANDA LIVING IN COMMUNITIES WHERE WOMEN AGED 20-49 HAVE LITERACY RATES BELOW THE MEAN FOR WOMEN IN THAT AGE GROUP

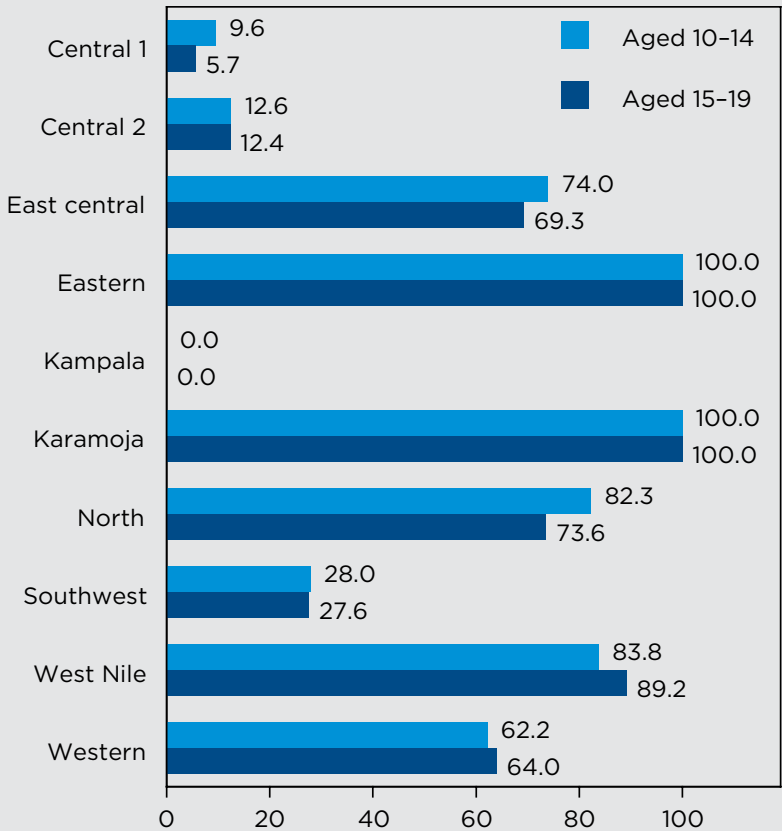

Source: DHS 2011

\section{FIGURE 19}

PERCENTAGE OF ADOLESCENT GIRLS AGED 15-19 WHO ARE LITERATE BY PERCENTAGE WHO REPORT ATTENDING SCHOOL AT ANY TIME DURING THE CURRENT SCHOOL YEAR, EAST AND SOUTHERN AFRICA

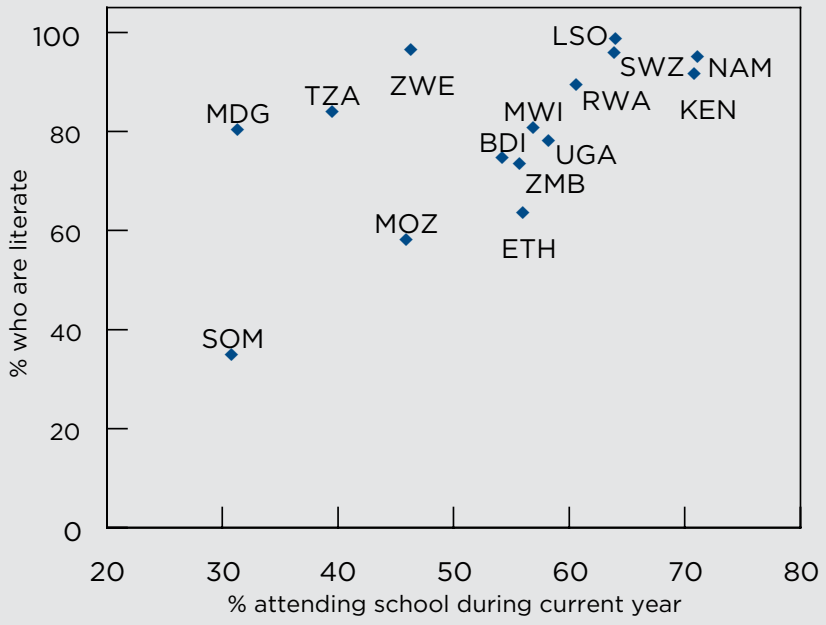

Source: DHS 2007-2011; MICS 2006-2008.

\section{FIGURE 21}

PERCENTAGE OF ADOLESCENT GIRLS IN UGANDA AGED 15-19 WHO ARE LITERATE, BY REGION, 2011

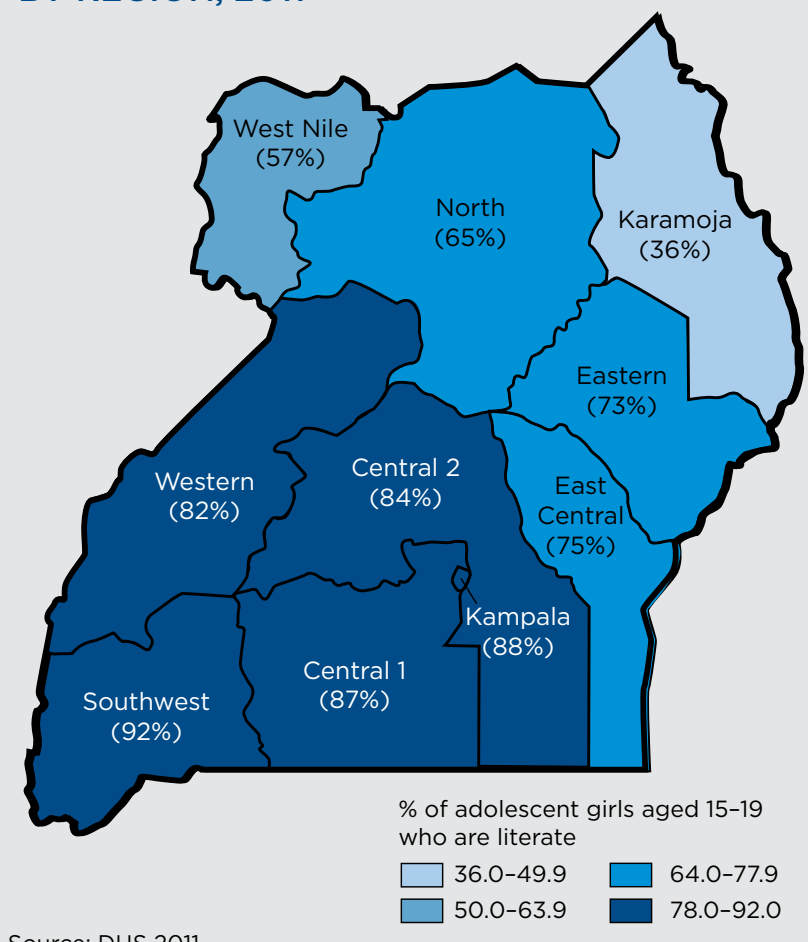

Source: DHS 2011 
and Namibia (Table 8). Lesotho has the highest rate of literacy with nearly 99 percent of adolescent girls able to read. Literacy rates for girls are lowest in Somalia and Mozambique where less than 60 percent of adolescent females are literate. Although literacy is not universal among males, available rates show boys often fare better than girls. In 8 out of the 13 countries examined, literacy rates among girls are lower than among boys. The largest gap in literacy rates appears in Ethiopia where only 82 girls are literate for every 100 adolescent males. Literacy estimates show a potential link to school attendance. Figure 19 shows a scatter plot of school attendance rates of adolescent girls aged 15-19 compared to literacy rates for the group. As expected, countries with lower rates of literacy tend to have lower rates of girls attending school in the age group.

The literacy of women in the community provides us with another context in which to understand the vulnerabilities of adolescent girls. Community contexts have influences on family systems as well as individuals. Norms within communities and among older women can shape views on the importance of educating girls, which can affect schooling, literacy, marriage, and the livelihoods of girls. Community-level rates can also be a reflection of available resources within regions. Areas where literacy rates are low may have fewer education resources or lower quality schooling. Figure 20 shows the percentage of girls living within communities where women aged 20-49 have literacy rates lower than the national rate. For the purposes of our analysis, communities are defined as groupings of Demographic and Health Survey sampling clusters within Uganda's districts; they do not necessarily reflect communities. This measure is relative to the mean for the country; it identifies adolescent girls living in the worst-performing communities of Uganda. In Karamoja and the Eastern regions, all girls live in communities where literacy rates for women 20-49 are among the lowest in the country. The East Central, North, and West Nile regions also contain large proportions of girls living in communities with low literacy. At the other extreme, since literacy rates in Kampala are among the highest in the country, no girls live in communities where rates are below the mean in the country.

These community-level literacy rates of older women appear to be correlated with the secondary schooling rates and literacy levels of adolescent girls aged 15 to 19 . Figure 18 shows that adolescent girls in the Eastern, Karamoja, North, and West Nile regions are least likely to attend secondary school. Within Uganda, two thirds of girls ages 15 to 19 are literate. Figure 21 shows Karamoja has the lowest literacy rates among girls aged 15 to 19 and similarly, Karamoja's community rate of female literacy is the lowest in Uganda. In the Southwest, overall 92 percent of 15-19 year old girls are literate but community rates show 28 percent live in communities where literacy among older women is relatively low.

Literacy rates by schooling categories show the clear correlations between school attendance and literacy. By schooling category, those who are in school and at grade for age are all literate. Among girls who have never been to school, only six percent are literate (Table 9). For the remaining two schooling categories, despite having gone to school, not all girls can read. For those who have been to school but have not attended during the school year, fewer than two thirds are literate and of those currently in school but not at grade for age, 87 percent are literate.

\section{Employment}

Employment allows individuals to build human and financial assets but it can also be a source of vulnerability. Access to paid work and the ability to secure a livelihood provide economic security and a sense of individual engagement in society. However, working conditions are often worse for youth compared to adults (Coenjaerts et al. 2009). Moreover, working can lead to a forgone opportunity for increased educational attainment. Adolescents who work rather than pursue higher levels of education may be shortchanging themselves in potential future earnings.

Table 10 shows rates of adolescents aged 15 to 19 by sex who are in school, working, both in school and working, or doing neither for a selection of East and Southern African countries. In all countries except Madagascar, boys are more likely to be involved in paid or unpaid work than girls. Rates of work for both sexes vary widely across countries. Swaziland has the lowest rates of employment among both males and females, with 8 percent of girls and 10 percent of boys working. Combined with adolescents who are also attending school, 9 percent of girls and 17 percent of boys are involved in work activities. In contrast, Madagascar has the highest rates of adolescents who are involved in only work activities. Overall, Uganda has one of the highest proportions of adolescents involved in work and school activities. Forty-seven percent of girls and 75 percent of boys are either in school and employed or employed alone.

Adolescents in the category of not employed and not in school may be most vulnerable to future hardships. Time spent neither working nor attending school results in forgone opportunities to deepen individual human capital during this critical period. Across East and Southern Africa, girls are 


\begin{tabular}{l} 
TABLE 9 \\
\begin{tabular}{lr} 
LITERACY RATES OF ADOLESCENT GIRLS AGED & 15-19 \\
BY EDUCATIONAL CATEGORIES, UGANDA, 2011 & Percentage literate \\
\hline & 5.9 \\
\hline Never been to school & 64.6 \\
\hline Been to but not currently in school & 87.0 \\
\hline In school, not at grade for age & 100.0 \\
\hline In school and at grade for age
\end{tabular} \\
\hline Source: DHS 2011.
\end{tabular}

\begin{tabular}{|c|c|c|c|c|c|c|c|c|}
\hline $\begin{array}{l}\text { PERCENTAGE } \\
\text { STATUS, EAST }\end{array}$ & $\begin{array}{l}\text { ESCEN } \\
\text { THER }\end{array}$ & $\begin{array}{l}\text { NT BOYS } \\
\text { N AFRICA }\end{array}$ & ND GIRL & GED 1 & $\mathrm{SCHC}$ & DOL AND & EMPLOY & \\
\hline & & Gi & & & & Bo & oys & \\
\hline & School & $\begin{array}{l}\text { School + } \\
\text { Employed }\end{array}$ & Employed & Neither & School & $\begin{array}{l}\text { School + } \\
\text { Employed }\end{array}$ & Employed & Neither \\
\hline Burundi 2011 & 38.3 & 15.6 & 37.6 & 8.6 & 36.3 & 31.3 & 31.4 & 1.0 \\
\hline Ethiopia 2011 & 43.0 & 13.8 & 13.5 & 29.8 & 25.4 & 33.9 & 31.2 & 9.6 \\
\hline Kenya 2009 & 64.3 & 7.6 & 12.4 & 15.7 & 37.7 & 44.6 & 15.4 & 2.3 \\
\hline Lesotho 2010 & 58.6 & 4.5 & 9.1 & 27.8 & 47.2 & 16.8 & 21.5 & 14.5 \\
\hline Madagascar 2009 & 27.9 & 3.6 & 54.8 & 13.7 & 34.8 & 4.2 & 53.3 & 7.7 \\
\hline Malawi 2010 & 38.4 & 18.3 & 18.4 & 24.9 & 32.7 & 37.7 & 22.5 & 7.0 \\
\hline Namibia 2007 & 63.3 & 8.4 & 7.4 & 20.9 & 54.3 & 13.1 & 15.3 & 17.3 \\
\hline Rwanda 2011 & 36.9 & 23.9 & 28.3 & 10.9 & 24.8 & 39.8 & 32.5 & 2.9 \\
\hline Swaziland 2007 & 62.9 & 1.8 & 7.7 & 27.6 & 67.5 & 7.0 & 9.6 & 16.0 \\
\hline Tanzania 2010 & 34.4 & 6.3 & 42.6 & 16.7 & 41.5 & 10.7 & 41.5 & 6.3 \\
\hline Uganda 2011 & 37.8 & 20.5 & 26.9 & 14.7 & 23.0 & 47.7 & 27.4 & 2.0 \\
\hline Zambia 2007 & 49.1 & 6.4 & 12.6 & 31.9 & 61.4 & 16.8 & 12.7 & 9.1 \\
\hline Zimbabwe 2011 & 43.8 & 2.0 & 12.9 & 41.3 & 48.5 & 8.6 & 18.4 & 24.5 \\
\hline
\end{tabular}

Source: DHS 2007-2011.

\section{TABLE 11}

PERCENTAGE OF ADOLESCENT BOYS AND GIRLS AGED 15-19 BY SCHOOL AND EMPLOYMENT STATUS, UGANDA, 2011

\begin{tabular}{|c|c|c|c|c|c|c|c|c|}
\hline & \multicolumn{4}{|c|}{ Girls } & \multicolumn{4}{|c|}{ Boys } \\
\hline & School & $\begin{array}{l}\text { School + } \\
\text { Employed }\end{array}$ & Employed & Neither & School & $\begin{array}{l}\text { School + } \\
\text { Employed }\end{array}$ & Employed & Neither \\
\hline National & 37.8 & 20.5 & 26.9 & 14.7 & 23.0 & 47.7 & 27.4 & 2.0 \\
\hline Central 1 & 57.2 & 5.5 & 18.0 & 19.3 & 4.2 & 46.6 & 46.3 & 2.8 \\
\hline Central 2 & 47.6 & 16.4 & 24.7 & 11.3 & 12.6 & 49.8 & 36.5 & 1.1 \\
\hline East Central & 38.8 & 22.5 & 24.8 & 13.9 & 27.2 & 51.1 & 19.3 & 2.3 \\
\hline Eastern & 33.7 & 28.8 & 23.4 & 14.1 & 23.1 & 61.6 & 11.5 & 3.8 \\
\hline Kampala & 36.5 & 3.9 & 40.1 & 19.5 & 45.4 & 21.5 & 27.4 & 5.7 \\
\hline Karamoja & 6.9 & 19.7 & 58.5 & 14.9 & 5.6 & 28.6 & 50.1 & 15.7 \\
\hline North & 47.0 & 11.9 & 20.1 & 21.0 & 24.5 & 54.0 & 21.5 & 0.0 \\
\hline Southwest & 26.7 & 38.2 & 27.0 & 8.1 & 14.2 & 54.4 & 31.4 & 0.0 \\
\hline West Nile & 28.2 & 22.2 & 32.2 & 17.4 & 16.8 & 54.7 & 27.1 & 1.4 \\
\hline Western & 36.3 & 24.2 & 27.0 & 12.5 & 31.3 & 39.2 & 29.6 & 0.0 \\
\hline
\end{tabular}

Source: DHS 2011. 
more likely to be unemployed and not attending school compared to boys. The percent of adolescent boys who are neither in school nor working ranges from a low of only one percent in Burundi to a high of 24.5 percent in Zimbabwe. Rates for girls are higher; in some cases, two to five times greater than those of boys. The percent of girls who are neither working nor in school ranges from 9 percent in Burundi to 41 percent in Zimbabwe.

Within Uganda, rates of adolescents in school, work, both, or neither show similarities to the broader East and Southern Africa region. Boys are much more likely to be involved in a work activity. Across the country, employment rates (both school + employed, and employed only) for boys range from 49 percent in Kampala to 93 percent in the Central 1 region (Table 11). Girls, however, are much more likely to be neither working nor in school. Among adolescent boys, rates are at or below 6 percent in every region except Karamoja. Rates for girls, however, are as high as 21 percent in the North region. The lowest rate is in the Southwest where 8 percent of girls are neither in school nor working. Rates for being neither in school nor employed also appear to be rising for adolescent girls (Figure 22). In 2006, only 10 percent were out of school or not working. In 2011, this number rose significantly to 14.7 percent. In Kampala and the Eastern and Western regions, rates increased significantly.

\section{Sexual and reproductive health}

Sexual activity can expose individuals to disease and, for girls, risks of pregnancy and childbearing. Within sub-Saharan Africa, trends toward later marriage have reduced rates of sexual initiation at marriage (Lloyd 2006). Premarital sexual initiations during adolescence have increased or remain unchanged in the region (Lloyd 2006). Within or outside the context of marriage, however, sexual practices have the potential to be unsafe. Educating adolescents on safe sexual practices will enable individuals to protect themselves from sexually transmitted diseases and unwanted pregnancies.

Across the East and Southern Africa region, rates of ever having sex vary by sex and marital status (Table 12). Among adolescent boys, between 8 percent in Ethiopia and 60 percent in Lesotho have ever had sex. Among adolescent girls, rates range from 15 percent in Rwanda to 71 percent in Mozambique. Within this group are married girls, who are more likely than never-married girls to have had sex. Among never-married females, rates are lower than the overall rates, ranging from 3 percent in Ethiopia to 48 percent in Mozambique.
Early sexual initiation increases lifetime exposure to sexual and reproductive risks. In Uganda, 2011 adolescent rates of sexual activity and ever having had sex show associations with several demographic characteristics (Table 13). Factors associated with increased prevalence of ever having sex or being sexually active among adolescent girls include lower educational attainment and being married. Rates of ever having sex and sexual activity among adolescent girls do not vary widely across the country. Kampala has the highest rates of ever having had sex. Rates are lowest in the Southwest where 23 percent have had sex and 10 percent are sexually active. High-risk sex, defined as having had sex before age 15 , having multiple partners, or having a last partner that was casual (non-spouse or live-in partner), is a measure of potential unsafe sexual relations. Again, high-risk sex among adolescent girls is lowest in the Southwest. Rates are highest in the East Central and Eastern regions of the country. Since 2006, most regions have shown no significant changes in ever having had sex, being sexually active, or high-risk sex among adolescent girls aged 15 to 19. The exceptions are Kampala and West Nile, which have seen significant increases in ever having had sex and having high-risk sex.

Risky sexual behaviors such as not using condoms and having multiple partners can put adolescents at greater risk of contracting HIV. Large age differences between adolescent girls and their partners may mean girls have less power to negotiate sex and condom use with older men. In all regions, males 15-24 were more likely than females to have more than two partners in the past 12 months (Table 14). Condom use at first sex varied by region but in the two regions with the highest prevalence rates, more males than females had used a condom at last sex. Among girls 15-19 who had had sex in the last 12 months, around 13 percent had a partner who was ten or more years older.

The use of contraceptives and condoms protects against sexually transmitted diseases and unintended pregnancies. Rates of reported condom use at last sex and use of modern contraceptives are higher among adolescent males compared to females (Table 15). However, for both groups, rates are low. Only half of boys and less than a third of girls who have ever had sex report using a condom at last sex. Use of modern contraception is similarly low among those who have had sex. Thirty-two percent of boys and only 13 percent of adolescent girls report using modern methods of contraception. Among adolescent females, condoms used at last sex and use of modern forms of contraception show relationships with several characteristics. Adolescent girls who are in the 


\section{FIGURE 22}

PERCENTAGE OF ADOLESCENT GIRLS IN UGANDA AGED 15-19 WHO ARE NEITHER IN SCHOOL NOR EMPLOYED, BY REGION, 2006 AND 2011

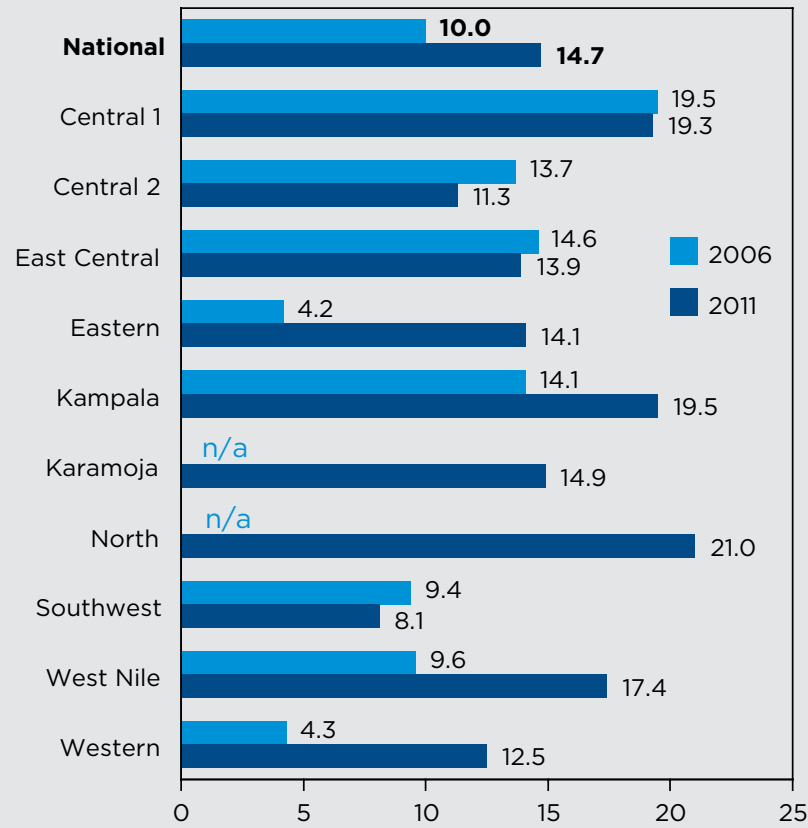

Source: DHS 2006 and 2011.

\section{TABLE 12}

PERCENTAGE OF ADOLESCENTS AGED 15-19 WHO HAVE EVER HAD SEX, EAST AND SOUTHERN AFRICA

\begin{tabular}{|c|c|c|c|}
\hline & \multirow{2}{*}{$\begin{array}{r}\text { Boys } \\
\text { All }\end{array}$} & \multicolumn{2}{|c|}{ Girls } \\
\hline & & All & $\begin{array}{r}\text { Never } \\
\text { married }\end{array}$ \\
\hline Rwanda 2011 & 21.5 & 14.6 & 11.5 \\
\hline Burundi 2011 & 17.4 & 16.5 & 7.2 \\
\hline Ethiopia 2011 & 7.8 & 24.7 & 3.1 \\
\hline Zimbabwe 2011 & 27.0 & 33.7 & 10.7 \\
\hline Kenya 2009 & 43.9 & 37.0 & 27.5 \\
\hline Swaziland 2007 & 21.6 & 41.3 & 36.7 \\
\hline Namibia 2007 & 51.7 & 42.8 & 39.3 \\
\hline Malawi 2010 & 54.4 & 44.0 & 24.0 \\
\hline Uganda 2011 & 34.9 & 44.4 & 28.5 \\
\hline Tanzania 2010 & 40.1 & 45.3 & 32.1 \\
\hline Lesotho 2010 & 59.7 & 46.4 & 35.0 \\
\hline Zambia 2007 & 45.0 & 48.2 & 35.6 \\
\hline Madagascar 2009 & 42.8 & 54.0 & 24.9 \\
\hline Mozambique 2008 & $\mathrm{n} / \mathrm{a}$ & 71.1 & 48.3 \\
\hline
\end{tabular}

Source: DHS 2007-2011; MICS 2008

Note: The Somalia MICS survey does not contain indicators on sexual behavior.

\section{TABLE 13}

PERCENTAGE OF ADOLESCENT GIRLS IN UGANDA AGED 15-19 WHO HAVE EVER HAD SEX, ARE SEXUALLY ACTIVE, AND HAVE HAD HIGH-RISK SEX, BY CHARACTERISTICS, 2011

\begin{tabular}{|c|c|c|c|c|c|c|}
\hline & \multicolumn{2}{|c|}{ Ever had sex } & \multicolumn{2}{|c|}{ Sexually active } & \multicolumn{2}{|c|}{ High-risk sex } \\
\hline & 2006 & 2011 & 2006 & 2011 & 2006 & 2011 \\
\hline All & 43.0 & 44.4 & 19.2 & 18.4 & 13.2 & 11.9 \\
\hline \multicolumn{7}{|l|}{ Region } \\
\hline Central 1 & 47.4 & 45.5 & 15.2 & 19.3 & 16.5 & 16.2 \\
\hline Central 2 & 46.0 & 42.3 & 20.1 & 19.9 & 14.1 & 13.6 \\
\hline East Central & 44.4 & 50.1 & 17.8 & 20.3 & 14.1 & 18.0 \\
\hline Eastern & 51.4 & 47.7 & 27.3 & 22.8 & 18.7 & 17.7 \\
\hline Kampala & 39.4 & 52.9 & 12.3 & 15.4 & 10.1 & 15.7 \\
\hline Karamoja & $\mathrm{n} / \mathrm{a}$ & 51.5 & $n / a$ & 20.0 & $\mathrm{n} / \mathrm{a}$ & 8.8 \\
\hline North & $\mathrm{n} / \mathrm{a}$ & 44.0 & $\mathrm{n} / \mathrm{a}$ & 22.0 & $\mathrm{n} / \mathrm{a}$ & 10.8 \\
\hline Southwest & 21.4 & 23.3 & 7.3 & 10.4 & 4.2 & 3.5 \\
\hline West Nile & 32.7 & 43.5 & 12.2 & 16.8 & 4.7 & 7.8 \\
\hline Western & 48.4 & 50.1 & 25.8 & 17.6 & 17.0 & 16.5 \\
\hline \multicolumn{7}{|c|}{ Educational attainment } \\
\hline No education & 56.0 & 56.1 & 33.5 & 39.2 & 18.0 & 16.6 \\
\hline Primary & 43.3 & 45.3 & 21.1 & 20.5 & 14.3 & 14.5 \\
\hline Secondary & 40.3 & 41.5 & 13.0 & 12.3 & 10.2 & 11.2 \\
\hline \multicolumn{7}{|l|}{ Marital status } \\
\hline Never married & 26.5 & 28.5 & 4.4 & 4.9 & 9.8 & 9.7 \\
\hline Ever married & 100.0 & 100.0 & 70.3 & 65.8 & 25.2 & 26.7 \\
\hline
\end{tabular}

Note: Sexually active is defined as having had sex in the past month. High-risk sex is defined as having had sex before 15 , having multiple partners, or last partner was casual. 
Adolescent health has received far less attention than it deserves. Adolescents are generally perceived as a relatively healthy group. They lack the widespread exposure to infectious disease compared to children in their early years. However, among those aged O through 19, 15-19 year olds experience the next greatest burden of disease after those below age 5 (Gore et al. 2011). While many enter this period relatively healthy, social and physical changes and risky behaviors can put adolescents on a path toward poorer health. Greater attention to this age group can reduce the factors associated with development of health risks. To limit our scope, this report focuses on sexual and reproductive health indicators included in the Adolescent Girls Multilevel Vulnerability Index. Below we briefly highlight a selection of adolescent health issues:

Leading causes of death and disability among adolescents vary by region and sex. Accidents and injuries are among the leading causes of death and disability among adolescents, particularly boys. Transport accidents, burns, falls, poisoning, and drowning are among those included in the list (UNICEF 2012).

In developing countries, boys are at greater risk for accidents and injury. Violence and suicide are also major causes of mortality in this group (Viner et al. 2011). Among adolescent girls in Africa, childbirth and maternal causes are the leading causes of death (UNICEF 2012).

Nutrition is also a health concern among adolescents. Obesity is a rising health problem facing adolescents in developing countries. In Swaziland and Lesotho, over a fifth of adolescent girls aged 15-19 are overweight (UNICEF 2012). Undernutrition and malnutrition remain as health issues. In Ethiopia, 33 percent of adolescent girls are underweight with a body mass index below 18.5 (UNICEF 2012). Anemia is a widespread problem affecting as many as 43 percent of individuals in countries with low development; Africa has the highest prevalence of anemia (Balarajan et al. 2011). Children and women are at greatest risk. Consequences of anemia include cognitive impairment and increased susceptibility to infection.

Tobacco, alcohol, and drug abuse are among the risky behaviors that begin during adolescence. An analysis by UNICEF of tobacco, alcohol, and reported drug use among adolescents shows high rates in regions of Africa. In sub-Saharan Africa 13 percent of girls and 19 percent of boys aged 13-15 used tobacco in the past 30 days. In Swaziland, 30 percent of boys and 14 percent of girls in the age group reported drinking alcohol in the past month. Between 37 and 39 percent of Zambian girls and boys aged 13-15 reported using illicit drugs at least once (UNICEF 2012).

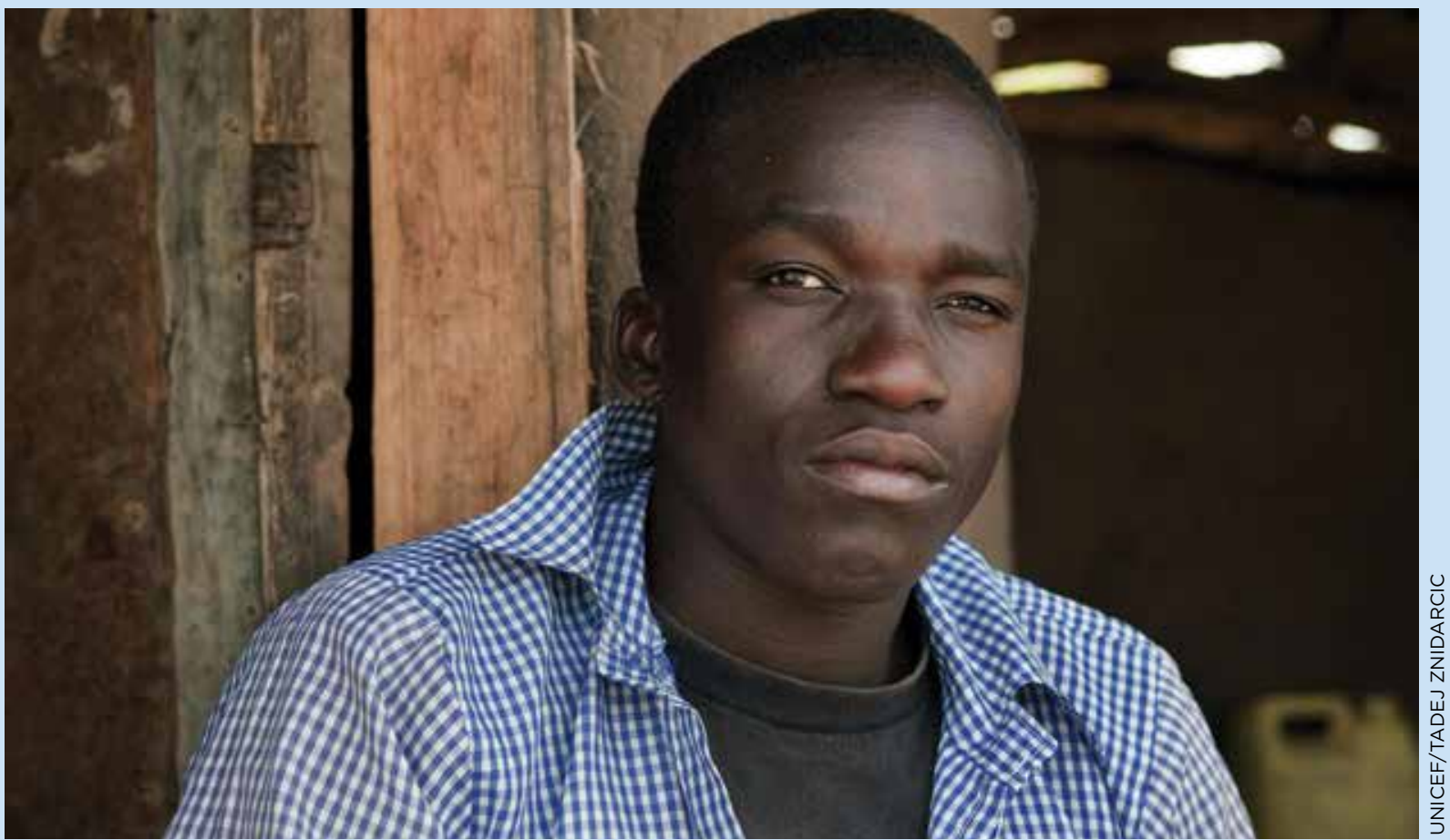

Accidents and injuries are among the leading causes of death and disability among adolescents, particularly boys. 
TABLE 14

SEXUAL BEHAVIORS AMONG ADOLESCENTS IN UGANDA, BY PERCENT AND REGION, 2011

\begin{tabular}{|c|c|c|c|c|c|}
\hline & \multirow[t]{2}{*}{$\begin{array}{r}\text { Percentage of sexually } \\
\text { active girls aged } 15-19 \\
\text { who had sexual intercourse } \\
\text { with a man } 10+\text { years older }\end{array}$} & \multicolumn{2}{|c|}{$\begin{array}{c}\text { Percentage aged } \\
15-24 \text { with } \\
2+\text { partners in the last } \\
12 \text { months }\end{array}$} & \multicolumn{2}{|c|}{$\begin{array}{l}\text { Percentage aged } \\
15-24 \text { who } \\
\text { used a condom } \\
\text { at first sex }\end{array}$} \\
\hline & & Female & Male & Female & Male \\
\hline National & 12.7 & 3.1 & 9.9 & 35.2 & 34.1 \\
\hline Central 1 & 19.7 & 5.3 & 13.3 & 39.2 & 43.4 \\
\hline Central 2 & 6.6 & 4.0 & 6.7 & 44.2 & 35.9 \\
\hline East Central & 10.5 & 4.4 & 17.1 & 40.7 & 26.7 \\
\hline Eastern & 12.4 & 2.5 & 7.2 & 27.0 & 22.2 \\
\hline Kampala & 17.9 & 4.6 & 8.5 & 55.7 & 52.9 \\
\hline Karamoja & 9.7 & 1.1 & 6.8 & 37.0 & 43.2 \\
\hline North & 10.4 & 2.2 & 4.1 & 29.7 & 43.1 \\
\hline Southwest & 13.9 & 1.1 & 8.2 & 18.4 & 21.2 \\
\hline West Nile & 5.0 & 2.1 & 9.6 & 31.0 & 38.5 \\
\hline Western & 16.4 & 3.2 & 14.2 & 30.2 & 26.5 \\
\hline
\end{tabular}

Source: Uganda AIDS Indicator Survey 2011

Note: Sexually active is defined as having sex within the last 12 months.

\section{TABLE 15}

\section{CONTRACEPTIVE USE AMONG}

ADOLESCENTS AGED 15-19 WHO HAVE EVER HAD SEX, UGANDA

\begin{tabular}{lrr}
\hline & $\begin{array}{r}\text { Condom } \\
\text { used at } \\
\text { last sex }\end{array}$ & $\begin{array}{r}\text { Currently } \\
\text { using modern } \\
\text { method of } \\
\text { contraception }\end{array}$ \\
\hline Boys & 50.4 & 31.9 \\
\hline Girls & 27.5 & 13.4 \\
Wealth quintile & 11.4 & 6.7 \\
Poorest & 16.0 & 11.9 \\
Poorer & 30.8 & 13.5 \\
Middle & 32.7 & 16.4 \\
Richer & 41.8 & 16.5 \\
Richest & & 13.1 \\
Educational attainment & 8.5 & 6.8 \\
No education & 22.4 & 12.1 \\
Primary & 41.9 & 17.2 \\
Secondary & & \\
Marital status & 53.6 & 13.2 \\
Never married & & \\
Married & & \\
\hline Source: DHS 2011 & & \\
\hline
\end{tabular}

\section{FIGURE 23}

PERCENTAGE OF ADULTS 15-49 WHO ARE HIV-POSITIVE, EAST AND SOUTHERN AFRICA

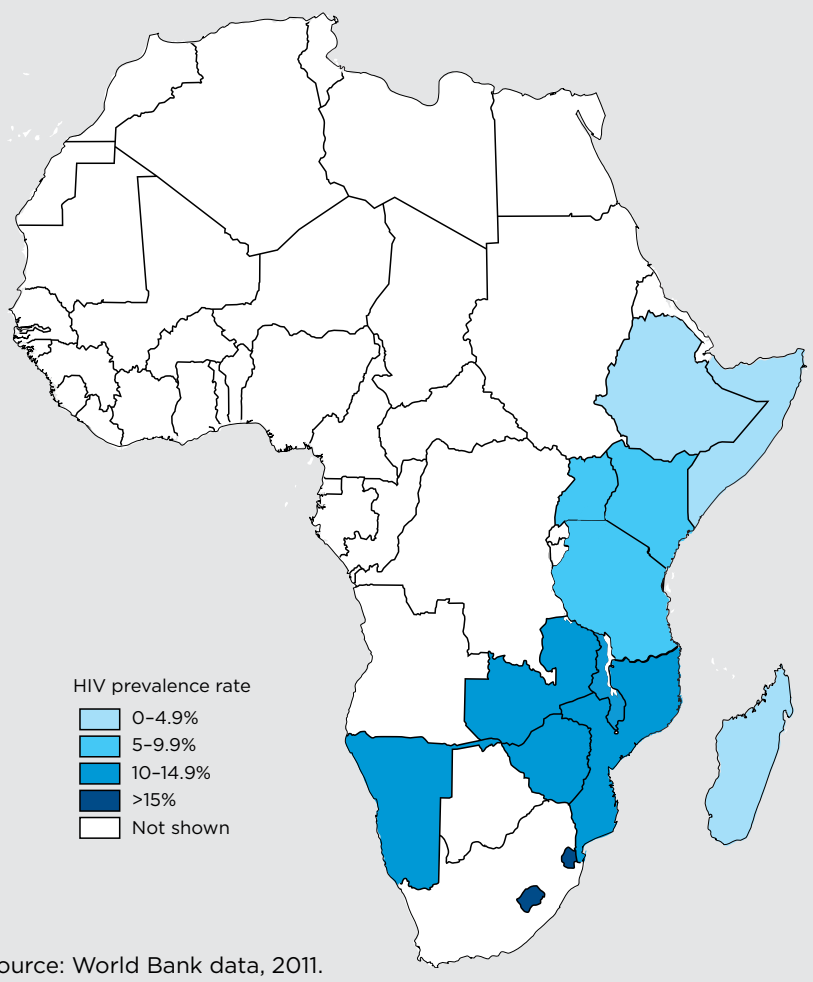


poorest quintile are least likely to have used a condom during last sex or to be currently using a modern method of contraception. Educational levels are also correlated with use of contraceptives. Adolescent girls with higher levels of education have greater likelihoods of using a condom at last sex or using a modern method of contraception. These findings suggest adolescents may not know about these contraceptive options or not have the resources to access them. Other reasons behind these numbers may be that although modern methods of contraception are effective, many either do not know about them or resist their use as a result of cultural or misinformed beliefs (Cleland, Ndugwa, and Zulu 2010).

\section{HIV/AIDS}

HIV and AIDS pose one of the greatest risks to adolescent well-being in sub-Saharan Africa. Although this region as a whole bears the brunt of the global HIV burden, trends in prevalence vary by subregion. In Southern Africa, the epidemic reached a peak in the mid-90s but has since stabilized at still relatively high rates. Within East African countries, rates have declined over time. However, prevalence rates are still high. By country, Figure 23 shows adult prevalence rates, which vary from 0.07 percent in Somalia to the highest rate in the world in Swaziland at 26.0 percent in 2011 (World Bank 2011).

Uganda is at the lower end of the range of adult HIV prevalence rates for the region. HIV prevalence among adults age 15-49 in Uganda has increased from 6.4 percent in 2004 to 7.3 percent in 2011 (Uganda AIDS Indicator Survey 2011). However, this increase in HIV prevalence may be due to an increase in the number of people living with AIDS or knowing their HIV status rather than in HIV incidence.

Gender disparities in prevalence rates show that the disease disproportionately affects girls. HIV prevalence rates for young women aged 15-24 in sub-Saharan Africa is over twice the prevalence of men in the age group-3.3 percent versus 1.1 percent (USAID 2012). In Uganda, the HIV prevalence rate for adolescent females is dramatically higher than males, with the exception of ages 15 to 17 where prevalence rates are relatively similar (Figure 24). HIV prevalence has risen from 2005 to 2011 for both girls and boys (Table 16). HIV prevalence is higher in urban areas for females 15 to 24 but higher in rural areas for males of the same age (Uganda AIDS Indicator Survey 2011). The regions with the highest adolescent HIV prevalence rates are Central 1 and the North (Table 17).

\section{Prevention knowledge}

Knowledge of prevention methods is essential for reducing the risk of contracting $\mathrm{HIV}$ and protecting individuals. The ABC approach is a commonly known strategy for HIV prevention: $A$ ) abstinence from sex; B) be faithful to one, uninfected partner, and C) correct and consistent use of condoms. Comparisons across countries show no consistent patterns in rates of knowledge of the three methods of HIV prevention (Table 18). Rates of knowledge are highest in Swaziland, which also has the highest rates of HIV in the world. However, comparisons between boys and girls show gaps in knowledge between sexes across several countries. The gap is largest in Ethiopia for all three methods. However, rates for all three knowledge areas are similar across sex in Swaziland, Madagascar, and Kenya. Among adolescent girls knowledge of condom use appears to be the lowest of the three. Knowledge of abstinence as a method of HIV prevention is remarkably low among girls in Malawi and Somalia at only 42 and 43 percent. In Uganda, knowledge of HIV prevention methods is slightly higher among boys than girls, despite the higher HIV prevalence among girls this age.

Comprehensive knowledge of HIV includes knowing that consistent condom use and having only one uninfected partner can reduce HIV risk, and rejecting common local misconceptions about HIV transmission and prevention. Comprehensive knowledge of HIV is around 40 percent for both males and females 15-24 in Uganda (Table 19). Knowledge for males and females is highest in Kampala. Regional percentages are consistent with patterns that show that knowledge is higher among adolescents living in urban compared to rural areas (Uganda AIDS Indicator Survey 2011).

\section{Family formation}

\section{Marriage}

According to the UN Convention on the Elimination of All Forms of Discrimination against Women, marriage before the age of 18 is considered child marriage. Despite many adolescents being inadequately prepared for this transition, societal norms and economic pressures allow early marriage practices to continue. Although families believe child marriage will protect girls, it can often lead to a decline in social assets. Adolescent girls who marry early are often separated from their families and friends, increasing social exclusion. They are also more likely to leave school, isolating them from peers and jeopardizing their future economic security. Child marriage also leads to 


\section{FIGURE 24}

PERCENTAGE OF FEMALE AND MALE ADOLESCENTS IN UGANDA AGED 15-24 WHO ARE HIV-POSITIVE, BY AGE GROUP

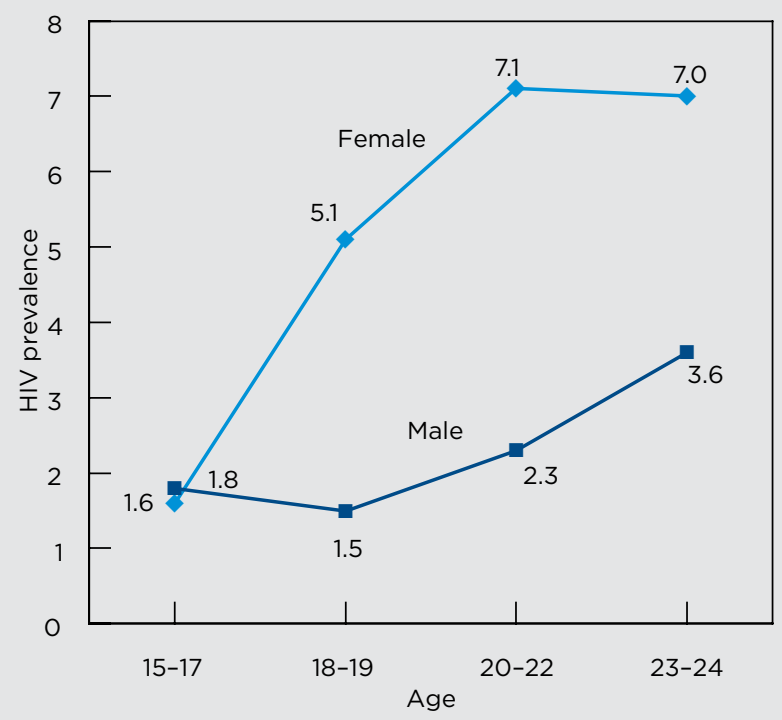

Source: Uganda AIDS Indicator Survey 2011

\section{TABLE 16}

PERCENTAGE OF FEMALE AND MALE ADOLESCENTS IN UGANDA AGED 15-24 WHO ARE HIV-POSITIVE, 2005 AND 2011

\begin{tabular}{|c|c|c|c|c|c|c|}
\hline & \multicolumn{2}{|c|}{ Female } & \multicolumn{2}{|c|}{ Male } & \multicolumn{2}{|c|}{ Both sexes } \\
\hline & 2005 & 2011 & 2005 & 2011 & 2005 & 2011 \\
\hline Age $15-19$ & 2.6 & 3.0 & 0.3 & 1.7 & 1.5 & 2.4 \\
\hline Age $20-24$ & 6.3 & 7.1 & 2.4 & 2.8 & 4.7 & 5.4 \\
\hline
\end{tabular}

Source: Uganda AIDS Indicator Survey 2011.

\section{TABLE 17}

PERCENTAGE OF FEMALE AND MALE

ADOLESCENTS IN UGANDA AGED 15-24 WHO ARE HIV-POSITIVE, BY REGION

\begin{tabular}{lrr}
\hline & Female & Male \\
\hline National & $\mathbf{4 . 9}$ & $\mathbf{2 . 1}$ \\
\hline Central 1 & 8.0 & 6.3 \\
\hline Central 2 & 5.1 & 4.3 \\
\hline East Central & 3.8 & 2.8 \\
\hline Eastern & 1.9 & 1.7 \\
\hline Kampala & 5.7 & 3.4 \\
\hline Karamoja & 3.5 & 2.6 \\
\hline North & 6.7 & 4.9 \\
\hline Southwest & 4.6 & 3.9 \\
West Nile & 2.3 & 2.1 \\
\hline Western & 5.5 & 4.0 \\
\hline
\end{tabular}

Source: Uganda AIDS Indicator Survey 2011.

\section{TABLE 18}

PERCENTAGE OF ADOLESCENTS AGED 15-19 WHO KNOW THE FOLLOWING HIV PREVENTION METHODS, EAST AND SOUTHERN AFRICA

\begin{tabular}{|c|c|c|c|c|c|c|}
\hline & \multicolumn{2}{|c|}{ Abstinence } & \multicolumn{2}{|c|}{ Having one uninfected partner } & \multicolumn{2}{|c|}{ Using condoms } \\
\hline & Girls & Boys & Girls & Boys & Girls & Boys \\
\hline Burundi 2011 & 89.0 & $\mathrm{n} / \mathrm{a}$ & 82.6 & 87.0 & 80.8 & 89.3 \\
\hline Ethiopia 2011 & 78.0 & 79.9 & 71.0 & 74.3 & 64.1 & 83.6 \\
\hline Kenya 2009 & 88.6 & 88.3 & 89.0 & 89.7 & 67.9 & 76.1 \\
\hline Lesotho 2010 & 78.4 & 74.8 & 86.5 & 83.9 & 85.2 & 83.8 \\
\hline Madagascar 2009 & 80.1 & 79.4 & 82.9 & 85.0 & 77.7 & 79.4 \\
\hline Mozambique 2008 & 77.9 & 76.4 & 84.0 & 86.1 & 69.0 & 74.5 \\
\hline Malawi 2010 & 42.0 & $\mathrm{n} / \mathrm{a}$ & 63.0 & $\mathrm{n} / \mathrm{a}$ & 78.0 & $\mathrm{n} / \mathrm{a}$ \\
\hline Namibia 2007 & 83.2 & 85.9 & 88.2 & 90.7 & 82.1 & 86.4 \\
\hline Rwanda 2011 & 87.9 & 87.0 & 83.0 & 81.2 & 87.9 & 88.3 \\
\hline Somalia 2006 & 43.0 & $\mathrm{n} / \mathrm{a}$ & 64.0 & $\mathrm{n} / \mathrm{a}$ & 36.0 & $\mathrm{n} / \mathrm{a}$ \\
\hline Swaziland 2007 & 93.7 & 94.1 & 90.9 & 90.4 & 87.1 & 87.8 \\
\hline Tanzania 2010 & $\mathrm{n} / \mathrm{a}$ & $\mathrm{n} / \mathrm{a}$ & 83.5 & 83.1 & 71.1 & 69.3 \\
\hline Uganda 2011 & $n / a$ & $n / a$ & 85.7 & 90.5 & 76.3 & 83.1 \\
\hline Zambia 2007 & 81.7 & 83.3 & 84.5 & 85.8 & 67.6 & 74.0 \\
\hline Zimbabwe 2011 & $n / a$ & $\mathrm{n} / \mathrm{a}$ & 86.8 & 86.4 & 73.9 & 77.6 \\
\hline
\end{tabular}

Source: DHS 2007-2011; MICS 2006-2008. 
childbearing at younger ages and the associated risks to reproductive and maternal health (UNICEF 2011). Girls who marry early are likely to have greater numbers of children (Raj et al. 2009). Being in a relationship can also expose child brides to sexually transmitted diseases and, in some cases, domestic violence. In most cases, there are large gaps in age between young wives and their husbands, leading to imbalances in relationship dynamics. Delaying marriage to older ages can reduce several of these risks.

Age at first marriage is increasing within developing countries. One study found that rates of marriage among 15 to 19 year old girls in East and Southern Africa declined over 12 percentage points in the twenty-year period between the 70s and the 90s (Mensch, Singh, and Casterline 2005). Despite these overall declines, child marriage rates in this region remain among the highest in the world. Figure 25 shows child marriage rates for males and females ages 20 to 24 in East and Southern Africa. Child marriage is an issue that largely affects girls. Among boys aged 20 to 24, in the vast majority of the region, fewer than 8 percent are married before the age of 18 . Among 20 to 24 year old girls, marriage by age 18 is greater than 8 percent in all but one country; rates range from a low of 5 percent in Swaziland to 52 percent in Mozambique. Uganda falls in the middle of the range for the region. Within the region, rates of child marriage by age 15 range from less than 1 percent in Swaziland to 17 percent in Mozambique (data not shown).
At the community level, child marriage is a product of social values, cultural norms, and available opportunities for women. Thus, living in a region where older women were married before age 18 can be a potential indicator of a girl's risk of entering into child marriage. For this reason, the Adolescent Girls Multilevel Vulnerability Index includes this community indicator to highlight potential vulnerability to child marriage for girls. Figure 26 shows percentages of 10 to 14 and 15 to 19 year old girls in Uganda living in communities where rates of child marriage among 20-49 year old women are higher than the national rate. This measure is relative and meant to highlight communities that are most at risk of child marriage. Among adolescent girls aged 10 to 19, large proportions in the East Central and North regions live in communities where rates of child marriage among women aged 20-49 are higher than average. These two regions also have among the highest child marriage rates for 15-24 year olds (data not shown). And in Kampala, which has Uganda's lowest child marriage rate, no girls live in communities where the child marriage rates for older women are greater than the national rate.

Marriage rates among adolescent girls ages 15-19 vary widely across East and Southern Africa (Figure 27). Rwanda has the lowest rates of adolescent girls ever married at less than 4 percent. Namibia and Swaziland also have relatively low rates of 6 and 7 percent, respectively. Mozambique has the highest proportion of girls who are married with nearly 45 percent ever married. Rates of marriage in Uganda fall in the middle of the range with over 20 percent of girls between the ages 15 and 19 being ever married.

Within Uganda, the distributions of characteristics among adolescents by marital status show patterns according to wealth and education (Table 20). As economic deprivation can often drive child marriage, lower wealth shows significant correlations with higher rates of being married. Greater proportions are in the poorest quintile and those with lower education levels have higher prevalence of current marriage. The Eastern and Karamoja regions contain greater proportions of adolescent girls who are married compared to other regions. No significant changes in these proportions have occurred since 2006.

\section{Parenthood}

Childbearing and parenthood are considered hallmarks of adulthood. However, many girls reach these milestones before they are physically and emotionally prepared for these roles. Adoles- 


\begin{tabular}{|c|c|c|}
\hline \multicolumn{3}{|c|}{$\begin{array}{l}\text { PERCENTAGE OF ADOLESCENTS AGED } \\
\text { 15-24 WITH COMPREHENSIVE KNOWLEDGE } \\
\text { OF HIV/AIDS IN UGANDA }\end{array}$} \\
\hline & Female & Male \\
\hline National & 38.6 & 39.3 \\
\hline Central 1 & 39.8 & 33.9 \\
\hline Central 2 & 41.4 & 42.0 \\
\hline East Central & 41.0 & 36.2 \\
\hline Eastern & 36.8 & 29.2 \\
\hline Kampala & 50.4 & 60.5 \\
\hline Karamoja & 31.9 & 45.1 \\
\hline North & 27.7 & 41.7 \\
\hline Southwest & 46.5 & 37.7 \\
\hline West Nile & 20.0 & 38.6 \\
\hline Western & 40.2 & 36.4 \\
\hline
\end{tabular}

Source: Uganda AIDS Indicator Survey 2011.

\section{FIGURE 26}

PERCENTAGE OF ADOLESCENT GIRLS

AGED 10-14 AND 15-19 LIVING IN COMMUNITIES WHERE RATES OF CHILD MARRIAGE AMONG WOMEN AGED 20-49 EXCEED THE NATIONAL AVERAGE, UGANDA

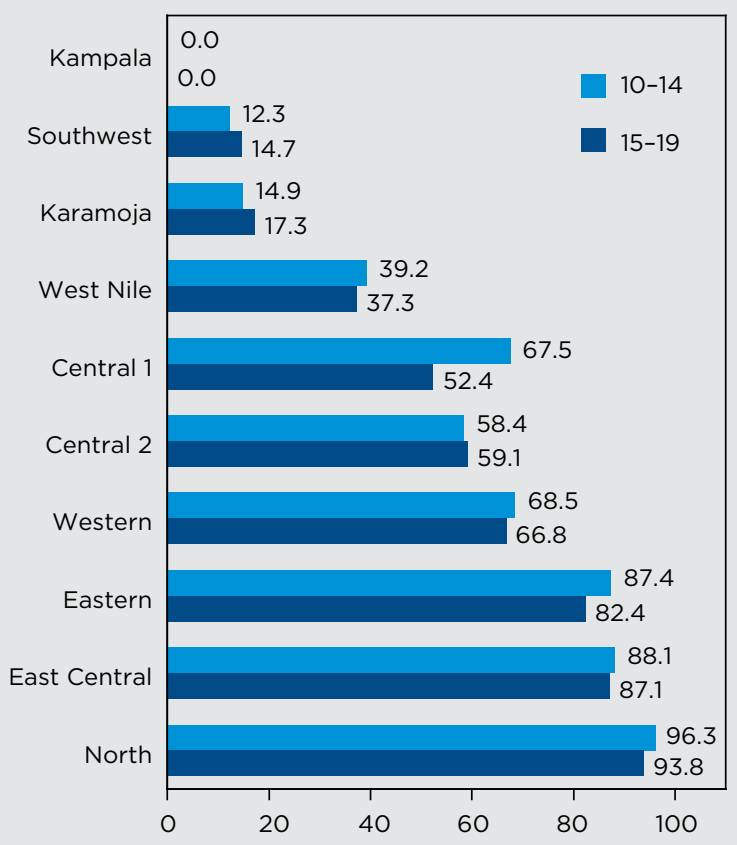

Source: DHS 2011

\section{FIGURE 25}

PERCENTAGE OF FEMALES AND MALES AGED 20-24 WHO WERE MARRIED BY AGE 18, EAST AND SOUTHERN AFRICA

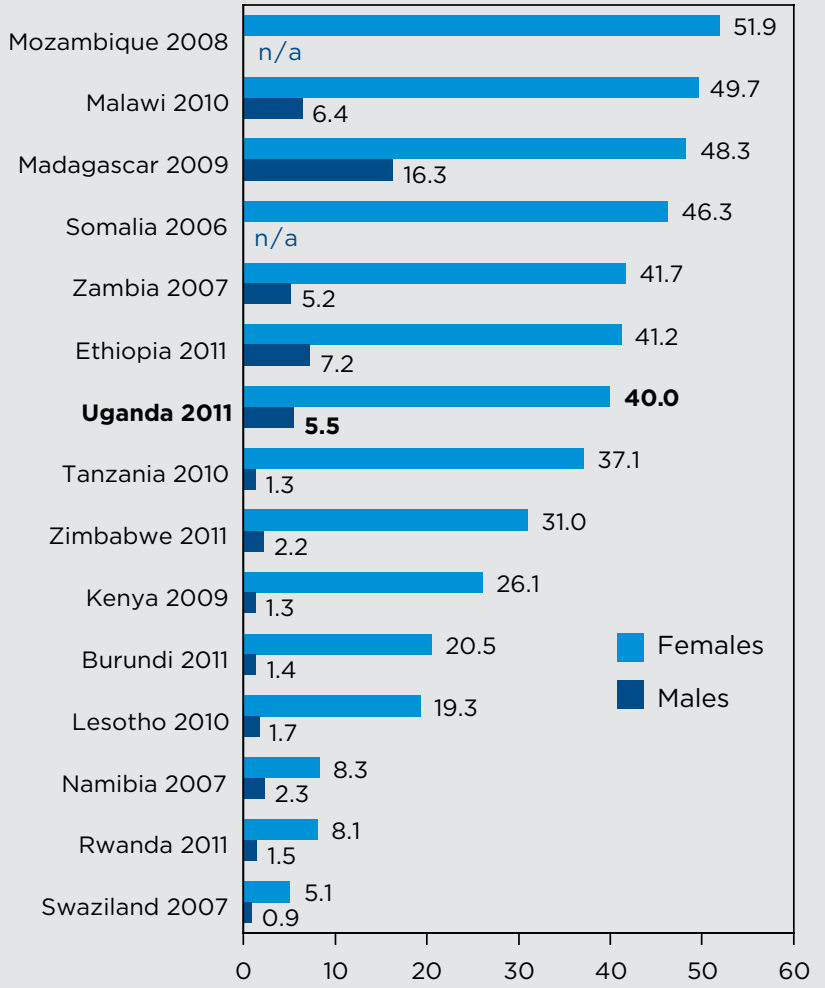

Source: DHS 2007-2011; MICS 2006-2008.

\section{FIGURE 27}

PERCENTAGE OF ADOLESCENT GIRLS AGED 15-19 WHO ARE EVER-MARRIED, EAST AND SOUTHERN AFRICA

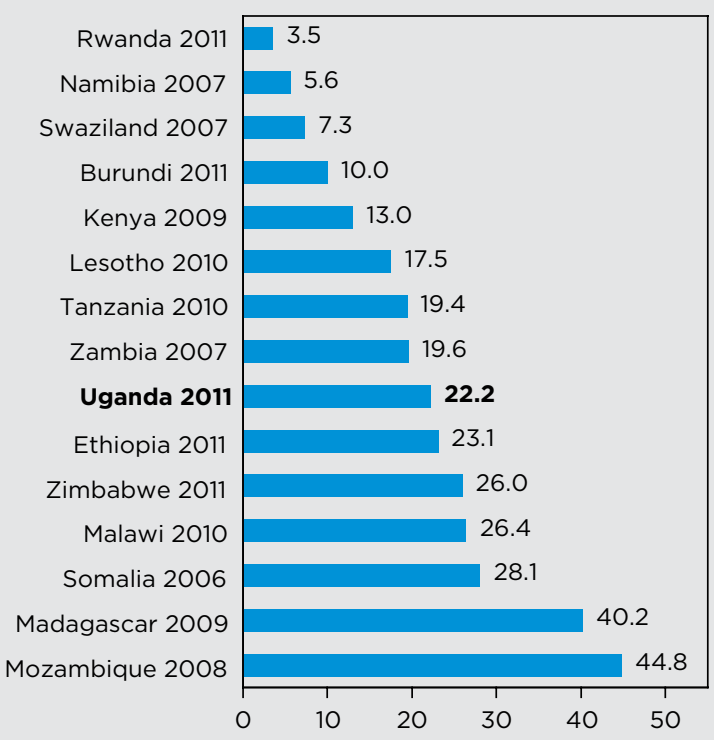

Source: DHS 2007-2011; MICS 2006-2008. 


\section{TABLE 20}

PERCENTAGE OF ADOLESCENT GIRLS IN UGANDA AGED 15-19 WHO ARE CURRENTLY MARRIED, BY REGION, EDUCATIONAL ATTAINMENT, AND WEALTH QUINTILE, 2006 AND 2011

\begin{tabular}{|lrc|}
\hline National & $\mathbf{2 0 0 6}$ & $\mathbf{2 0 1 1}$ \\
\hline Region & $\mathbf{1 9 . 5}$ & $\mathbf{1 9 . 6}$ \\
$\quad$ Central 1 & & \\
Central 2 & 13.4 & 12.9 \\
East Central & 20.2 & 20.1 \\
Eastern & 18.3 & 22.1 \\
Kampala & 27.4 & 28.4 \\
Karamoja & 10.7 & 14.5 \\
North & $\mathrm{n} / \mathrm{a}$ & 30.7 \\
Southwest & $\mathrm{n} / \mathrm{a}$ & 25.4 \\
West Nile & 9.6 & 12.0 \\
Western & 18.9 & 22.1 \\
Educational attainment & 24.0 & 15.6 \\
\hline No education & & \\
Primary & 43.0 & 47.6 \\
Secondary or higher & 22.0 & 23.8 \\
Wealth quintiles & 10.7 & 8.5 \\
Poorest & & \\
Poorer & 33.8 & 34.5 \\
Middle & 27.7 & 29.2 \\
Richer & 16.8 & 17.2 \\
Richest & 16.3 & 13.9 \\
\hline
\end{tabular}

Source: DHS 2006 and 2011 .

\section{FIGURE 28}

PERCENTAGE OF ADOLESCENT GIRLS AGED 15-19 WHO HAVE EVER GIVEN BIRTH, EASTERN AND SOUTHERN AFRICA

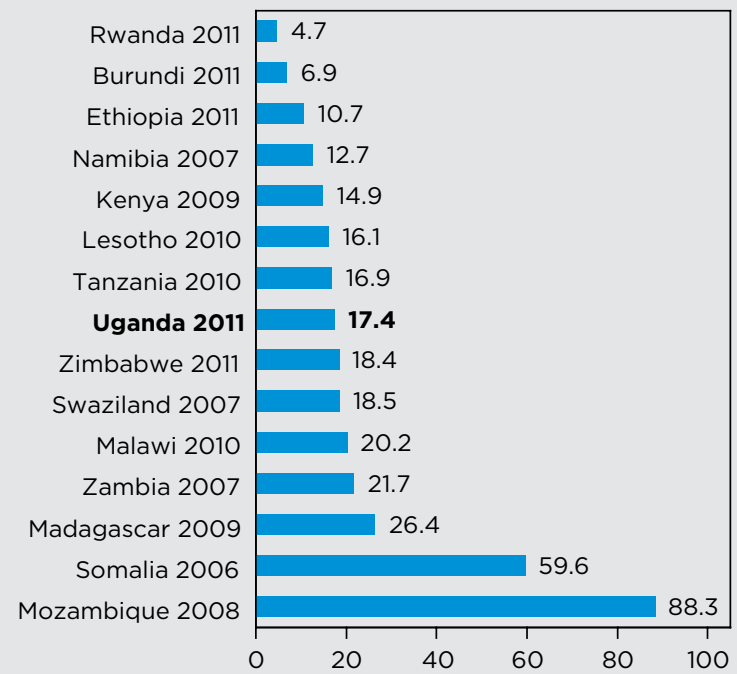

Source: DHS and MICS, 2000-2010.

\section{TABLE 21}

PERCENTAGE OF ADOLESCENT GIRLS IN UGANDA AGED 15-19 WHO ARE CURRENTLY PREGNANT OR HAVE EVER GIVEN BIRTH, BY REGION, MARITAL STATUS, AND EDUCATIONAL ATTAINMENT, 2006 AND 2011

\begin{tabular}{lrr} 
& $\mathbf{2 0 0 6}$ & $\mathbf{2 0 1 1}$ \\
National & $\mathbf{2 4 . 8}$ & $\mathbf{2 3 . 1}$ \\
Region & & \\
Central 1 & 20.8 & 17.4 \\
Central 2 & 30.6 & 23.0 \\
East Central & 24.7 & 30.5 \\
Eastern & 30.7 & 28.2 \\
Kampala & 14.2 & 20.8 \\
Karamoja & $\mathrm{n} / \mathrm{a}$ & 33.3 \\
North & $\mathrm{n} / \mathrm{a}$ & 25.2 \\
Southwest & 12.4 & 14.6 \\
West Nile & 24.5 & 26.2 \\
Western & 27.4 & 20.6 \\
Marital status & & \\
Never married & 6.9 & 5.9 \\
Ever married & 87 & 83.2 \\
Educational attainment & & \\
No education & 46.7 & 42.4 \\
Primary school & 28.9 & 26.3 \\
Secondary school or higher & 15.1 & 14.7 \\
\hline
\end{tabular}

Source: DHS 2006 and 2011. 
cent childbearing carries severe risks. Pregnancy and childbirth complications are the leading causes of death worldwide for adolescent girls between the ages of 15 and 19 (UNICEF 2011). Compared to women aged 20 to 24 , girls who give birth before age 15 are five times more likely to die during pregnancy or childbirth; girls who are 15 to 19 are twice as likely to die. Adolescents with children must also take on the responsibilities of caring for and economically supporting family members.

Along with trends toward later ages at first marriage, age at first birth has been increasing as well. However, the percentages of female adolescents who have given birth are still high in many East and Southern African countries (Figure 28). In Mozambique, 88 percent of girls aged 15 to 19 have given birth. Rwanda has the lowest rates of ever giving birth at 5 percent.

The likelihood of having given birth or being currently pregnant varies by several factors for adolescent girls in Uganda. The North and Central 2 regions have the highest proportions who have ever given birth or are currently pregnant (Table 21). Lower levels of education among adolescent girls are also associated with higher prevalence of having given birth or being currently pregnant. Among adolescent girls who are ever married, 83 percent have given birth or are pregnant compared to only 6 percent of those who never married. No significant changes have occurred in these rates since 2006 .

\subsection{Conclusion}

This report uses an ecological framework to examine individual-, household-, and communitylevel factors influencing adolescent well-being in Uganda and the surrounding East and Southern African region. Based on our analysis, several key messages emerge:

\section{Adolescent girls are often worse off} than boys.

Across multiple indicators, adolescent girls experience greater deprivations compared to boys. In the domain of education, older adolescent girls attend school at lower rates than boys in nearly all countries examined. Literacy rates are also lower for girls in several regions. In terms of employment, in all countries except Madagascar, adolescent boys aged 15 to 19 are engaged in paid and unpaid work at higher levels than girls. Moreover, older girls are less likely to be engaged in employment or to attend school. For several sexual and re- productive health outcomes, girls do not fare as well as boys. In several countries including Uganda, girls aged 15 to 19 have higher rates of ever having sex compared to boys. Reported use of condoms and modern methods of contraceptives is higher among boys. Gender disparities in HIV prevalence rates show the disease disproportionately affects girls in the region. HIV prevention knowledge rates are generally similar between the sexes. In cases where it is not, girls are less likely to know various HIV prevention methods. Lastly, child marriage rates are significantly higher among girls compared to boys.

\section{Uganda falls in the middle of the range on measures of adolescent vulnerability within the region.}

Across indicators on adolescent vulnerability, Uganda fared neither worst nor best across the age groups.

\section{Household characteristics are generally improving in Uganda.}

Access to improved water and sanitation, head of household education levels, and proportions of children living in households with their biological parents are still not at optimal levels. However, improvements have been made in the past five years. Access to improved water sources and sanitation has increased and the proportion of children living with parents has increased significantly. Head of household education levels remained the same.

\section{Adolescent girls lag behind in schooling.}

Younger adolescents aged 10 to 14 have high levels of school attendance but over half of those attending school in Uganda are behind in grade for age. Older adolescents aged 15 to 19 drop out of school at high rates. In Uganda, only 58 percent of girls in this age group attended school at some time during the school year and only 16 percent are in school and at grade for age. In terms of educational attainment, 69 percent of girls aged 15 to 19 have not attended any secondary school.

\section{A significant proportion of older adolescent girls are neither in school nor engaged in employment.}

In Uganda, nearly 15 percent of older adolescent girls are neither in school nor employed. Adolescents in this category may be at great- 
est risk of future hardships. Girls in the North region of Uganda have the highest proportions at 21 percent.

\section{The sexual and reproductive health} needs of adolescent girls require greater attention.

Within Uganda, 44 percent of adolescent girls aged 15 to 19 have ever had sex and 18 percent are sexually active. Adolescent girls also display risky sexual behaviors. Twelve percent have engaged in high-risk sex which includes having had sex before age 15 , having multiple partners, or having a last partner that was casual. Contraceptive use is also low. Among 15-19 year olds who have had sex, only 28 percent report using a condom at last sex and 13 percent report using a modern method of contraception. Rates of HIV knowledge are generally high but still in need of improvement.

\section{Child marriage remains a risk for} adolescent girls.

Child marriage is associated with many negative outcomes for adolescent girls. In Uganda, 40 percent of girls aged 20 to 24 were married before the age of 18 . Girls who are married are less likely to be in school. They are also more likely to have given birth or ever been pregnant. 
There is a wealth of evidence, including from UNICEF, on the extreme vulnerabilities that adolescent girls face and the role of such vulnerabilities in the intergenerational transmission of poverty. Despite this, the example of Uganda-and of East and Southern Africa more generally-shows that adolescent girls receive far too little attention from policymakers and program implementers. This is reflective of UNICEF programming specifically, and more generally of inadequate Government focus and programming.'

A well-constructed index that highlights the needs of adolescent girls could help to shift this focus. The history of indices ranging from the Human Development Index to the Corruption Perceptions Index shows that, where a composite measure can effectively quantify complex concepts that are not easily captured by any one indicator, there is great potential to bring greater awareness and focus to the issue among the public and policymakers.

The Adolescent Girls Multilevel Vulnerability Index (AGI) looks to follow in this tradition. By bringing together key indicators, it will allow us to summarize and analyze the situation of adolescent girls and understand and highlight the vulnerabilities they face, and to examine disparities within and between countries. The goal of the index is to provide both high-level visibility to adolescent girls and a user-friendly tool to guide and assess programming for adolescents.

In this section we review relevant work on the use of indices to measure child, adolescent, and social well-being. We then discuss various technical approaches to creating an adolescent girls index and present our analysis and recommendations.

\subsection{Putting the AGI in context}

The development of the AGI follows more than 50 years of research on child and social well-being. We summarize this history, note the current thinking about the prospects and pitfalls of composite measures, and review recent work on the development of vulnerability indices.
Child and social well-being indices: A brief history

\section{Child well-being}

Statistical indicators have long been used to assess social trends, but there is consensus among scholars that today's field is an outgrowth of the "social indicators movement" of the 1960s. R. A. Bauer's book Social Indicators defined the field and sparked a tremendous amount of research and writing that shaped how we think about child well-being today. ${ }^{2}$

Lippman (2007) points to the 1970s as the origin of efforts to synthesize data on child well-being into "state of the child" reports, which included the first UNICEF State of the World's Children report and the World Bank's World Atlas on the Child, both published in 1979. These reports also pioneered the international monitoring of child welfare by illustrating the importance of childspecific indicators (Black 1996). As attention was drawn to indicators of child well-being and the lack of statistical data about children, the 1989 United Nations Convention on the Rights of the Child (CRC) was used to promote the collection and production of indicators. Following CRC, there was a growth in the number of international studies and other international reports focused on children, such as the U.S. Census Bureau's international comparative report on well-being (Hobbs and Lippman 1990) and the Measuring and Monitoring Child Wellbeing: Beyond Survival project (Ben-Arieh 2000).

Around the same time we also saw the emergence of indices to measure child well-being with a single number. An index is a composite measure used to quantify complex concepts that are not easily captured by any one indicator (DeVellis 1991). Composite indices have become popular tools for decision-making and awareness-raising because they make it easy to quantify and compare complex constructs across space and time. Early examples of child well-being indices include the Disorganized Poverty (Kogan and Jenkins 1974), or DIPOV index, the Index of Social Health (Miringoff 1990), and the National Index of Quality of Life (Jordan 1993), an index based on data from UNICEF's State of the World's Children reports. More recently, Land et al. (2001) created the Foundation for Child Development Child and Youth Wellbeing Index, or the CWI. The Annie E. Casey Foundation followed in these footsteps by creating an index using data from the KIDS COUNT report series they began to compile in 1991 (O'Hare and Bramstedt 2003).

1 Refer to sections on policy analysis for East and Southern Africa (Chapter 5) and program scan for Uganda (Chapter 4)

2 See Lippman (2007) and Ben-Arieh (2008) for comprehensive reviews of this history. 
Over time, normative and conceptual changes in our understanding of childhood and child rights, in addition to a shift toward accountability-based public policy, have influenced the emergence of indicators and indices for measuring and monitoring child well-being (Ben-Arieh 2008). In his review of various "state of the child" reports, Ben-Arieh (2006) finds a shift in focus from indicators on child survival and negative outcomes to more inclusive indicators of child well-being and positive outcomes.

\section{Social well-being}

Just as the measurement of child well-being evolved into a more holistic enterprise over time, so too has the measurement of social well-being. Until the 1960s, the dominant conceptualization of human progress was seen through the lens of economic growth, as measured by GDP and GNP. In 1963 the United Nations Research Institute for Development, or UNRISD, was formed as part of the UN's first development decade-"a new approach to development." UNRISD was a leader in the development of new, more holistic socioeconomic indicators (Drewnowski 1966). ${ }^{3}$ In its first 10 years of existence, UNRISD proposed a level of living index (Drewnowski and Scott 1966) and ultimately created the first general index of socioeconomic development (McGranahan et al. 1972). This was followed by Morris's (1980) Physical Quality of Life Index (PQLI).

With the publication of the first Human Development Report in 1990, the United Nations Development Programme (UNDP) shifted the conceptualization of development again, this time from socioeconomic development to human development (UNDP 1990). The creation of the Human Development Index (HDI), as used in the Human Development Report, refocused the measurement of economic well-being toward a more people-centered approach rather than a strict focus on commodities. The report was influenced by the work of Amartya Sen who saw development as the provision of conditions that allow people to lead fulfilling lives (Sen 1979 and 1987; Stewart and Deneulin 2002). He argued that the basic capabilities for all people should include both social and economic factors. Therefore, HDI is a measure of human development and well-being that is not constrained by poverty level alone. In the creation of this measure, HDI also brought attention to the issues and challenges of measuring complex concepts that are based on more than one indicator or dimension.

\section{The goal of the} Adolescent Girls Multilevel Vulnerability Index is to provide both high-level visibility to adolescent girls and a user-friendly tool to guide and assess programming for adolescents.

Index construction methodology has continued to evolve toward the development of more multidimensional measures, which consist of several indicators and factors that contribute to a composite statistic. Since HDI, there has been a proliferation of indices that rank or assess country performance on a range of topics from security and governance to climate change (Bandura 2008). In the realm of development, indices like the Human Development Index and the Multidimensional Poverty Index enable us to analyze changes over time within and between countries, and to assess progress toward development goals. The ability to illustrate complex concepts in an easily understandable manner makes indices an important tool for decision-making and for stimulating public interest.

\section{Composite indices: Prospects and pitfalls}

A single composite measure can be used to highlight areas of need, help facilitate dialogue, and measure progress in the policy arena over time (OECD 2008). Indices are useful for eliciting opinions and guiding discussion between policymakers, private and public organizations, and citizens about ways to address areas of need. For the same reason that an index can be useful, however, it can also be the subject of criticism. Indices are reductionist by nature, and the process of reducing complex concepts to a singular metric is controversial (Lustig 2011; McGillivray 1991).

3 For a concise history, see Prasad (2005). 
The construction of an index involves several conceptual and technical decisions that can influence the results and interpretation. The quality of an index is based on the soundness of the theoretical framework, available data, and the methodology used in construction (Alkire and Foster 2011; McGillivray 1991). Critics have argued that once an appropriate set of indicators has been created, there is no point in future aggregation if this is based on subjective and sometimes arbitrary decisions (OECD 2008). Examples include the selection of cutoff points, the weighting of indicators and even the basic theoretical framework.

All indices are by nature based on subjective decisions, yet this does not discount the attention that indices have received. Indices such as the HDI have been useful in providing information for advocacy and decision-making, which is precisely their purpose (Raworth and Stewart 2003). On the other hand, this is also why a poorly constructed index can result in misinterpretations, or invite simplistic policy conclusions. For instance, a composite statistic can mask serious failings within domains and indicators. If an index is poorly constructed it can send misleading policy messages or lead to inaccurate conclusions (OECD 2008). Similarly, indices can easily be misinterpreted or misconstrued if they are not provided in context. All of these issues are magnified by the fact that the construction of composite indices can be complicated and difficult to understand. If the audience is not able to understand the index and its construction, this can pose a risk for how it is interpreted and replicated.

In light of the potential problems and opportunities for criticism of new indices, we use this report to outline the key decisions for the creation of the AGI. Before shifting to a discussion of our technical approach, however, we review other recent work to measure vulnerability in an effort to put the AGI in context.

\section{Recent work on measuring vulnerability}

We divide vulnerability indices into two main categories: primary data collection and secondary data analysis (Table 22). Indices in the primary data collection category are those that use original data that do not exist as part of national surveys like the DHS or MICS. In contrast, the secondary data analysis indices use a standard set of indicators collected as part of ongoing national surveys. Given the scope and objectives of the current project, the AGI more closely resembles the latter category of indices.

\section{Primary data collection and analysis}

Vulnerability Scale and Vulnerability Score. The Vulnerability Scale (Forsyth et al. 1996) and the Vulnerability Score (Kalibala et al. 2012) have been used to identify children as vulnerable on the basis of a set of indicators. The vulnerability scale uses 12 components, each with a score of 0-3 points. The points are totaled and children with a score over 10 are identified as vulnerable. The vulnerability score consists of 49 indicators with eight domains. Again, each indicator is scored and children are grouped on the basis of their vulnerability status.

Child Status Index (CSI). The CSI is a programlevel tool created by researchers at MEASURE Evaluation for screening and monitoring vulnerability among individual children (MEASURE Evaluation 2009). Therefore, assessment is done at the level of the individual child where an observer scores a child on each component during a home visit and through informal interviews. The summary score is an average of domains, which are averaged by components. Although the CSI is designed to focus on an individual child, the scores can also be aggregated at other levels to be used for program evaluation.

\section{Secondary data analysis}

Child and Youth Wellbeing Index (CWI). The CWI measures well-being trends over time among US children and young people (Land et al. 2001). The index combines 28 indicators into seven quality of life domains.

Child Poverty and Deprivation Index (CPDI). The CPDI uses DHS data to examine deprivations across several domains, including: food and nutrition, shelter and care, protection, health care, psychosocial and education (UNICEF and Tanzania National Bureau of Statistics 2009).

Bristol Approach. The Bristol Approach was the first method used for measuring multidimensional child poverty (Gordon et al. 2003). This method uses eight dimensions: food, safe drinking water, sanitation facilities, health, shelter, education, information, and access to services. Measurement occurs through the use of two distinct cutoff points.

The number of deprivations per child is calculated by using a cutoff within each domain. A second cutoff is then applied to define a child as poor based on a particular number of deprivations. The number of poor children is summed to create a headcount. 
Child Vulnerability Index in Ethiopia. The Child Vulnerability Index in Ethiopia was intended to provide a basis for the geographic targeting of vulnerable children. This index is the most similar to AGI. DHS and MICS data were combined from the individual and household level using five domains: material deprivation, health, nutrition, education, and protection (Pullum et al. 2011). Data are aggregated by geographical unit to identify areas with a high score for child vulnerability.

It should be clear from this review that there are ample composite measures for children, but a dearth of information on adolescents. Thus AGI is the first international composite measure of adolescent girls' vulnerability that could inform policy and programming decisions.

\subsection{Creating the Index}

We followed a four-step process for developing the AGI based on the approach outlined in the Handbook on Constructing Composite Indicators (OECD 2008). The first step was the development of a theoretical framework that could serve as a basis for selecting and combining indicators into a composite score. We then matched our framework with the available data sources and indicators and prepared the data for index construction. Lastly, we tested the validity and robustness of the index through a sensitivity analysis. In this section, each step is outlined and discussed in relation to the methods used in the AGI.

\section{Step 1: Developing the theoretical framework}

\section{Defining adolescence}

Adolescence can be difficult to define because of the individual variation in the physical, cognitive, emotional, social, and behavioral changes that occur during this time. Puberty is often used as a line of demarcation, yet puberty can also occur at different points for boys and girls and for individuals of the same sex (Marshall and Tanner 1969 and 1970). Similarly, laws that set thresholds for activities considered adult (such as alcohol consumption) tend to vary widely (ICAP 1998). For the purpose of the index, we follow the United Nations definition of adolescence, which refers to individuals between the ages of 10 and 19 years (UNICEF 2011).

The AGI is focused on adolescent girls rather than boys because of the unique risks faced by girls in this age group. The indicators included in the index are based on research and expertise on adolescent girls. Risks such as child marriage, limited economic opportunities, and parenthood have different
TABLE 22

VULNERABILITY INDICES

\section{INDEX}

DIMENSIONS

Primary Data Collection

Vulnerability Score

Parental status

Household relationships and situation

Household characteristics

Child's disabilities

Child's school attendance

Child's risk taking

Child's health and nutrition

Child's basic material needs

Child Status Index

Education

Food and nutrition

Health care

Protection

Psychosocial

Shelter and care

\section{Secondary Data Analysis}

Child and Youth

Wellbeing Index

Social relationships domain

Safety/behavioral concerns domain

Community connectedness domain

Health domain

Family economic well-being domain

Emotional/spiritual well-being domain

Educational attainment domain

Child Poverty and

Deprivation Index

Education

Health

Information

Nutrition

Sanitation

Shelter

Water

Child Vulnerability

Protection

Index in Ethiopia

Nutrition

Material deprivation

Health

Education

Bristol Approach

Access to basic services

Education

Food

Health

Information

Sanitation

Shelter

Water

Sources: Forsyth et al. 1996; Kalibala et al. 2012; MEASURE Evaluation 2009; Land et al. 2001; Gordon et al. 2003; Pullum et al. 2011. 


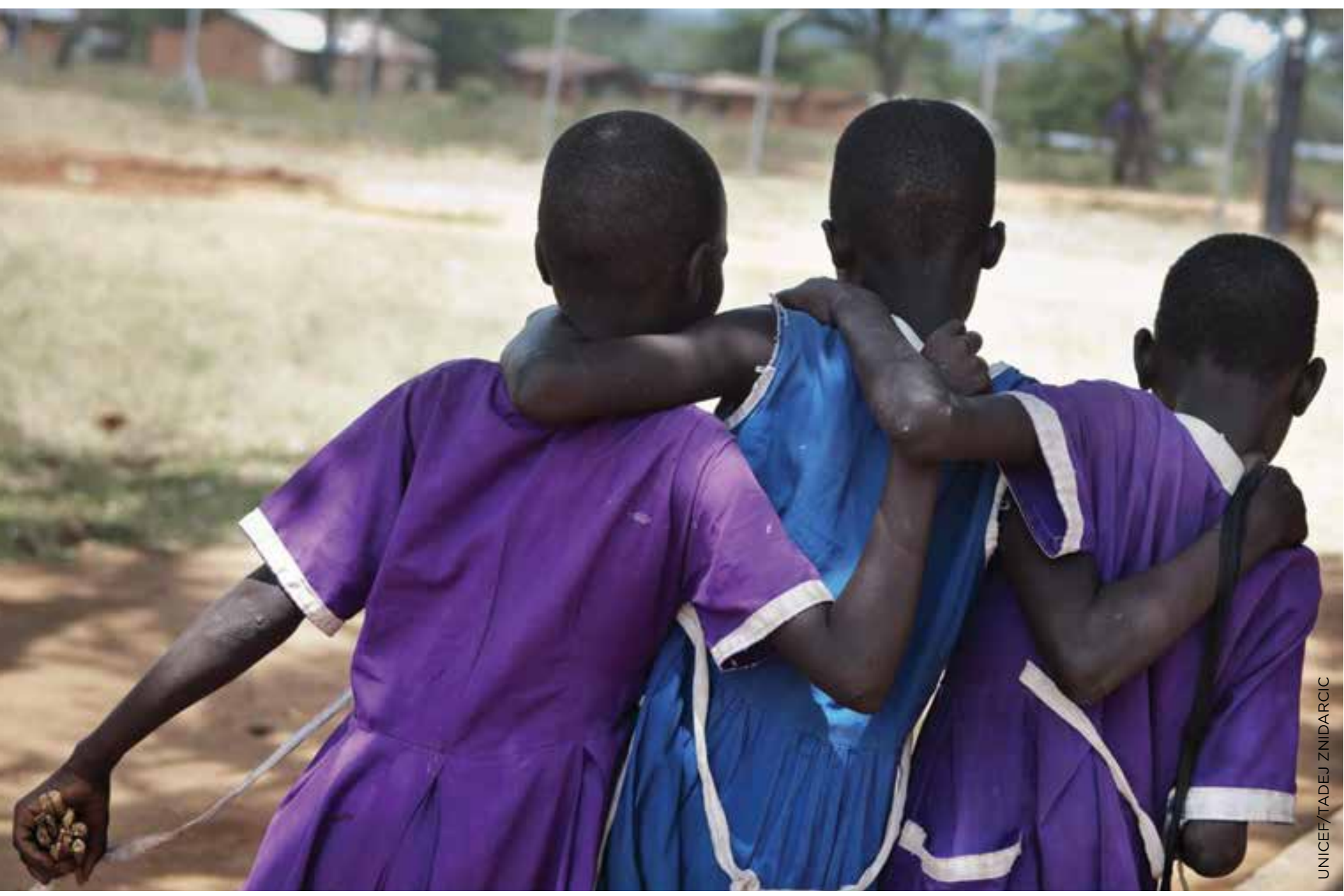

The Adolescent Girls Multilevel Vulnerability Index is focused on adolescent girls rather than boys because of the unique risks faced by girls in this age group.

implications for adolescent girls compared to boys. An index of adolescent boy vulnerability should be created but should be similarly tailored to the population rather than simply an extension of adolescent girl vulnerability.

\section{Defining vulnerability}

Vulnerability is not a synonym for poverty (Chambers 1989). Vulnerability can be thought of as a transactional relationship between the context in which a girl lives and a set of factors that put her "at-risk" ${ }^{4}$ for negative outcomes
(Sameroff and Chandler 1975). 5,6 These factors are present at multiple levels, including the level of the individual girl; her proximal social settings, such as family, ${ }^{7}$ peer networks, school, and community; and more distal levels that include societal, political, and historical influences (Fischhoff, Nightingale, and lannotta 2001).

At the level of the girl, risk factors can be biological (e.g., a chronic health condition like asthma), genetic (e.g., predispositions to disease), and psychological (e.g., thoughts, emotions, and behaviors). Her immediate social settings can

4 Blum (1998) defines risk as the "factors that limit the likelihood of successful development."

5 Transactional refers to the idea that a girl is affected by and can affect her environment. See Dodge and Pettit (2003) for a review of this and other combinatory models of development (e.g., additive, interactive) that recognize that no one factor predicts variance in outcomes.

6 Development occurs through multiple pathways (Cicchetti and Rogosch 1996). In the field of child psychopathology, the principle of equifinality suggests that different early life experiences can lead to the same outcome. For instance, the path to marriage before 18 can look different for different girls. Conversely, mutifinality is the idea that the same condition can lead to different outcomes, depending on the person and her environment. A clear example is poverty, a condition that can lead to a variety of diseases and disorders or a more positive outcome.

7 In a recent analysis of child vulnerability, Akwara et al. (2010) found that household wealth was a key predictor of vulnerability across outcomes. 
also confer risk, such as familial structures (e.g., orphan), peer networks (e.g., older, more experienced peers), classrooms (e.g., teachers who do not show up for work), and community characteristics (e.g., violence, gangs). More distally, a girl can also be influenced negatively by societal practices and beliefs (e.g., female genital cutting) and a policy environment that does not recognize her rights. ${ }^{8}$

Importantly, a girl's resources, assets, and protective factors-whether individual in nature or attributable to the various levels of her social setting-can offset or protect her from vulnerability (Fischhoff et al. 2001). Adolescents are said to be resilient when they do not exhibit negative outcomes in the face of repeated assaults. Bandura (1977) defined resilience as "the capacity to recover and maintain adaptive behavior after insult."

Over the past 20 years, this risk-resilience dichotomy has evolved from a study of how to reduce risk (deficit models) to how to promote positive youth development (Fischhoff, Nightingale, and lannotta 2001). This shift is based on research showing that positive interactions between the developing young person and her context can increase the likelihood that she will thrive (Lerner et al. 2010). Thriving in adolescence is marked by the growth of positive attributes including competence, confidence, character, connection, and caring (Bowers et al. 2010). This perspective suggests that programs and policies should focus not only on prevention and problem reduction, but also on creating contexts to promote thriving.

Despite the important implications of the positive youth development approach for adolescent policymaking and programming, the international framework on adolescents is still cast in a deficits model. As such, the indicators measured in national surveys reflect this deficit approach (e.g., mortality, child marriage). Thus, the AGI focuses on deprivations as a result of data limitations. It does, however, reflect the ecological nature of deprivations that can exist at the individual, family, and community levels.

\section{Multilevel vulnerability}

The Adolescent Girls Multilevel Vulnerability Index is based on an ecological approach to vulnerability. Vulnerability is a relationship between the actions of an individual girl and the context in which she lives (Sameroff and Chandler 1975). Risk factors are present at the level of the individual girl, her household, the community in which she lives, and even broader political, societal, and historical influences. The most vulnerable adolescents are those who experience risk factors at multiple levels of influence.

The AGI is an innovative index that conceptualizes vulnerability beyond multidimensional measures to include multiple levels of risk. AGI measures vulnerability at three different levels-the individual, household, and community level. This structure was selected as a way of measuring the theoretical concept that risk factors for adolescent girls are present at multiple levels. All of the indicators that were selected for inclusion in the index are based on extensive research on adolescence. The indicators relate to common themes of poverty, household and family structures, region and communities, housing conditions, education, employment, sexual and reproductive health, HIV/AIDS, and family formation (marriage and parenthood).

A study by Burt et al. modeled the payoffs of interventions to reduce adolescent vulnerability and found that comprehensive actions are more effective than population-based actions that focus on a single issue. Context is fundamental for understanding the choices that adolescents make about their own behaviors (Burt, Zweig, and Roman 2001). It is critical to intervene at multiple levels in order to establish broader economic and social opportunities for adolescents. In creating a measure of adolescent vulnerability, the AGI identifies areas with high percentages of extreme vulnerability and encourages actions that address these multiple levels of risk.

\section{Step 2: Selecting the data and potential indicators}

To create an index that could be used to compare across time and countries, we relied on DHS and MICS data. These surveys are nationally representative, publicly available, and generated on a periodic basis. They contain information on adolescent vulnerability and are implemented through standardized guidelines at the national level. The use of these sources will enable future users to build similar indices and allow for comparisons over time.

8 In the health sector, this relationship between biological, psychological, and social factors is known as the biopsychosocial model, an approach that grew out of the conventional medical or disease model that did not consider a broader range of factors that influence health outcomes (Engel 1977). The biopsychosocial model overlaps with another, widelyreferenced model of development called ecological systems theory (Bronfenbrenner 1979) in which the individual is situated at the center of a nested system of proximal and distal influences. 
Although the DHS and MICS surveys allow comparability, they offer limited information about the full range of adolescence. Aside from a few variables about household composition and education collected for all individuals in a household, much of the data come from the individual survey of girls and women age 15 to 49 . This means that the AGI cannot be as informative for the youngest adolescent girls (ages 10 to 14). Analogous data for individual men aged 15 to 49 are not available across all DHS and MICS countries included in the AGI. Table 23 shows the indicator topics available for inclusion in the AGI, by each age group.

The DHS and MICS surveys are household-based, which means that they exclude subpopulations that are possibly the most vulnerable-adolescents not living in households (e.g., homeless and living in residential care). When extremely vulnerable and marginalized groups are captured in household surveys, they are often not identifiable.

In preparing a list of eligible indicators, we began by reviewing the indicators that are available in most DHS and MICS surveys as well as indicators and domains used by other indices. Eligibility for inclusion was based on several criteria, including: the indicator is available in both MICS and DHS surveys, the indicator is available for the correct age group (10 to 14 or 15 to 19), the indicator is available for most target AGI countries, and the indicator is comparable across countries or subnational regions. ${ }^{9}$ Each indicator was then considered in light of the conceptual framework and prior research in the field. Indicators were selected to capture factors of adolescent vulnerability (i.e. education and family formation) and risks that are present at each level (i.e. household characteristics and norms). We were careful to select and construct indicators that complement one another to avoid double counting. A complete list of indicators and eligibility is included in Table 24 and Table 25. The majority of these indicators became ineligible for use because they are not available across all countries.

All surveys used in construction were combined into a single dataset for use in future analyses and construction. This required intensive data cleaning and standardization both between countries within a single type of survey (either MICS or DHS) and across types of surveys. This also made it possible to calculate means based on all countries at once.

\section{Indicators in the Adolescent Girls Multilevel Vulnerability Index}

The indicators selected at each level of the AGI are listed in Table 26. As previously mentioned, the DHS and MICS surveys contain more information on girls ages 15 to 19 compared to younger adolescents ages 10 to 14 . To maximize the existing information, we used different individual-level specifications for these two groups. Specifications for each age group also allow for further examination of the different vulnerabilities and needs of adolescents at these ages.

Individual level, ages 10 to 14 . Indicators at the individual level were selected based on availability across countries as well as their relevance to adolescent vulnerability. Choices are limited as there are few indicators available for this age group and the majority of these indicators are related to education. There are no eligible indicators for nutrition or measures of inter-generational transmission of vulnerability, despite the importance of these indicators at the individual level. The indicators selected for this level relate to schooling and family structure. Grade for age is an important indicator of whether children are "on track" and thus how vulnerable they are to poor outcomes. It is appropriate to identify adolescents who are behind by two years to reflect the fact that many students in the AGI target countries fall behind at some point but are not necessarily "off track" or vulnerable. Grade for age is based on national ages at which children should start primary school. Children with no education were also included in this indicator to account for children who have never been in school and are also off track. Adolescents were classified as vulnerable if they were two or more years behind or were not currently in school.

Young adolescents who are not living with either parent are often orphans and are at a higher risk of participating in illegal and unsafe work and

Note: Complete lists of all indicators that were considered for inclusion are found in Tables 24 and 25.

9 Target AGI countries: Burundi, Ethiopia, Kenya, Lesotho, Madagascar, Malawi, Mozambique, Namibia, Rwanda, Somalia, Swaziland, Tanzania, Uganda, Zambia, and Zimbabwe 

IN THE AGI ( = indicator used in AGI)

Ages 10-19

Not in school OR two or more years behind grade for age

Not in school

No education

Two years behind grade for age

Not living with parents

Mother deceased

Father deceased

Both parents deceased

Not related to the head of household

Adopted/foster child

Violent discipline

Disability

Child labor

Working

Gender Parity Index

Parent sick for $3+$ months

Have a bank account

\section{Ages 15-19 only}

Ever had sex

Condom use at last sex

Sex with multiple partners

Sex with non-regular partners

Never used contraceptive

No access to family planning information

Ever given birth

Currently pregnant

Marriage before 18

Marriage before 15

Currently married

More than 10 years age difference with spouse

Incorrect knowledge of HIV prevention methods: condom

Incorrect knowledge of HIV prevention methods: sex with one partner

Incorrect knowledge of HIV prevention methods: abstinence

Never heard of HIV

Never tested for HIV

Comprehensive knowledge of HIV

Never tested and received results of HIV test

Illiterate

Age at first birth: before the age of 18 or 15

Sex before the age of 15

More than 10 years age difference with last partner

High-risk sexual activity: Multiple partners, sex under the age of 15 ,

or non-regular

Think that domestic violence is justified

FGM/C is accepted

Polygyny

Experience of violence

Low body mass index

Anemia

Unmet need for contraception

No assistance at delivery

Did not receive Vitamin A shot

Did not receive tetanus shot

Never had antenatal visit

Husband makes all decisions in household

First sex forced

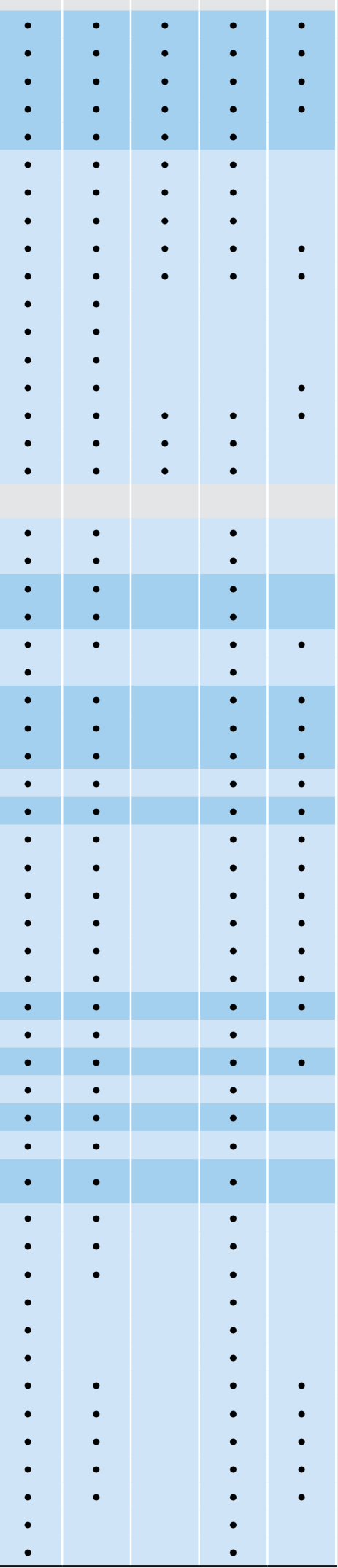


early marriage. Some may already be married and are thus living with their spouse or their spouse's family. Research has proven that not living with parents is an important risk factor for adolescents despite certain cases where living with a relative or an individual other than a parent is beneficial.

Individual level, ages 15 to 19. Indicators at the individual level for girls ages 15 to 19 were selected based on availability across countries as well as their implications for vulnerability of girls in this age group. The indicators included for this level and age group are related to schooling, sexual and reproductive health and family formation. Marriage at a young age can put a girl "off track" or make her more vulnerable to poor outcomes throughout her life. Marital status was included since marriage during this age period can have broad implications and in many countries is illegal under the age of 18 . Ever given birth or currently pregnant was included as another measure of "off track" because of the challenges associated with childbirth at a young age. Never having attended secondary school is an indication that a girl this age is not likely to receive further education, which will limit the opportunities she has for work outside the home.

A composite indicator for high-risk sex was included as a measure of vulnerability in terms of sexual and reproductive health. The indicator includes sex before the age of 15, sex with multiple partners, or sex with non-regular partners. Any of these behaviors increases risk of sexually transmitted diseases and pregnancy for girls ages 15-19. We were unable to include violence as an indicator because direct violence is not available in all surveys and the indicator relating to social norms was not comparable across areas. Opinions of violence vary with the prevalence of violence in a community as well as programming around violence. Nutrition indicators were not available across MICS and DHS surveys.

Household level. The indicators included at the household level are related to housing conditions and household and family structure. After considering several indicators of vulnerability, the following were selected for inclusion: access to improved sanitation, access to an improved water source, and household head with no education. Access to an improved source of water and sanitation is dependent on urban/rural location and the different risks that are present in these areas. Despite this limitation, both indicators have important health implications and are representative of household wealth. The wealth index was not included because it cannot be compared across countries and because it has a strong urban bias. Education of the household head has been shown to be associated with the health, well-being, and education of other household members.
Community level. There are no community-level indicators available in DHS and MICS surveys related to social capital, social networks, social cohesion, and other critical community influences. Given the lack of direct measures of community risk factors, a measure of social climate was constructed using data from older women in the community. The indicator is based on the idea that the behaviors and advice of older women are reflective of the context in which a girl lives and will influence how she acts and perceives her own opportunities. Living in a community that increases exposure to risk factors will increase adolescent vulnerability. The concept of social climate and the importance of the behaviors of older women were confirmed by the qualitative participatory assessment in Appendix I. Girls in regions throughout Uganda stated that they were influenced by the advice and behaviors of older women.

To construct the community-level indicators we had to 1) select the appropriate indicators, 2) define communities and 3 ) identify communities that are high-risk.

\section{Community risk factors were constructed} based on the behaviors of women aged 20 to 49 years. We were unable to use women aged 20 to 30 because sample sizes were too small. The construction of these indicators also allowed us to use additional data available for women ages 15 to 49 that are not available in DHS or MICS surveys for girls aged 10 to 14 . Three indicators were included for which high prevalence would represent a negative social climate for young adults: child marriage, illiteracy, and low comprehensive knowledge of HIV. Girls in communities that have a high prevalence of child marriage or illiteracy have fewer opportunities. In communities where these practices are more prevalent, girls are more likely to be socially isolated and have less control over their future.

No indicators for HIV/AIDS were directly comparable across countries with different prevalence rates. For example, HIV knowledge is higher in areas with a higher prevalence rate or more programming on HIV. To create an eligible measure for HIV, we combined the comprehensive HIV knowledge indicator with data from the World Bank and the Uganda AIDS indicator survey on HIV prevalence. The HIV indicator is a composite indicator including living in a community with a high adult prevalence of HIV (aged 15 to 49) and a low comprehensive knowledge of HIV among women 20 to 49. Living in a community with little knowledge of HIV despite a high prevalence rate will put girls at greater risk of HIV infection. 
COMPLETE LIST OF HOUSEHOLD INDICATORS* CONSIDERED FOR INCLUSION IN THE AGI ( $\quad$ indicator used in $\mathrm{AGI})$

\section{INDICATORS}

\begin{tabular}{|l|l|l|l|l|} 
DHS & MICS & $10-19$ & $15-19$ & All \\
\hline
\end{tabular}

\section{Ages 10-19}

Poorest wealth quintile

No access to improved water source

Over 15 minutes to get water

No access to improved sanitation or shared facilities

No hand washing facility

Water in household is not treated

Household does not own soap

Does not own a radio or TV

Material of floor: natural or rudimentary

Material of roof: natural or rudimentary

Material of wall: natural or rudimentary

Household does not have electricity

Uses solid fuels for cooking: wood, charcoal, or animal dung

Food cooked on open stove or fire

Female head of household

Household head has no education

Child head of household (under the age of 18)

Elderly head of household (over 65)

IIIness in the household $3+$ months in the last year

Crowding: more than 3 people sleeping in each room

No mosquito net present in the household

Household is located in a slum area

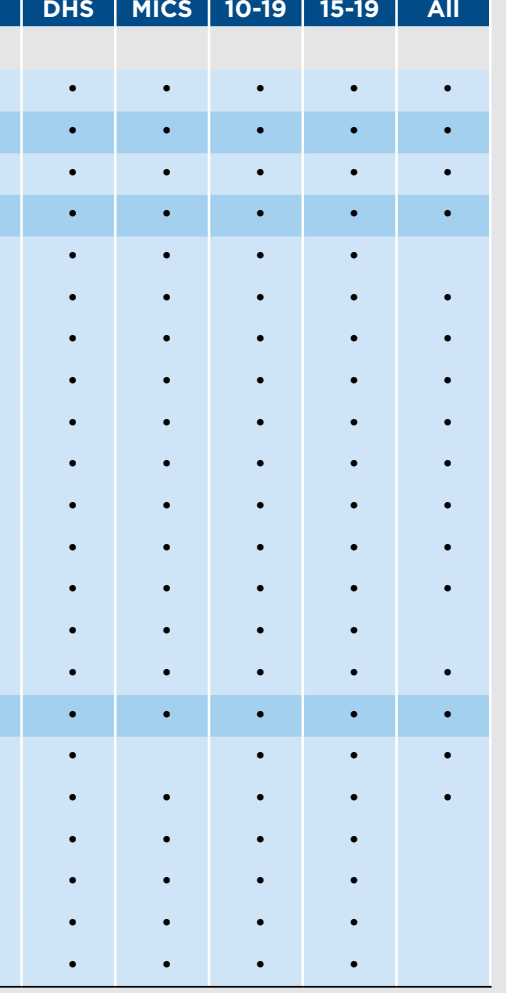

* Community-level indicators are aggregated from individual and household data and will therefore depend upon availability at that level.

\section{TABLE 26}

\section{ADOLESCENT GIRLS MULTILEVEL VULNERABILITY INDEX: LEVELS AND INDICATORS}

\begin{tabular}{|c|c|c|}
\hline INDICATOR & 10 TO 14 & 15 TO 19 \\
\hline $\begin{array}{l}\text { Individual } \\
\text { (10-14: } 1 \text { of } 2) \\
\text { (15-19: } 1 \text { of } 4)\end{array}$ & $\begin{array}{l}\text { Two years behind grade for age OR no education } \\
\text { Not living with parents }\end{array}$ & $\begin{array}{l}\text { Currently married } \\
\text { Ever given birth or currently pregnant } \\
\text { Did not attend secondary school } \\
\text { High-risk sex: Sex under the age of } 15, \text { multiple } \\
\text { partners or non-regular partners }\end{array}$ \\
\hline $\begin{array}{l}\text { Household } \\
(2 \text { of } 3)\end{array}$ & \multicolumn{2}{|c|}{$\begin{array}{l}\text { No access to an improved source of water } \\
\text { No access to improved sanitation } \\
\text { Household head has no education }\end{array}$} \\
\hline $\begin{array}{l}\text { Community } \\
\text { (1 of } 3 \text { ) }\end{array}$ & \multicolumn{2}{|c|}{$\begin{array}{l}\text { High rate of early marriage before } 18 \text { for women } 20-49 \text { (above mean*) } \\
\text { High rate illiteracy in women ages } 20-49 \text { before the age of } 18 \text { (above mean*)** }\end{array}$} \\
\hline
\end{tabular}

*Mean is calculated as regional mean for regional rankings and national mean for national rankings. ${ }^{* *}$ Either did not attend secondary school or higher or cannot read a whole sentence or part of a sentence. ${ }^{* * *}$ Comprehensive knowledge means knowing that consistent use of a condom during sexual intercourse and having just one uninfected faithful partner can reduce the chance of acquiring HIV, knowing a healthy-looking person can be HIV-positive, and knowing that you can't acquire HIV from mosquito bites or sharing food. 


\section{A girl would be} considered most at risk if she experienced deprivations at all three levelsindividual, household, and community-and therefore the AGI threshold for extreme vulnerability is set as being vulnerable at all three levels.

\begin{abstract}
An indicator for violence was not eligible for inclusion in the AGI. Indicators of direct violence are not universally available across DHS and MICS surveys, and the indicator related to acceptance of violence was not comparable across countries and subregions with different prevalence rates. Our analysis showed that attitudes related to violence did not always correspond to general knowledge of violence in Uganda. Attitudes towards violence are affected by prevalence, programming, and policies in an area and can be misleading.
\end{abstract}

2. The ideal definition of a community is the network of people with whom a girl interacts regularly. DHS and MICS do not release data on districts or levels of size below the regional level. The lowest level available is the survey cluster, but there were too few women aged 20 to 49 in each cluster to provide an accurate community percentage for each indicator. Given these limitations, the best method to provide a robust estimate of community for DHS surveys was to use the GPS points for each cluster. Clusters were sorted by their longitude and latitude within each district and aggregated into groups of between 75 and 150 women. The "communities" used in the AGl are clusters that are close in proximity and grouped together to have a large enough sample of women to provide a reliable estimate.
The units used to represent community are not necessarily the ideal definition but we believe that they give a good indication of the vulnerabilities girls face as a result of their environment. A girl interacts with and is influenced by the 75 to 150 women who live closest to her. For all MICS surveys, districts were used to represent communities, as GPS data are not available at the cluster level.

\section{High-risk communities were identified using a relative rather than an absolute bench- mark. A relative measure was selected because of difficulties in determining arbitrary cutoffs using an absolute measure. The relative benchmarks that were considered are one standard deviation above the mean, above the $75^{\text {th }}$ percentile, above the median, and above the mean. The mean of the communities was ultimately selected as the best measure because it is intuitive and provided sound estimates. Indicators are interpreted as a girl living in a community with a high percentage (above the mean) of women aged 20 to 49 with an indicator of vulnerability.}

To provide better comparability across rankings, the mean of communities was calculated at the level for which comparisons would be made. In the regional index, the regional mean was calculated using the average prevalence rate for each indicator based on the entire dataset of grouped clusters in each AGI target country. All communities with prevalence rates above the regional mean were flagged as "vulnerable." The regional average was selected because users will compare country rankings relative to one another in their interpretation of the results. In the index for Uganda, the national average was calculated for each indicator based on all communities within Uganda. Communities with prevalence rates above the national mean were flagged as "vulnerable." The national average was selected because users will compare subnational rankings relative to one another in their interpretation of the results for Uganda. Individual girls aged 10 to 19 are "vulnerable" at the community-level if they live in a vulnerable community as measured by higher than average vulnerability indicators for women aged 20 to 49 in the community.

\section{Step 3: Constructing the index}

Index construction involved decisions about the structure of the index (e.g., number of dimensions and number and type of indicators per dimension), method of normalization, and weighting scheme (e.g., equal or unequal). 


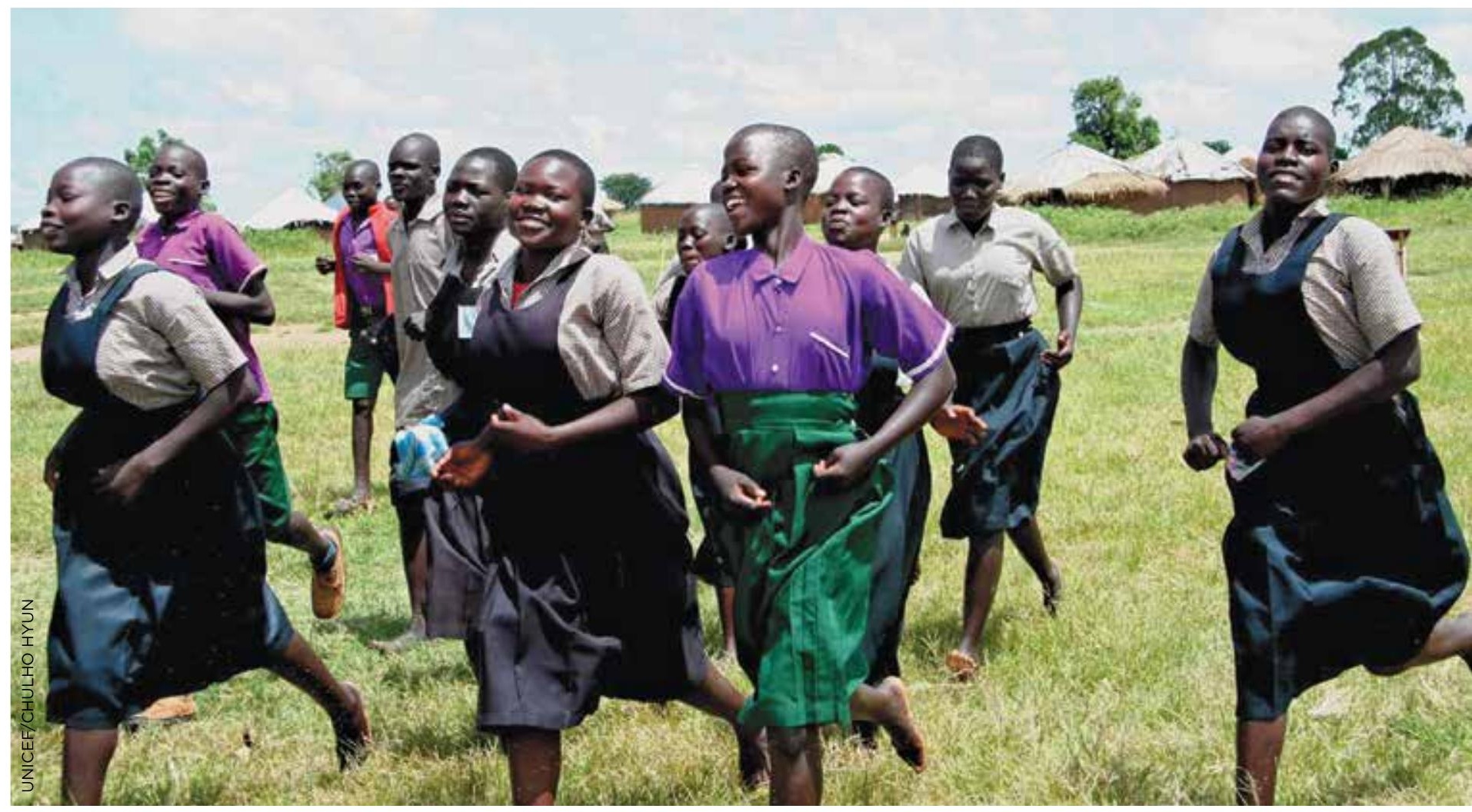

The ideal definition of a community is the network of people with whom a girl interacts regularly. The "communities" used in the AGl are clusters that are close in proximity and grouped together to have a large enough sample of women and girls to provide a reliable estimate.

\section{Identifying the structure of the index}

An index can have one or more dimensions. In the construction of a multidimensional index, there are two main approaches to identify the dimensions: using theory only or using theory and data. The first approach is very common. In this approach, one relies on previous literature to determine the number and composition of domains. The definition of the construct is defined prior to the creation of the index and the index is constructed to fit this definition. A more complex (but not necessarily better) approach is to combine qualitative research with expert consultation and multivariate data analysis, such as factor analysis. The goal of factor analysis is to take a single set of variables (indicators) and determine which variables form meaningful and relatively independent subsets (factors).

After considering the various options presented above, we decided to use a multilevel structure that includes deprivations at the individual, household, and community level. This decision was informed by our reading of the literature rather than multivariate analysis. Vulnerability is defined as risk factors within three dimensions (household, individual, and community) and the index is constructed around this definition. While all indices are imperfect and open to criticism, easily interpretable results and a strong conceptual framework are essential for index use (Raworth and Stewart 2003).

\section{Aggregating the indicators}

Once the structure is identified, data must be summed to create the composite indicator. Before summing, however, indicators with different measurement units are normalized to have the same scale. Common normalization techniques include ranking, standardization, min-max normalization, and categorical normalization.

In the AGI, all indicators were first standardized to account for missing data (OECD 2008; Pullum et al. 2011). The indicators were dichotomous and coded as O for "no" and 1 for "yes." Variables were standardized so that each contributed equally to the overall summary statistic. The denominator includes all girls in the age group.

We follow a cut-off method similar to the Bristol Approach and the Multidimensional Poverty Index. Using multiple cut-offs, it is possible to identify the regional prevalence of girls classified 
as vulnerable at multiple levels. A cutoff was first set for the number of indicators a girl needed to be classified as vulnerable within each level (Figures 29 and 30). For instance, at the household level a girl is classified as vulnerable if she has at least two of the three deprivations. A second cutoff is then established for multidimensional deprivations. In the case of the AGI, a girl is considered "multidimensionally" vulnerable if she is deprived on enough levels to cross the threshold. A girl would be considered most at risk if experiencing deprivations at all three levels-individual, household, and communityand therefore the AGI threshold for extreme vulnerability is set as qualifying as vulnerable at all three levels.

At the community level, girls are considered vulnerable if they experience 1 of 3 deprivations. At the household level girls are considered vulnerable if they experience 2 of 3 deprivations. The cutoff at the household level is higher to account for the extremely high prevalence of no access to water and sanitation in many countries. A higher cutoff is necessary to give this indicator an equal weight. At the individual level for girls aged 10 to 14 , a girl is classified as vulnerable if she is deprived on one or more indicators. The cutoff for individual girls ages 15 to 19 is also one or more deprivations.

This cutoff technique was used to provide a directly interpretable percentage of vulnerable girls rather than a score. Using this method the final estimate is a direct percentage of households or individuals who fit a particular definition. Other methods of normalization and aggregation result in an index score that is more abstract and harder to interpret. However, without an empirical basis for setting the cutoffs, the method requires subjective decision-making about the definition of a construct such as vulnerability. For instance, there is no empirical basis for determining that a deprivation in education should be that no household member has at least five years of education. Furthermore, if the index is intended for use across countries, it is not clear that one definition of deprivation fits all countries.

\section{Weighting the dimensions}

We combine indices using the simple approach of giving all indicators equal weights. Weights can be used in index construction to increase or decrease the importance of the contributing indicator or domain. The use of weights can be controversial because of the subjective nature of their application. Proponents of weighting argue that not weighting results is implicitly giving each indicator the same importance, which may be equally arbitrary. Most vulnerability indices use equal weighting for simplicity.

For the purposes of the AGI index, dimensions and indicators were not weighted. This decision was informed by other relevant indices that used equal weighting and by the difficulty of assigning a clear weight to any of the indicators or dimensions. ${ }^{10}$

\section{Step 4: Testing the index}

\section{Deconstruction}

The first step in testing an index is deconstruction. Composite measures such as the AGI often mask problems or inaccuracies within their construction. Deconstruction is a way of examining how individual indicators contribute to the overall end statistic. In the AGI, deconstructed percentages were examined through percentages by indicator and by level for all countries. Deconstruction of indicators and levels within the index ensures that percentages are within an accurate range across countries and add up to the correct aggregated amount.

Deconstruction was also used to highlight indicators that were not compatible with previous research and general knowledge about a certain topic or country. For example, many indicators measuring knowledge or behaviors that could be contingent on programming in the area were excluded from the index. The index does not include an indicator on social norms around violence because subnational patterns were not compatible with general knowledge about violence in Uganda. All indicators included in the final index remain consistent after deconstruction.

10 The absence of purposefully applying weights in an aggregated measure does not necessarily mean that dimensions are weighted equally. Dimensions with unequal numbers of indicators will have varying weights (OECD 2008). For example, if one dimension includes two indicators and a second dimension includes three, there is an inherent weighting difference between the two. Similarly, variables with a higher number of categories contribute unequally. In the $A G I$, dimensions and indicators have been standardized to contribute evenly to the summary statistic. 
FIGURE 29

INDICATORS AT EACH LEVEL

\begin{tabular}{|l|c|}
\hline \multicolumn{2}{|c|}{ INDIVIDUAL LEVEL } \\
\hline \begin{tabular}{c|c}
$10-14$ & $15-19$ \\
$(1$ of 2$)$ & $(1$ of 4$)$
\end{tabular} \\
\hline
\end{tabular}

No education

OR

two or more

years behind

grade for age

Not living with

parents

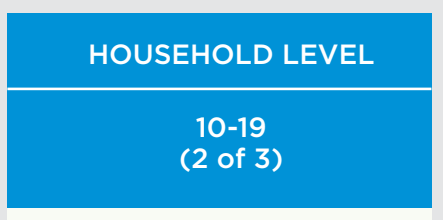

No access to an improved source of water

No access to improved sanitation or shared facilities

Household head has no education

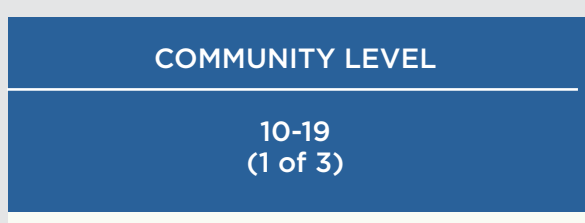

Lives in a community that is above the mean with respect to the following indicators among women aged 20-49:*

a) Marriage before 18

b) Illiteracy**

c) High national prevalence of HIV (\% of population aged 15-49) and high rate of no comprehensive knowledge*** of HIV for women aged 20-49

${ }^{*}$ Calculated relative to Uganda for Uganda rankings and relative to countries in region for regional rankings.

**Either did not attend secondary school or higher or cannot read a whole sentence or part of a sentence.

***Comprehensive knowledge means knowing that consistent use of a condom during sexual intercourse and having just one uninfected faithful partner can reduce the chance of acquiring HIV, knowing that a healthy-looking person can be HIV-positive, and knowing that you can't acquire HIV from mosquito bites or sharing food.

\section{FIGURE 30}

CUTOFFS AT EACH LEVEL

\section{CONSTRUCTING THE AGI}

INDIVIDUAL LEVEL (10-14 and 15-19)

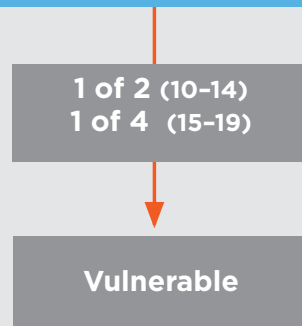

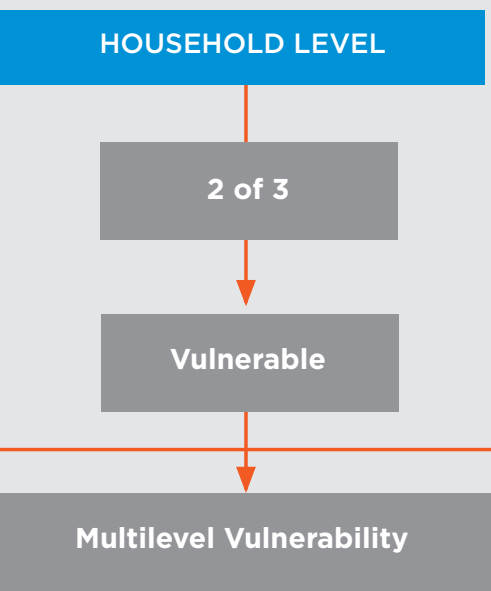

COMMUNITY LEVEL

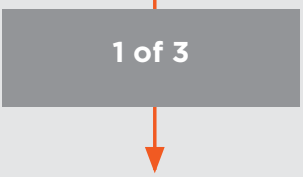

Vulnerable 


\section{Conducting an uncertainty and sensitivity analysis}

Uncertainty analysis is a test of how uncertainty in the development of a composite indicator is propagated throughout its construction and affects the end value of the composite statistic. Uncertainty analysis is linked closely with sensitivity analysis, which is used to assess the contribution of individual sources of uncertainty to determine how to minimize the variance in the composite value. Uncertainty analysis is first used to quantify the uncertainty or realm of error in country rankings. Uncertainty analysis allows us to see how rankings change according to error in index development. This is similar to confidence intervals, which are used to show error in a summary statistic. Uncertainty analysis is followed by a sensitivity analysis, which determines how this uncertainty or variation in rankings can be attributed to different specific sources. This approach explores sources of uncertainty by filtering through a series of input values for other methods of construction and assessing the shift in individual country rankings or average rankings for all countries relative to the initial construction (OECD 2008). Uncertainty and sensitivity analysis are typically done using a technique called Monte Carlo simulations. While this technique was too complicated for the purposes of the AGI, several versions of the index were tested and compared to determine how these changes would affect overall index rankings.

\section{AGI testing}

The index was constructed by testing different indicators at each level. The impact of each indicator was examined both by level and by impact on the overall index rankings. Indicators that deviated from expected patterns in relation to other indicators, age, country, or region required further testing. Indicator correlations and associations by wealth and urban-rural residence were also examined. Indicators selected capture unique aspects of vulnerability at each level and are compatible with the literature on adolescent vulnerability. The household indicators we selected minimized urban-rural bias.

Multivariate analysis was used to re-create the index and to verify index results. Principal components analysis (PCA) is commonly used to create indices. PCA was used to re-create the index based on the full set of indicators. Our analysis showed that the AGI construction through original indicator testing yielded rankings that were more similar to general knowledge on vulnerability in Uganda than when creating the index using PCA.

\section{TABLE 27}

COMPARISONS OF AGI RANKINGS TO OTHER WEALTH AND DEVELOPMENT INDICES, BY COUNTRY

\begin{tabular}{|l|c|ccc|}
\hline & AGI & HDI & MPI SCORE & $\begin{array}{c}\text { GDP PPP } \\
\text { (per capita) }\end{array}$ \\
\hline Burundi 2011 & 33.5 & 178 & 0.53 & 604 \\
\hline Ethiopia 2011 & 59.4 & 173 & 0.562 & 1109 \\
\hline Kenya 2009 & 12.0 & 145 & 0.229 & 1710 \\
\hline Lesotho 2010 & 6.8 & 158 & 0.156 & 1691 \\
\hline Madagascar 2009 & 38.3 & 151 & 0.357 & 996 \\
\hline Malawi 2010 & 27.3 & 170 & 0.381 & 893 \\
\hline Mozambique 2008 & 53.6 & 185 & 0.512 & 975 \\
\hline Namibia 2007 & 6.7 & 128 & 0.187 & 6801 \\
\hline Rwanda 2011 & 8.7 & 167 & 0.426 & 1282 \\
\hline Somalia 2006 & 65.2 & NA & 0.514 & NA \\
\hline Swaziland 2007 & 15.6 & 141 & 0.184 & 6053 \\
\hline Tanzania 2010 & 28.6 & 152 & 0.367 & 1512 \\
\hline Uganda 2011 & $\mathbf{2 0 . 6}$ & $\mathbf{1 6 1}$ & $\mathbf{0 . 3 6 7}$ & $\mathbf{1 3 4 5}$ \\
\hline Zambia 2007 & 34.3 & 163 & 0.328 & 1621 \\
\hline Zimbabwe 2011 & 6.5 & 172 & 0.18 & $\mathrm{n} / \mathrm{a}$ \\
\hline
\end{tabular}

Sources: Alkire, Conconi, and Roche 2013; UNDP 2013; World Bank 2013. 
These results verified our current method of index construction.

\section{Testing community-level indicators}

At the community level, indicators were constructed using four different cutoffs. These cutoffs are the mean, standard deviation, $75^{\text {th }}$ percentile and the median. Indicator values, community-level rankings, and overall index rankings were compared using these different cutoffs. The mean was ultimately selected as the best measure because the standard deviation and $75^{\text {th }}$ percentile made countries at either end of the spectrum appear even better or worse in comparison to the other countries. The mean is intuitive to understand.

Once the mean was selected as an appropriate measure, we had to determine whether this mean should be calculated using all AGI countries or all regions within each country. The mean was calculated using both of these methods. Rankings were compared with country rankings from the Human Development Index and Multidimensional Poverty Index. It was determined that for the regional index, a regional mean would be used that creates an average using the values for all countries together. For the national index, a national mean is used that averages values within each country, creating a separate mean for each country. Using a different mean for the regional versus national index is a more appropriate way of ranking these units in comparison to one another. When we created the regional index using a separate national mean for each country, rankings were not compatible with other sources or with general knowledge about country differences. Creating the national index based on a regional mean inflated cross-national differences at the community level.

To further verify our results, means were calculated using a random effects model and a population-averaged model. Both of these methods account for error that is introduced in the mean calculation when averaging clusters rather than individuals or when using a smaller number of observations. Results from this analysis were similar to the AGI rankings from original indicator testing and index construction. The Southwest was the only region in Uganda that was ranked differently when using a random effects or population-averaged mean. This analysis verified that error in calculating the mean does not factor largely into the Adolescent Girls Multilevel Vulnerability Index.

\section{Assessing validity}

The Adolescent Girls Multilevel Vulnerability Index was compared with three other measures of country wealth and development: the Human Develop-

\section{The aims of the participatory}

assessment were to consult adolescent girls about the issues most important to them, understand the challenges and risks girls face in their lives, and validate the index and report findings.

ment Index (HDI), Multidimensional Poverty Index (MPI) and Gross Domestic Product (GDP) Purchasing Power Parity (PPP) per capita. When comparing the Adolescent Girls Multilevel Vulnerability Index with other country-level rankings of development, we find that rankings do not always correspond to a country's wealth (Table 27). Rankings from the AGI appear most similar to those from the Multidimensional Poverty Index, which is a measure of poverty that is not constrained by income level alone. The Multidimensional Poverty Index includes measures of education and health in addition to living standards. Findings suggest that adolescent vulnerability is a product of factors beyond those present at the household level alone.

\section{Participatory assessment}

In addition to comparisons with other indices, a participatory assessment was added to the report to validate the indicators included in the index. The Population Council conducted nine discussion sessions with adolescent girls in and out of school across six regions in Uganda. The aims of the participatory assessment were to consult adolescent girls about the issues most important to them, understand the challenges and risks girls face in their lives, and validate the index and report findings. See Appendix I for a more in-depth discussion.

Index conceptualization at the individual level was largely validated by the participatory assessment. 
Indicators capture common themes of living apart from parents, school dropout, marriage, pregnancy and risky sexual behaviors. Gaps at the individual level were the lack of indicators for work and individual experience of violence, and the lack of indicators for girls aged 10 to 14 . Age clustering of topics discussed during the discussion groups showed that most events of relevance happen between ages 14 and 16 and become common as early as 12 years. There is little information across countries about what makes girls vulnerable at these young ages.

Conceptualization at the community level was validated by the assessment. Girls universally mentioned the influence of the attitudes and behaviors of older women. The participatory assessment supported the use of community-level indicators in the AGI.

There are gaps in the conceptualization of the index at the household level. Girls repeatedly mentioned the importance of economic and social support from parents and other family members. Girls who had more positive reports also had more support. No indicators for social or economic support from household members are available in DHS and MICS surveys. These absences highlight the importance of developing indicators to measure support for adolescent girls within the household. 

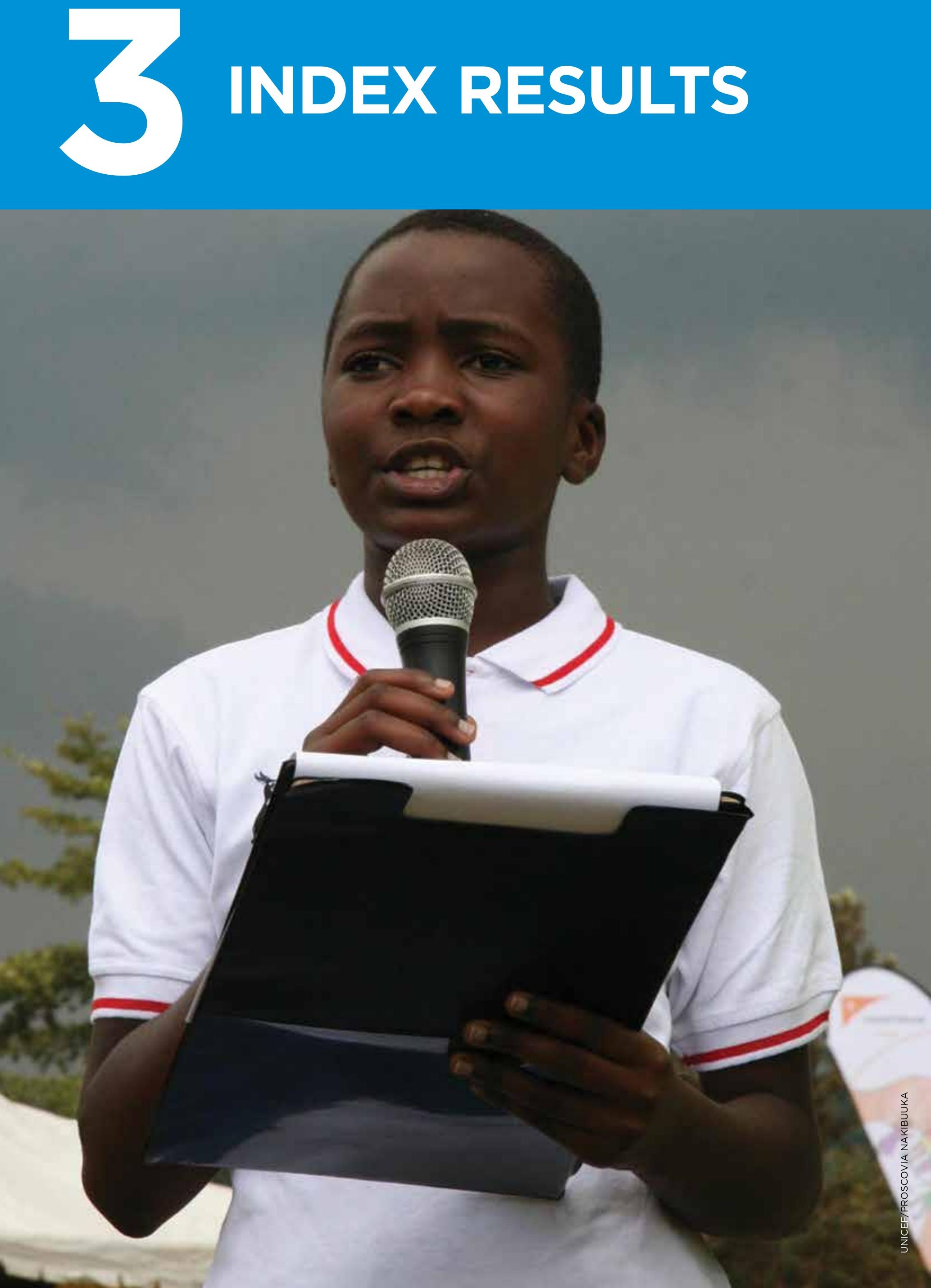
The Adolescent Girls Multilevel Vulnerability Index $(A G I)$ is an innovative index that captures adolescent vulnerability at the individual, household, and community level. The AGI allows us to analyze the situation of adolescent girls, understand vulnerabilities at different levels, and examine disparities both within Uganda and between countries in East and Southern Africa.

\subsection{Uganda}

In the overall multilevel vulnerability index, percentages of girls 10 to 19 experiencing vulnerability at all three levels range from 6.5 percent in Zimbabwe to 65.2 percent in Somalia (see Table 28). Uganda falls in the middle of cross-national rankings of multidimensional adolescent vulnerability with 21 percent of girls who are vulnerable at all three levels. Compared to all countries in East and Southern Africa, girls ages 10 to 19 in Uganda have higher than average rankings of individual- and community-level vulnerability but lower rankings at the household level. Uganda has lower than average percentages of all three household indicators.

Within Uganda, the regions with the highest AGI rankings are again those with the highest percentages of girls experiencing community and individual level vulnerabilities (Figure 31). While there are vulnerable girls who live in households with no access to water or sanitation or where a household head has no education, the most vulnerable girls in Uganda have high vulnerabilities at the community and individual levels.

Trends in vulnerability data show that the percentage of girls with multilevel vulnerability in Uganda has declined from 32.7 percent in the 2006 DHS to 20.6 percent in the $2011 \mathrm{DHS}$ (Figure 32). This decrease in extreme vulnerability is concentrated in a decrease in household vulnerability and is due to a large improvement in access to improved water and sanitation. Individual- and community-level vulnerabilities were generally unaffected over the five-year period. The percentage of girls 10-14 not living with parents decreased from 28 percent in 2006 to 19 percent in 2011 but all other individual and community indicators remained similar (not shown; refer to Section 1.3 of the report for indicator trends).

Changes in index rankings between 2006 and 2011 were most dramatic in the Western and West Nile regions (Figure 33 ). In both of these regions, there were reductions in vulnerabilities at all three lev- els. Changes in other regions were much smaller and were concentrated in reductions in household-level vulnerability. There was little reduction in individual- or community-level vulnerability in most regions. The high levels of individual- and community-level vulnerabilities and lack of change in these areas suggest that investments are needed to reduce individual- and communitylevel vulnerabilities.

Within Uganda, the prevalence of multilevel vulnerability among adolescent girls aged 10 to 19 is highest in Karamoja, where 53.6 percent of girls are vulnerable at all three levels (Table 29; Figure 34). According to AGI findings, Karamoja has the highest percentages of vulnerable girls at the individual (91.9 percent), household (57.0 percent) and community levels (100 percent). Education disparities drive vulnerability across all three levels.

Karamoja is a rural area characterized by a nomadic pastoralist society. Karamojong people rely on cattle rearing as a means of survival. Recent changes in climate and prolonged episodes of drought have led to an increase in violence related to cattle-rustling and raids between clans (Powell 2010). Roughly 87 percent of adolescents in Karamoja live in the two poorest wealth quintiles, making this a particularly vulnerable region of Uganda.

When broken down by age group, Karamoja remains highest on multilevel vulnerability for girls aged 10 to 14 and aged 15 to 19 (Table 30). Rankings and levels of individual vulnerability are similar between the two age groups despite the slight differences in indicators.

The Eastern, Western, and Central 2 regions have a higher level of extreme vulnerability for girls aged 15 to 19 than for girls 10 to 14 (Figure 36). This is due to higher percentages of individual-level vulnerability for girls 15 to 19 in these regions. However, it is difficult to make meaningful comparisons between age groups as indices for the two groups include different indicators at the individual level. Karamoja, West Nile, Central 1, and the Southwest have higher vulnerability for girls aged 10 to 14 due to differences at the household rather than individual level.

Yet, despite high levels of vulnerability in Karamoja, population distributions of adolescent girls show that rural Karamoja contains only 4 percent of the adolescent population. Although girls in this region are highly vulnerable, they represent a very small proportion of all girls in Uganda. Conversely, the Eastern and Western regions contain the largest proportions of the adolescent population. Urban migration and the distribution of adolescent girls highlight the need to increase our understanding of vulnerability in an urban context. 


\begin{tabular}{|c|c|c|c|c|c|c|}
\hline \multicolumn{7}{|c|}{$\begin{array}{l}\text { PERCENTAGE OF ADOLESCENT GIRLS AGED 10-19 WITH MULTILEVEL VULNERABILITY AND } \\
\text { PERCENTAGE WHO ARE VULNERABLE AT EACH LEVEL, EAST AND SOUTHERN AFRICA }\end{array}$} \\
\hline & \multicolumn{3}{|c|}{ MULTILEVEL VULNERABILITY } & \multicolumn{3}{|c|}{ LEVEL } \\
\hline & 3 LEVELS & 2 LEVELS & 1 LEVEL & INDIVIDUAL & HOUSEHOLD & COMMUNITY** \\
\hline Burundi 2011 & 33.5 & 74.6 & 94.7 & 76.9 & 48.5 & 77.4 \\
\hline Ethiopia 2011 & 59.4 & 87.6 & 98.1 & 79.8 & 70.7 & 94.6 \\
\hline Kenya $2009^{*}$ & 12.0 & 37.6 & 74.3 & 47.6 & 42.9 & 33.4 \\
\hline Lesotho 2010 & 6.8 & 31.4 & 71.8 & 49.8 & 30.2 & 30.0 \\
\hline Madagascar 2009 & 38.3 & 66.7 & 88.2 & 66.8 & 61.4 & 65.0 \\
\hline Malawi 2010 & 27.3 & 75.2 & 98.1 & 70.2 & 34.6 & 95.8 \\
\hline Mozambique 2008 & 53.6 & 89.1 & 100.0 & 82.5 & 60.2 & 100.0 \\
\hline Namibia 2007 & 6.7 & 27.1 & 65.2 & 48.8 & 29.6 & 20.7 \\
\hline Rwanda 2011 & 8.7 & 38.4 & 82.1 & 72.4 & 24.4 & 32.5 \\
\hline Somalia 2006 & 65.2 & 93.3 & 100.0 & 83.7 & 74.8 & 100.0 \\
\hline Swaziland 2007 & 15.6 & 48.6 & 81.0 & 54.3 & 44.9 & 46.0 \\
\hline Tanzania 2010 & 28.6 & 61.3 & 88.3 & 56.1 & 54.8 & 67.3 \\
\hline Uganda 2011 & 20.6 & 71.8 & 96.1 & 70.4 & 27.0 & 91.2 \\
\hline Zambia 2007 & 34.3 & 64.8 & 89.5 & 65.2 & 48.7 & 74.9 \\
\hline Zimbabwe 2011 & 6.5 & 29.9 & 68.9 & 40.7 & 22.4 & 42.2 \\
\hline
\end{tabular}

Source: DHS 2007-2011; MICS 2006-2008.

Note. Preferred specification highlighted with white box. $\quad$ *Kenya does not include not living with parents. $\quad{ }^{* *}$ Community indicators are constructed using the regional mean.

\section{FIGURE 31}

PERCENTAGE OF ADOLESCENT GIRLS AGED 10-19 VULNERABLE AT EACH AGI LEVEL, BY REGION, UGANDA

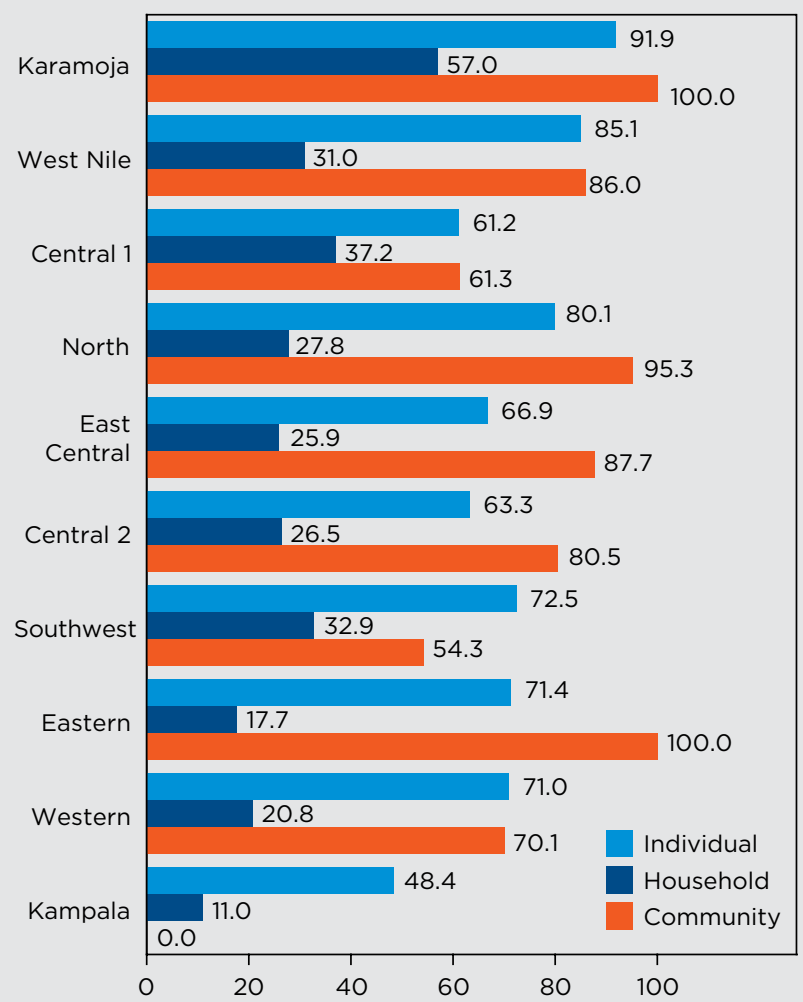

Source: DHS 2011

\section{FIGURE 32}

PERCENTAGE OF ADOLESCENT GIRLS AGED 10-19 VULNERABLE AT EACH AGI LEVEL, UGANDA, 2006 AND 2011

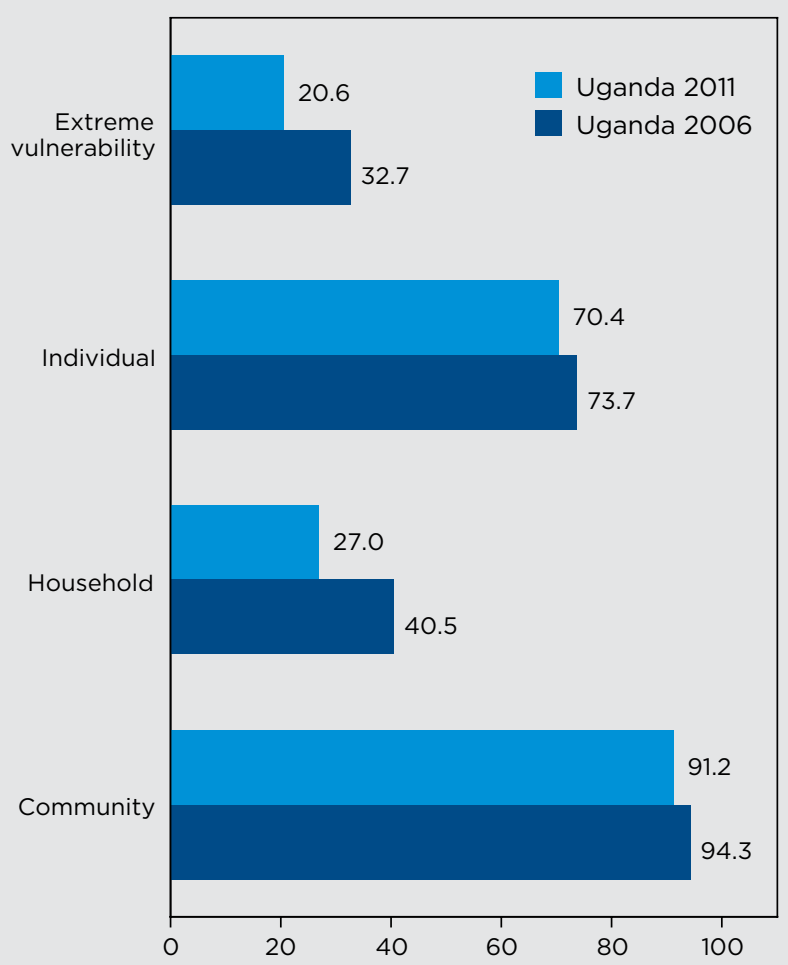

Source: DHS 2006 and 2011.

Note: Extreme vulnerability is defined as experiencing deprivations at all three levels. 


\section{TABLE 29}

PERCENTAGE OF ADOLESCENT GIRLS AGED 10-19 WITH MULTILEVEL VULNERABILITY AND PERCENTAGE WHO ARE VULNERABLE AT EACH LEVEL, BY REGION, UGANDA

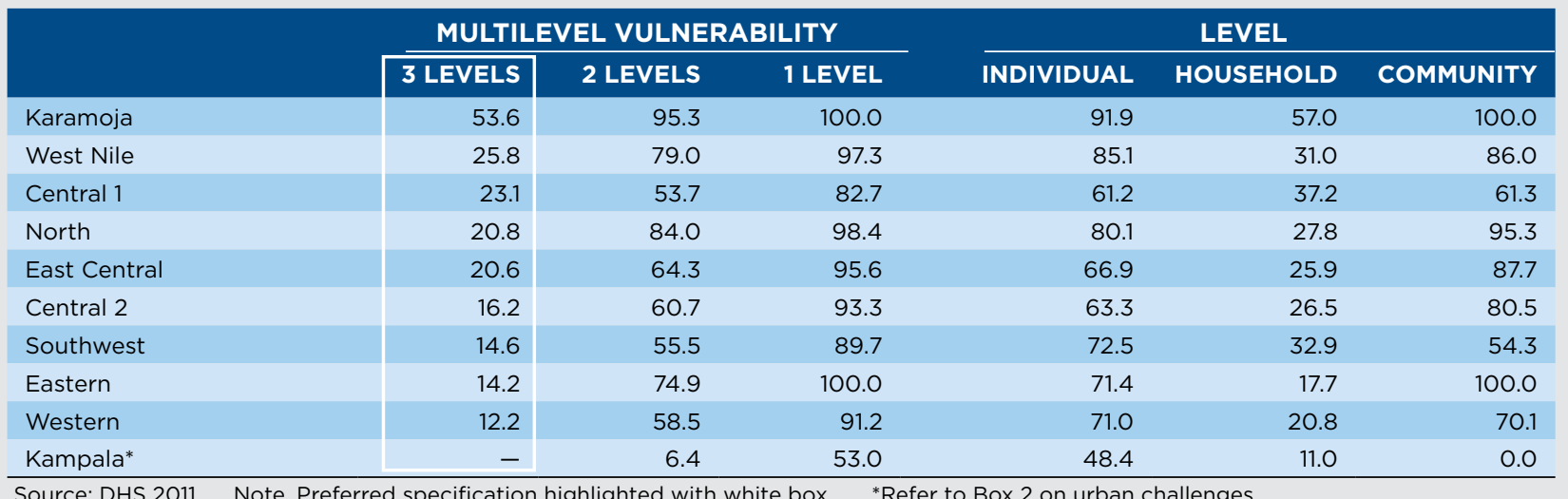

Source: DHS 2011. Note. Preferred specification highlighted with white box. ${ }^{*}$ Refer to Box 2 on urban challenges.

\section{TABLE 30}

PERCENTAGE OF ADOLESCENT GIRLS AGED 10-14 AND 15-19 WITH MULTILEVEL VULNERABILITY AND PERCENTAGE WHO ARE VULNERABLE AT EACH LEVEL, BY REGION, UGANDA

\begin{tabular}{|c|c|c|c|c|c|c|c|c|c|c|c|c|}
\hline & \multicolumn{6}{|c|}{ MULTILEVEL VULNERABILITY } & \multicolumn{6}{|c|}{ LEVEL } \\
\hline & \multicolumn{2}{|c|}{3 LEVELS } & \multicolumn{2}{|c|}{2 LEVELS } & \multicolumn{2}{|c|}{1 LEVEL } & \multicolumn{2}{|c|}{ INDIVIDUAL } & \multicolumn{2}{|c|}{ HOUSEHOLD } & \multicolumn{2}{|c|}{ COMMUNITY } \\
\hline & $10-14$ & 15-19 & $10-14$ & 15-19 & $10-14$ & 15-19 & $10-14$ & 15-19 & $10-14$ & $15-19$ & $10-14$ & $15-19$ \\
\hline Karamoja & 54.0 & 50.5 & 95.1 & 94.8 & 100.0 & 100.0 & 90.3 & 94.2 & 58.9 & 51.2 & 100.0 & 100.0 \\
\hline West Nile & 26.7 & 22.3 & 73.4 & 87.7 & 96.8 & 98.1 & 81.0 & 90.8 & 32.1 & 27.3 & 83.8 & 90.0 \\
\hline Central 1 & 25.7 & 20.4 & 57.2 & 53.1 & 83.4 & 81.2 & 57.0 & 65.9 & 41.7 & 32.9 & 67.5 & 56.0 \\
\hline East Central & 21.1 & 21.0 & 61.9 & 70.5 & 95.2 & 96.3 & 63.1 & 76.1 & 27.0 & 25.0 & 88.1 & 86.8 \\
\hline North & 20.0 & 22.6 & 80.2 & 90.5 & 99.0 & 97.9 & 73.8 & 92.0 & 29.1 & 24.2 & 96.3 & 94.8 \\
\hline Central 2 & 16.3 & 17.0 & 59.2 & 64.5 & 93.3 & 94.5 & 59.8 & 70.5 & 27.7 & 23.5 & 81.3 & 82.0 \\
\hline Southwest & 16.0 & 12.5 & 56.9 & 53.7 & 89.7 & 89.7 & 72.9 & 71.3 & 34.0 & 31.5 & 55.7 & 53.0 \\
\hline Eastern & 12.3 & 16.9 & 68.1 & 84.6 & 100.0 & 100.0 & 63.2 & 82.8 & 17.2 & 18.8 & 100.0 & 100.0 \\
\hline Western & 10.8 & 14.6 & 54.9 & 62.9 & 90.5 & 91.2 & 67.7 & 75.4 & 18.8 & 24.2 & 69.7 & 69.0 \\
\hline Kampala* & - & - & 4.0 & 8.3 & 45.5 & 59.8 & 39.8 & 55.6 & 9.8 & 12.6 & 0.0 & 0.0 \\
\hline
\end{tabular}

\section{FIGURE 33}

PERCENTAGE OF VULNERABLE ADOLESCENT GIRLS AGED 10-19, BY REGION, UGANDA, 2006 AND 2011

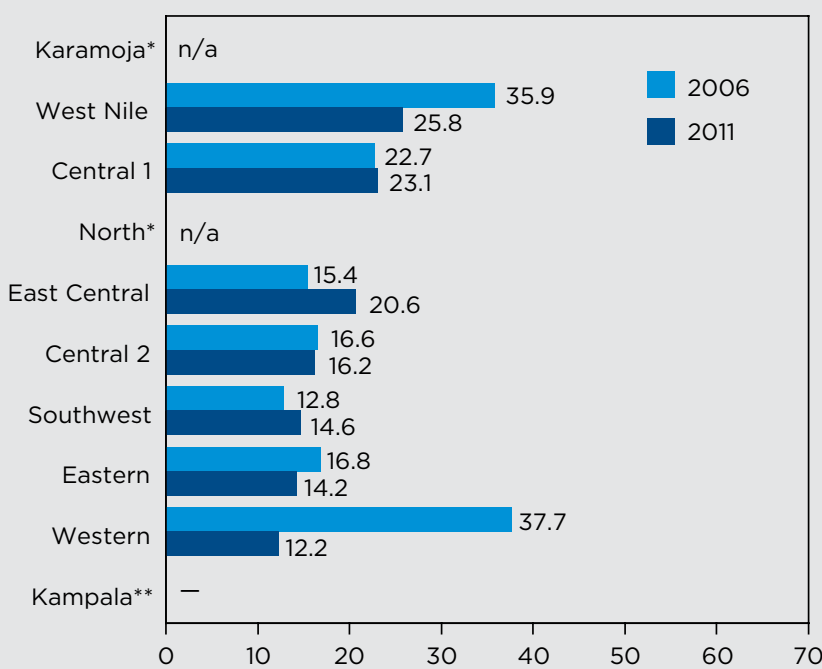
Source: DHS 2006 and 2011.

${ }^{*}$ Category changes in the DHS surveys for Karamoja and the North from 2006 and 2011 limited comparability, therefore these regions were excluded from this analysis. ${ }^{* *}$ Refer to Box 2 on urban challenges.

\section{FIGURE 34}

AGI MULTILEVEL VULNERABILITY (3 LEVELS) RESULTS FOR ADOLESCENT GIRLS AGED 10-19, UGANDA

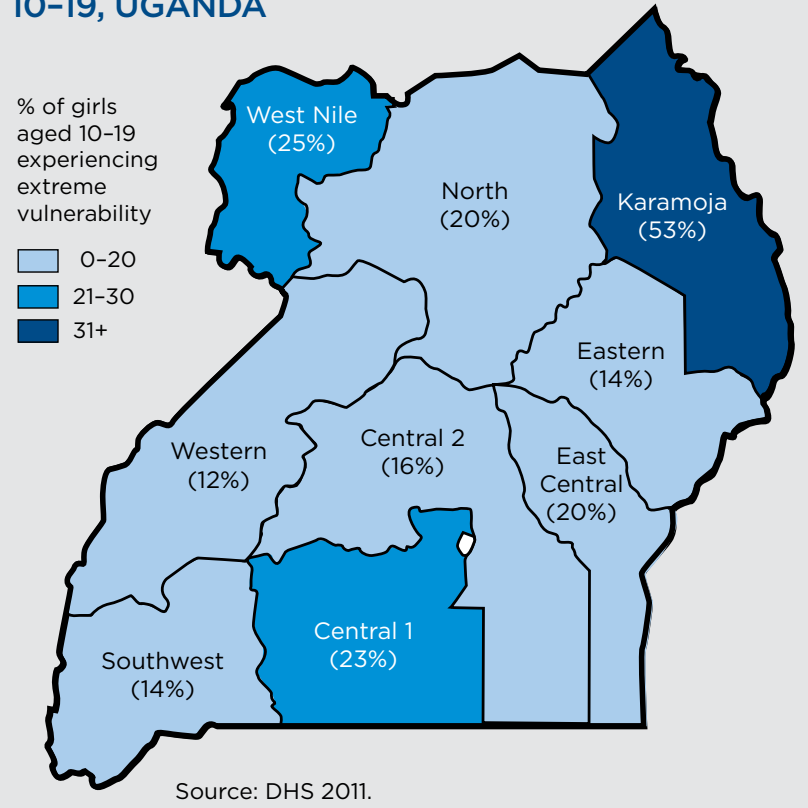




\section{MEASURING VULNERABILITY IN POOR URBAN ADOLESCENT POPULATIONS}

Research on vulnerability in urban areas shows that large inequalities in wealth make it increasingly difficult for poor urban adolescents to take advantage of the resources offered by urban settings. Many residents of poor areas do not have formal jobs or ownership of their homes. These informal living arrangements make it difficult for the urban poor to access services, have consistent employment, exercise legal rights, or secure tenure and other assets.

In addition to disparities in standard indicators of vulnerability, poor urban girls face unique risks. Many poor urban adolescents are migrants. A study in low-income and slum areas in Ethiopia found that 77 percent of out-of-school adolescent girls did not live with parents, largely because of migration (Erulkar et al. 2004.). High proportions of adolescent urban migrants lead to low social cohesion and high levels of isolation. A study in South Africa found that HIV prevalence was higher in informal areas and was associated with low levels of social cohesion and poverty (Shisana and Simbayi 2002). Social isolation has been found to be associated with early sexual initiation, a greater risk of coercive or economically motivated sex and lower negotiating power in sexual relationships among girls (Bruce et al. 2006). High levels of unemployment and weak social protection schemes force many urban girls to engage in informal and often exploitative labor such as sex work (Erulkar et al. 2004). Additional data on social cohesion, migration, and informal labor would be useful in understanding vulnerability among urban adolescent girls.

In the current version of the AGI, all girls living in Kampala are classified as not vulnerable. Kampala appears to have extremely low levels of vulnerability because DHS and MICS surveys do not collect detailed data for urban neighborhoods, and geographic identifiers used to classify regions do not correspond to slum versus non-slum areas. The vulnerabilities of poor girls in these areas are masked by averages that include girls who are not vulnerable but living in close proximity to those who are. For example, data from a slum and a bordering wealthy area could be lumped together as one community, making the slum girls seem better off. Detailed data that can be further disaggregated to examine disparities within urban centers are critical for understanding urban vulnerability.

To identify disparities that are not captured in the AGI percentage for Kampala, the DHS wealth quintile was recalculated relative to only urban areas. The urban poor are used as a proxy for slum populations that are typically the most vulnerable. Indicators of vulnerability were disaggregated by recalculated quintiles within Kampala. Community-level indicators are not displayed because they do not identify real urban communities.

Results based on urban wealth quintiles show that adolescent girls aged 10 to 19 living in Kampala and in the poorest and second poorest quintiles have much higher levels of vulnerability at the individual and household level (Figure 35). High levels without access to improved water and sanitation are indicative of poor access to services in informal settlements (Table 31). Disparities in vulnerabilities by wealth quintile show that the vulnerabilities of poor urban girls are missed in the aggregated percentages for Kampala. More detailed data on neighborhoods within urban areas are necessary to appropriately use the AGI to guide policymaking and program planning in urban centers.

\section{FIGURE 35}

AGI RESULTS FOR GIRLS AGED 10-19 BY WEALTH QUINTILE WITHIN KAMPALA, UGANDA

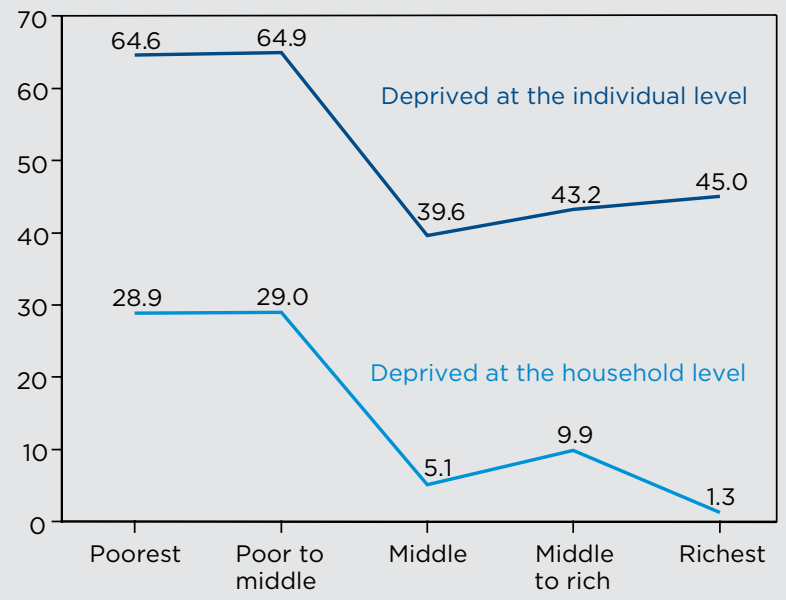

Significant at $\mathrm{p}<0.05$.

Source: DHS 2011

\section{TABLE 31}

HOUSEHOLD-LEVEL RESULTS FOR GIRLS AGED 10-19 BY WEALTH QUINTILE WITHIN KAMPALA, UGANDA

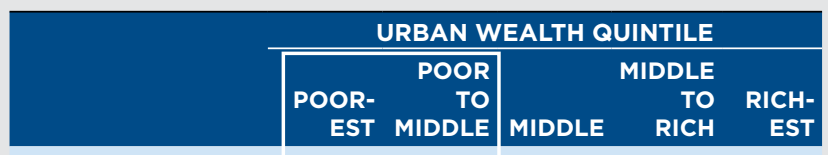

No access

to improved

sanitation or

shared access

97.4

92.0

33.7

No access to

improved water

source

Household head

has no education

(19.1)

15.2

4.0

8.6

Significant at $\mathrm{p}<0.05$

Source: DHS 2011.

Notes: Estimates in parenthesis on based on between 25 and 50 respondents. Indicators were only presented for girls aged 10-19 as sample sizes were too small to disaggregate by small age groups. 


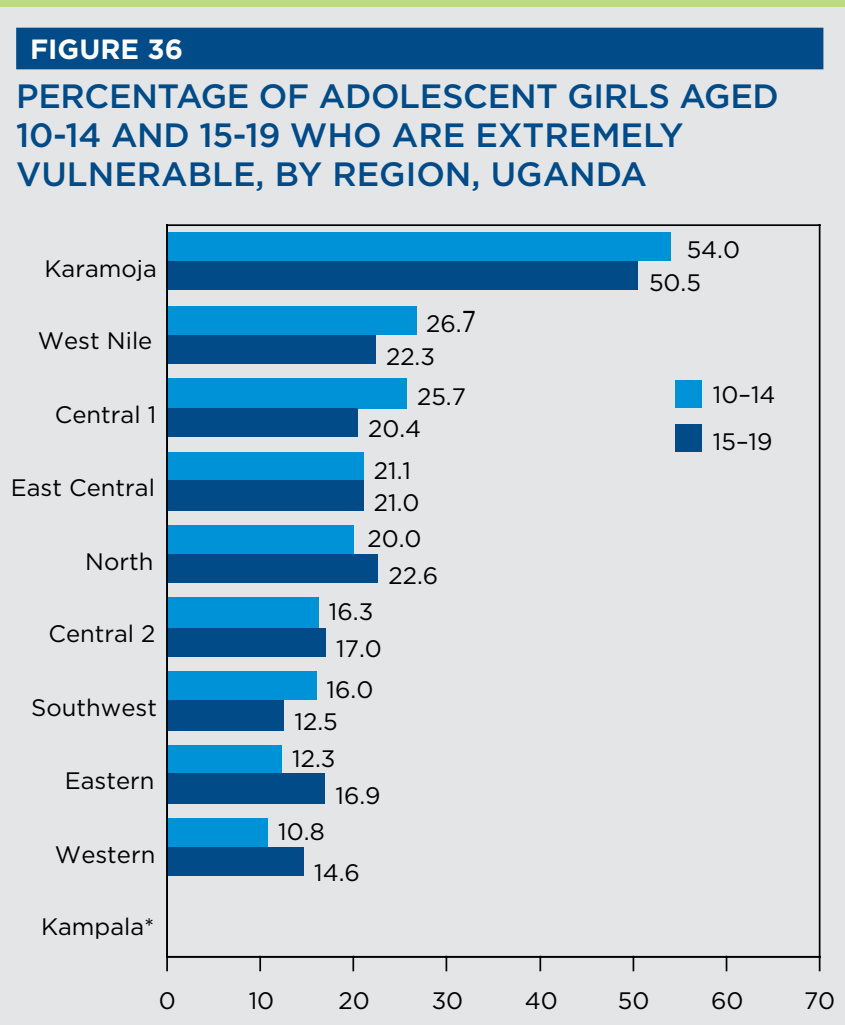

Source: DHS 2011.

${ }^{*}$ Refer to Box 2 on urban challenges.

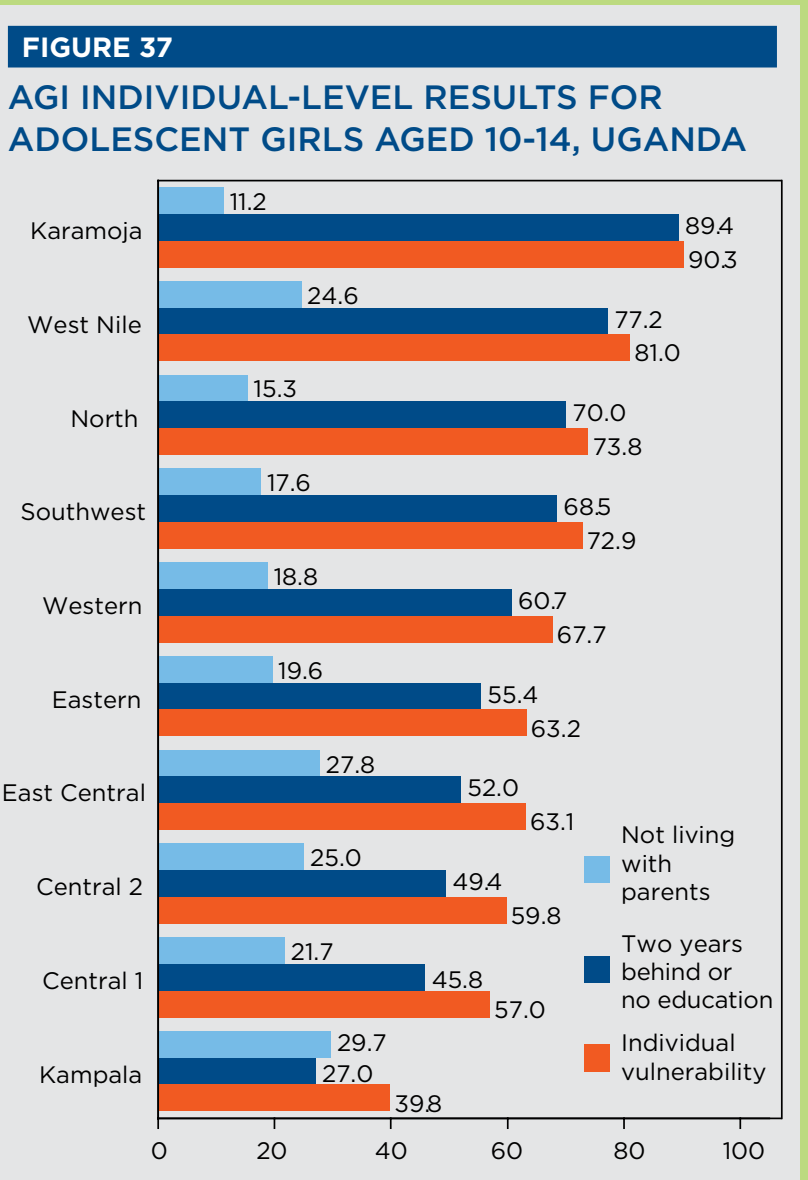

Source: DHS 2011.
19 live in "vulnerable communities" marked by above national average prevalence rates of child marriage among women aged 20 to 49 . Similarly in the Eastern region, 100 percent of adolescent girls ages 10 to 19 live in communities that have above national average prevalence rates of illiteracy.

Zero percent of girls in the Eastern region live in a region that is above the national average for adult HIV prevalence (all adults 15 to 49) and above the national average for no comprehensive knowledge of HIV among women aged 20 to 49. Moving back to the first column, we read the overall prevalence of community vulnerability defined by one or more deprivations at this level. So 100 percent of girls in the Eastern region and Karamoja are vulnerable at the community level because they live in communities identified as being vulnerable on at least one specific indicator.

Unlike the regional community-level index, the average benchmarks for the subnational indices are calculated within each country. The rankings of communities in $U$ ganda are relative to other areas within the country.
At the community level, regions above the mean for national HIV prevalence are the North, Central 2, Western, Central 1, and the Southwest. Central 2 and the Western regions have much lower levels of comprehensive knowledge among women, despite having high prevalence rates. Living in a community with high HIV prevalence but a low knowledge of HIV puts girls at an increased risk of contracting HIV. Increased programming is needed around HIV in these areas.

In Karamoja and the Eastern regions, every community has a higher than average rate of illiteracy. These areas also have high rates of educational vulnerabilities at the individual level, stressing the need for a focus on improved education. In the North and Eastern regions, many girls live in communities with high rates of women married before the age of 18. Percentages of girls who live in a community with a high rate of child marriage are low in Karamoja despite high percentages of girls 15 to 19 who are currently married in this region. This finding contradicts expectations given what is known about child marriage trends and could be related to the effects of conflict in the region. 


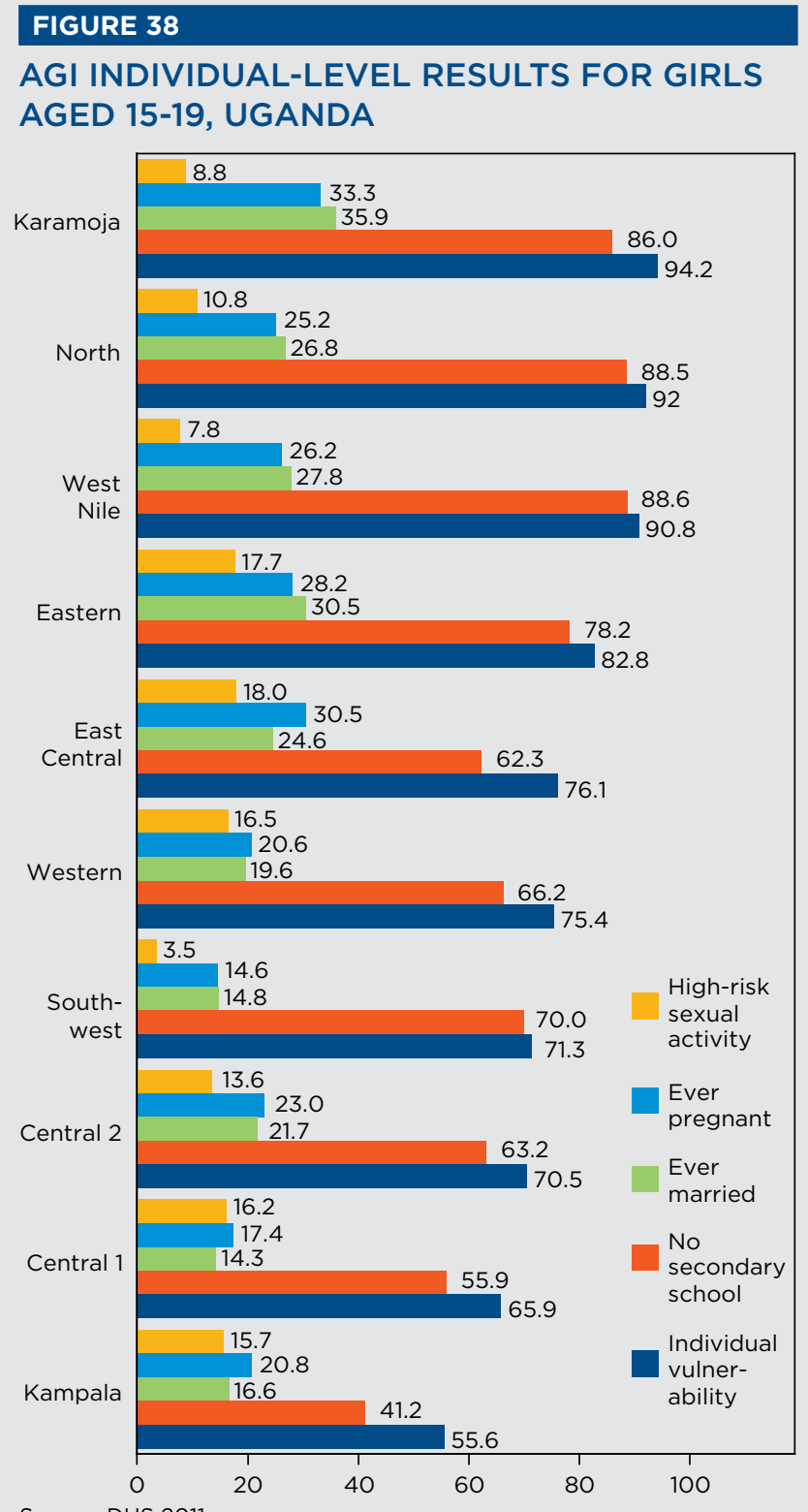

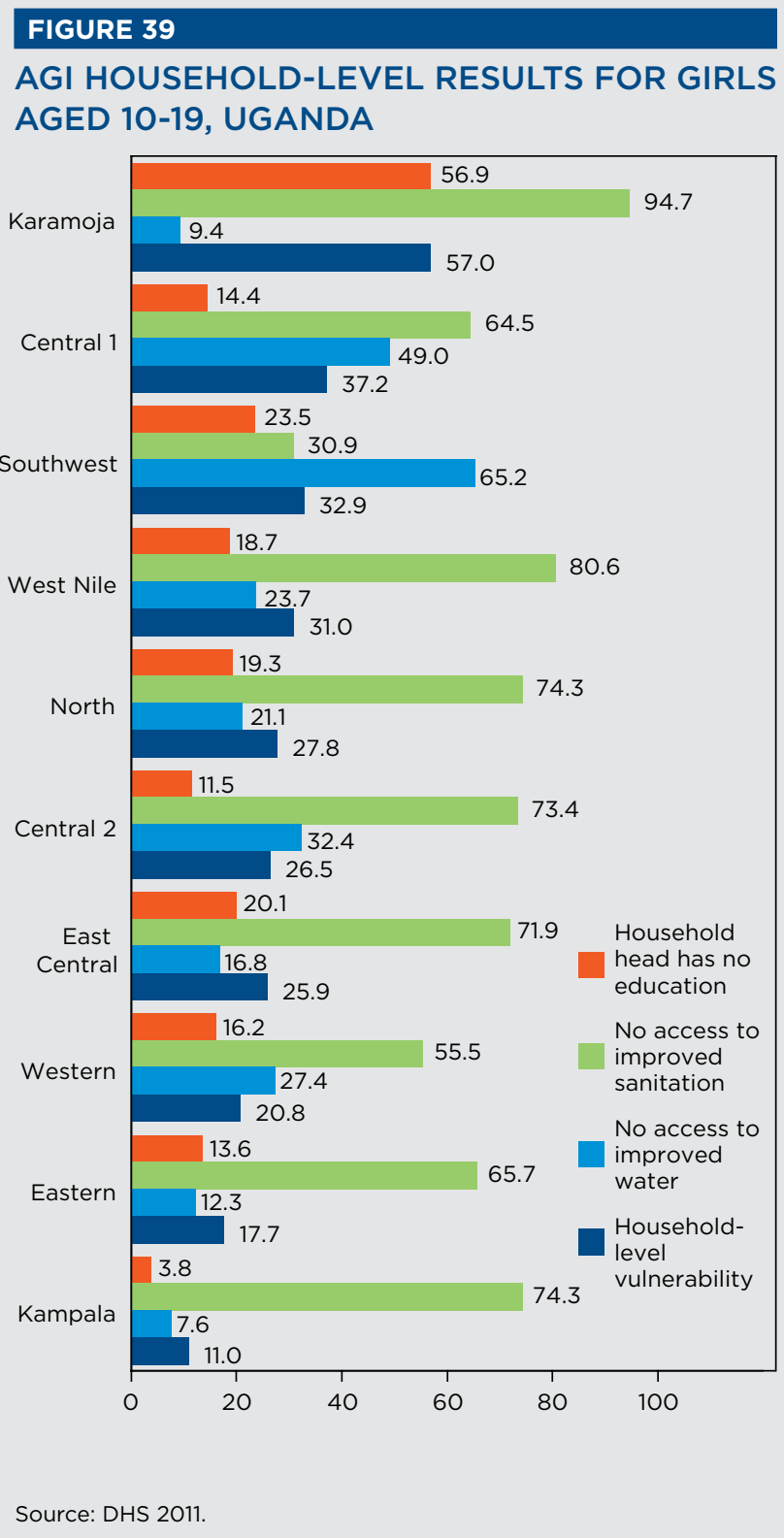

Source: DHS 2011.

Source: DHS 2011.

\section{TABLE 32}

\section{AGI COMMUNITY-LEVEL RESULTS FOR ADOLESCENT GIRLS AGED 10-19, UGANDA}

\begin{tabular}{|c|c|c|c|c|}
\hline & PERCENT AT OR & INDICATO & MONG WOM & AGES 20 TO 49) \\
\hline & ABOVE CUTOFF & & & NO COMPREHENSIVE HIV \\
\hline & $\geq 1$ & THE AGE OF 18 & ILLITERATE & HIGH HIV PREVALENCE \\
\hline Eastern & 100.0 & 85.3 & 100.0 & 0.0 \\
\hline Karamoja & 100.0 & 15.7 & 100.0 & 0.0 \\
\hline North & 95.3 & 95.3 & 78.9 & 40.3 \\
\hline East Central & 87.7 & 87.7 & 72.2 & 0.0 \\
\hline West Nile & 86.0 & 38.4 & 86.0 & 0.0 \\
\hline Central 2 & 80.5 & 58.7 & 12.5 & 71.0 \\
\hline Western & 70.1 & 67.9 & 62.9 & $58 . C$ \\
\hline Central 1 & 61.3 & 61.3 & 8.0 & 26.5 \\
\hline Southwest & 54.3 & 13.3 & 27.8 & 44.8 \\
\hline Kampala & 0.0 & 0.0 & 0.0 & 0.0 \\
\hline
\end{tabular}

\section{Source: DHS 2011}

Note. Indicator percentages represent the percentage of girls ages 10 to 19 living in a community (survey cluster) that is above the regional mean. *Indicator defined as subnational HIV prevalence (\% adult 15 to 49) above national mean and no comprehensive HIV knowledge above national mean for women 20 to 49. HIV prevalence data from Uganda AIDS Indicator Survey 2011. 


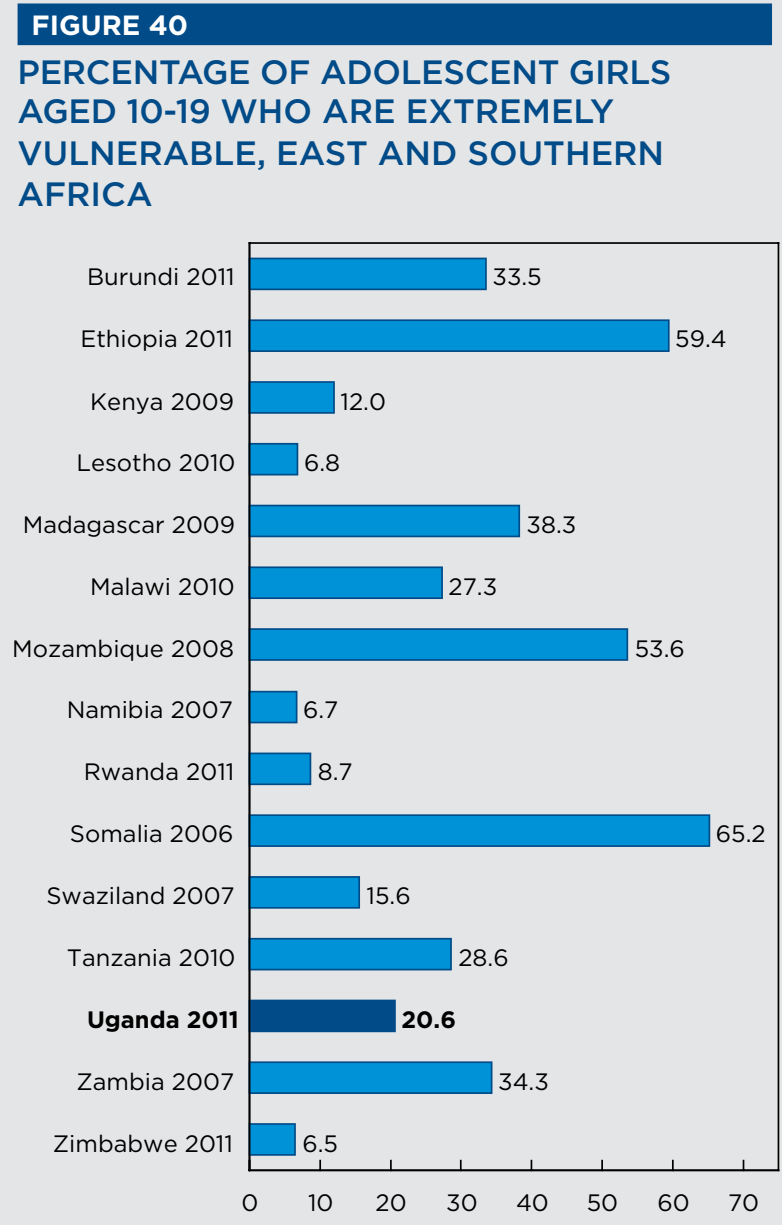

Source: DHS 2007-2011; MICS 2006-2008

\section{FIGURE 41}

AGI INDIVIDUAL-LEVEL RESULTS FOR GIRLS AGED 10-14, EAST AND SOUTHERN AFRICA

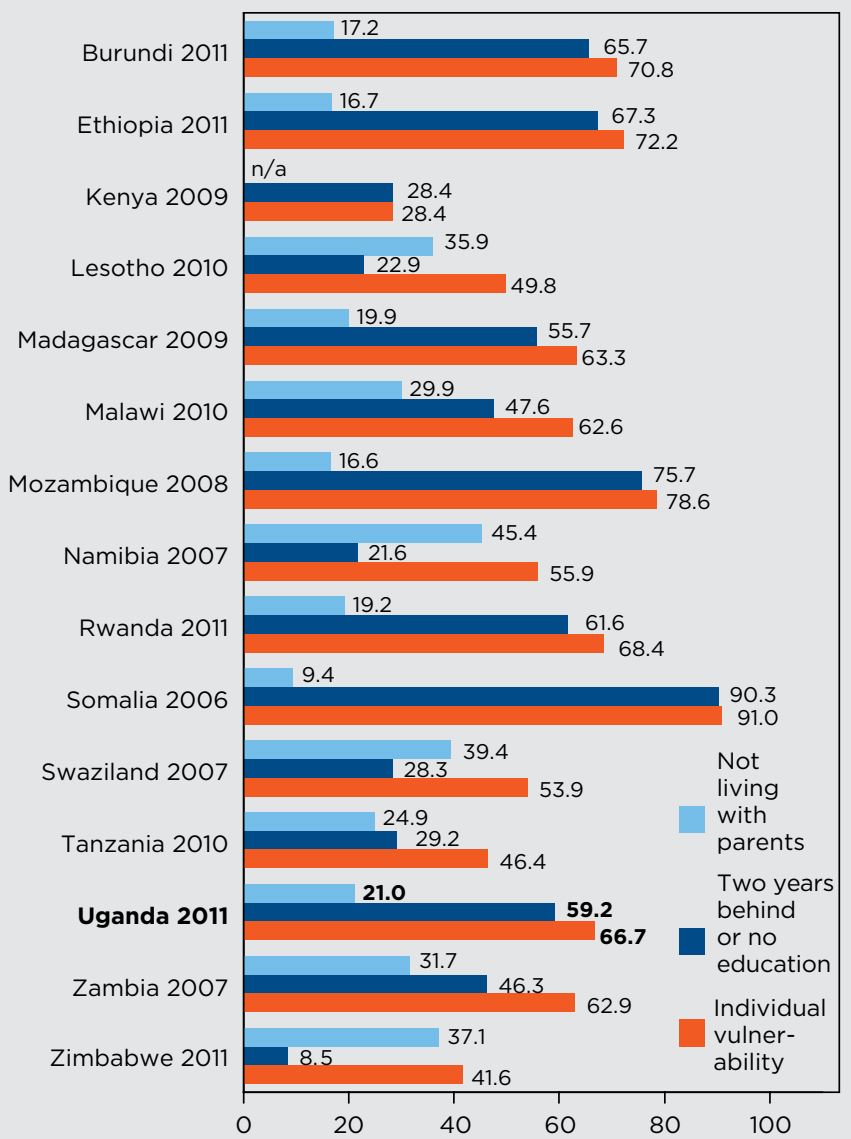

Source: DHS 2007-2011; MICS 2006-2008.

Note: Kenya does not include not living with parents.

\section{TABLE 33}

AGI RESULTS FOR EAST AND SOUTHERN AFRICA, BY AGE GROUP

\begin{tabular}{|c|c|c|c|c|c|c|c|c|c|c|c|c|}
\hline & \multicolumn{6}{|c|}{ MULTILEVEL VULNERABILITY } & \multicolumn{6}{|c|}{ LEVEL } \\
\hline & \multicolumn{2}{|c|}{3 LEVELS } & \multicolumn{2}{|c|}{2 LEVELS } & \multicolumn{2}{|c|}{1 LEVEL } & \multicolumn{2}{|c|}{ INDIVIDUAL } & \multicolumn{2}{|c|}{ HOUSEHOLD } & \multicolumn{2}{|c|}{ COMMUNITY } \\
\hline & $\mid 10-14$ & 15-19 & 10-14 & 15-19 & 10-14 & 15-19 & $10-14$ & 15-19 & $10-14$ & 15-19 & 10-14 & 15-19 \\
\hline Burundi 2011 & 32.3 & 35.0 & 72.8 & 77.0 & 94.9 & 94.8 & 70.8 & 85.0 & 50.1 & 46.8 & 79.2 & 75.1 \\
\hline Ethiopia 2011 & 55.0 & 64.7 & 86.7 & 88.7 & 98.1 & 98.1 & 72.2 & 89.2 & 72.0 & 68.9 & 95.6 & 93.3 \\
\hline Kenya 2009 & 9.3 & 15.7 & 30.1 & 48.1 & 66.8 & 84.6 & 28.4 & 74.7 & 44.1 & 41.0 & 33.7 & 32.8 \\
\hline Lesotho 2010 & 6.8 & 7.1 & 31.8 & 31.6 & 74.5 & 70.8 & 49.8 & 54.7 & 31.9 & 26.7 & 31.4 & 28.2 \\
\hline Madagascar 2009 & 37.1 & 39.8 & 67.0 & 66.7 & 88.5 & 88.0 & 63.3 & 72.4 & 62.7 & 59.5 & 66.6 & 62.6 \\
\hline Malawi 2010 & 26.3 & 28.8 & 71.3 & 81.0 & 98.3 & 97.9 & 62.6 & 82.2 & 36.6 & 31.2 & 96.6 & 94.3 \\
\hline Mozambique 2008 & 53.0 & 55.6 & 87.8 & 91.0 & 100.0 & 100.0 & 78.6 & 89.3 & 62.1 & 57.3 & 100.0 & 100.0 \\
\hline Namibia 2007 & 7.2 & 6.3 & 30.5 & 23.3 & 71.2 & 58.5 & 55.9 & 41.3 & 31.5 & 28.1 & 21.5 & 18.7 \\
\hline Rwanda 2011 & 8.6 & 9.0 & 37.9 & 38.9 & 80.4 & 84.2 & 68.3 & 77.3 & 24.6 & 24.2 & 33.9 & 30.6 \\
\hline Somalia 2006 & 72.2 & 57.1 & 95.0 & 91.3 & 100.0 & 100.0 & 91.0 & 75.4 & 76.1 & 73.1 & 100.0 & 100.0 \\
\hline Swaziland 2007 & 15.6 & 15.8 & 50.6 & 47.4 & 82.8 & 79.4 & 53.9 & 56.0 & 48.2 & 41.3 & 46.9 & 45.3 \\
\hline Tanzania 2010 & 25.1 & 33.4 & 60.3 & 61.7 & 88.0 & 88.0 & 46.4 & 69.2 & 58.1 & 48.8 & 68.9 & 65.0 \\
\hline Uganda 2011 & 21.0 & 20.1 & 70.2 & 73.7 & 96.9 & 95.1 & 66.7 & 75.9 & 28.1 & 25.3 & 93.3 & 87.7 \\
\hline Zambia 2007 & 33.5 & 34.9 & 65.5 & 63.6 & 90.2 & 88.2 & 62.9 & 69.6 & 51.0 & 44.0 & 75.5 & 73.1 \\
\hline Zimbabwe 2011 & 6.7 & 6.4 & 32.5 & 27.0 & 73.5 & 64.2 & 41.6 & 41.2 & 25.4 & 18.0 & 45.7 & 38.4 \\
\hline
\end{tabular}

Source: DHS 2007-2011; MICS 2006-2008.

Note. Preferred specification highlighted with white box. Kenya does not include not living with parents. 


\subsection{Regional index results}

Within East and Southern Africa, Uganda falls in the middle of index rankings (Figure 40 ). When broken down further by age group (Table 33), regional country rankings for girls 10 to 14 and 15 to 19 largely match the overall 10 to 19 rankings. Similarities between the rankings verify that the age-specific constructions capture similar notions of vulnerability.

At the individual level among girls ages 10 to 14 (Figure 41), the most vulnerable countries are those with high rates of girls who are not in school or are two or more years behind in school. Somalia is ranked first based on a very high percentage of children with poor educational outcomes but has a low percentage of children not living with parents. The HIV burden in countries such as Swaziland and Namibia is reflected in the high rates of children living without parents. Uganda, which ranks sixth in vulnerability among this age group, has relatively high rates of both poor educational outcomes and young adolescent girls living apart from their parents.

At the individual level among girls ages 15 to 19 , education also plays a large role in dictating vulnerability (Figure 42). Malawi and Rwanda move up in the vulnerability rankings due in large part to high rates of girls who fail to make the transition to secondary school. Madagascar remains in the middle of the rankings with above-average prevalence rates on all individual indicators. Despite above-average rankings on two of the four indicators (ever married and ever pregnant), Zimbabwe is ranked last-reflecting the fact that vulnerability is concentrated among a relatively smaller group of girls.

In terms of household-level vulnerability (Figure 43), no access to improved sanitation was the most widely experienced vulnerability. Countries that had poor access to improved water did not always follow the same patterns as those with access to improved sanitation. In Malawi, 20.3 percent of girls had no access to an improved water source but 89.9 percent did not have improved sanitation. Education of the household head also varied. In Zambia, only 11.1 percent of girls lived in a household where the household head had no education but 54.8 percent had no access to improved water and 70.6 percent had no access to improved sanitation. These indicators capture different elements of household-level vulnerabilities. No access to improved sanitation was very common but not all of these girls were without access to improved water or lived in a household where the head had no education.

There is wide variability in the rankings between countries on community-level vulnerability, defined as one deprivation of the three indicators shown in Table 34. This reflects the fact that communities within each country were identified as "vulnera- ble" based on their standing compared to a set of regional means on the selected indicators.

Table 34 should be read as follows: In Somalia, 67.9 percent of adolescent girls ages 10 to 19 live in "vulnerable communities" marked by above regional average prevalence rates of child marriage among women aged 20 to 49 . Similarly, 100 percent of adolescent girls ages 10 to 19 live in communities that have above regional average prevalence rates of illiteracy among women 20 to 49. Moving back to the first column, we read the overall prevalence of community vulnerability defined by one or more deprivations at this level. So, 100 percent of girls in Somalia are vulnerable at the community level because they live in communities identified as being vulnerable on at least one indicator.

The average benchmarks are calculated using all groups of clusters in every survey in this set of African countries.

\subsection{Limitations}

The conceptual framework of the index is based on the idea of multilevel vulnerability, which is intuitive and has been validated by much of the literature on adolescent vulnerability. In addition, the index captures many key factors and indicators that have been proven to be relevant to adolescent girls. Despite the strengths and innovative nature of the index, there are some limitations to its construction. Limitations to the index are in data availability and creating indicators to represent community level influences.

The construction of the Adolescent Girls Multilevel Vulnerability Index has shown that there are several gaps in data on adolescent vulnerability. At the individual level, very few indicators are available for girls aged 10 to 14 . New questions need to be developed and tested to better understand what makes girls vulnerable at these young ages and to inform a preventive approach to programming. At the household level, the participatory assessment highlighted the need for more data on support networks for adolescent girls. Both material and psychosocial support from parents emerged as an extremely important component of adolescent vulnerability. At the community level, there is a need for more detailed data that can be further disaggregated beyond the regional level. The construction of the community-level indicators has required extensive data manipulation and may not correspond to actual community boundaries. More detailed data are critical for understanding community risk factors as well as urban vulnerability. In addition, there are no eligible indicators for several key aspects of adolescent vulnerability including violence, civil participation, community protective mechanisms, and employment. Sugges- 


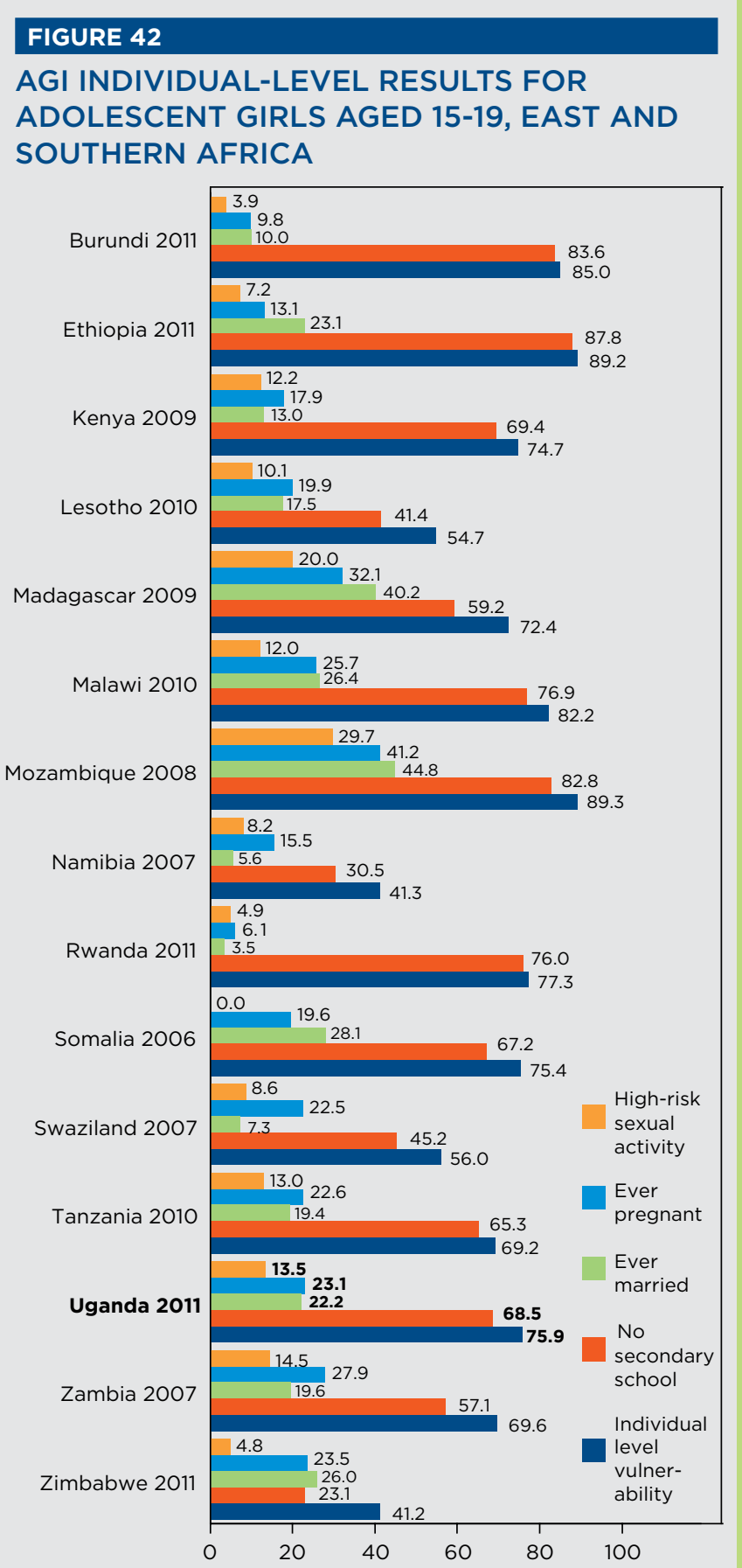

Source: DHS 2007-2011; MICS 2006-2008.

\section{FIGURE 43 \\ AGI HOUSEHOLD-LEVEL RESULTS FOR ADOLESCENT GIRLS AGED 10-19, EAST AND SOUTHERN AFRICA}

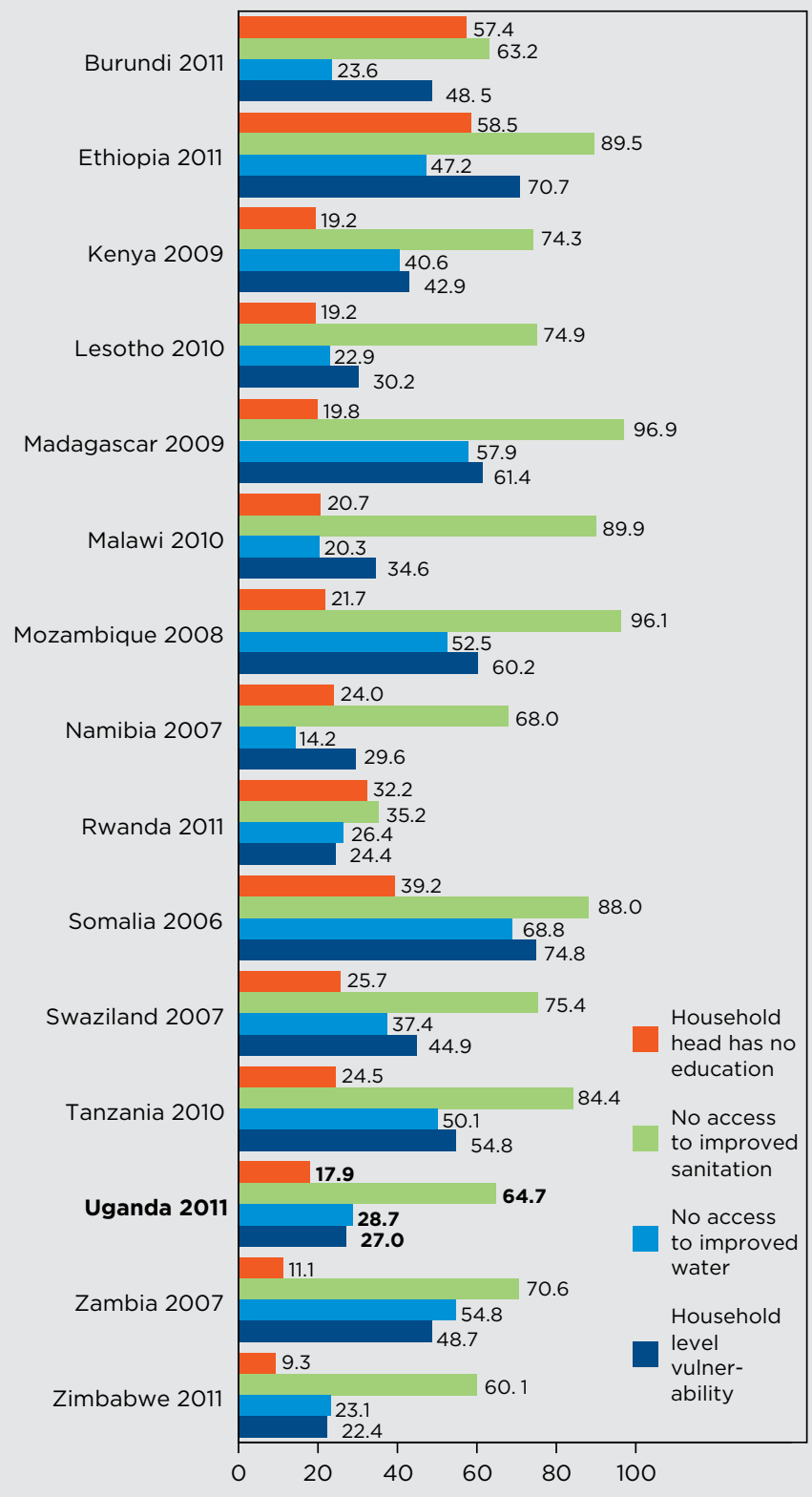

Source: DHS 2007-2011; MICS 2006-2008 tions for additional survey topics can be found in Appendix II. The appendix should be used as guidance regarding the types of questions that should be developed to accurately measure vulnerability among adolescent girls.

No measures of community-level risk factors are directly available in DHS and MICS surveys. Given the lack of direct measures of community risk factors, a measure of social climate was constructed using data from older women in the community.
The biggest limitation of this method has been the selection of a cutoff for high-risk communities. A relative cutoff method was selected as the best approach but this method exaggerates differences between areas. Indicators should be adapted and added or removed based on regional comparisons and data availability. In addition, different cutoffs are used for the regional and national indices. This is the best method for rankings and comparing areas, but makes it difficult to compare national and regional indices to one another. 
AGI COMMUNITY-LEVEL RESULTS FOR ADOLESCENT GIRLS AGED 10-19, EAST AND SOUTHERN AFRICA

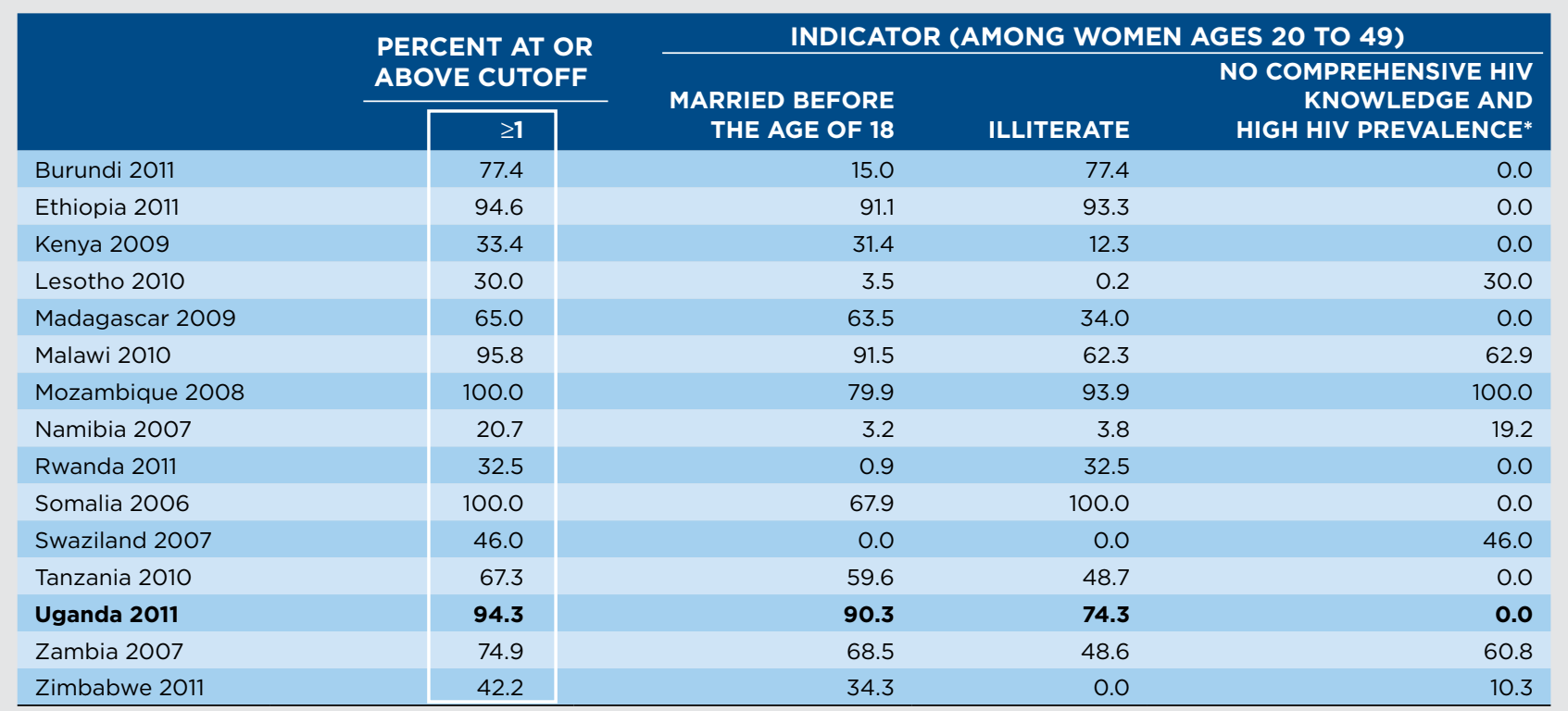

Source: DHS 2007-2011; MICS 2006-2008.

Note. Indicator percentages represent the percentage of girls ages 10 to 19 living in a community (survey cluster) that is above the regional mean. *Indicator defined as national HIV prevalence (\% adult 15 to 49) above regional mean and no comprehensive HIV knowledge above regional mean for women 20 to 49. HIV prevalence data from World Bank 2011.

\subsection{Conclusions}

Results from the index support the use of the Adolescent Girls Multilevel Vulnerability Index as an important and useful tool to generate discussion at the regional and national levels, highlight geographical differences in vulnerability, identify gaps in our knowledge on adolescents, and inform future programming and policy. Several key conclusions have emerged from the construction of the AGI:

In Uganda, there is a need to focus investments on individual- and community-level vulnerabilities over those at the household level.

Emphasis should be placed on developing education programs to reduce extreme vulnerability in Karamoja. Programs should be tailored to the pastoralist lifestyle of girls in this region.

More information should be collected on the unique vulnerabilities of girls in urban contexts.

Investments in individual- and community-level vulnerabilities will be most effective by:

- Increasing educational attainment and encouraging girls to stay in school

- Strengthening HIV awareness programming in the Central 2, Western, North, Southwest and East Central regions

- Targeting social values and cultural norms that promote child marriage and early childbearing
In summary, the Adolescent Girls Multilevel Vulnerability Index allows us to analyze the situation of adolescent girls, understand vulnerabilities at different levels, and examine disparities both within and between countries. The AGI is an innovative index that captures adolescent vulnerability at the individual, household, and community level. The AGI is a new way of understanding risks at multiple levels and encourages comprehensive actions rather than those focused on a single issue. In addition, the index has highlighted gaps in data on adolescent girls such as the lack of information about what makes girls vulnerable at very young ages and how material and psychosocial support influences adolescent vulnerability at the household level. 


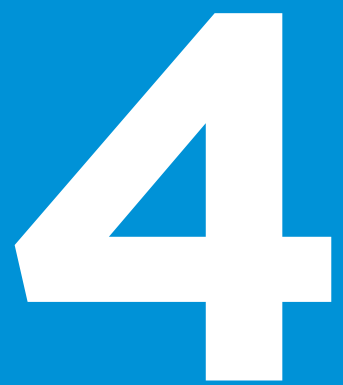

\section{PROGRAM ANALYSIS}

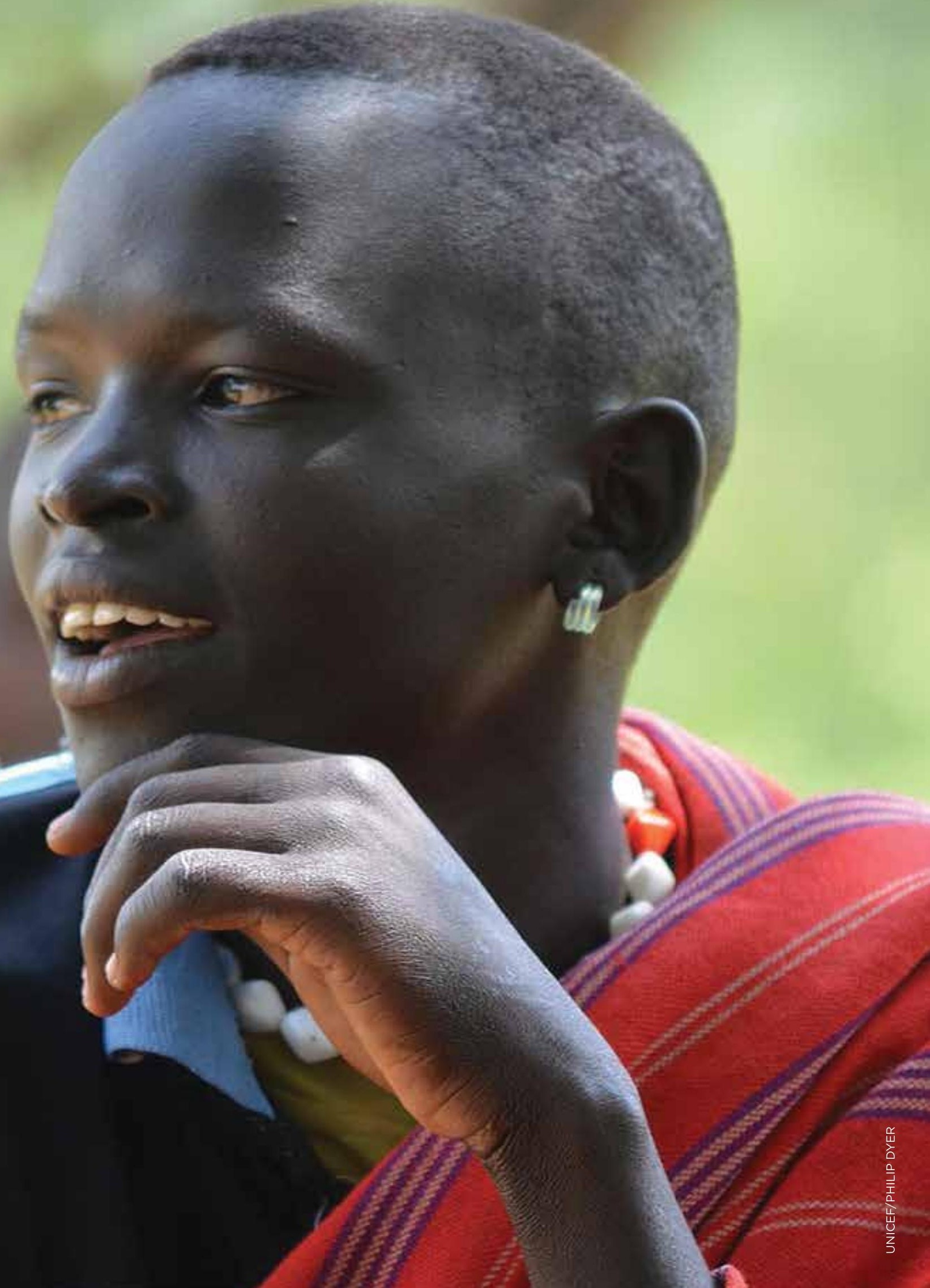


This section presents findings from fieldwork assessing the spread and reach of programs that could benefit adolescent girls in Uganda. Analysis will address both the number of programs available in various parts of the country and the young people whom these programs serve.

\subsection{What is a coverage exercise?}

A coverage exercise (CE) is a simple assessment methodology that profiles the beneficiaries of a particular service or program. Population Council researchers developed the CE methodology to help programs serving adolescents and youth to better understand who is being reached by their services and to inform decision-making and priority-setting among governmental and donor agencies.

Before describing the CE methodology, it is useful to review the different types of data that can inform decision-making related to policies and programs for young people and consider what can be learned from each. Figure 44 shows common data sources that exist or could be collected at each administrative level (Uganda is shown as an example). No one data source can answer every question about youth and adolescents. There is always a tradeoff between depth and breadth when planning a data collection exercise.

For instance, a population census can be disaggregated to small geographical and administrative units, but is often limited in the questions that it can answer because of its brevity. A more in-depth national survey like the Demographic and Health Survey (DHS) can answer a wider variety of questions, but cannot, on its own, be disaggregated below the level of subnational regions because of the sampling design. ${ }^{11}$ In other words, a population census can say how many adolescents ages 15 to 19 are out of school in a particular community, but it will not answer the question, "What percentage of adolescents ages 15 to 19 in that community are sexually active?"

This level of detail is not included in a population census that covers everyone, but it could be included in a survey administered to a representative sample of individuals. Even the biggest national surveys like a DHS, however, are not designed to answer this question in every community. Since surveys are sample-based, meaning they use the responses of a small set of people to represent the larger population, it is necessary to survey enough people for the desired degree of precision at each level (whether geographical or population subgroups, like different ethnicities). A DHS survey will often survey several thousand people in order to produce representative data at the regional level. The "Subnational Region" map shows Uganda's 10 regions; the 2011 Uganda DHS is representative at this level (Figure 45).

For national policymakers and international advocates, regional data, particularly longitudinal data that show trends over time, are a critical source of information for macro-level planning and policymaking. For the manager of a small community-based organization operating in several towns outside of the nation's capital, however, knowledge about regional trends will not be sufficient for her objectives. She will want to know about the needs and resources present in her community, and a national survey will not answer this question.

Instead, this program manager will need to collect new data herself or petition the local government or a larger organization to sponsor a project to collect new data that will benefit everyone working in the area. If her objective is to learn more about who is served by adolescent programs, a program scan and coverage exercise might be good options.

\section{Methodology}

A CE can be used to monitor or evaluate a single program or network of services in a local area, or it can be used to identify who is served by programs on a much larger, even national scale. The methodology will vary based on the objectives of the exercise because of the tradeoff between depth and breadth. When monitoring or evaluating a single program or small cluster of services, it is possible to collect detailed information and maximize the number of observations from program participants. On the other hand, if the objective is to conduct a nationally representative survey of adolescent-serving organizations, it may be necessary to trade detail for the ability to reach as many programs and locations as needed to produce representative results.

In the case of Uganda, our objective was to conduct a nationally representative survey of adolescent-serving organizations. This involved completing a subcounty-level program scan and a 30-day coverage exercise with a sample of identified programs. A program scan answers the questions

11 It is possible to combine census and survey data to generate small-area estimates, but this technique requires advanced statistical skills and is not yet common practice. 
DATA THAT INFORM POLICIES AND PROGRAMS FOR ADOLESCENTS

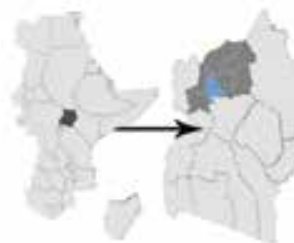

Crossnational

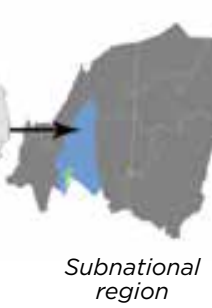
region

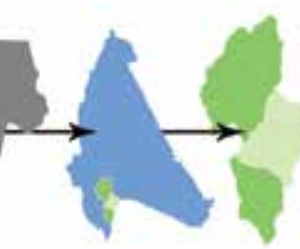

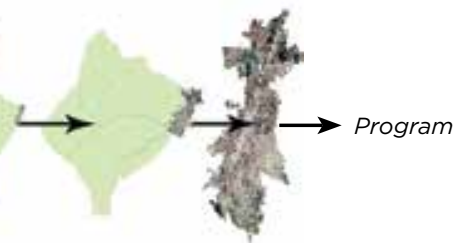

Community

\begin{tabular}{|c|c|c|c|c|c|c|c|c|}
\hline National Census & 0 & 0 & 0 & 0 & 0 & 0 & 0 & \\
\hline National Survey & O & O & O & & & & & \\
\hline Policy Analysis & $\bullet$ & $\bullet$ & $\bullet$ & $\bullet$ & & & & \\
\hline Program Scan & O & O & O & $\bullet$ & $\bullet$ & $\bullet$ & $\bullet$ & \\
\hline Coverage Exercise & 0 & 0 & O & $\bullet$ & $\bullet$ & $\bullet$ & $\bullet$ & $\bullet$ \\
\hline Subnational Survey & & & & $\bullet$ & $\bullet$ & $\bullet$ & $\bullet$ & $\bullet$ \\
\hline Outcome Evaluation $^{\dagger}$ & & & & & & & & $\bullet$ \\
\hline Process Evaluation ${ }^{\dagger}$ & & & & & & & & $\bullet$ \\
\hline Participatory Mapping & & & & $\bullet$ & $\bullet$ & $\bullet$ & $\bullet$ & $\bullet$ \\
\hline
\end{tabular}

Key: - Most likely to organize data collection at specified level (not necessarily representative).

o Population-based data collection would require significant resources.

† Programs (and policies) can be evaluated across administrative/geographic units.

"How many?" and "What type?" A coverage exercise uses this information to answer the question "Who is served?"

\section{Program scan}

\section{Sample size primer}

When taking a sample of a larger population-for instance, a subset of all the adolescent programs operating in a country-there will be some degree of error in the "true" answer for the larger population. The degree of error is a function of the total population size, in our case the universe of all adolescent programs in the area of interest, and the size of the sample. As the size of the sample increases, the expected error decreases. Table 35 shows this relationship.

In the first row of this table, the population of programs is 10 . Continuing with the country example, this would mean there are only 10 programs in the entire country. This is of course very unlikely. If we imagine that this were indeed the case, we would need to sample 9 of the 10 programs in order to have a margin of error of \pm 10 percent. This means that, in order to say with 95 percent confidence that the "true" answer falls between 40 and 60 percent, for instance, we would need to sample 9 out of the 10 programs. Of course, a population this small does not lend itself to sampling-it is better just to conduct a census.

To have the same 10 percent margin of error with a population of 100 programs, we would need to sample 49 out of the 100 programs. This is better than in the first example, but still not very efficient. If we assume that there are at least 500 programs, we would need to sample 81 to 96 programs for a 10 percent margin of error. To reduce the error to 8 percent-for example, to be able to state with 95 percent confidence that the "true" value is between 42 and 58 percent-we would need to sample at least 116 programs. The sample size requirement continues to go up as the desired margin of error goes down.

\section{Uganda sampling}

In Uganda, our objective was to conduct a nationally representative program scan and coverage exercise that could estimate, respectively, the average number of programs per subcounty and the average profile of program beneficiaries. We selected subcounties as the unit of analysis for the program scan because this is the level of local government at which most services are organized and delivered to citizens. 
To create the first estimate, the average number of programs per subcounty, we selected a random sample of Uganda's 964 subcounties using a two-stage cluster sampling strategy. ${ }^{12}$ Clustering is often the most efficient sampling strategy from a logistical viewpoint, but clustering increases error due to a design effect. Complex survey samples thus require a larger sample size to achieve the same margin of error as surveys using simple random sampling. If we had taken a simple random sampling of subcounties across all 112 districts in Uganda, we would have needed to sample approximately 88 subcounties to achieve a margin of error of \pm 10 percent. To account for the design effect of a cluster randomized sampling strategy, we randomly selected 120 subcounties.

In the first stage of selection, we randomly selected 40 districts proportional to the Uganda Bureau of Statistics 2009 projected population for DHS regions; regions with a higher percentage of the population were allocated more of the 40 districts (see Table 36). In the second stage, we randomly selected 3 subcounties per selected district for a total of 120 (see Figure 45). We ultimately decided to drop Kampala and its subcounties due to the logistical challenges of conducting a program scan in this urban setting in the time allotted for the exercise.

\section{TABLE 35}

\section{SAMPLE SIZE}

\begin{tabular}{|c|c|c|c|c|}
\hline \multirow[b]{2}{*}{ Program population } & \multicolumn{4}{|c|}{ MARGIN OF ERROR } \\
\hline & $\pm 10 \%$ & $\pm \mathbf{8 \%}$ & $\pm \mathbf{5 \%}$ & $\pm 1 \%$ \\
\hline 10 & 9 & 9 & 10 & 10 \\
\hline 25 & 20 & 22 & 24 & 25 \\
\hline 50 & 33 & 38 & 44 & 50 \\
\hline 100 & 49 & 60 & 80 & 99 \\
\hline 250 & 70 & 94 & 152 & 244 \\
\hline 500 & 81 & 116 & 217 & 475 \\
\hline 1,000 & 88 & 131 & 278 & 906 \\
\hline 2,500 & 93 & 142 & 333 & 1,984 \\
\hline 5,000 & 94 & 146 & 357 & 3,288 \\
\hline 10,000 & 95 & 148 & 370 & 4,899 \\
\hline 100,000 & 96 & 150 & 383 & 8,762 \\
\hline
\end{tabular}

Source: Authors' calculations.

\begin{tabular}{|c|c|c|}
\hline \multicolumn{3}{|c|}{$\begin{array}{l}\text { FIRST-STAGE SELECTION } \\
\text { DISTRICT ALLOCATION }\end{array}$} \\
\hline DHS regions & $\begin{array}{r}\% 2009 \\
\text { population }\end{array}$ & Districts \\
\hline Eastern & 14.6 & 6 \\
\hline North & 14.1 & 6 \\
\hline South Western & 12.6 & 5 \\
\hline Western & 12.6 & 5 \\
\hline East Central & 11.4 & 5 \\
\hline Central 1 & 10.7 & 4 \\
\hline Central 2 & 10.3 & 4 \\
\hline West Nile & 8.8 & 4 \\
\hline Kampala & 5.0 & 1 \\
\hline
\end{tabular}

Source: Authors' calculations.

\section{FIGURE 45}

\section{RANDOM SELECTION OF DISTRICTS IN UGANDA, AND SUBCOUNTIES WITHIN DISTRICTS}

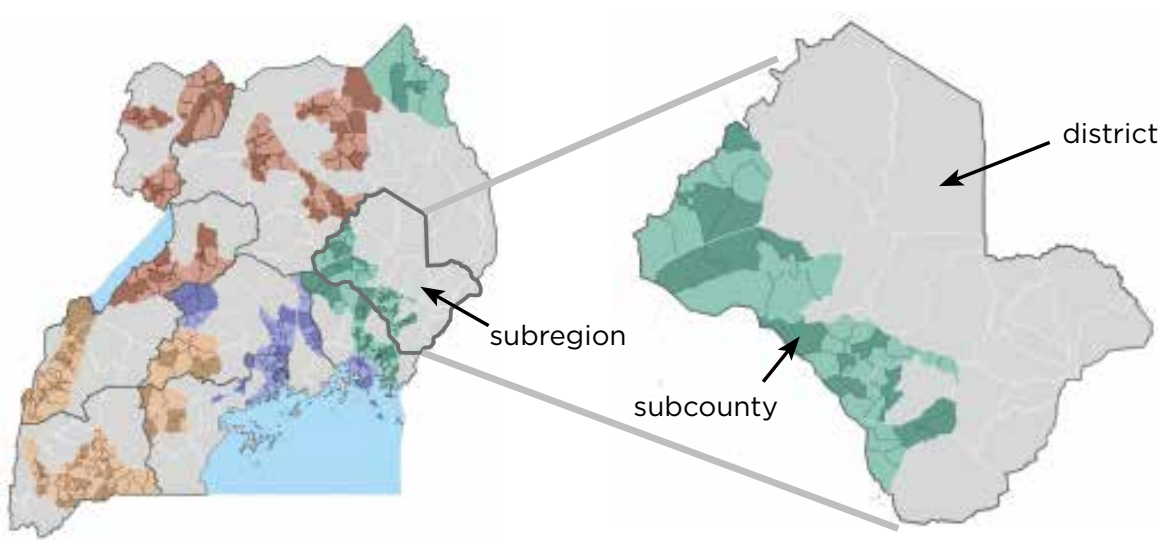

12 A good resource is a United Nations guide to conducting household surveys. It is available at http://unstats.un.org/unsd/hhsurveys/ 


\section{Procedure}

We trained four Ugandan enumerators to visit each randomly selected subcounty and carry out a program scan to enumerate all eligible adolescent-serving programs. Enumerators carried a letter of authorization from the Ministry of Gender to each district administration office to request access to the selected subcounties. In each subcounty, team members met with one or more representatives of the subcounty administration to list all eligible programs operating in the subcounty using the program scan form (see Appendix III). Enumerators attempted to talk to several knowledgeable individuals in each subcounty to cross-check the completeness of this list.

A program was deemed to be eligible if it served any adolescents ages 10 to $19 .{ }^{13}$ Programs had to have a physical meeting place, and their primary role could not be to support orphans and vulnerable children (OVC). We sought out all programs, including those organized by the government, faith-based groups, communitybased organizations, and non-governmental organizations.

In addition to the listing activity, enumerators asked each subcounty informant to consider a series of "ladder" questions designed to have the informant rate the subcounty's ability to meet the needs of adolescents relative to other subcounties in the district and nationally (see Table 37).

If more than five eligible programs were listed in a subcounty, the enumerator randomly selected five programs to participate in the coverage exercise. The enumerator then visited the meeting place of each selected program, captured the spatial coordinates using a GPS-enabled smartphone, and conducted a brief survey (see Appendix III).

Enumerators also provided the program representative with a 30-day attendance roster (see Appendix III) designed to record basic demographics of program participants and their attendance. Program visits took place between 17 September and 30 November 2011. Programs were asked to begin the 30-day attendance cycle the day following the enumerator's visit, regardless of whether the program was scheduled to operate on that day. Given the proximity to the holiday season in December for the last subcounties visited, we only use the first 20 days of each program's attendance roster in the analysis.
For national

policymakers and international advocates, regional data, particularly longitudinal data that show trends over time, are a critical source of information for macro-level planning.

\subsection{Results}

Because of the complex survey design, the analysis accounts for unequal probabilities of selection and the increased variability due to clustering.

\section{Program Scan}

The average subcounty reported having 2.9 eligible programs for adolescents ages 10 to 19 (Table 38). The Central 1 and East Central regions have the highest average number of programs per subcounty; the Eastern region has the lowest. The number

\section{TABLE 37}

\section{LADDER QUESTIONS ASKED OF SUBCOUNTY} OFFICIALS

\section{Questions}

Imagine a ladder with 10 steps. This ladder represents the quality and reach of programs for adolescents. On the first step are subcounties that do not meet the needs of adolescents. On the top, the 10th step, are subcounties that provide excellent services for the greatest number of adolescents. On which step is your subcounty located TODAY?

Is your subcounty on a higher, lower or the same step as other subcounties in this DISTRICT?

Is your subcounty on a higher, lower or the same step as other subcounties across the country?

On which step was your subcounty 5 years ago?

On which step will your subcounty stand 5 years from now? 
of programs per subcounty is not associated with projected 2011 subcounty population sizes, so subcounties with larger populations do not necessarily have more programs than small subcounties as expected. Approximately 13 percent of subcounties reported having no programs for adolescents.

Our estimate of the total number of adolescent programs in the country (excluding Kampala) is 3,095 (Table 39). The 95 percent confidence interval around this estimate ranges from 2,189 to 4,000 . According to the Bureau of Statistics, one-quarter of Uganda's 2011 projected population of 32.9 million (excluding Kampala) is between the ages of 10 and 19. Thus we estimate that Uganda has approximately 3,095 adolescent programs for 8.2 million adolescents, or 2,500 adolescents per program. The North region has the highest number of adolescent programs; West Nile has the lowest.

Overall, subcounty officials appear to agree that current resources are not meeting the needs of adolescents. The average subcounty reported standing on step 4.2 on a 10-step ladder representing the quality and reach of programs for adolescents in the subcounty. An average score of 4.2 falls just below the midpoint of the ladder, suggesting that programming is perceived to be below a moderate level of quality and reach. The average subcounty, however, reported improvement from five years ago ( $M=2.6)$ and optimism about the state of programming five years from now $(M=6.6)$.

As shown in Table 40, slightly less than onethird of subcounties believe that programs in the subcounty are of a lower quality compared to other subcounties in the district. Only 7 percent of subcounties perceive themselves to be doing better than subcounties across the nation. There is no association between perceived quality and subcounty population size.

\section{Coverage exercise}

Following the program scan, we invited 266 of the 320 eligible programs to participate in a 30-day coverage exercise. A total of 247 programs participated, a response rate of 92.9 percent. A plausible reason for not participating is that the listed program does not meet regularly, leading program representatives to decline the invitation to record attendance for 30 days. Thus, exclusion of these non-functional programs may inflate the results (e.g., excluded programs might have been more likely to be closed more often).

\section{Program representative report}

Table 41 displays the characteristics of the programs as described by program representatives on the enumerators' first visit. Most programs classified themselves as community-based organi- zations. More than half of the programs indicated that they address HIV, life skills, livelihoods, and other non-specified topics.

Program representatives reported that, on average, 58.9 percent of participants are boys; the West Nile has the greatest proportion who are boys (Table 42). They indicated that adolescents ages 15 to 19 make up the greatest proportion of participants at 38.2 percent, followed by young adults older than 19 years (34.9 percent) ( $\mathrm{Ta}$ ble 43 ). The average program size is reportedly 57 participants -32 of whom are adolescents between the ages of 10 and 19. Based on these self-reported data, we estimate that less than 2 percent of Uganda's non-Kampala adolescent population has access to these types of programs.

Most programs are reportedly coeducational (88.0) (Table 44). Boys-only programs are more common than girls-only programs (9.9 percent vs. 2.4 percent).

\section{Program rosters}

Following the initial interview that generated the above-referenced data, each program completed a coverage exercise that involved tracking the attendance of individual participants. The average program was operational for 6.2 of the 20 days following the enumerators' first visit. Slightly less than a third of programs were not open any days in the attendance window (32.1).

Among programs that were open at least one day, the mean number of adolescents ages 10 to 19 who attended at least once was 19. The average adolescent attended 7.1 days, and the average attendance rate (days attended/days program was open) was 70.4 percent. Participant demographics are listed in Table 45.

Males and females did not differ significantly on any of the key demographic indicators recorded on each program's attendance form. However, the profile of program participants ages 15 to 19 does not reflect the national averages estimated by the 2011 Uganda DHS. For instance, only 23.6 percent of females ages 15 to 19 who attended programs during the coverage exercise were not in school, compared to 36.1 percent of females ages 15 to 19 nationally according to the DHS. This means that the profile of adolescents who have access to programming is less vulnerable than the national profile of adolescents.

Programs recorded 34,835 encounters among 4,658 people ages 10 to 35 during the 20-day window following the initial interview, representing an estimated 300,000 encounters among more than 42,000 people in the weighted dataset (see Table 46). Adolescents, those aged 10 to 19 , 


\begin{tabular}{lr}
\hline \multicolumn{2}{l}{ TABLE 38} \\
AVERAGE NUMBER OF \\
ELIGIBLE PROGRAMS \\
FOR ADOLESCENTS PER \\
SUBCOUNTY, BY REGION, \\
UGANDA \\
\hline REGION \\
\hline Central 1 \\
\hline East Central & MEAN \\
\hline North & 4.6 \\
\hline Central 2 & 4.4 \\
\hline Western & 3.8 \\
\hline Southwest & 3.0 \\
\hline West Nile & 2.2 \\
\hline Eastern & 2.1 \\
\hline National & 2.0 \\
\hline & 1.3 \\
\hline
\end{tabular}

\section{TABLE 39}

TOTAL NUMBER OF

ADOLESCENT PROGRAMS, BY REGION, UGANDA

\begin{tabular}{|lr|}
\hline REGION & NUMBER \\
\hline North & 829 \\
\hline Central 1 & 488 \\
\hline East Central & 433 \\
\hline Southwest & 340 \\
\hline Central 2 & 334 \\
\hline Western & 309 \\
\hline Eastern & 208 \\
\hline West Nile & 155 \\
\hline National & $\mathbf{3 , 0 9 5}$ \\
\hline
\end{tabular}

\section{TABLE 40}

SUBCOUNTY OFFICIALS COMPARISONS OF PROGRAM QUALITY TO OTHER SUBCOUNTIES IN THE DISTRICT AND NATION, UGANDA

\begin{tabular}{lr}
\hline & PERCENT \\
\hline Compared to district & \\
\hline Higher & 30.8 \\
Same & 41.3 \\
Lower & 27.9 \\
\hline Compared to nation & \\
\hline Higher & 7.0 \\
Same & 32.7 \\
Lower & 60.3 \\
\hline
\end{tabular}

\section{TABLE 41}

\section{DISTRIBUTION OF PROGRAM TYPE} AND CONTENT

\begin{tabular}{lc}
\hline & PERCENT \\
\hline Program type & \\
\hline Community-based organization & 68.1 \\
Non-governmental organization & 22.1 \\
Faith-based organization & 9.2 \\
Government-sponsored & 0.6 \\
Program content & \\
HIV & 57.4 \\
Nutrition & 37.8 \\
Reproductive health & 46.4 \\
Life skills & 53.3 \\
Livelihoods & 51.5 \\
Sports & 45.7 \\
Other & 58.0 \\
\hline
\end{tabular}

\section{TABLE 42}

\section{AVERAGE PERCENTAGE OF PROGRAM}

PARTICIPANTS, BY SEX AND REGION, UGANDA

\begin{tabular}{|lr|lr|}
\hline BOYS & PERCENT & GIRLS & PERCENT \\
\hline West Nile & 69.1 & Central 1 & 50.5 \\
\hline Central 2 & 65.3 & East Central & 47.9 \\
\hline Western & 62.1 & Eastern & 46.2 \\
\hline Southwest & 59.8 & North & 41.4 \\
\hline North & 58.6 & Southwest & 40.2 \\
\hline Central 1 & 54.3 & Western & 37.9 \\
\hline Eastern & 53.8 & Central 2 & 34.7 \\
\hline East Central & 52.1 & West Nile & 26.8 \\
\hline National & $\mathbf{5 8 . 9}$ & National & $\mathbf{4 1 . 4}$ \\
\hline
\end{tabular}

\section{TABLE 43}

AVERAGE PERCENTAGE OF PROGRAM PARTICIPANTS, BY AGE GROUP AND REGION, UGANDA

\begin{tabular}{lrrrr} 
& \multicolumn{3}{c}{ AGE GROUP } \\
\cline { 2 - 5 } REGION & UNDER $\mathbf{1 0}$ & $\mathbf{1 0 - 1 4}$ & $\mathbf{1 5 - 1 9}$ & OVER 19 \\
\hline Central 1 & 22.7 & 28.4 & 47.2 & 35.5 \\
\hline Central 2 & 9.2 & 19.9 & 37.7 & 33.2 \\
\hline East Central & 6.4 & 27.9 & 37.1 & 28.6 \\
\hline Eastern & 8.2 & 16.8 & 32.1 & 42.8 \\
\hline North & 9.8 & 21.6 & 38.3 & 30.4 \\
\hline Southwest & 6.6 & 23.3 & 33.8 & 36.3 \\
\hline West Nile & 4.2 & 18.3 & 45.3 & 35.4 \\
\hline Western & 4.7 & 20.8 & 38.7 & 35.8 \\
\hline National & $\mathbf{8 . 7}$ & $\mathbf{2 2 . 2}$ & $\mathbf{3 8 . 2}$ & $\mathbf{3 4 . 9}$ \\
\hline
\end{tabular}

Source for Tables 38-43: Authors' calculations, based on Uganda program scan and coverage exercise. 


\section{TABLE 44}

PERCENTAGE OF PROGRAMS THAT ARE CO-ED, GIRLS-ONLY, OR BOYS-ONLY, BY REGION

\begin{tabular}{|lrrr|} 
& \multicolumn{3}{c|}{ PROGRAM TYPE } \\
\cline { 2 - 4 } REGION & CO-ED & GIRLS-ONLY & BOYS-ONLY \\
\hline Central 1 & 90.6 & 2.7 & 6.6 \\
\hline Central 2 & 91.4 & 8.6 & 0.0 \\
\hline East Central & 91.2 & 2.3 & 6.5 \\
\hline Eastern & 79.4 & 0.0 & 20.6 \\
\hline North & 88.7 & 2.6 & 8.7 \\
\hline Southwest & 87.5 & 0.0 & 12.5 \\
West Nile & 66.0 & 3.9 & 34.0 \\
\hline Western & 93.9 & 0.0 & 6.1 \\
\hline National & $\mathbf{8 8 . 0}$ & $\mathbf{2 . 4}$ & $\mathbf{9 . 9}$ \\
\hline
\end{tabular}

\section{FIGURE 46}

SELF-REPORTED PROGRAM DEMOGRAPHICS

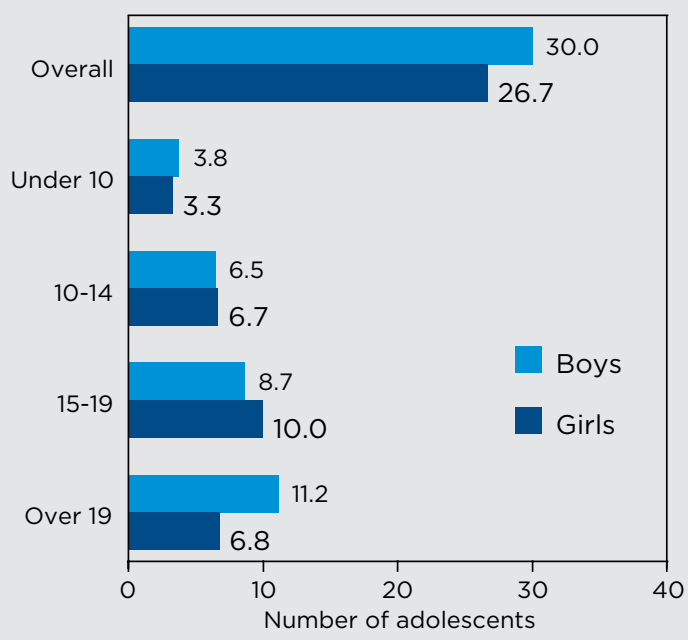

\section{TABLE 45}

\section{DESCRIPTIVE STATISTICS AND COMPARISONS TO UGANDA DHS 2011}

\begin{tabular}{|c|c|c|c|c|c|c|c|c|c|c|}
\hline & \multicolumn{5}{|c|}{ AGES 10-14 } & \multicolumn{5}{|c|}{ AGES 15-19 } \\
\hline & \multicolumn{3}{|c|}{ COVERAGE EXERCISE } & \multicolumn{2}{|c|}{ DHS 2011} & \multicolumn{3}{|c|}{ COVERAGE EXERCISE } & \multicolumn{2}{|c|}{ DHS 2011} \\
\hline & MALE & FEMALE & $p$ & MALE & FEMALE & MALE & FEMALE & $p$ & MALE & FEMALE \\
\hline $\begin{array}{l}\text { Minutes walk: from } \\
\text { home to program }\end{array}$ & $\begin{array}{l}37.0 \\
{[3.1]}\end{array}$ & $\begin{array}{r}35.4 \\
{[3.4]}\end{array}$ & 0.65 & & & $\begin{array}{r}30.8 \\
{[2.4]}\end{array}$ & $\begin{array}{r}35.1 \\
{[3.8]}\end{array}$ & 0.24 & & \\
\hline Out of school (\%) & $\begin{array}{r}9.5 \\
{[2.4]}\end{array}$ & $\begin{array}{r}5.6 \\
{[2.6]}\end{array}$ & 0.05 & 5.4 & 5.9 & $\begin{array}{r}25.8 \\
{[2.5]}\end{array}$ & $\begin{array}{r}23.6 \\
{[4.0]}\end{array}$ & 0.57 & 27.4 & 36.1 \\
\hline Ever married (\%) & & & & & & $\begin{array}{r}17.6 \\
{[3.9]}\end{array}$ & $\begin{array}{r}16.5 \\
{[3.3]}\end{array}$ & 0.79 & 3.1 & 22.7 \\
\hline $\begin{array}{l}\text { Ever fathered or given } \\
\text { birth to child (\%) }\end{array}$ & & & & & & $\begin{array}{r}8.1 \\
{[1.3]}\end{array}$ & $\begin{array}{l}14.3 \\
{[3.1]}\end{array}$ & 0.07 & 1.8 & 18.1 \\
\hline
\end{tabular}

Note: Estimated means adjusted for sampling design. Mean differences tested through separate regressions of the dependent variables on a dummy variable for gender. Regressions weighted by inverse probability of selection and adjusted for clustering.

\section{FIGURE 47}

TOTAL DAYS ATTENDED (ENCOUNTERS) AND MEAN ATTENDANCE RATE, BY AGE
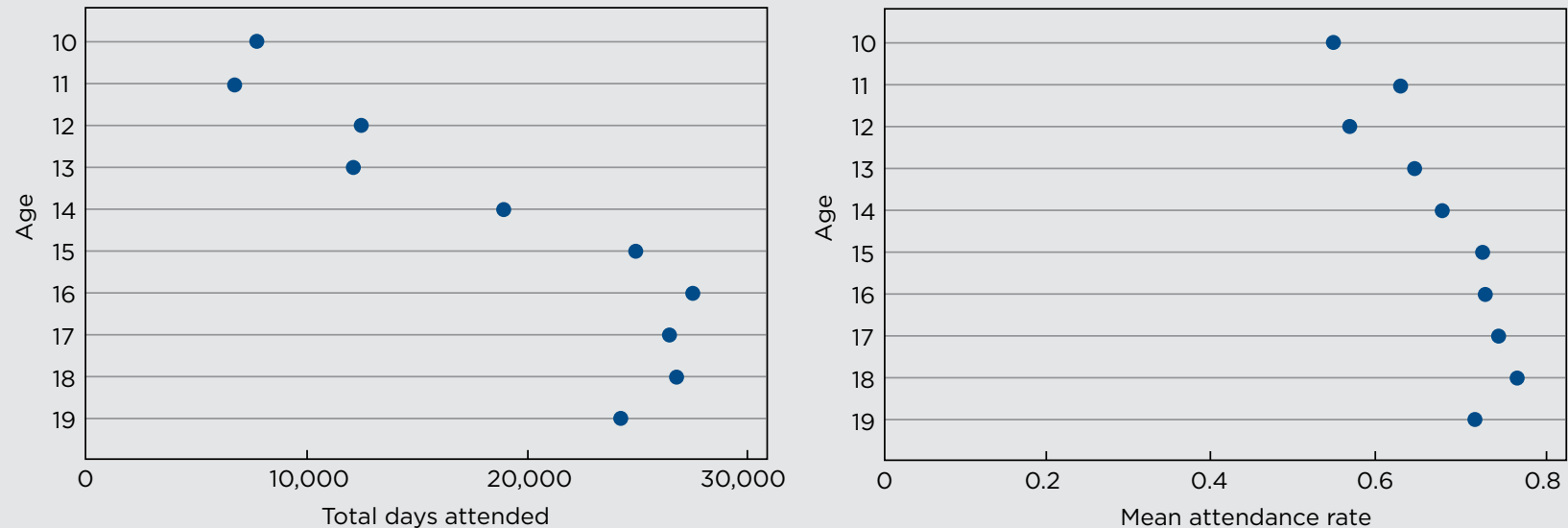

Source for Tables 44-45 and Figures 46-47: Authors' calculations, based on Uganda coverage exercise. 


\section{TABLE 46}

WEIGHTED AND UNWEIGHTED PARTICIPANTS AND ENCOUNTERS, BY AGE AND SEX

\begin{tabular}{|c|c|c|c|c|c|c|c|c|}
\hline & \multicolumn{4}{|c|}{ ALL (AGES 10-35) } & \multicolumn{4}{|c|}{ ADOLESCENTS (AGES 10-19) } \\
\hline & вотн & FEMALE & MALE & \% FEM & вотн & FEMALE & MALE & $\%$ FEM \\
\hline Unique participants & $\begin{array}{r}42,118 \\
{[7,625]}\end{array}$ & $\begin{array}{r}16,719 \\
{[3,605]}\end{array}$ & $\begin{array}{l}24,847 \\
{[4,188]}\end{array}$ & 39.7 & $\begin{array}{c}26,394 \\
{[5,998]}\end{array}$ & $\begin{array}{r}12,507 \\
{[2,855]}\end{array}$ & $\begin{array}{c}13,742 \\
{[3242]}\end{array}$ & 47.4 \\
\hline Mean participants & $\begin{array}{r}27.8 \\
{[2.4]}\end{array}$ & $\begin{array}{r}8.9 \\
{[1.3]}\end{array}$ & $\begin{array}{r}10.2 \\
{[0.8]}\end{array}$ & & $\begin{array}{r}18.6 \\
{[2.6]}\end{array}$ & $\begin{array}{c}11.4 \\
{[1.7]}\end{array}$ & $\begin{array}{c}10.8 \\
{[1.6]}\end{array}$ & \\
\hline Encounters & $\begin{array}{r}299,617 \\
{[50,815]}\end{array}$ & $\begin{array}{r}110,058 \\
{[22,955]}\end{array}$ & $\begin{array}{r}189,559 \\
{[32,902]}\end{array}$ & 36.7 & $\begin{array}{r}187,714 \\
{[34,798]}\end{array}$ & $\begin{array}{l}84,073 \\
{[18,134}\end{array}$ & $\begin{array}{r}103,641 \\
{[19,990]}\end{array}$ & 44.8 \\
\hline Mean encounters & $\begin{array}{r}7.1 \\
{[0.7]}\end{array}$ & $\begin{array}{r}6.5 \\
{[0.7]}\end{array}$ & $\begin{array}{r}7.6 \\
{[0.8]}\end{array}$ & & $\begin{array}{r}7.1 \\
{[0.9]}\end{array}$ & $\begin{array}{r}6.7 \\
{[1.0]}\end{array}$ & $\begin{array}{r}7.5 \\
{[0.9]}\end{array}$ & \\
\hline Attendance rate & $\begin{array}{r}74.3 \\
{[5.7]}\end{array}$ & $\begin{array}{r}73.5 \\
{[6.6]}\end{array}$ & $\begin{array}{r}74.9 \\
{[5.2]}\end{array}$ & & $\begin{array}{l}70.4 \\
{[7.7]}\end{array}$ & $\begin{array}{r}71.3 \\
{[7.9]}\end{array}$ & $\begin{array}{l}69.6 \\
{[7.7]}\end{array}$ & \\
\hline
\end{tabular}

\begin{tabular}{|c|c|c|c|c|c|c|c|c|}
\hline & \multicolumn{4}{|c|}{ ALL (AGES 10-35) } & \multicolumn{4}{|c|}{ ADOLESCENTS (AGES 10-19) } \\
\hline & вотн & FEMALE & MALE & $\%$ FEM & вотн & FEMALE & MALE & $\%$ FEM \\
\hline Unique participants & $\begin{array}{r}4,658 \\
{[231]}\end{array}$ & $\begin{array}{l}1,773 \\
{[155]}\end{array}$ & $\begin{array}{c}2,829 \\
{[145]}\end{array}$ & 38.1 & $\begin{array}{l}2,823 \\
{[223]}\end{array}$ & $\begin{array}{l}1,322 \\
{[143]}\end{array}$ & $\begin{array}{c}1,483 \\
{[118]}\end{array}$ & 46.8 \\
\hline Mean participants & $\begin{array}{r}27.1 \\
{[1.3]}\end{array}$ & $\begin{array}{r}8.4 \\
{[0.7]}\end{array}$ & $\begin{array}{r}10.4 \\
{[0.5]}\end{array}$ & & $\begin{array}{r}17.6 \\
{[1.4]}\end{array}$ & $\begin{array}{c}11.0 \\
{[1.2]}\end{array}$ & $\begin{array}{r}10.4 \\
{[0.8]}\end{array}$ & \\
\hline Encounters & $\begin{array}{r}34,835 \\
{[411]}\end{array}$ & $\begin{array}{l}11,617 \\
{[228]}\end{array}$ & $\begin{array}{r}23,218 \\
{[338]}\end{array}$ & 33.3 & $\begin{array}{r}21,424 \\
{[318]}\end{array}$ & $\begin{array}{r}8,916 \\
{[200]}\end{array}$ & $\begin{array}{r}12,508 \\
{[243]}\end{array}$ & 41.6 \\
\hline Mean encounters & $\begin{array}{r}7.5 \\
{[0.1]}\end{array}$ & $\begin{array}{r}6.4 \\
{[0.1]}\end{array}$ & $\begin{array}{r}8.1 \\
{[0.1]}\end{array}$ & & $\begin{array}{r}7.6 \\
{[0.1]}\end{array}$ & $\begin{array}{r}6.7 \\
{[0.1]}\end{array}$ & $\begin{array}{r}8.4 \\
{[0.2]}\end{array}$ & \\
\hline Attendance rate & $\begin{array}{r}77.0 \\
{[0.4]}\end{array}$ & $\begin{array}{c}76.3 \\
{[0.7]}\end{array}$ & $\begin{array}{r}77.4 \\
{[0.5]}\end{array}$ & & $\begin{array}{r}74.2 \\
{[0.5]}\end{array}$ & $\begin{array}{r}74.8 \\
{[0.8]}\end{array}$ & $\begin{array}{r}73.7 \\
{[0.7]}\end{array}$ & \\
\hline
\end{tabular}

Source: Authors' calculations, based on Uganda coverage exercise.

Note: Estimated means adjusted for sampling design.

\section{TABLE 47}

PREDICTORS OF DAYS ATTENDED (ENCOUNTERS) AND ATTENDANCE RATE

\begin{tabular}{|c|c|c|c|c|c|c|}
\hline & \multicolumn{3}{|c|}{ DAYS ATTENDED } & \multicolumn{3}{|c|}{ ATTENDANCE RATE } \\
\hline & COEF & SE & ОВS & COEF & SE & OBS \\
\hline \multicolumn{7}{|c|}{ Adolescents, 10-19 } \\
\hline Age & 0.20 & 0.14 & 2,831 & $0.02^{*}$ & 0.01 & 2,831 \\
\hline Female & -0.82 & 0.66 & 2,831 & 0.02 & 0.02 & 2,831 \\
\hline Time to walk & 0.001 & 0.01 & 2,811 & -0.001 & 0.0007 & 2,811 \\
\hline Out of school & 0.77 & 1.09 & 2,809 & 0.03 & 0.04 & 2,809 \\
\hline \multicolumn{7}{|c|}{ Adolescents, 15-19 } \\
\hline Ever married & 1.06 & 1.66 & 1,834 & 0.06 & 0.03 & 1,834 \\
\hline Had child & 0.92 & 0.71 & 1,822 & -0.02 & 0.08 & 1,822 \\
\hline
\end{tabular}

*Significant at $p=0.10$.

Source: Authors' calculations, based on Uganda coverage exercise.

Note. Each row represents a separate regression. Regressions weighted on

inverse of probability of selection. Standard errors account for clustered design.

\section{FIGURE 48}

MAP OF CATCHMENT AREAS AROUND A SUBSET OF

PARTICIPATING PROGRAMS

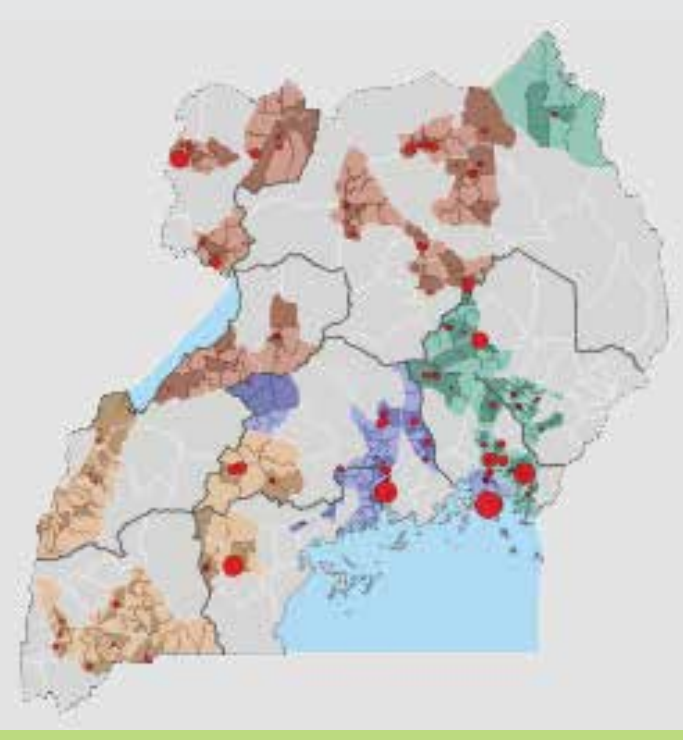


accounted for 62.7 percent of these weighted encounters, and males accounted for 55.2 percent of all adolescent encounters. The average program had 10.8 unique male participants and 11.4 unique female participants.

The ratio of male to female encounters was 1.2 among adolescents 10 to 19. Males and females had similar mean numbers of encounters; the average adolescent male attended 7.5 days, and the average adolescent female attended 6.7 days. Similarly, there was little difference in mean attendance rates (days attended divided by days program was operational); the average male attended 69.6 percent of the days his program operated, while the average female attended 71.3 percent of the days her program operated.

Older adolescents, those aged 15 to 19 , accounted for 69.2 percent of all adolescent encounters. As shown in Table 47, younger adolescents accounted for the fewest encounters and had the lowest rate of attendance. Each year of age among adolescents is associated with a 2 percent increase in attendance rate (see Table 47). However, age is the only significant predictor of days attended among younger adolescents ( $p<0.1)$. Sex, distance, schooling status, marital status, and parenthood do not significantly predict attendance among program participants.

The map in Figure 48 shows the catchment area of 234 programs (actual sample, not estimation sample); this area was calculated from the median distance in kilometers that adolescents must walk from their households to the program location. The average program has a catchment area of $26.3 \mathrm{sq}$. $\mathrm{km}$. We estimate that the total catchment area of programs nationally is $22,770 \mathrm{sq}$. $\mathrm{km}$. Uganda has 196,924 sq. km. of land area (excluding Kampala), so the estimated catchment area covers 11.6 percent of the country outside of Kampala.

This is a rough approximation as there are various sources of error, including inaccurate estimates from program participants about time to walk to the program from home and an assumption that all of the area within the median buffer zone around a program is land area. Nevertheless, the estimate supports the overall finding that there is lack of program supply. As discussed previously, we estimate that less than 2 percent of Uganda's adolescent population has access to these types of programs based on self-reported data from program representatives that put the average program size at 31.8 adolescents. This might overestimate the true coverage because attendance records show a mean program size of 18.6 adolescents.

\subsection{Discussion}

We conducted a nationally representative adolescent program scan and coverage exercise in Uganda to estimate, respectively, the average number of programs per subcounty and the average profile of program beneficiaries. Our findings suggest that the supply of programming for adolescents in Uganda is insufficient to meet the population demand. While the majority of subcounties have programs for adolescents, there is only 1 program for more than 2,500 adolescents; fewer than 2 percent of adolescents participate in regular programs.

This study did not measure program quality, but the average subcounty representative rated the subcounty's programming as being below a moderate level of quality and reach. Almost one-third of programs surveyed were not in operation during the 20-day period following our initial visit. The average program was operational for 6.2 of the 20 days following the enumerators' first visit.

While boys accounted for more total program encounters compared to girls, there were no striking discrepancies in program participation by sex. A notable finding, however, is that the profile of older adolescent male attendees was more vulnerable than the national average, whereas the profile of older female attendees was less vulnerable than the national average. This suggests that vulnerability is less of a barrier to participation for boys than for girls in later adolescence.

\section{Limitations}

The findings reported here do not take into consideration adolescent programs in Kampala's subcounties because we opted not to conduct a program scan and coverage exercise in this densely populated urban setting for logistical reasons. This likely lowered our estimates of program supply. Estimates could have been further diluted by a failure to fully enumerate all adolescent programs in each subcounty, but we believe our enumeration exercise was a success. 

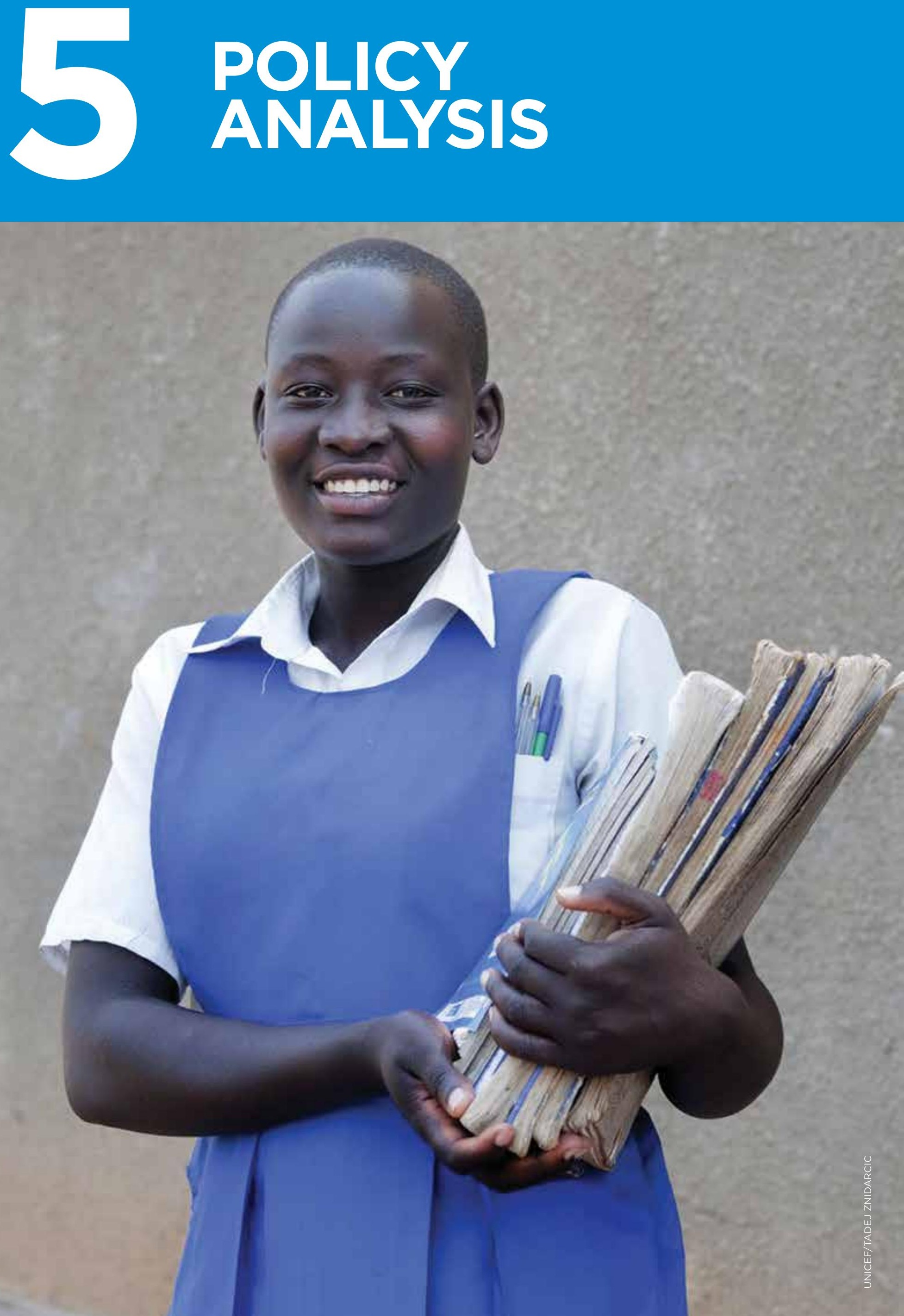
This analysis will assess Ugandan policy in the context of targeted interventions for adolescent girls. The following sections present an overview of policy mechanisms and discuss how they build girls' human, social, and economic assets to prepare them for decent livelihoods. Analysis identifies policy gaps and barriers to implementation.

\subsection{Introduction}

A policy environment supportive of adolescent girls creates space to build their autonomy and capacity to make free and informed decisions about their well-being. Girl-centered policies recognize young females' needs as distinct from those of their male counterparts, and consider the critical time-points when vulnerability is consolidated to shape strategic intervention (Bruce et al. 2006). They distinguish the needs of subgroups across the age span, and prioritize "preventive" interventions to target vulnerabilities before issues such as child marriage and early childbearing manifest.

Findings from this review and from consultation with key stakeholders indicate that adolescent girls do not feature as a distinct priority population in Ugandan policy. Adolescent issues fall under the mandates of both youth- and child-serving initiatives, and the country has yet to see a critical mass of public and private stakeholders converge into an adolescent "policy camp." Even within the Ministry of Gender-the main government agency responsible for adolescents-this work is divided between units charged with youth and with orphans and vulnerable children. Girls require explicit recognition in a policy environment that enables stakeholders to protect and educate them about their human, social, and economic rights; encourages them to participate fully and equally in society; and creates access channels to receive services in safe, supportive spaces. A set of recommendations for improved policymaking for adolescent girls in Uganda and in the region in general is outlined in Chapter 6.

\subsection{Methods}

This analysis pairs findings from a review of policy documents and consultation with key stakeholders in Kampala with demographic data from the 2011 DHS to map the policy landscape in Uganda and assess implementation in the context of adolescent girls.

\section{Policy scan}

The initial step was to conduct a thorough policy scan to identify instruments relevant to adolescents. The bulk of the scan was conducted through a review of documents available online. Researchers reviewed policy databases available on websites of Ugandan ministries, international organizations, and academic institutions. Policy documents were entered into a database and organized by topic area, type (e.g. strategic plan, law), geographic coverage, drafting and implementing organization, and adolescent- and gender-specific content. An additional review was conducted to catalogue key policies in select countries across the region. An overview of findings from Kenya, Ethiopia, Egypt, and Rwanda is presented to provide regional comparison and supplement the Uganda analysis.

\section{Key informant interviews}

Review of policies was supplemented by in-depth interviews with key informants in Uganda. Interviews were conducted in Kampala in February 2012 with ministry representatives and program staff from relevant agencies (Table 48). Stakeholders were asked to: describe how adolescent issues relate to their organizational mandate; identify policies that affect adolescents, how they came into being, and the adolescent- and gender-specific content in each policy mechanism; discuss policy implementation, including structure, challenges, and successes; describe their conceptualization of adolescent vulnerability; and suggest policy strategies to reach the most vulnerable populations.

\section{Linking policy to data}

Results of the policy scan and interviews were synthesized into findings on availability and implementation of policies addressing adolescents, specifically adolescent girls. These findings were then compared against available demographic and program-level data, presented in Chapters 1 and 4 . Researchers collected social, health, and economic indicators for adolescent girls to frame policy challenges within the demographic context. The following analysis presents findings and highlights gaps where investment can target vulnerabilities and improve adolescent well-being.

\subsection{Policy review}

\section{How does Ugandan policy define the 'adolescent' age group?}

Before we discuss how the Ugandan policy environment affects adolescents, we must first understand who is targeted as the "adolescent" population. Overall, Ugandan policy lacks consensus on the 


\section{TABLE 48}

\section{PERSONS CONSULTED}

\section{REPRESENTATIVE}

\section{AGENCY}

\begin{tabular}{ll}
$\begin{array}{l}\text { Commissioner } \\
\text { Acting Commissioner } \\
\text { Senior Youth Officer }\end{array}$ & $\begin{array}{l}\text { Ministry of Gender, Labour and Social Development } \\
\text { Department of Youth and Children's Affairs }\end{array}$ \\
\hline $\begin{array}{l}\text { Assistant Commissioner, Policy Analysis } \\
\text { Principal Nursing Officer }\end{array}$ & Ministry of Education and Sports \\
\hline Principal Economist, Education \& Social Development & Ministry of Health \\
\hline Technical Advisor & Ministry of Finance, Planning and Economic Development \\
Acting Director & Justice, Law and Order Sector \\
Senior Administrative Officer & Population Secretariat \\
\hline Senior Research Fellow & National Planning Authority \\
Consultant & Economic Policy Research Centre \\
Executive Director & USAID/International Youth Foundation Youth Map \\
Executive Director & Girls Education Movement (GEM) \\
Coordinator & Straight Talk Foundation \\
Economist & USAID Straight Project \\
\hline
\end{tabular}

\section{BOX 3}

\section{"YOUTH" AND "ADOLESCENCE": DEFINITIONS ACROSS UGANDAN POLICY}

"This National Youth Policy defines youth as all young persons; female and male aged 12 to 30 years. This is a period of great emotional, physical and psychological changes that require societal support for a safe passage from adolescent to full adulthood. The definition does not look at youth as a homogeneous group with clearcut age brackets but rather as a process of change or a period of time where an individual's potential, vigor, adventurism, experimentation with increased risks and vulnerabilities show themselves in a socially meaningful pattern. The definition considers youth and children to be mutually inclusive at some stage of their lives. So this definition reinforces the definition of a child and seeks to nurture, protect, and ensure their welfare." National Youth Policy, 2001

"The definition of the youth varies from country to country. Generally, the period between childhood and adulthood is called Youth. It is a transitional period from family dependent childhood to independent adulthood and integration in the society as a responsible citizen. This policy defines Youth as a person who is within the age bracket of 15 to 35 years. Uganda definition has been informed by international and regional definitions namely the United Nations, Commonwealth, and African Union. The definition also acknowledges the fact that youth is not a homogeneous group, but a diverse group with different sub-groups differing in social roles and requirements." National Youth Policy (revised), draft, January 2013

"The term 'adolescent' refers to young people between 10-19 years, and "youth" to those between 15-24 years. 'Young people' is a term that covers both age groups i.e. those aged between 10-24 years. Adolescence is defined as a period of physical, psychological, and social transition from childhood to adulthood and may fall within either age group. Adolescence is characterized by dramatic physical, psychological and social changes that are often not well understood by adults. What makes the adolescents particularly vulnerable is, on the one hand, their dependency, inexperience and lack of positive guidance. This is compounded by lack of clear legal structures and systems for the protection of adolescents, conflicting social value systems, social change and economic constraints." National Adolescent Health Policy, October 2004 
definition of the adolescent age bracket (Box 3). For example, the National Adolescent Health Policy codifies "adolescents" as young people between 10 and 19 years and "youth" as between 15 and 24. "Young people" covers both age groups (10-24 years of age). The revised National Youth Policy (2012), however, defines youth as all young persons aged 15 to 35 years. According to the Constitution of the Republic of Uganda, youth are individuals between 18 and 30 years of age; anyone below the age of 18 is legally a child. Various line ministries, government, and nongovernmental organizations operate by different categorizations of what constitutes "youth" versus "adolescent."

Adolescents are most often grouped with priorities and interventions intended for children or young adults. Ugandan policy documents typically refer to youth in general and do not specify adolescents as a separate group. According to the National Adolescent Health Policy, "adolescence is defined as a period of physical, psychological and social transition from childhood to adulthood and may fall within either age group" (Reproductive Health Division, Ministry of Health 2004). Lack of a clear niche reduces visibility for the adolescent population among competing government demands and compromises resource allocation. As stated in the Adolescent Health Policy, biological, social, and economic vulnerabilities are compounded by "lack of clear legal structures and systems for the protection of adolescents" (Ministry of Health 2004). Aside from the Adolescent Health Policy, there is minimal language explicitly addressing adolescence as a distinct stage of life and the critical transitions within it.

Key informants were asked to define the age groups that they conceptualize as youth, adolescents, and children (Table 49). Broad categorizations of these terms mask the internal diversity of the adolescent population, understanding of which is of critical importance for development efforts (Bruce and Chong 2003). Existing resources are too often spread amongst the general youth population and not strategically directed at the most marginalized groups. This means that the populations that stand to benefit most are largely unreached by conventional policy mechanisms and suffer worse outcomes as a result of inequity in resource allocation and access (Bruce, personal communication).

Uganda has a wealth of health, social, and economic policy (for more detail see the policy review by topic area, Section 5.5 and 5.6). In fact, as one key informant reported, Uganda has "one of the best legal environments on paper." Uganda's poverty alleviation policies and national development plans state that youth are of critical demographic importance. Policies designed to reach adolescent girls are largely tied to health and education priorities. Examples include the National Youth Policy, Adolescent Health Policy, the Gender Policy, the National Population Policy and its accompanying Action Plan, and the Domestic Violence Act. These instruments include provisions for improving girls' educational attainment, providing youth-friendly sexual and reproductive health services, promoting awareness of sexual and reproductive rights, and supporting women's economic empowerment. The Constitution of Uganda, the Local Government Act, and the Land Act include affirmative action clauses to increase participation of women and girls in education and government, and provide women and dependent children rights to land ownership. However, there is little specificity for identifying high-risk subpopulations where intervention could be prioritized, and policies lack operational and prescriptive guidelines on specific action for girls at high risk of poor outcomes.

\section{Very young adolescents: A critical constituency}

Adolescents ages 10-14, particularly those not in school and/or living apart from parents, are vastly under-represented in traditional "youth-serving" initiatives such as youth centers, HIV prevention programs, and economic empowerment initiatives. Social isolation, a structural barrier to participation and access to development efforts, begins at an early age; the transition to secondary school in early adolescence is a major turning point when girls are drawn into domestic chores and caregiving, employment, or marriage to help support the family (Bruce 2007a; Sewall-Menon et al. 2012). A wealth of prior research conducted by the Population Council throughout sub-Saharan Africa reinforces the fact that girls, and particularly younger girls, have fewer social assets than their male counterparts such as reliable peer networks, safe spaces in the community to gather and meet friends, and access to media and public messaging (Bruce 2007b; Erulkar et al. 2004; Hallman and Diers 2004; Erulkar and Matheka 2007). Social capital deficits have been linked to increased likelihood of experiencing sexual coercion, forced sex, having multiple partners, and a lower likelihood of receiving HIV prevention information and testing (Hallman 2004, 2005; Hallman and Diers 2004; Hallman et al. 2007).

Rights abuses such as school dropout and sexual violence begin long before a girl reaches 15 years of age, yet this age is the marker where many "youth" policies begin. Policies designed to reach girls ages 10 to 14 are virtually absent. Childcentered policies that do reach this age group neglect critical issues such as reproductive health (Ministry representative, personal communication). Of particular concern, the National Youth Policy 
TABLE 49

\section{REPORTED DEFINITIONS OF ADOLESCENT, YOUTH, AND CHILD}

\begin{tabular}{|c|c|}
\hline Ministry Representative & $\begin{array}{l}\text { Youth: } 13 \text { to } 30 \text {; Child: } 0 \text { to } 18 \\
\text { "So a big part of the children are actually youth. We don't have a policy on adolescents, but we have } \\
\text { a policy on vulnerable children and are developing a new policy on youth. The interventions overlap. } \\
\text { I want to confess that the policies we have on children, with certain issues, certain characteristics are } \\
\text { not addressed. Like reproductive health for example-maybe the mindset of people is that children } \\
\text { shouldn't have this, even though children includes up to age 18." }\end{array}$ \\
\hline Ministry Representative & $\begin{array}{l}\text { Youth: } 18-30 \text { (Constitution), } 12-30 \text { (Policy); Child: } 0-18 \\
\text { "We have two definitions of youth. Youth by definition in the Constitution is } 18 \text { to } 30 \text {, but for policy- } \\
\text { the National Youth Policy-it is } 12 \text { to } 30 . "\end{array}$ \\
\hline Ministry Representative & $\begin{array}{l}\text { Adolescent: } 14-24 \text {; Youth: } 18 \text { to } 30 \\
\text { "Anything below that, those are still children." }\end{array}$ \\
\hline Ministry Representative & $\begin{array}{l}\text { Youth: up to age } 30 \\
\text { "Adolescence is a sub-set of youth; different organizations will tell you different things." }\end{array}$ \\
\hline Policy Researcher & $\begin{array}{l}\text { Youth: } 15 \text { to } 35 \\
\text { "Youth are not children-youth is a term that has received different definitions ... basically we are } \\
\text { talking about individuals between the ages of } 15 \text { to } 35 \text {. But definitions vary. There is thinking that age } \\
15 \text { is too high for a lower limit, it should come down to } 12 \text { or so. Or maybe } 35 \text { is too high of an upper } \\
\text { limit and we should stop at } 30 \text {. But it lacks a clear-cut definition." }\end{array}$ \\
\hline Program Representative & $\begin{array}{l}\text { Adolescent: } 15-19 ; \text { Youth: } 10 \text { to } 24 \\
\text { "I think adolescence is } 15-19-\text { a small group. We target the age groups together in our programs." }\end{array}$ \\
\hline Program Representative & $\begin{array}{l}\text { Adolescent: } 10 \text { to } 24 \text {, split into older }(15-24) \text { and younger (10-14); Youth: to age } 35 \\
\text { "We are targeting adolescence but know that some of these are also youth. We look at adolescence } \\
\text { because it a period of vulnerability to many risks. We want to make sure there is a safe transition to } \\
\text { young adults and we support them through this adolescent stage. I don't think there is much policy } \\
\text { specifically on adolescents-adolescents are lumped under youth. Policy should differentiate the } \\
\text { period and distinct needs of adolescents, so people implementing programs like us choose to focus } \\
\text { on a particular age group. The challenges at different ages are very much different. }\end{array}$ \\
\hline Program Representative & $\begin{array}{l}\text { Youth: Under age } 30 \\
\text { "Primary school up to age } 12 \text { are their own group, then } 13-18 \text { and } 19-30 . "\end{array}$ \\
\hline
\end{tabular}

in its 2012 revision raises the definition of "youth" from age 12 to 15 . With the architecture of poverty established in advance of intervention, governments and civil society organizations are continually engaging in the far less efficient "catch up" work of treating rather than preventing negative outcomes (Bruce, personal communication).

\section{Inversion of care and "hot spots" of vulnerability}

Figure 49 illustrates the inversion of care whereby the most disadvantaged girls-typically the poorest girls in the poorest communities-are most excluded from available social services and spaces. Boys typically face fewer safety threats and have more free time to visit services and use public spaces, and therefore have greater access to community resources. Better-off girls have some, but more limited, access. The most vulnerable girls (e.g. socially isolated girls who are out of school, living apart from their parents, married as children, caring for HIV-infected family members, and those who have migrated to urban areas and are working in domes-

\section{FIGURE 49}

EXCLUSION OF THE MOST DISADVANTAGED GIRLS FROM COMMUNITY SERVICES AND RESOURCES

\section{What Is Needed?}

Correct the current investment failure to reach the critical bottom $40 \%$ of girls.

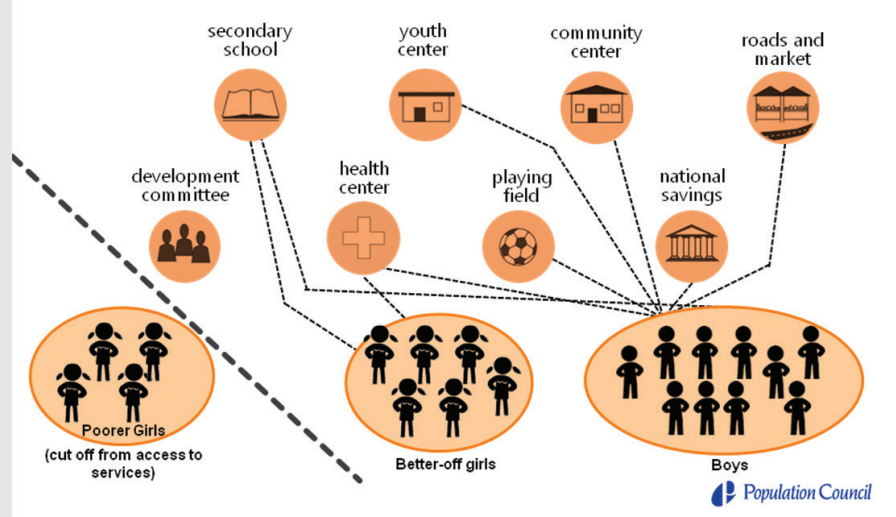

Source: Bruce 2011. 


\section{Prioritizing regions}

with the highest

concentrations of

vulnerable populations

and where girls are most

cut off from services is

important for allocating

scarce development

resources effectively.

tic service, etc.) are supporting themselves in highrisk contexts yet are largely blocked from services. Despite the fact that these girls would often benefit most from development efforts to improve health status, financial literacy, and educational attainment, they are the least likely to benefit if policies and programs are not explicitly designed with them in mind (Sewall-Menon et al. 2012).

Prioritizing regions with the highest concentrations of vulnerable populations and where girls are most cut off from services is important for allocating scarce development resources effectively. Returning to the results of the index and coverage exercise presented in Chapters 3 and 4, respectively, we can identify regions to begin designing strategic investments in the most vulnerable adolescent girls. The following analysis discusses three areas in Uganda characterized by different contextual factors for policy and program design.

\section{Karamoja}

Karamoja is the region with the highest percentage of adolescent girls vulnerable at the individual level (92 percent). Further, 100 percent of girls in Karamoja experience community-level deprivations (Table 30). Living in a low-density, post-conflict setting with a largely nomadic population, girls face extreme vulnerabilities as discussed in previous chapters. Individual-level vulnerability rates are driven by educational deprivations, and being young and out of school is a serious risk factor for persistent poverty and outcomes such as exploitative employment, child marriage, and early childbearing. In Karamoja, over half of girls ages 10-19 and nearly 75 percent of girls ages 15-19 are not in school. Karamoja has by far the highest multilevel vulnerability of all regions, with over half of girls (53 percent) vulnerable at all three levels (Table 30). While only 4 percent of Uganda's adolescent population resides in Karamoja, the intensity of vulnerability in this region merits policy and programmatic attention.

Given data constraints, Karamoja is included in the results for the North region in the program scan and coverage exercise. On average in the North, there are 3.8 programs in each subcounty that meet the criteria of the program scan for adolescents (Table 38). Per the coverage exercise, only 2.6 percent of programs surveyed in this region are designed as girl-only spaces, while 8.7 percent are boy-only and 88.7 percent are co-ed (Table 44). The profile of the average participant in these programs is an older male: 68.7 percent of participants are over the age of 15 (Table 43) and 59 percent of participants are boys (Table 42). Therefore, while comparatively there are many programs available in the North (an estimated 829 programs in total, by far the most of any region), they are clearly not reaching the girls most in need and should be redesigned to target these populations.

\section{West Nile and Western regions}

In the West Nile region, ranking second behind Karamoja in terms of multilevel vulnerability, 85 percent of girls are vulnerable at the individual level and 86 percent at the community level. Half of the female population ages 15-19 is not in school. Despite these indicators for girls, programs surveyed in West Nile have the highest average percentage of male participants (69 percent) of all regions in Uganda (Table 42), and 80.7 percent of program participants, on average, are over the age of 15 (Table 43). West Nile has the fewest (155) adolescent programs (Table 39).

The Western region has roughly 300 programs available for adolescents (Table 39); only West Nile and the Eastern region have fewer. Among programs surveyed, 75 percent of participants, on average, are over 15 (Table 43); 94 percent of programs are mixed sex (Table 44); and, on average, 62 percent of program participants are male (Table 42). The Western region has the highest percentage, nearly 15 percent, of the adolescent population. Seventy-one percent of girls in the Western region ages 10-19 are vulnerable at the individual level (Table 30). Since educational indicators drive individual vulnerability rates, this means that a substantial number of Uganda's adolescent girls live in a community where it is common either to be out of school or two years behind grade for age. Policymakers can use these data to locate investments to improve educational attainment and quality for the adolescent population. 


\section{Kampala}

As discussed previously, Kampala is a high-density urban area with unique risk factors for adolescent well-being (see Box 2). Aggregate index results mask marked urban internal disparities, and policymakers require more detailed data to identify areas for investment in the capital region. On the aggregate, 40 percent of girls ages 10-14 and 56 percent ages 15-19 in Kampala are considered vulnerable at the individual level (Table 30). When separated by wealth quintile, indicators of vulnerability rise to 65 percent of girls in the poorest quintile experiencing individual-level deprivation, as compared to 45 percent of girls in the richest quintile (Figure 35). Girls in the poorest and second poorest quintiles also experience exacerbated household-level deprivation. Kampala was not included in the program scan and coverage exercise for methodological reasons, and further investigation into service availability and access for specific populations living in urban poverty-such as girls living away from parents, work- ing in domestic service, etc.-would help to inform more effective investment at the policy level.

\subsection{Policy areas in the context of the Adolescent Girls Multilevel Vulnerability Index}

This section presents an assessment of policy areas captured by the selection of indicators included in the Adolescent Girls Multilevel Vulnerability Index. Uganda has numerous policy instruments for social and economic development (Table 50). However, weak implementation and enforcement limit the degree to which Ugandan policy affects the vulnerable populations it seeks to protect.

Uganda has ratified numerous international instruments that relate to child and adolescent well-being, including: the UN Convention on the Rights of the Child (ratified 1990); the Convention on The Elimination of All Worst Forms of Discrimination

\section{TABLE 50}

\section{LIST OF POLICIES BY AGI INDICATORS}

\begin{tabular}{|c|c|c|}
\hline CATEGORY & INDEX INDICATORS & POLICY \\
\hline $\begin{array}{l}\text { Child } \\
\text { protection }\end{array}$ & $\begin{array}{l}\text { Not living with parents } \\
\text { No access to improved } \\
\text { source of water } \\
\text { No access to improved } \\
\text { sanitation }\end{array}$ & $\begin{array}{l}\text { - Constitution of the Republic of Uganda } \\
\text { - Children's Act } \\
\text { - National Strategic Progamme Plan of Interventions for Orphans and Other } \\
\text { Vulnerable Children } \\
\text { - Orphans and Other Vulnerable Children Policy }\end{array}$ \\
\hline Education & $\begin{array}{l}\text { Two years behind grade } \\
\text { for age or no education } \\
\text { No secondary school } \\
\text { Household head has no } \\
\text { education } \\
\text { Lives in a community } \\
\text { with a high percentage of } \\
\text { illiteracy }\end{array}$ & $\begin{array}{l}\text { - Constitution of the Republic of Uganda } \\
\text { - National Youth Policy } \\
\text { - National Action Plan on Women } \\
\text { - Education Act } \\
\text { - Gender Policy } \\
\text { - Government White Paper on Education } \\
\text { - Ministry of Education and Sports Budget Framework Paper } \\
\text { - National Strategy for Girls' Education } \\
\text { - Revised Education Sector Strategic Plan 2007-2015 } \\
\text { - Universal Primary Education } \\
\text { - Universal Post Primary Education and Training } \\
\text { - Business, Technical, Vocational Education and Training }\end{array}$ \\
\hline $\begin{array}{l}\text { Child } \\
\text { marriage }\end{array}$ & $\begin{array}{l}\text { Currently married } \\
\text { Lives in a community with } \\
\text { higher rates of marriage } \\
\text { before age } 18 \text { than the } \\
\text { regional average }\end{array}$ & $\begin{array}{l}\text { - Constitution of the Republic of Uganda } \\
\text { - National Youth Policy } \\
\text { - Customary Marriage (Registration) Act } \\
\text { - Domestic Relations Bill } \\
\text { - Marriage and Divorce Bill }\end{array}$ \\
\hline $\begin{array}{l}\text { Sexual and } \\
\text { reproductive } \\
\text { health } \\
\text { services }\end{array}$ & $\begin{array}{l}\text { High-risk sex: } \\
\text { - Sexual initiation under } \\
\text { the age of } 15 \\
\text { - Multiple partners } \\
\text { - Non-regular partners }\end{array}$ & $\begin{array}{l}\text { - National Youth Policy } \\
\text { - Adolescent Health Policy } \\
\text { - National Population Policy and Action Plan 2011-2015 } \\
\text { - Health Sector Strategic Plan III and Health Sector Strategic and Investment Plan } \\
\text { - National Policy Guidelines and Service Standards for Reproductive Health } \\
\text { - National Training Curriculum for Health Workers on Adolescent Health \& Development } \\
\text { - National HIV/AIDS Strategic Plan } \\
\text { - Uganda Policy for the Reduction of Maternal to Child Transmission } \\
\text { - National Policy Guidelines for HIV Counseling and Testing } \\
\text { - Education and Sports Sector National Policy Guidelines on HIV/AIDS }\end{array}$ \\
\hline
\end{tabular}


Against Women (ratified 1979); ILO Convention 138 Minimum Age of Admission to Employment (ratified 1973); ILO Convention 182 Worst forms of Child Labour (ratified 2001); UN Convention for the Suppression of the Traffic in Persons and the Exploitation of the Prostitution of Others (ratified 1949); Protocol to Prevent, Suppress and Punish Trafficking in Persons, Especially Women and Children (ratified 2000); Optional Protocol to the Convention on the Rights of the Child on the Involvement of Children in Armed Conflict (ratified 2002); and the African Charter on the Rights and Welfare of the Child (ratified 1990) (Uganda Youth Development Link 2011).

\section{Child protection}

\section{Relevant indicators in AGI}

- Not living with parents

- No access to an improved source of water

- No access to improved sanitation

Article 25 of the Constitution of the Republic of Uganda provides for the protection of all children.14 The Uganda Human Rights Commission classifies access to food, water, housing, health care, work, adequate standard of living, education, and social security as economic and social rights for all people. Child protection frameworks such as the Children's Act and the Convention on the Rights of the Child guarantee every child the right to basic nutrition, shelter, health care, and social services; protection from exploitative labor practice; and protection from performing work that is inappropriate for the child's age or places the child's well-being, education, physical, mental, or spiritual health, and moral or social development at risk (Uganda Human Rights Commission). ${ }^{15}$

The Ministry of Gender's Orphans and Other Vulnerable Children National Implementation Unit (OVC-NIU), which receives a substantial portion of the Ministry's resources, coordinates national child protection efforts. The OVC-NIU carries out the National Strategic Programme Plan of Interventions for Orphans and Other Vulnerable Children and the Orphans and Other Vulnerable Children Policy to provide social and economic protections with a focus on orphans and children living with HIV. The national program is coordinating efforts and building capacity to prevent abuse, neglect, and exploitation. A National Strategic Programme Plan of Interventions II is under development.
Pending amendments to the Children's Act would more closely regulate adoption, foster care, and legal guardianship and increase protections against child trafficking. Current immigration law on trafficking is weak, and prevention and protection services are limited (Uganda Youth Development Link 2011).

\section{Education}

Relevant indicators in AGI

- Two years behind grade for age or no education

- No secondary school

- Household head has no education

- Lives in a community with a high percentage of Illiteracy

The Constitution recognizes education as a right for all, and recommends affirmative action to allow groups marginalized on the basis of gender or age to realize their right to social services. The National Youth Policy acknowledges the right of all youth to meaningful education.

With the introduction of Universal Primary Education (UPE) in 1997, Uganda established a district-level UPE capitation grant to provide free primary education for up to four children in every family (expanded to all children in 2003) (Nishimura et al. 2009). The Education Act of 2008 instituted penalties for failure to enroll a child in compulsory UPE. Uganda followed its successes in increasing primary enrollment by instituting Universal Post Primary Education and Training in 2007, becoming the first country in Africa with a Universal Secondary Education (USE) policy.

Despite improving access to a basic level of schooling, universal education policies have stressed an already constrained educational system, resulting in over-crowded classrooms and under-resourced educational facilities. Instruction quality is generally poor, and school completion rates are low (International Youth Foundation 2011). For both sexes, school enrollment drops from 92 percent of girls and 94 percent of boys ages 10-14 to only 54 percent of girls and 64 percent of boys ages 15-19 despite free universal secondary education (International Youth Foundation 2011). Further, there is question as to the relevance of the school curriculum and concern over the resulting imbalance between curricular content and

14 The definition of a child in Uganda includes all individuals up to age 18; therefore, most adolescents are covered by child protection policies.

15 Article 34 of the Constitution of Uganda also prohibits economic exploitation of children. 


\section{PROGRAM SNAPSHOT: GIRLS EDUCATION MOVEMENT}

In recent years, the Government of Uganda has made notable progress toward achieving its 2007 goal of implementing universal primary education. The primary net enrollment rate (NER) currently stands at $96.1 \%(96.5 \%$ boys, $96 \%$ girls)-extremely encouraging progress toward meeting the Millennium Development Goal on primary education. However, despite this high NER, just over half of enrolled students complete school. Challenges toward completion are particularly notable among girls, who face additional risks. In 2010 , only $56 \%$ of boys and $51 \%$ of girls completed seven years of primary school. The gap is also highly pronounced in secondary and higher school levels, with a transition rate of $63 \%$ of girls compared to $66 \%$ of boys.

One major factor affecting timely enrollment and retention is the continued prevalence of abuse, particularly of the girl-child, both within the home and school environment. The power relations underlying many of these challenges continue to marginalize women and girls in Uganda and prevent them from participation in education, decisionmaking, and representation. A 2009 study on the Girls Education Movement (GEM)-a program to increase educational access and attainment for girls in Uganda-and UNGEI (Ezati 2009) highlight that these unfavorable circumstances lead to early marriage of girls, pregnancy, violence against women and girls, sexual harassment, high dropout rates of girls, a shortage of female teachers and female role models, and a value system in which some parents and communities still do not fully appreciate the importance of educating girls.

There is a regional dimension to these challenges as well. It has been particularly difficult to bridge gender gaps in education in Karamoja and the post-conflict regions of Uganda. In these areas, studies have highlighted a number of factors presenting barriers to girls' education, including: household chores, child labor, and lack of safety and privacy for girls at puberty. Such factors also tend to lead to poor performance in school, contributing to dropout before primary examinations and low transition into secondary and higher education.

In response to these challenges, the Girls Education Movement (GEM) was born in 2001, in close partnership with the government of Uganda and other members of the Gender Task Force. Their primary aim is to increase school enrollment and retention (especially of girls). This has been achieved through a number of initiatives including GEM clubs and chapters that unite girls in schools across the country around education-for example, through "Go to school, back to school, stay in school" (GBS) campaigns and more recently through a scholarship program which supports beneficiaries in entering secondary and even BTVET (Business, Technical, Vocational Education and Training) educational institutions.

\section{Program Targets:}

- Established GEM clubs in primary schools increase from $10 \%$ (1797) to $23 \%$ (4005) and in secondary schools from less than $1 \%$ (4) to $20 \%$ (506).

- GEM and UNGEI District chapters established in all districts in Uganda (increase in number of districts with functional District GEM Chapters from 21 districts in 2010 to 117 districts in 2014).

- At least 40,000 children who dropped out of school return and stay in school every year (an average of at least ten children returned in each school).

- At least four technical reports/briefs prepared for policy development, directives, and guidelines on girls' education.

- At least $8 \%$ improvement in primary school completion rates in each of the districts where GEM has a chapter.

- Increase in transition rates from primary to secondary, vocational, and other post-primary institutions by $11 \%$ for girls (from $63.0 \%$ to $74.0 \%$ ).

- At least 800 disadvantaged girls complete four years of lower secondary school through the bursary program.

- Improved safety and security of children, especially girls, in and out of school. 


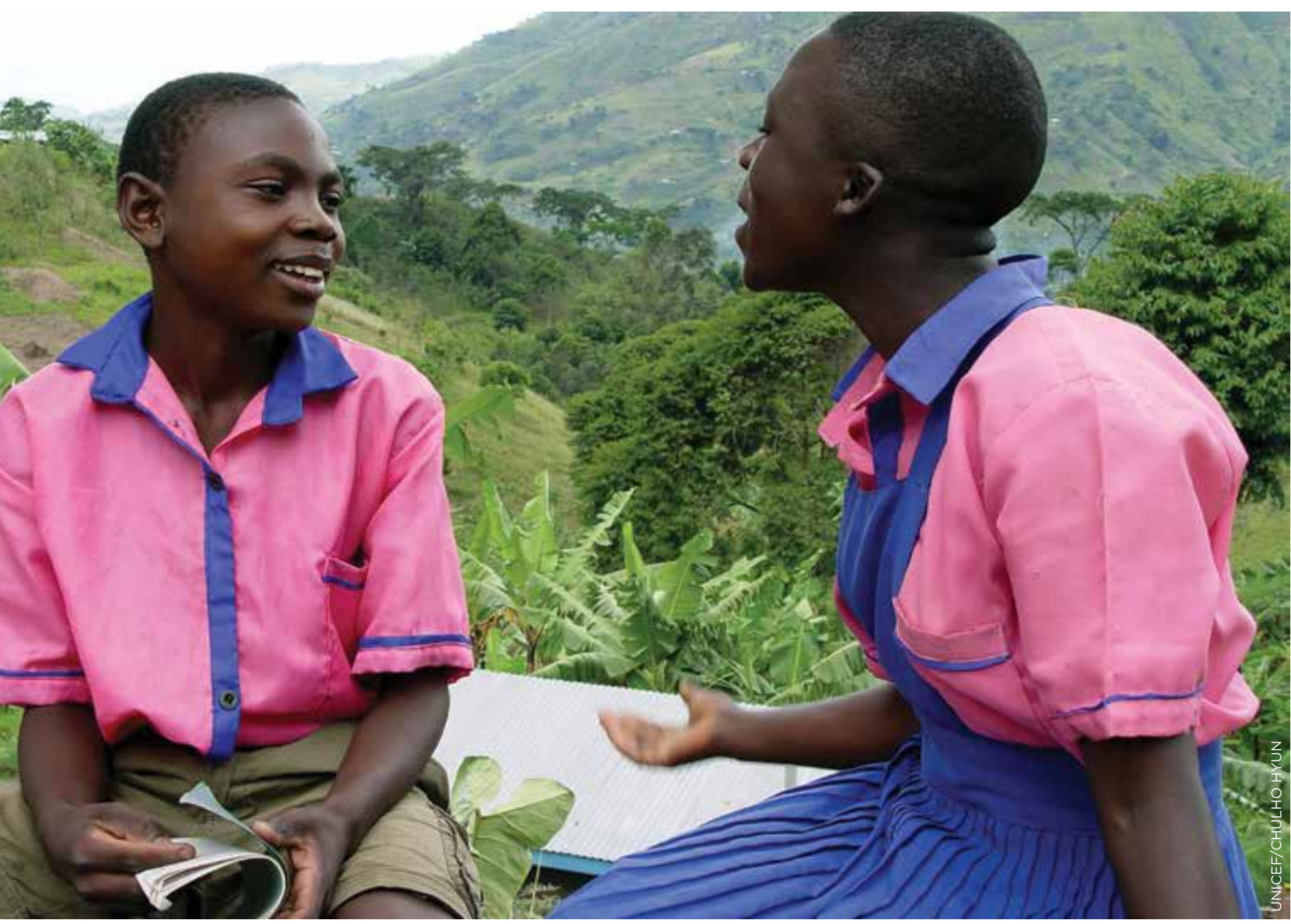

In Uganda, child protection frameworks are designed to guarantee every child the right to basic nutrition, shelter, health care, and social services.

labor market demands. The 2008 Business, Technical, Vocational Education and Training Act addresses the need for more applied, practical training in the formal education system and aims to reduce redundancies in institutions providing vocational training (UNESCO-IBE 2010; Young Leaders Think Tank 2011).

For girls, low educational attainment is associated with poorer health outcomes and financial dependence, and limits their negotiating power to prevent child marriage and early childbearing. As discussed previously, greater educational attainment is positively correlated with reduced fertility and improved socioeconomic outcomes for individuals, communities, and nations as a whole. Uganda's National Development Plan for 2010-2015 states that the country's primary constraints to sustainable population growth are the "low levels of education and lack of skills which are mainly a result of high dropout rates, especially among girls in both primary and secondary schools, which in turn leads to teenage pregnancies and early marriages" (National Planning Authority 2010).

The Government's 1992 White Paper on Education and National Strategy for Girls' Education sparked a review of the education system and set the foundation and goals for Uganda's official education policies. Gender-specific interventions that followed include: affirmative action policies to increase gender parity in educational attainment (e.g. a system of awarding girls 1.5 points for university admission to facilitate their entry into tertiary education); curriculum revisions to make content more gender-responsive; the Promotion of Girls' Education scheme to improve retention and performance; and the Complementary Opportunity for Primary Education (COPE) and Alternative Basic Education for Karamoja (ABEK) programs that aim to increase access to educational opportunities for disadvantaged children (Muhwezi 2003). 
The National Strategy for Girls' Education, National Population Policy \& Action Plan and the Revised Education Sector Strategic Plan promote girls' education and include targets such as improving retention and completion for girls' schooling and enhancing practical and relevant vocational training. The 2007 Gender Policy encourages gender-responsive development planning from national to district and local levels. It specifically delegates responsibility to the National Curriculum Centre to mainstream gender into primary, secondary, and tertiary course syllabi and to design gender education and girls' empowerment programs in schools (Ministry of Gender, Labour and Social Development 2007b).

Despite legal and policy frameworks that recognize the right to equal education and promote strategies for gender inclusiveness, there are persistent gaps in attainment at critical transition points in a girl's life. Poverty, child marriage, early childbearing, domestic responsibilities, and cultural perceptions of the value of educating girls continue to drive disparities in completion rates. Gender parity indices for secondary school and higher education are 0.89 and 0.83 , respectively, below the target GPI of 0.96 (GPI less than 0.96 indicates girl disadvantage). According to the 2011 Uganda DHS, 29 percent of girls ages 10-19 in the poorest wealth quintile are not in school, 58 percent of girls ages 15-19 in the poorest wealth quintile are not in school, and 96 percent of girls who have ever been married and 97 percent of girls who have a child are not enrolled in school. Data reflect regional hot spots where girls appear to be at particular risk for dropout: over half of girls aged 10-19 in Karamoja are not in school, increasing to nearly 74 percent for girls ages 15-19, and half of girls ages 15-19 are not in school in the West Nile region (UDHS 2011).

\section{Child marriage}

\section{Relevant indicators in AGI}

- Currently married

- Lives in a community with a high percentage of child marriage

Child marriage is a gross rights violation that heightens girls' vulnerability to early pregnancy and related maternal morbidity and mortality, social isolation, and financial dependence (UNICEF 2005). As a party to the Convention on the
Elimination of All Forms of Discrimination Against Women (CEDAW), the Constitution of Uganda recognizes 18 years as the legal minimum age at marriage, and the National Youth Policy acknowledges the right to remain unmarried until reaching the legal age. Despite this fact, roughly 40 percent of girls ages 20-24 report having been married by age 18 (UDHS 2011).

The prevalence of child marriage stems from customary law and practices. The Customary Marriage (Registration) Act regulates unions recognized by customary law. The original legislation (1973) set the minimum age of marriage for girls at 16 and boys at 18 . Amendments to the Act have subsequently rendered any law in violation of the Constitution null and void and required that statutes be brought in line with the law setting 18 as the legal age of marriage for both sexes (Justice, Law, and Order Sector, personal communication).

Additional legislation to protect women in marital unions and prevent child marriage has been tabled in Parliament. In 1987, a Domestic Relations Bill was introduced that provoked controversy over marital consent, pre-nuptial agreements, cohabitation rights, bride price, and widow inheritance. The Bill emphasized individual rights and regulated relations between men and women traditionally governed by local customs (Immigration and Refugee Board of Canada 2004). The Bill would establish in national statute the minimum age of marriage at 18 , criminalize marital rape and widow inheritance, ${ }^{16}$ negate any requirement for bride price to legitimize customary marriages (bride price as a practice would not be illegal, but demanding compensation as a condition for marriage would be an offense), establish more equitable grounds for divorce, and provide guidelines for the economic support of all wives in polygamous unions (Von Struensee 2004). The Domestic Relations Bill has become the longest-pending legislation in Parliament; its 2009 iteration, the Marriage and Divorce Bill, contains many of the same provisions to reform and consolidate the law relating to marriage, separation, and divorce and more explicitly recognize women's rights within marriage or cohabitation (to property, freedom from sexual violence, etc.) (Marriage and Divorce Bill 2009). The Bill is stalled in Parliament, largely due to conflicts with religious and customary interests (Justice, Law, and Order Sector, personal communication). Passing this legislation would offer critical protections to child brides and girls at

16 Widow inheritance is a common practice in sub-Saharan Africa wherein a man (usually, but not required to be, a relative of the deceased) assumes responsibility for the social and economic support of a widow upon the death of her husband. Widow inheritance has been linked to the spread of HIV (Agot et al. 2010). 
risk of child marriage, especially girls in rural areas, girls living in poverty, and girls who have received only primary or no education.

\section{Sexual and reproductive health services}

\section{Relevant indicators in AGI}

- Ever given birth/currently pregnant

- High-risk sex: before age 15; multiple/ non-regular partners

The National Youth Policy and Adolescent Health Policy recognize the right to health and differentiate the health needs of adolescents from those of young children, adults, and the elderly. The Adolescent Health Policy advocates for young people's rights to health education, information and care, and emphasizes anti-discrimination and service availability at all levels. The National Population Policy's Action Plan calls for the development of a rights-based approach to reproductive health services. Ugandan policy does not require women to obtain spousal consent before obtaining reproductive services, and there are no legal restrictions on contraceptive access (Center for Reproductive Rights 2011). Verbal or written consent is not required from a parent or guardian before a minor client can be given family planning services.

\section{Youth-friendly services}

Strengthening youth-friendly sexual and reproductive health services is a priority in Uganda's population and development policy (National Population Policy Action Plan 2011-2015, National Policy Guidelines and Service Standards for Reproductive Health, National Youth Policy.) It is the first component listed in the strategic framework for Youth and Health in the revised National Youth Policy. The National Population Policy includes metrics such as: (1) establishing a policy on the implementation of youth-friendly sexual and reproductive health services (YFS), and (2) tracking the number of adolescent sexual and reproductive health personnel trained, the number of "YFS corners" established and functional, and the number of youth reached with YFS (Ministry of Finance, Planning and Economic Development 2010). Activities are designated to implementing partners including the Ministry of Gender, Ministry of Education, and other development agencies.

The Adolescent Health Policy calls for a review of existing legal, medical, and social barriers to accessing information and health care in order to facilitate uptake of adolescent health services (Ministry of Health 2004). The government provides free adolescent and maternal health services
(Health Sector Strategic Plan III (HSSP III)), and seeks to create supportive services for adolescents ages 10-24 across the spectrum of reproductive health needs (National Policy Guidelines and Services Standards for Reproductive Health). Areas targeted for improvement include family planning; emergency contraception; maternal care; STI/HIV/ AIDS testing and care; protection against harmful traditional practices; and information, education and communication (IEC) activities with parents/ guardians, service providers, school teachers, NGOs, religious bodies, high-risk male groups, and community leaders on sex, life skills, substance abuse, nutrition and hygiene, etc. (Ministry of Health 2001).

Despite considerable written policy, the HSSP III notes that "adolescent sexual and reproductive health services are limited and they do not address the needs of adolescents" (Ministry of Health 2010). As of 2007, according to a Ministry of Health service provision assessment, only five percent of facilities were providing youth-friendly services (Ministry of Gender, Labour, and Social Development 2012). Service availability is far outstripped by demand, and access where services do exist is inequitable. The HSSP calls for an increase in the proportion of health facilities providing adolescent-friendly services to 75 percent, and integration of adolescent sexual and reproductive health in school health programs. The Ministry of Health's Division of Reproductive Health carries out implementation of the HSSP III and is responsible for providing coordination and technical support to District Health Services, CSOs, and health care providers at delivery points within the district. Stronger implementation at the local level will be necessary to improve availability, accessibility, and appropriateness of service delivery for adolescent populations.

The gap between policy and action puts girls in particular at risk for negative sexual and reproductive health outcomes. Roughly 12 percent of girls ages 15-19 in Uganda report having engaged in high-risk sex (UDHS 2011). According to the 2011 DHS, 13.4 percent of girls report that they currently use a modern method of contraception, compared to 31.9 percent of boys. Half of boys and 27.5 percent of girls report having used a condom at last sex. Adolescent girls in the poorest quintile are least likely to have used a condom at last sex or to be currently using a modern method of contraception. Adolescent girls ages 15-19 also report lower levels of HIV knowledge than boys. Girls in both the West Nile and North regions have more limited HIV knowledge than boys in any region (Uganda AIDS Indicator Survey 2011). These data point to regional and socioeconomic variables that can guide more focused policy-making for sexual and reproductive health service provision. 


\begin{abstract}
Abortion
Abortion is legal in cases where the woman's life or her physical or mental health is in danger, or in cases of fetal abnormalities not compatible with survival outside the uterus. The Ministry of Health's 2001 National Training Curriculum for Health Workers on Adolescent Health and Development states that providers can offer referral for abortion "if appropriate and possible" in the case of rape, incest, and defilement (Center for Reproductive Rights 2011), and the National Policy Guidelines and Service Standards for Sexual and Reproductive Health and Rights grants access to termination of pregnancy in cases of sexual violence or if the woman is HIV-positive. For the most part, however, Uganda's abortion policies are vague and inconsistently implemented (Guttmacher Institute 2013).
\end{abstract}

\section{HIV prevention and treatment}

The Ministry of Health, Ministry of Gender, Labor and Social Development, and Ministry of Education and Sports have ample policy and training documents covering HIV prevention and care. Some of these policy frameworks directly address adolescents or youth. HIV care and support services take a pediatric or adult orientation, though, and the needs of HIV-positive adolescents are not sufficiently addressed (Obare, Birungi, and Kavuma 2011). The National HIV/AIDS Strategic Plan, the Ministry of Health's comprehensive HIV prevention and treatment plan, states that women and girls are the most affected by the epidemic but the least served. The plan focuses on vulnerable groups and outlines resource allocation and a results framework for priority populations including female sex workers, internally displaced persons, schoolteachers, and youth (UAC 2007). The Uganda Policy for the Reduction of Maternal to Child Transmission acknowledges that girls ages 15 and older constitute a large share of the policy's target population, but does not make specific provisions to address their needs. The National Policy Guidelines for HIV Counseling and Testing addresses adolescents directly in one section, stating that those individuals who have attained the legal age of majority (18 years) can consent to voluntary counseling and testing (VCT), and children under 12 years of age can consent with approval of a parent or guardian. For children without a parent or guardian, the head of the institution or adult responsible for the child may give approval. Counselors are not obligated to release test results to the individuals who gave consent for testing (Ministry of Health 2005). The Ministry of Education's Education and Sports Sector National Policy Guidelines on HIV/AIDS outlines objectives for incorporating adolescent sexual and reproductive health and HIV prevention into education and sports programs.

\section{Stronger}

implementation at the local level will be necessary to improve availability, accessibility, and appropriateness of service delivery for adolescent populations.

\author{
5.5 Review of policy areas \\ not covered by the AGI
}

Technical constraints detailed in prior chapters of this report limited the indicators available for inclusion in the AGI. Several key policy areas outside the parameters of the index were highlighted in research and discussions with key informants (Table 51). These policy areas are critical to adolescent development and merit discussion in this policy review.

\section{Gender-based violence and sexual exploitation}

Gender inclusiveness and equity-including the elimination of gender discrimination and violence-are core principles of the National Youth Policy. The policy promises the right to protection from sexual exploitation and abuse, and includes marginalized populations such as out-of-school youth, female youth, domestic servants/helpers, and sex workers as priority target groups. The new National Youth Policy will include an action plan to realize these priorities. The National Population Policy \& Action Plan sets targets for the elimination of gender-based violence and promotes awareness among men, women, and communities of their roles and responsibilities in sexual and reproductive health and rights. Uganda also has a National Gender Policy and National Action Plan on Women to promote gender sensitivity across sectors and public and private interventions to protect reproductive rights and ensure freedom from violence. 
Rape is a criminal offense in Uganda. Still, rape is common and enforcement of the law is weak. Defilement, or sexual intercourse with a minor (under the age of 18), is prohibited by the Penal Code Act. Its 2007 amendment includes protections against 'aggravated defilement'-particularly damaging sexual offenses such as those perpetrated by a serial offender, an individual infected with HIV, a legal guardian or teacher, or offenses against a child below 14 years of age or a person with a disability (Republic of Uganda 2007b). Parliament enacted the Domestic Violence Act in 2010 that penalizes acts of cruelty within the home and recognizes for the first time spousal rape as a crime. The Act also provides the first protective measures for abused women in Ugandan law (OECD Development Centre n.d.). The pending Domestic Relations Bill would expand the definition of punishable domestic offenses to include physical, sexual, emotional, verbal, psychological, and economic violence and harassment. The Domestic Relations Bill and Marriage and Divorce Act would recognize the right to refuse sexual relations within marriage and punish offenses of adultery and marital rape. A National Plan of Action on Child Sexual Abuse and Exploitation, in draft form, would coordinate national and local actors and interventions for victims of-and children at risk for-sexual abuse and exploitation. Protections against the sexual abuse of a child would be increased under a pending Sexual Offenses Bill (2010) (Uganda Youth Development Link 2011). While such statutory efforts are critical, permissive attitudes toward interpersonal violence and husbands' rights will require attention beyond the legislative sphere (OECD Development Centre n.d.).

\section{TABLE 51}

\section{ADDITIONAL POLICIES REVIEWED: GENDER-BASED VIOLENCE AND SEXUAL EXPLOITATION, PARTICIPATION, EMPLOYMENT AND ENTREPRENEURSHIP, AND PROPERTY RIGHTS}

\begin{tabular}{|c|c|}
\hline CATEGORY & POLICY \\
\hline $\begin{array}{l}\text { Gender-based violence and } \\
\text { sexual exploitation }\end{array}$ & $\begin{array}{l}\text { - National Youth Policy } \\
\text { - National Population Policy \& Action Plan } \\
\text { - Gender Policy } \\
\text { - National Action Plan on Women } \\
\text { - Penal Code Act } \\
\text { - Domestic Violence Act } \\
\text { - National Action Plan on Child Sexual Abuse and Exploitation (draft) } \\
\text { - Sexual Offenses Bill } \\
\text { - Adolescent Health Policy } \\
\text { - Female Genital Mutilation Act } \\
\text { - Trafficking in Persons Act }\end{array}$ \\
\hline Participation & $\begin{array}{l}\text { - Constitution of the Republic of Uganda } \\
\text { - Youth Council Act and Amendment Acts }\end{array}$ \\
\hline $\begin{array}{l}\text { Employment and } \\
\text { entrepreneurship }\end{array}$ & $\begin{array}{l}\text { - Constitution of the Republic of Uganda } \\
\text { - National Youth Policy } \\
\text { - Children's Act } \\
\text { - National Child Labour Policy } \\
\text { - National Policy on HIV/AIDS and the World of Work } \\
\text { - Employment Act } \\
\text { - National Action Plan on Women } \\
\text { - Business, Technical, and Vocational Education and Training Act } \\
\text { - National Population Policy for Social Transformation and Sustainable Development } \\
\text { - National Agriculture Advisory Services } \\
\text { - Youth Venture Capital Fund }\end{array}$ \\
\hline Property rights & $\begin{array}{l}\text { - Land Act } \\
\text { - Domestic Violence Act } \\
\text { - Domestic Relations Bill }\end{array}$ \\
\hline
\end{tabular}


A core objective of the National Adolescent Health Policy is "to provide legal and social protections of young people especially the girl child against harmful traditional practices and all forms of abuse including sexual abuse, exploitation, trafficking and violence." The policy includes strategies for advocacy, behavior change communication, training, resource mobilization, coordination, and development of adolescent-friendly services (Ministry of Health 2004). In 2009, Parliament passed the Female Genital Mutilation Act, criminalizing the practice with a penalty of up to 10 years' imprisonment. The President, however, has not yet given his assent to the bill (OECD Development Centre n.d.). The 2009 Trafficking in Persons Act, along with numerous international conventions that Uganda has ratified, addresses the issue of child trafficking and other forms of commercial sexual exploitation (Uganda Youth Development Link 2011).

While gender-based violence and sexual exploitation are not covered by an indicator in the AGI, extensive research and consultation were carried out on this topic given the centrality of the issue to adolescent girls' well-being in the African context. The research team decided that discussion of sexual and reproductive health policy in the following regional analysis would be incomplete without exploring this priority area, and that a rights-based approach to preventing child marriage, early childbearing, and other fundamental violations merited assessment across the region. Gender-based violence and sexual exploitation are thus included in the topics assessed in section 5.7 of this report.

\section{Participation}

Young people in Uganda are afforded national and local representation by their peers through the National Youth Council Act and Youth Council (Amendment) Acts. The Constitution of Uganda's affirmative action clause guarantees representation of marginalized groups including youth, and was used to allocate representation of five Youth Members of Parliament in the national assembly and two Youth Councillors on district local councils (National Youth Council Act 2006). Youth Council structures extend through local units in the country, enabling young people to participate in decisionmaking at all levels of government. Despite these mechanisms for participation, the International Youth Foundation's 2011 YouthMap survey found that "youth reported feeling marginalized and manipulated by their political leadership; dismissed by their elders; and ill-served by the programs designed to serve them" (International Youth Foundation 2011).

\section{Employment and entrepreneurship}

\section{Child labor}

Child labor is addressed in numerous policy instruments that include protections against harmful or exploitative employment-such as the Constitution, the Children's Act, the Employment Act, the National Child Labour Policy (2006), and the National Policy on HIV/AIDS and the World of Work. Children under age 12 are prohibited from employment unless it is light work approved by statutory order (Employment Act 2006). However, policies and laws are not harmonized and set varied ages to define child labor (e.g. 14 according to the Child Labour Policy, 16 by the Constitution). Some districts have established child labor committees for policy implementation at the local level, but functionality of these groups is reportedly limited (Uganda Youth Development Link 2011).

\section{Youth employment}

According to the revised National Youth Policy, all youth (ages 15-35) have the right to gainful employment, protection from economic exploitation, and protection from work that is likely to be hazardous, interfere with their education, or be harmful to their health or holistic development. Supporting young people's ability to realize these rights is increasingly critical as unemployment emerges as a top policy issue. With over three-quarters of its population under 30, Uganda has the highest youth unemployment rate in sub-Saharan Africa (International Youth Foundation 2011). Persistent inability to find work can lead to economic and social exclusion and increase the risk of exploitation. Adolescents who are both out of school and not working face higher risk for negative sexual and reproductive health outcomes than their counterparts engaged in either schooling or the workforce.

For both sexes, urban dwellers are more likely than rural to be neither working nor in school. This is particularly important given trends in rural-to-urban migration. Girls often migrate to cities out of desire for financial independence, and once settled in an urban area become engaged in exploitative employment where they face sexual harassment, health risks, and minimal compensation. With limited work opportunities in increasingly crowded cities, girls are often able to find only low-paid casual labor, odd jobs, engage in bar work or domestic work where bosses have little to no accountability for payment and fair treatment, or resort to exploitative labor such sex work (Erulkar et al. 2004). 
The Government of Uganda has made youth employment a central priority. The pairing of Uganda's large underemployed youth population and the country's anticipated expansion in several key economic sectors creates an important opportunity to build the workforce and capitalize on potential for economic growth. According to stakeholders at the National Planning Authority (NPA), Uganda's development plans are increasingly focused on improving the skills of the young population and generating gainful employment in priority sectors such as tourism, oil and gas, agro-processing, mining, and off-shore manufacturing (National Planning Authority, personal communication). Stakeholders discussed the need to revise educational curricula to incorporate more practical skills aligned with market opportunities and offer entrepreneurship training-both for economic development and as a strategy to alleviate vulnerability:

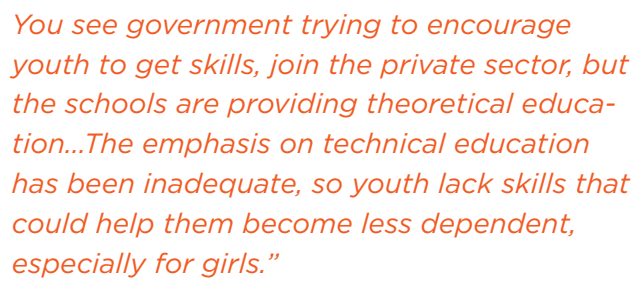

Toward these objectives, national policies and programs seek to improve adolescents' prospects for decent work by creating relevant training opportunities; providing access to capital, markets, and income-generating opportunities for women and youth; and instituting protections to prevent exploitative or forced labor (National Youth Policy, National Population Policy). National development strategies stress vocational training in key sectors and at all levels of education, and creation of BTVET institutions. However, the BTVET Act (2008) discussed previously is underfunded, and lack of training facilities, equipment shortages, and the high cost of inputs block students' entry into the labor market (Youth Leaders Think Tank 2011).

The revised National Youth Policy for 2011-2016 stresses youth-led enterprise as a vehicle for employment creation and calls for development of a national youth employment policy, increased linkages between the private sector and training institutions, and educational reform focused on market-relevant skills development, apprenticeships, and entrepreneurship training. The National Employment Plan stresses developing a market-oriented agricultural sector, and the National Agricultural Advisory Services (NAADS) - a government body charged with developing an agricultural service delivery system targeting poor subsistence farmers-has new provisions targeting women and youth (International Youth Foundation 2011).

While girls' economic rights are recognized in policies such as the National Action Plan on Women and the National Population Policy for Social Transformation and Sustainable Development, value statements and strategic objectives have not been translated into change on the ground. Ineffective implementation, discriminatory cultural norms, and cumbersome beneficiary requirements likely limit the degree to which mechanisms such as a Youth Trust Fund (which the new National Youth Policy advocates) and the Youth Venture Capital Fund (Box 5) will benefit adolescent girls in practice. Girls are, in general, at higher risk for financial depen-

\section{BOX 5}

\section{THE YOUTH VENTURE CAPITAL FUND}

The Youth Venture Capital Fund-sponsored by the Government of Uganda, DCFU Bank, Stanbic Bank, and Centenary Bank-pairs skills development with access to capital and markets to lend venture capital to viable projects proposed by young entrepreneurs and to enable the young people to benefit from associated mentoring services from the participating banks (Ministry of Finance et al. n.d.).

The Fund is a three-pronged approach to youth employment generation including:

1. Training-US\$3 billion over one year for training youth in entrepreneurship skills.

2. Capital-venture capital available for eligible youth to access through partner banks.

3. Markets-resources allocated to create worker spaces in urban areas to organize youth entrepreneurs; specialized markets will be created where youth can meet, learn and practice a trade, and sell their product. 
dence and have specific needs for accessing capital, savings, and productive employment. According to the DHS, 11 percent of girls in Uganda ages 15-19 are neither working nor in school, compared to 2 percent of boys. These disparities are even more exaggerated in particular regions: in East Central, Kampala, Central 1, and Central 2, 15-20 percent of girls are neither working nor in school, compared to 0-3 percent of boys (UDHS 2006).

Policies do not contain focused provisions that address the socioeconomic barriers that disproportionately affect adolescent girls. For example, the Venture Capital Fund only supports business ventures owned by "eligible youth entrepreneurs" between 18 and 35 years of age and, as a result, adolescents are almost entirely excluded as beneficiaries. The Fund has stringent eligibility requirements, follows standard commercial loan procedures, and does not make special provisions by sex (Ministry of Finance 2012). One stakeholder consulted for this analysis felt that affirmative action should be instituted to ensure that resources are allocated to girls. Therefore, while the Fund may serve as an incentive for entrepreneurship among an underemployed youth population, it seems unlikely to reach the poorest, most vulnerable adolescent girls. A later section includes recommendations for specific policies and innovative programs to build girls' economic and financial assets.

\section{Property rights}

Uganda claims nearly half of the arable land in East Africa, and agriculture is the centerpiece of the country's labor market. About 80 percent of the total population works in agriculture, 60 percent of which are youth (International Youth Foundation 2011). However, customary law and discriminatory cultural practices block women and girls from participating fully in this sector through access to land ownership and administration. The topic of property rights is legislatively complex. Provisions are set-often with minimal harmonization-under land title, marriage and divorce, and constitutional law (Knox, Duvvury, and Milici 2007).

Uganda has made substantial progress in building a progressive body of constitutional and statutory law to recognize and protect women's property rights and inheritance (Knox et al. 2007). The Constitution theoretically recognizes the rights of women to administer property without their husbands' consent, but realizing this provision requires statutory specificity and implementation efficiency that are lacking in practice. The 1998 Land Act governs land tenure, administration, and ownership, and includes protective clauses for women-for example, prohibiting decisions pertaining to cus- tomary land that deny women access, ownership, or occupation. The law is considered particularly progressive because it contains a consent clause that requires prior written consent of both spouses in transactions for land sale or transfer (Knox, Duvvury, and Milici 2007). However, decision-making powers in land administration are still typically granted to men because the law does not include an express co-ownership clause for land holdings (OECD Development Centre n.d.). The Domestic Violence Act prevents the denial of rights to property separately or jointly owned by the victim, including household rent and necessities for the victim and children.

Despite progressive policies, in a recent survey led by the International Youth Foundation, Uganda's Center for Basic Research, and FHI 360, "female youth reported having no rights or being denied those rights that they do have" (International Youth Foundation 2011). The Ugandan government should seek to harmonize legislation governing women's access to property, with particular attention to how customary and religious laws affect implementation (Knox, Duvvury, and Milici 2007). Pending legislation on domestic and marital relations would protect spousal property rights prior to, during, and following marriage, and could make existing property law more proactive in terms of women's ownership and inheritance (OECD Development Centre n.d.).

\subsection{Barriers to policy implementation}

\author{
We have one of the best legal regimes \\ in Africa on paper, but implementation is \\ the problem. \\ - MINISTRY REPRESENTATIVE
}

Uganda has a solid policy base to protect and promote youth livelihoods. While policies could more explicitly target adolescent girls, the government has set priorities and targets to empower youth socially and economically-most prominently through the National Youth Policy, the Adolescent Health Policy, and the inclusion of youth in population and development policy. However, written policy has not been accompanied by sufficient resource allocation or coordination among implementing structures. Policy advances are stalled by funding deficiencies, bureaucratic delays, and limited dissemination among stakeholders (Obare et al. 2011). Chronic implementation failure prevents vulnerable young people from benefiting from policies designed explicitly to address them. Reforms to improve implementation are reportedly prioritized in the country's third Strategic and 
Investment Plan, with the goals of (1) enhancing the legal, policy, and regulatory framework; (2) enhancing access to legal services for the vulnerable; and (3) enhancing accountability and human rights observation (Justice, Law and Order Sector, personal communication).

\section{Dissemination and enforcement}

Multiple stakeholders discussed lack of policy dissemination at the local level as a primary implementation challenge. Paucity of buy-in and awareness, particularly from community leaders, is a critical point given the role of customary and religious law and influence of local councils on how policies play out on the ground. After policies launch, uptake at the district and subdistrict levels is generally low. Village- and community-level organizations often operate unaware of the instruments in place to guide their work, and young people are not aware of or empowered to exercise the rights they are afforded by policy.

The Ministries of Gender and Health try to disseminate information locally through district population and youth officers or village health teams. However, staffing levels are quite low and imbalanced across districts, and these entities often are able to provide only limited coverage. Youth in school are easier to reach. The Ministry of Health pairs with the Ministry of Education to disseminate and implement their initiatives to adolescents through schoolteachers. The Ministry of Gender plans to engage young people in peer-to-peer dissemination of the revised youth policy in schools (Ministry of Gender, personal communication). However, targeting only in-school youth neglects more vulnerable populations, and ministries need to work more effectively with youth councils, civil society, and community- and faith-based organizations to reach youth who are not in school.

The original National Youth Policy was developed without an action plan to guide dissemination and implementation. The new version of this policy includes coordination structures and a cost-assessed action plan to facilitate dissemination by government partners at the local level. A representative from the Ministry of Gender indicated that committing to follow-up on the action plan and addressing how to effectively disseminate information to girls at the grassroots level are central priorities in the policy's revision-stressing that attention is on "real dissemination, not distribution of copies of the policy." The plan will have a communications and advocacy strategy to employ social media for dissemination, and the policy will be translated into local languages where possible to reach communities where girls are not likely to speak or read English. To address varying literacy levels,

\section{BOX 6}

\section{IMPLEMENTATION CHALLENGES}

Dissemination and enforcement

Policy dissemination is a problem. They just lie on the bookshelves and collect dust.

$$
\text { -PROGRAM REPRESENTATIVE }
$$

We have so many policies, but you go on the ground and they have not reached the community. They end in our offices.

$$
\text { -MINISTRY REPRESENTATIVE }
$$

\section{Coordination}

The whole system is getting more and more fragmented. -DONOR REPRESENTATIVE

There are so many policies and they are not harmonized. -MINISTRY REPRESENTATIVE

I don't see the connection between policy development at national level and formulation at district level. Districts have policies and by-laws, but we don't see the coordination between levels. There is a feedback mechanism lacking for communication at all levels. -PROGRAM REPRESENTATIVE

\section{Social sector funding}

There is simply no funding and so there can be no implementation.

-MINISTRY REPRESENTATIVE

We need to fix infrastructure and training to mitigate youth vulnerabilities; the answer lies in the use of government revenue and where we allocate it. Government and donors need to get serious and need to compel government to spend money on priority sectors.

-POLICY RESEARCHER

Data collection and management

We need strong databases to capture info by district, region, and by cases, which we are not able to do so much now with current systems. We need to harmonize systems so we don't need to go to different ministries to get data...we need a central, harmonized database with data by age group and geographic location.

-MINISTRY REPRESENTATIVE 
the government will issue an abridged version of the policy and plans to disseminate it through TV and radio broadcasts (Ministry of Gender, personal communication).

Despite the breadth and depth of legislation in Uganda, law enforcement is often limited or absent. Provisions setting the age of consent for sexual activity and marriage at 18 and prohibiting female genital mutilation/cutting are weakly enforced and continue in settings where permissive cultural attitudes dominate under-resourced government systems. The Prevention of Trafficking in Persons Act, passed in 2009 to prevent commercial sexual exploitation, has not yet been operationalized for enforcement because of lack of coordination between the Ministries of Justice and Internal Affairs. Bodies established to enforce the laws designed to protect children and adolescents and are largely ineffective. Task forces, such as the inter-ministerial Anti-Child Sacrifice/ Human Trafficking Task Force developed under the Uganda Police, lack resources to convene and exist often in name only (Uganda Youth Development Link 2011). The Justice, Law, and Order Sector reports that it is focusing on reviewing, simplifying, and harmonizing laws for better enforcement and public awareness; conducting civic education in communities; and allocating resources to build the capacity of and empower local council courts to execute laws at the local level (Justice, Law and Order Sector, personal communication).

\section{Coordination}

Government bodies are not strategically or operationally harmonized. Disconnects between planning and budgeting exacerbate resource deficiencies and limit policy impact. For example, targets and indicators set in guiding national planning documents are not reflected in budget line items. Misalignment between the outputs of various ministries reflects a lack of consultation and coordination at the national level.

The National Council for Children (NCC), established in 1996 by Act of Parliament, is mandated to ensure proper coordination, monitoring and evaluation of activities addressing child survival, protection, development, and participation. The NCC is responsible for coordinating actors across Uganda, assisting with the planning and coordination of policies and programs, compiling reports on children's issues, serving as a clearinghouse for disseminating research findings, and communicating priorities to Parliament. An interministerial council provides overall coordination. However, the Uganda Youth Development Link's extensive study on commercial sexual exploitation of children in Uganda found that the NCC has yet to fully realize its mandate because of limited funding and staff capacity, and the majority of its work is duplicated by parallel agencies (Uganda Youth Development Link 2011).

\section{Social sector funding}

Uganda is below international benchmarks for social sector spending, and there is insufficient funding for individual line ministries to allocate resources across priority interventions. Uganda's GDP grew 6.7 percent over FY2010/11 (Ministry of Finance, Planning and Economic Development 2011). Social spending, however, decreased as both a percentage of GDP and in real terms. Taking into account population growth, the decrease in per beneficiary spending is even more drastic (UNICEF, personal communication). Adolescents are over-represented in poor populations as a result of high fertility rates and are substantially affected by low social spending.

Uganda misses global targets in key sectors for adolescent well-being, spending 5.6 percent of government expenditure on the health sector (global target is set at 15 percent of government expenditure), 15.3 percent of government expenditure on education (global target is 20 percent of government expenditure), 0.3 percent of GDP on water and sanitation (global target is 1.5 percent of GDP), and less than 0.1 percent of GDP on social protection (global target is 4.5 percent) ( $\mathrm{Ha}$ gen-Zanker and McCord 2010). Out of these scarce resources, minimal funding reaches the districts or subcounties where the bulk of implementation is carried out. Decentralized administrative structures and bureaucratic inefficiencies result in understaffed services and under-skilled personnel who are unable to meet client demand. District officers charged with carrying out policies are overtaxed and unable to track policy dissemination and coordination. As one stakeholder commented regarding personnel gaps, "implementation is the biggest problem we have."

The Ministry of Gender, Labour and Social Development, the central agency responsible for adolescent girls, is particularly under-resourced. The Ministry operates through two directorates: Gender, Culture and Community Development and Labour, Employment and Industrial Relations. Within the Directorate of Gender, Culture and Community Development are four departments: Youth and Children; Poverty Eradication, Economic and Civic Rights; Disability and Elderly; and Gender, Culture and Community Development. The Ministry operates on a budget of roughly $\$ 16$ million USD to cover the two directorates and their individual departments (Ministry of Finance, personal communication). Much of this funding is used to cover overhead, and minimal funds remain for service delivery. Further, a substantial portion of the Ministry's scarce resources for the Department of Youth and Children Affairs is allocated to 
orphans and vulnerable children-with an emphasis on younger children and not on the needs and issues specific to adolescent populations.

According to the Forum for Women in Democracy (FOWODE), a nonprofit organization that works with the Parliamentary Budget Office to conduct gender audits of government policies and programs, underinvestment in health negatively affects service delivery for women in both rural and urban areas. The sector has made significant strides in addressing gender issues, but inadequate funding for reproductive health, non-communicable diseases, and medical personnel limits benefits realized from policy efforts (Forum for Women in Democracy 2010).

Funding for universal education initiatives is insufficient, with budget gaps at all levels detrimentally affecting school quality. The education system confronts both enrollment surges and facility and staff shortages. Capitation grants are insufficient to sustain schools at basic operating level and often arrive too late into the school year to prevent shut-down, interrupting teaching and management processes (Ministry of Education, personal communication). Chronic underfunding drives teacher absenteeism. Poor instruction quality, overcrowded facilities, and insufficient supplies lead to school dropout and grade repetition. The 2010 FOWODE gender budgeting analysis cited shortages in funding for science instruction, congestion in classrooms, absenteeism of teachers and pupils, and poor teacher pay and facilitation skills as critical gender issues in the education sector (Forum for Women in Democracy 2010).

\section{Data collection and management}

Uganda's weak registration systems and lack of centralized databases limit capacity to isolate, track, and reach vulnerable populations. Individual line ministries have systems for monitoring and evaluation. The Ministry of Gender, Labour and Social Development, for instance, maintains the Management Information System for Orphans and other Vulnerable Children (OVC-MIS) as a central hub for OVC-related data. However, there is minimal linkage of information systems across ministries and other government agencies. Incompatible data management systems mean missed opportunities for needs assessment and intervention design across the spectrum of adolescent development (education, health, employment, etc.). Creating robust data systems that gather information on young people by age group and location with interagency cross-referencing capabilities would help to identify vulnerabilities across key adolescent transitions and geographic hot spots, tailor more efficient and targeted policy, and track progress.

\subsection{Policy analysis: Regional assessment}

This section presents an overview of policies in four other countries in East and Southern Africa for a comparison of regional policymaking for adolescent girls. These countries were selected by the research team based on location of Population Council offices and staff (Ethiopia, Kenya, Zambia) to facilitate analysis, as well as the existence of girl-centered programs and projects in each country that could pair with policy intervention to create a more supportive climate for adolescent girls. In each country, policies were assessed in the areas included in the Adolescent Girls Multilevel Vulnerability Index (child protection, education, child marriage, and sexual and reproductive health services), as well as gender-based violence and sexual exploitation. Table 52 presents an overview of policies reviewed for the countries selected, and is followed by a summary of findings from the region.

Before we begin the policy review, it is helpful to revisit some of the demographic statistics presented earlier in this report to frame the "problem statements" that policy intervention should address.

\section{Uganda (DHS 2011)}

- $\mathbf{9 4 \%}$ of girls and $\mathbf{9 5 \%}$ of boys ages $10-14$ are enrolled in school. Enrollment for girls drops to only $\mathbf{5 8} \%$ for ages 15-19 and boys' enrollment drops to $\mathbf{7 3 \%}$.

- 98 girls are literate for every 100 adolescent boys ages $15-19$ (literacy rates $78 \%$ for girls and $80 \%$ for boys).

- $15 \%$ of girls are neither working nor in school, compared to only $2 \%$ of boys.

- $\mathbf{4 4 \%}$ of girls ages 15-19 report ever having had sex, compared to $\mathbf{3 5 \%}$ of boys. Of ever-married girls ages 15-19, 100\% report having ever had sex. Of never-married girls ages $15-19$, only $\mathbf{2 9 \%}$ report having ever had sex.

- Only $\mathbf{7 6 \%}$ of girls aged $15-19$ reported knowledge of condom use as an HIV prevention method.

- $10 \%$ of girls aged $20-24$ report being married by age $15 ; \mathbf{4 0} \%$ report being married by $\mathbf{1 8}$ (the legal age at marriage).

- $\mathbf{1 7 \%}$ of girls aged 15 to 19 have ever given birth. 


\section{Ethiopia (DHS 2011)}

- $\mathbf{5 5 \%}$ of girls and $\mathbf{5 8 \%}$ of boys ages $10-14$ are enrolled in school. Enrollment for girls drops to only 45\% for ages 15-19 (boys' enrollment stays the same). Enrollment across both age groups and sexes is markedly low.

- Only 69 girls are literate for every 100 adolescent boys ages 15-19 (literacy rates 51\% for girls and $74 \%$ for boys).

- $\mathbf{4 1 \%}$ of girls are neither working nor in school, compared to only $3 \%$ of boys.

- $\mathbf{2 7 \%}$ of girls ages 15-19 report ever having had sex, compared to $\mathbf{7 \%}$ of boys. Of ever-married girls ages $15-19$, $\mathbf{9 7 \%}$ report having ever had sex. Of never-married girls ages $15-19$, only $\mathbf{2} \%$ report having ever had sex-indicating that sex in Ethiopia occurs within the context of marriage.
- Only $\mathbf{5 3} \%$ of girls aged $15-19$ reported knowledge of condom use as an HIV prevention method.

- $\mathbf{2 4 \%}$ of girls aged 20-24 report being married by age $15 ; \mathbf{4 9 \%}$ report being married by $\mathbf{1 8}$ (the legal age at marriage).

- $\mathbf{1 2 \%}$ of girls aged 15 to 19 have had a child.

\section{Kenya (DHS 2009)}

- School enrollment for girls decreases from $\mathbf{9 6 \%}$ at ages $10-14$ to $\mathbf{7 1 \%}$ at ages $15-19$. Enrollment for boys decreases from $95 \%$ at ages $10-14$ to $\mathbf{8 2} \%$ at ages $15-19$. A $25 \%$ drop in girls' enrollment versus only a $13 \%$ drop for boys merits particular attention to the factors that cause school-leaving for girls at this age.

- $17 \%$ of girls are neither working nor in school, compared to only $3 \%$ of boys.

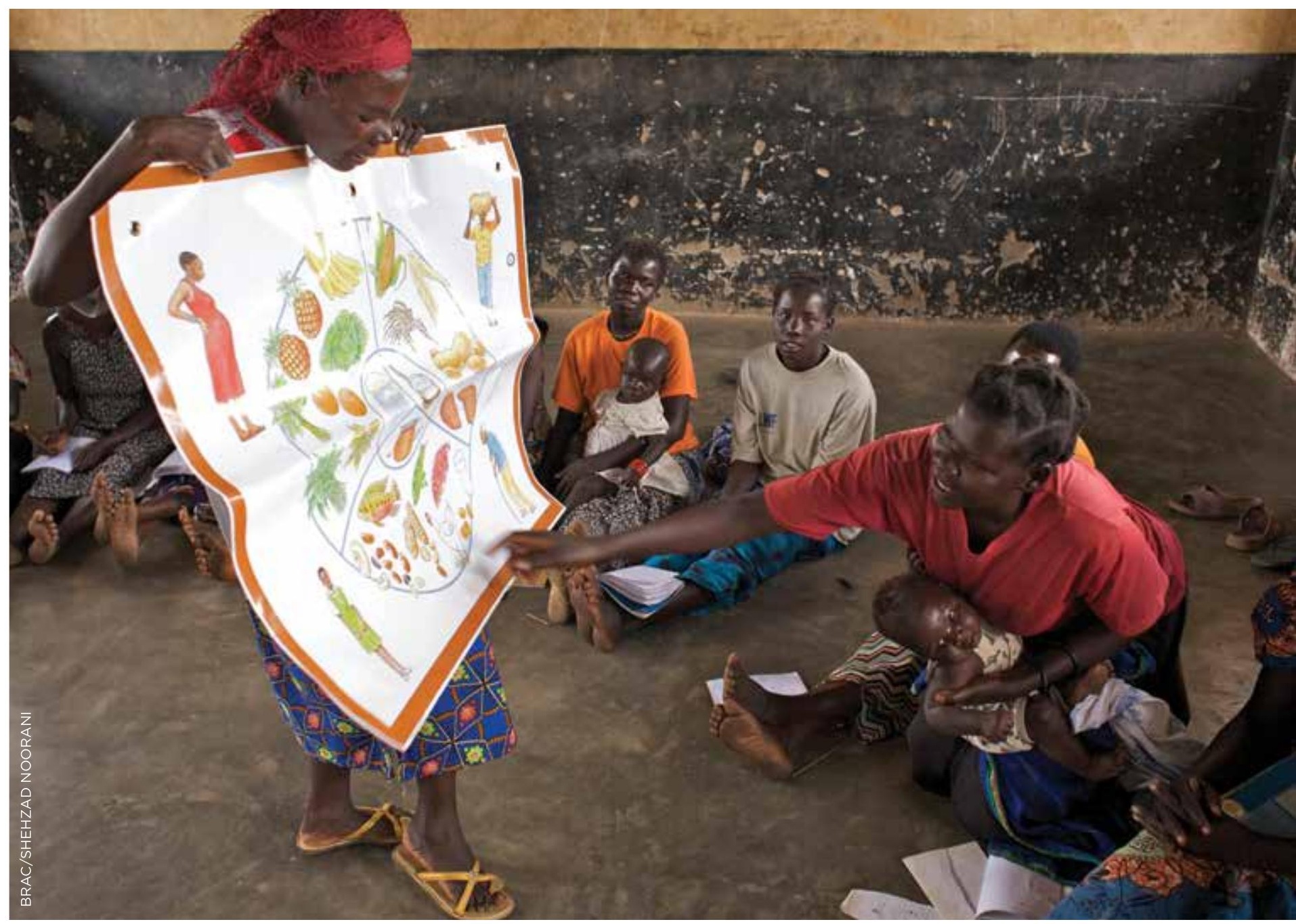

Young mothers gather at an Empowerment and Livelihood for Adolescents club in Uganda to learn more about proper nutrition. 
TABLE 52

LIST OF POLICIES BY COUNTRY

\begin{tabular}{|c|c|c|}
\hline POLICY AREA & INDEX INDICATORS & POLICIES \\
\hline \multicolumn{3}{|l|}{ Ethiopia } \\
\hline Child protection & $\begin{array}{l}\text { Not living with parents } \\
\text { No access to improved source of water } \\
\text { No access to improved sanitation }\end{array}$ & $\begin{array}{l}\text { - Constitution of the Federal Democratic Republic of } \\
\text { Ethiopia, Article } 36 \text { (1995) } \\
\text { - Family Code } \\
\text { - Labor Code }\end{array}$ \\
\hline Education & $\begin{array}{l}\text { No education or two or more years behind } \\
\text { grade for age } \\
\text { Lives in a community with higher rates of } \\
\text { illiteracy than regional average }\end{array}$ & $\begin{array}{l}\text { - Federal Constitution } \\
\text { - Education and Training Policy \& Strategy } \\
\text { - Education Sector Development Program }\end{array}$ \\
\hline Child marriage & $\begin{array}{l}\text { Currently married } \\
\text { Lives in a community with higher rates of } \\
\text { marriage before age } 18 \text { than the regional } \\
\text { average }\end{array}$ & $\begin{array}{l}\text { - Ethiopian Revised Family Code } \\
\text { - Criminal Code of the Federal Democratic Republic of } \\
\text { Ethiopia }\end{array}$ \\
\hline $\begin{array}{l}\text { Gender-based violence and } \\
\text { sexual exploitation }\end{array}$ & $N / A^{*}$ & $\begin{array}{l}\text { - Criminal Code } \\
\text { - Penal Code } \\
\text { - Family Code } \\
\text { - National Plan for Gender Equality } \\
\text { - National Policy for Women }\end{array}$ \\
\hline $\begin{array}{l}\text { Sexual and reproductive } \\
\text { health services }\end{array}$ & $\begin{array}{l}\text { High-risk sex: } \\
\text { - Sexual initiation before age } 15 \\
\text { - Multiple partners } \\
\text { - Non-regular partners }\end{array}$ & $\begin{array}{l}\text { - National Adolescent and Youth Reproductive Health Strategy } \\
\text { - National Reproductive Health Strategy } \\
\text { - Constructive Men's Engagement in Reproductive Health/HIV } \\
\text { - Criminal Code }\end{array}$ \\
\hline
\end{tabular}

\section{Kenya}

Child protection

Child protection

Education

Child marriage

Gender-based violence and sexual exploitation

Sexual and reproductive health services
Not living with parents

No access to improved source of water

No access to improved sanitation

No education or two or more years behind grade for age

Lives in a community with higher rates of illiteracy than the regional average

Currently married

Lives in a community with higher rates of marriage before age 18 than the regional average

N/A

High-risk sex:

- Sexual initiation before age 15

- Multiple partners

- Non-regular partners
- The Constitution of Kenya (2010)

- Children's Act

- Constitution of Kenya

- Ministry of Education Strategic Plan 2008-2012

- School Re-Entry Policy

- Children's Act

- Children's Act

- Marriage Act

- Hindu Marriage and Divorce Act

- Sexual Offences Act

- National Plan of Action for the Elimination of Female Genital Mutilation in Kenya

- Adolescent Reproductive Health and Development Policy

- National Guidelines for Provision of Adolescent YouthFriendly Services in Kenya

- National Youth Policy

- National Reproductive Health Strategy

- National Health Sector Strategic Plan

- Comprehensive National Health Policy Framework

- HIV/AIDS Prevention and Control Act

- Kenya National HIV/AIDS Strategic Plan

- Education Sector Policy on HIV and AIDS

* While gender-based violence (GBV) and sexual exploitation are not covered by an indicator in the AGI because of data limitations, extensive research and consultation were carried out on this topic given the centrality of the issue to adolescent girls' well-being in the African context. The research team decided that discussion of sexual and reproductive health policy would be incomplete without exploring this priority area, and that a rights-based approach to preventing child marriage, early childbearing, and other fundamental violations merited assessment across the region. GBV and sexual exploitation are therefore included in the regional assessment despite constraints in analytic framing for index construction. 


\begin{tabular}{|c|c|c|}
\hline POLICY AREA & INDEX INDICATORS & POLICIES \\
\hline \multicolumn{3}{|l|}{ Rwanda } \\
\hline Child protection & $\begin{array}{l}\text { Not living with parents } \\
\text { No access to improved source of water } \\
\text { No access to improved sanitation }\end{array}$ & $\begin{array}{l}\text { - Constitution of the Republic of Rwanda (2003) } \\
\text { - Integrated Child Rights Policy \& Strategic Plan } \\
\text { - National Policy for Family Promotion }\end{array}$ \\
\hline Education & $\begin{array}{l}\text { No education or two or more years behind } \\
\text { grade for age } \\
\text { Lives in a community with higher rates of } \\
\text { illiteracy than the regional average }\end{array}$ & $\begin{array}{l}\text { - Constitution of the Republic of Rwanda } \\
\text { - Nine Year Basic Education Policy } \\
\text { - Girls' Education Policy } \\
\text { - Strategic Plan for Girls' Education } \\
\text { - Integrated Child Rights Policy and Strategic Plan }\end{array}$ \\
\hline Child marriage & $\begin{array}{l}\text { Currently married } \\
\text { Lives in a community with higher rates of } \\
\text { marriage before age } 18 \text { than the regional } \\
\text { average }\end{array}$ & - Constitution of the Republic of Rwanda \\
\hline $\begin{array}{l}\text { Gender-based violence and } \\
\text { sexual exploitation }\end{array}$ & N/A & $\begin{array}{l}\text { - Legal Policy/Framework for Gender Equity } \\
\text { - National Gender Policy } \\
\text { - National Community Health Policy } \\
\text { - Integrated Child Rights Policy \& Strategic Plan }\end{array}$ \\
\hline $\begin{array}{l}\text { Sexual and reproductive } \\
\text { health services }\end{array}$ & $\begin{array}{l}\text { High-risk sex: } \\
\text { - Sexual initiation before age } 15 \\
\text { - Multiple partners } \\
\text { - Non-regular partners }\end{array}$ & $\begin{array}{l}\text { - National Reproductive Health Policy } \\
\text { - National Youth Policy } \\
\text { - National Family Planning Policy } \\
\text { - Health Sector Policy } \\
\text { - Integrated Child Rights Policy \& Strategic Plan }\end{array}$ \\
\hline
\end{tabular}

\section{Zambia}

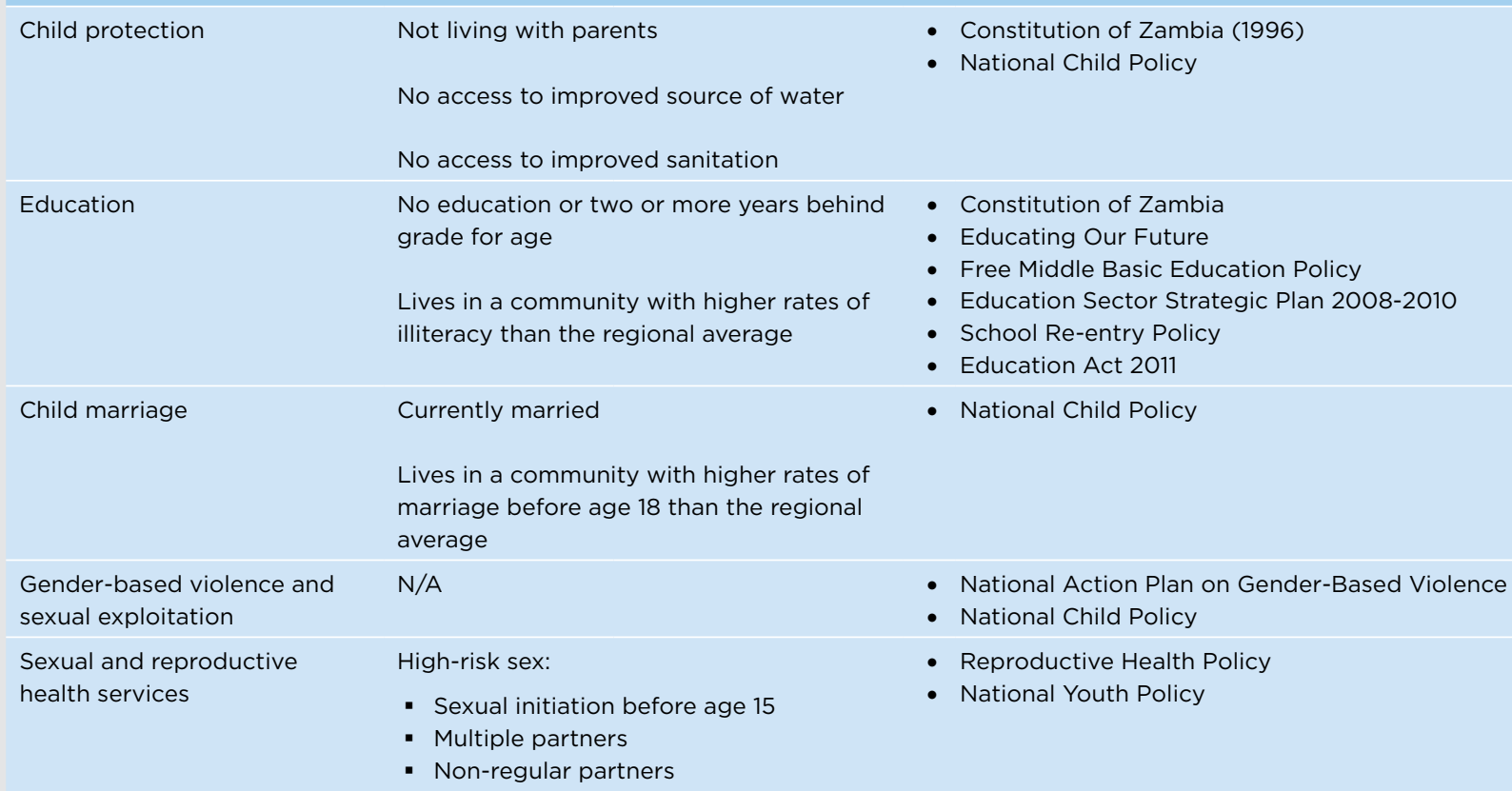


- $\mathbf{4 4 \%}$ of boys and $\mathbf{3 7 \%}$ of girls aged $15-19$ report ever having had sex. Of ever-married girls aged $15-19, \mathbf{1 0 0} \%$ report having ever had sex. Of never-married girls aged $15-19, \mathbf{2 7} \%$ report having ever had sex.

- $6 \%$ of girls aged $20-24$ report being married by age $15 ; \mathbf{2 6} \%$ report being married by age 18 (legal age at marriage is $\mathbf{1 6}$ ).

- $13 \%$ of girls aged 15 to 19 have had a child.

\section{Rwanda (DHS 2011)}

- $\mathbf{3 6 \%}$ of girls and $\mathbf{4 1 \%}$ of boys ages $15-19$ are enrolled in school (a drop from $87 \%$ and $85 \%$, respectively, for ages $10-14-$ the largest decrease across both sexes of any of the countries selected for analysis).

- $\mathbf{2 6 \%}$ of girls and $\mathbf{3 1 \%}$ of boys are neither working nor in school.

- $3 \%$ of boys and $12 \%$ of girls aged $15-19$ report ever having had sex. Of ever-married girls ages 15-19, 100\% report having ever had sex. Of never-married girls ages $15-19,9 \%$ report having ever had sex.

- $1 \%$ of girls aged 20-24 report being married by age $15 ; \mathbf{1 3} \%$ report being married by age 18 (legal age at marriage is 21).

- $\mathbf{3} \%$ of girls aged 15 to 19 have had a child.

\section{Zambia (DHS 2007)}

- $\mathbf{5 6 \%}$ of girls and $\mathbf{7 8 \%}$ of boys aged $15-19$ are currently enrolled in school (a drop from 90\% for both sexes for ages 10-14).

- 88 girls are literate for every 100 adolescent boys ages $15-19$ (literacy rates $75 \%$ for girls and $85 \%$ for boys).

- $33 \%$ of girls and $16 \%$ of boys are neither working nor in school.

- $\mathbf{4 5 \%}$ of boys and $\mathbf{4 8 \%}$ of girls aged 15-19 report ever having had sex. Of ever-married girls ages $15-19,100 \%$ report having ever had sex. Of never-married girls aged $15-19, \mathbf{3 5} \%$ report having ever had sex.

- $\mathbf{6 8 \%}$ of girls aged 15-19 reported knowledge of condom use as an HIV prevention method.

- $9 \%$ of girls aged 20-24 report being married by age $15 ; \mathbf{4 2} \%$ report being married by age 18 (legal age at marriage is $\mathbf{2 1}$ ).

- $\mathbf{2 0} \%$ of girls aged 15 to 19 have had a child.

\subsection{A note on national youth policies}

Nine of the 23 countries in East and Southern Africa have national youth policies. Ten additional countries have a policy currently under revision (Demokratie and Dialog 2013). The four countries selected for regional analysis here have all enacted national youth policies. These policies focus largely on involving youth in economic development (e.g. emphasis on business skills and entrepreneurship training) and aligning priorities for youth with national development plans and goals. Each defines the age group for "youth" differently: Ethiopia National Youth Policy (2004), ages 15-29; Kenya National Youth Policy (2007), ages 15-30; Republic of Rwanda National Youth Policy (2005), ages 14-35; Zambia National Youth Policy (1994), ages 15-25 (Demokratie and Dialog 2013). None of these definitions includes younger adolescents ages 10 to 13 . The youth policies cover broad age spans and, for the most part, do not isolate issues specific to adolescents girls-often missing the youngest and most vulnerable girls.

\section{Child protection}

Child protection is one of the more robust policy areas across the countries selected for regional analysis. Most countries have national child protection policies that provide for the guardianship, protection, and rights of minors, as well as ministry departments and units dedicated to vulnerable children.

Children in Ethiopia are protected under Article 36 of the Constitution, which replicates many of the rights outlined in the Convention on the Rights of the Child (Ministry of Labor and Social Affairs 2005). The Family Code contains provisions for guardianship for the child's well-being and development, and protect rights of minors such as the right to earned wages and inheritances. The Family Code states that a minor is incapable of exercising the functions of a guardian except for the care of his or her own children (Federal Negarit Gazetta of FDRE 2000). The Labor Code prevents the economic exploitation of children (Government of the FDRE 1993). Abduction, maltreatment and neglect are dealt with under Ethiopia's Penal Law.

Kenya refined and consolidated the rights of children in Article 53 of its new Constitution (2010). This article explicitly binds the state to the provision of health care, education, nutrition, and shelter for all children and creates more stringent requirements for state action. The Children's Act safeguards the rights and welfare of children, including protections for non-discrimination; the rights to parental care, education, and health care; 
protection from child labor and armed conflict; right to a name and nationality; and provisions for disabled children. The Act also establishes the National Council for Children's Services and outlines regulations for guardianship, foster care, adoption, children's courts, and children's charities (The Children's Act 2007).

The Constitution of the Republic of Rwanda states that "every child is entitled to special measures of protection by his or her family, society and the State that are necessary, depending on the status of the child, under national and international law" (Republic of Rwanda 2003). The Integrated Child Rights Policy and its accompanying Strategic Plan, produced by the Ministry of Gender and Family Promotion in August of 2011, consolidates and harmonizes Rwandan policy for children including orphans and other vulnerable children, street children, child labor, etc. The Strategic Plan indicates that a body will be established to oversee implementation of the Integrated Child Rights Policy and calls for the review and coordination of child protection systems in the country (Ministry of Gender and Family Promotion 2011).

The Zambian Constitution (Part III, Section 24) guarantees all young people (under the age of 15 years) protection from exploitation from work or occupation "which would prejudice his health or education or interfere with his physical, mental or moral development," and from physical or mental neglect and all forms of cruelty (Republic of Zambia 1991). The Juveniles Act (Chapter 53 of the Laws of Zambia) covers all youth up to 19 years of age and provides statutory protections for their care and custody, as well as their interaction with the judicial system (Republic of Zambia 1996).

\section{Education}

The Constitutions of Ethiopia, Kenya, and Rwanda recognize the right of all citizens to education. The Zambian Constitution does not include education among its fundamental individual human rights and freedoms, but this right is expected to be included in a revised Constitution (Right to Education Project 2012). The Zambian government directs under Article 112 that "the State shall endeavor to provide equal and adequate educational opportunities in all fields and at all levels for all" (Republic of Zambia 1991), and its Education Act of 2011 identifies individuals' rights to early childhood, basic, and high school education (Right to Education Project 2012). Both Kenya and Zambia have policies for the re-entry of girls into school after pregnancy.

Ethiopia's Constitution eliminates tuition fees for grades 1-10 in the education system. The Education and Training Policy and the Education Sector
Development Plan operationalize state actions to provide quality public education, particularly in response to lack of teacher training and motivation, facilities, and instructional materials. The Education Sector Development Plan, launched in 1997, rolls out a 20-year action plan to achieve universal primary enrollment by 2015 and improve quality, equity, and efficiency at all educational levels. The plan emphasizes girls' education and primary education in underserved and rural areas (Center for the Study of International Cooperation in Education n.d.). In July 2011, the UN Committee on the Elimination of Discrimination Against Women recognized "measures taken by the State party to promote women's and girls' access to education, in particular in rural and pastoralist areas, such as: (a) The introduction of girls' scholarship programs and the supply to girls of education materials and uniforms, with the support of NGOs; (b) The introduction of girl-friendly schools as well as the construction of separate latrines for girls and boys in schools; (c) Providing incentives to parents in pastoralist areas who send their daughters to school; and (d) Training and taking affirmative action to raise the share of female teachers in primary and secondary schools to 50 percent and to increase the number of female college and university instructors" (United Nations 2011).

Kenya prioritizes girls' education in its Ministry of Education Strategic Plan, which aims to "ensure that all children, particularly girls, have access to and complete quality primary education; and eliminate gender disparities in primary and secondary education and achieve gender equity in education, with a focus to ensuring girls' full and equal access to, retention and achievement in basic quality education" (Ministry of Education 2007a). Strategic Objective Eighteen of the Plan is to enhance access to education for hard-to-reach children. Strategies to achieve this objective include expanding existing non-formal education programs, establishing a voucher system in the five poorest districts, completing and operationalizing the Non Formal Education (NFE) Policy, and expanding support to Non Formal Schools and Education Centers. Strategic Objective Twenty, to "deepen the mainstreaming of cross-cutting issues in education," mandates adherence to affirmative action in school re-admission of girls who have given birth, and calls for a strategy to operationalize Kenya's gender policy (Ministry of Education 2007). The Children's Act states that all children are entitled to free, basic, compulsory education, but Kenyan law does not set a minimum age for beginning or ending compulsory education (Melchiorre 2004).

The Government of Rwanda made primary education compulsory and free in public and government-subsidized schools (Article 35 of Organic 
Law No. 20/2003), and added an additional three years of free secondary education with the Nine Year Basic Education Policy in 2006. The Education Sector Strategic Plan (ESSP), part of the Long Term Strategy and Financing Framework to meet the Millennium Development Goals, charts plans for the education sector including expanding access to and quality of basic, post-primary, and early childhood education (Ministry of Gender and Family Promotion 2011). The Special Needs Education Policy (2007) and the ESSP for 2010-2015 set out strategies for ensuring access to meaningful educational services, facilities, and equipment for orphans, street children, children infected with or affected by HIV/AIDS, children heading households, disabled children, and students with special needs (Ministry of Gender and Family Promotion 2011). The Ministry of Education developed a Girls' Education Policy and Strategic Plan for Girls' Education to promote gender equality in education and training at all educational levels. The Ministry has a comprehensive implementation, monitoring, and evaluation plan for these policies and has instituted a Girls' Education Task Force to provide strategic leadership, promote collaboration, and manage execution of the policies (Ministry of Education n.d.)

The Zambian government, under the Educating Our Future policy, aims to provide all children with nine years of free basic education (Ministry of Education 1996). The Free Middle Basic Education Policy of 2002 abolished all user fees for grades 1-7, eliminated compulsory uniforms, and prohibits the denial of education to any child on the basis of cost. The policy is implemented through school grants and provision of educational facilities and materials. The most recent strategic plan reviewed for this analysis, the Education Sector Strategic Plan 2008-2010, outlines the Ministry of Education's priority activities for equity in education, including gender mainstreaming in curricula and materials, review of policies for gender bias, and a sector-wide gender analysis to recommend appropriate interventions (Ministry of Education 2007b). Core educational policy provisions for adolescent girls in Zambia include the school re-entry policy and affirmative action to address school dropout among girls at Grades 7 and 9 . The affirmative action policy allows girls to proceed to the next grade level with lower scores than boys to promote retention, given the range of factors pulling girls out of school. The Ministry of Education also implemented the Girl-Friendly Schools Initiative and the Go Girls Initiative to address issues of sexual violence and abuse in schools and improve safety and increase attendance for girls, but these programs reportedly have not been mainstreamed beyond basic schools (Melchiorre 2004).

\section{Child marriage}

The legal age of marriage in the countries selected ranges from age 16 in Kenya, to 18 in Ethiopia, to 21 in both Rwanda and Zambia.

Ethiopia's Family Code (revised) details provisions for legal marriage, including free consent of both spouses who have attained 18 years of age. A spouse who entered into marriage under the influence of violence can apply to the court for dissolution, but must act within six months of the violence occurring. The Family Code further specifies that spouses shall have "sexual relations normal in marriage unless these relations involve a risk of seriously prejudicing their health" (Federal Negarit Gazetta of FDRE 2000). Marriage before the legal age and marriage by abduction are criminalized in Ethiopia's Criminal Code.

Across the region, tensions between customary/religious law and statutory law are a primary barrier to preventing child marriage. Kenya's Children's Act prohibits the marriage of any child-therefore, any individual under age 18. The Marriage Act and the Hindu Marriage and Divorce Act, however, allow for marriage for girls at age 16 and at 18 for boys. In Islamic and some customary laws, a girl is marriageable after reaching puberty (Melchiorre 2004). In Rwanda, the Constitution states that "no person may be married without his or her free consent" (emphasis added). Child marriage occurs in Rwanda, though at rates lower than the other countries included in this analysis, despite this provision in the highest law governing the state.

Zambia's National Child Policy defines child marriage as a form of sexual exploitation and aims to harmonize statutory and customary laws on marriage. A draft Education Bill of 2010 included a penalty of twenty years' imprisonment for any person who married a student who was still a child at the time of the union (National Assembly 2010).

\section{Gender-based violence and sexual exploitation}

In 1993, the Government of Ethiopia enacted the National Policy on Women to institutionalize the economic, social, and political rights of women, mainstream gender across programs and policies, and confront issues of harmful traditional and discriminatory practices against women (Ethiopian Embassy 1993). Violence against women, including extra-marital rape, harmful traditional practices (including FGM), and trafficking in women and children, are criminal offenses in Ethiopia (Government of the FDRE 2004). The Code contains 10 articles prohibiting harmful traditional practices. Female circumcision is punishable with a fine and 
imprisonment. The Code includes penalties for other traditional practices deemed harmful by the medical community. The Criminal Code promotes the establishment of "victim-friendly" benches and special units for crimes against women throughout the country (Government of the FDRE 2004). Ethiopia's Penal Code addresses violence against children, with specific provisions on infanticide, sexual violence, sexual exploitation of children, and trafficking. The Family Code protects against abusive adoptive environments, specifying that custody may be revoked in cases where a child is subjected to slavery and made to "engage in immoral acts for his [the adopter's] gain" (Federal Negarit Gazetta of FDRE 2000). Elimination of gender-based violence is included in the National Plan for Gender Equality and in Ethiopia's overarching development plan-the Plan for Accelerated and Sustainable Development to End Poverty (PASDEP).

Kenya's Sexual Offenses Act covers rape, sexual assault, defilement, child trafficking, child prostitution, and child pornography. Defilement offenses carry graduated sentences based on the age of the child, ranging from life imprisonment for offenses against a child up to 11 years of age to sentences up to 15 years for offenses against a child between the ages of 16 and 18. However, the Act allows for defense in cases where it can be proven that the child deceived the offender into believing he or she was over the age of 18 , or that the offender "reasonably believed" the child was above age 18considerable loopholes that weaken this law. The Act also deems it an offense for persons infected with HIV or any other life-threatening sexually transmitted disease to knowingly risk transmission to another person. The Act includes transmission between married couples under this law (Republic of Kenya 2006). Kenya also has a policy to prevent harmful traditional practices against girls and women-the National Plan of Action for the Elimination of Female Genital Mutilation.

Rwanda's National Gender Policy provides the overarching structure for integrating gender issues into sectoral policies and programs to allow women equal economic, social, and human rights in Rwandan society. The Government of Rwanda has "zero tolerance" legislation for gender-based violence; all physical, sexual, economic, or psychological violence is against the law. The Government has also included neglect or abuse of children on the basis of sex in its definition of GBV (Rwanda Public Policy Observatory 2011). The child protection system under the Strategic Plan for the Integrated Child Rights Policy has the mandate of preventing and redressing instances of such violence, abuse, or ex- ploitation. Rwandan law also includes as GBV cases of polygamy; living with another partner while still married; and relationships wherein a woman works for her partner without his providing for her (Rwanda Public Policy Observatory 2011). In these instances, a woman can use gender-based violence clauses as grounds for divorce. The Integrated Child Rights strategy includes a target to develop training packages to engage with men and boys to eliminate GBV, and stipulates that all community-based social workers should be trained in such capacities (Ministry of Gender and Family Promotion 2011).

Zambia addresses sexual exploitation and abuse of children through its National Child Policy, including provisions for exploitative relationships (such as child marriage) and child prostitution. The Policy calls for advocacy to promote children's rights, income-generating programs to "discourage habits that promote HIV and AIDS infection and sexual abuse," and interventions to prevent child prostitution (Ministry of Sports, Youth, and Child Development 2006). The Zambian Constitution guarantees freedom from all forms of trafficking. Zambia is implementing a National Action Plan on Gender-Based Violence to confront the issue as a global health, human rights, and development problem. The Plan includes objectives to review, strengthen, harmonize, and implement relevant legislation and policies to prevent GBV; generate awareness and community mobilization around the issue; and build sector capacity to prevent, mitigate, and respond to GBV with a detailed activity and monitoring plan to guide implementation (Zambia Gender in Development Division 2008).

\section{Sexual and reproductive health services}

Each country included in this analysis has a national reproductive health policy to guide delivery of sexual and reproductive health (SRH) services. Ethiopia and Kenya have separate reproductive health policies specifically for adolescents, and Kenya and Zambia dedicate sections of their national youth policies to SRH. Further, Kenya has operational guidelines for the provision of adolescent and youth-friendly services. National population policies and health strategies typically address issues of resource allocation, training, and access to services for family planning, maternal health, and sexually transmitted infections (STIs) including HIV/AIDS. Legal barriers to accessing reproductive health services include restricting access to contraceptive advice and products to women of at least 21 years of age (Rwanda), ${ }^{17}$ and

17 This restrictive law exists in spite of Rwanda's longstanding commitment to increased contraceptive access, as evidenced by the 1990 National Population Policy. 
restrictive abortion laws that make the practice illegal except in cases of danger to the life or health of the mother or child (Ethiopia, Kenya, Rwanda, Zambia), or the mental health of the mother (Ethiopia, Zambia), or for pregnancies that result from rape or incest (Ethiopia, Kenya). Abortion is also permitted in Zambia for economic and social exceptions (Rwanda Public Policy Observatory 2011). Kenya's 2010 Constitution expanded permissions for abortion to "when there is need, in the opinion of a trained health professional, for emergency treatment; if the life or health of the woman is in danger; or if it is permitted under any other written law" (previously, abortion was only allowed to protect a woman's life) (Guttmacher Institute 2012).
Despite ample policy statements and strategies to improve the health sector, youth-friendly infrastructures for service delivery across countries are lacking. For example, Ethiopia does not have an institutional framework to address the needs of young people and reports that youth perceive government reproductive health services to be unfriendly (Ethiopian Ministry of Health 2006). According to Rwanda's Strategic Plan for Integrated Child Rights, "Adolescent health has been recognized as an underserved area in Rwanda. Although the National Reproductive Health Policy and the National Youth Policy partially cover adolescent health, they fail to address key issues of adolescent health in a comprehensive manner. Sexual activity among adolescents is high and their contraceptive usage remains low" (Ministry of Gender and Family Promotion 2011)

This overview was intended as an introduction to the policy landscape in a selection of countries in East and Southern Africa. Policy gaps and recommendations for the region as a whole, with a focus on Uganda, are discussed in Chapter 6 of this document. 


\section{CONCLUSIONS}

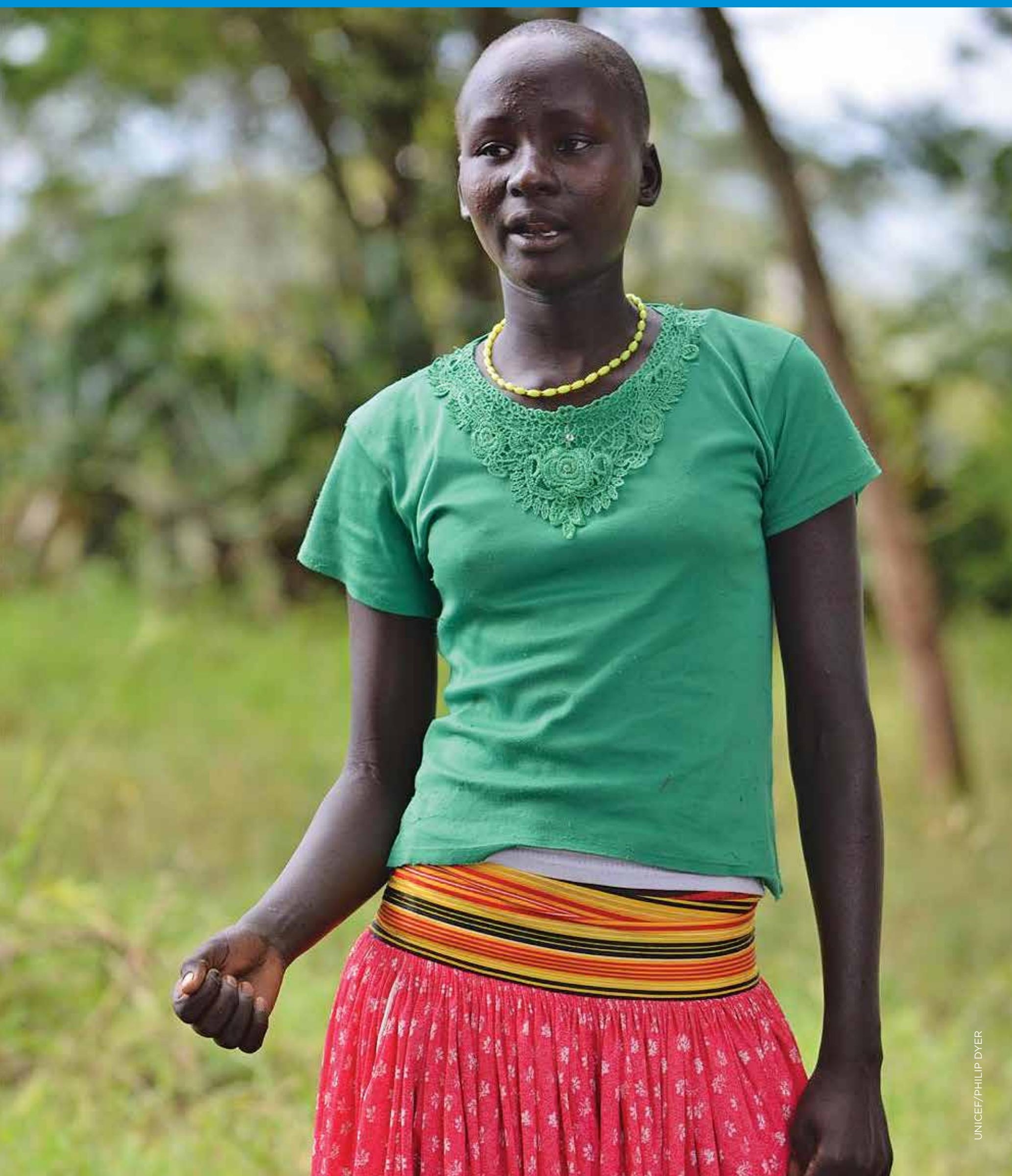




\subsection{Program and policy recommendations in the context of the AGI}

To move forward with recommendations for how programmers and policymakers can use results of the Adolescent Girls Multilevel Vulnerability Index, let us first return to a snapshot of the indicators and levels used to construct the index (see below).

\section{Summary of the policy landscape in Uganda}

Uganda has an extensive body of written policy across key sectors affecting adolescent development and well-being, particularly in terms of education, sexual and reproductive health, gender rights, and a growing emphasis on youth employment. Policymakers have made strides in raising the legal age of marriage, increasing gender parity in education, enhancing protections against gender-based violence and sexual exploitation, encouraging gender-responsive development planning, and prioritizing sexual and reproductive health services for adolescents. Recently, Uganda developed a more actionable National Youth Policy that targets underserved regions with strengthened dissemi- nation plans and acknowledges that young people are "not a homogenous group, but a diverse group with different subgroups differing in social roles and requirements" (National Youth Policy 2011).

While access to education has improved and enrollment (especially at primary level) has achieved near parity, completion rates for girls are still low relative to their male age-mates. School facilities are under-resourced and over-crowded, and the practicality and relevance of the curriculum remains questionable. Therefore, policies supporting improvements in the quality of the education sector, both in terms of infrastructure and instruction, would increase not only the length of time that girls stay in school but also their ability to apply and benefit from the education they receive.

Currently there is a call for a national youth employment policy. If drafted with attention to adolescent girls, this policy would differentiate priorities and interventions for subgroups across the 15-35 age span, with specific attention to helping older adolescent girls overcome barriers to safe and healthy economic activity as discussed previously in this report.

Finally, in the health sector, the need for youth-friendly services far outstrips availability.

\section{INDICATORS AT EACH LEVEL}

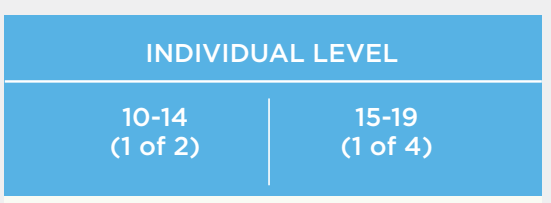

No education

OR

two or more years behind grade for age

Not living with parents
Ever married

Ever given birth OR currently pregnant

No secondary school

High-risk sex: Age at first sex under the age of 15

OR multiple partners OR non-regular partners
HOUSEHOLD LEVEL

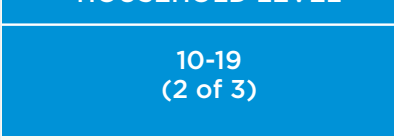

No access to an improved source of water

No access to improved sanitation or shared facilities

Household head has no education

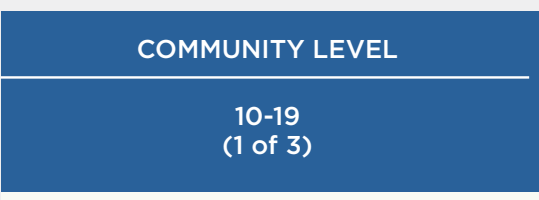

Lives in a community that is above the mean with respect to the following indicators among women aged 20-49:*

a) Marriage before 18

b) Illiteracy**

c) High national prevalence of HIV (\% of population aged 15-49) and high rate of no comprehensive knowledge*** of HIV for women aged 20-49

*Calculated relative to Uganda for Uganda rankings and relative to countries in region to regional rankings.

${ }^{* *}$ Either did not attend secondary school or higher or cannot read a whole sentence or part of a sentence.

${ }^{* * *}$ Comprehensive knowledge means knowing that consistent use of a condom during sexual intercourse and having just one uninfected faithful partner can reduce the chance of acquiring HIV, knowing that a healthy-looking person can have HIV, and knowing that you can't acquire HIV from mosquito bites or sharing food. 
Creating youth corners, training providers, and expanding services is a priority in current health sector frameworks. However, more attention should be paid to quality and implementation standards to ensure that these services are reaching the subgroups of adolescents typically cut off from care. A "minimum standards" for adolescent-friendly sexual and reproductive health services with differentiated strategies for girls ages 10-14 and 15-19 would help to streamline training and sensitization of providers and facilitate scaleup. Standardized training on caring for adolescent populations can improve the quality of services available to girls, thereby also increasing demand and access.

\section{Policy recommendations}

As the findings of this review emphasize, weak implementation blocks policy effectiveness throughout the system. Existence of general policies on paper is not sufficient to bring about real change in the lives of vulnerable and underserved populations. Failure to target, disseminate, enforce, and coordinate interventions means missed opportunities to prevent and mitigate girls' vulnerabilities. Adolescent girls experience unique health, social, and economic deprivations, and policies and programs that are not purposefully designed and implemented to address these conditions will not reach the girls most in need of support.

Gaps between policies and outcomes are present in virtually every country in East and Southern Africa. The following recommendations are offered for improving policy implementation and effectiveness in Uganda, and are applicable across the region:

\section{RECOMMENDATION 1}

\section{Create an inter-ministry committee at the national level to harmonize policy and coordinate government response for adolescent girls as a distinct priority population}

Multiple government ministries, particularly the Ministries of Education, Health, Finance, Gender, and Youth, develop policies that are relevant for adolescent girls. A clear problem identified in this policy analysis is that adolescents are divided among youth- and child-serving initiatives. Each ministry operates somewhat independently, with a variety of mandates and administrative and financial structures, The result is a lack of coordination among the different government entities that have a responsibility to address adolescent girls' issues.
An inter-ministry committee at the national level should be formed to create an institutional "home" for adolescent girl issues within the government. This committee would provide national coordination and set the groundwork for a uniform action plan. A first task would be for the Ministries of Gender, Health, and Education to agree on a universal definition of who is in the adolescent girl population and align policies with this definition. The committee should identify gaps where policy fails to address key areas of vulnerability and recommend action to harmonize contradictory policy provisions. Consolidating initiatives among these bodies will help to lessen the fracturing of both resources and impact. As a note of caution, though, government has created similar task forces in the past to little effect, and this committee should engage in a thorough assessment of such initiatives to generate "lessons learned" and avoid replicating past mistakes.

\section{RECOMMENDATION 2 \\ Design policies to reach very young adolescent girls with investments that can prevent negative outcomes before their onset}

Investing early can change the trajectory of a girl's life. Designing policy interventions that allocate resources to girls ages 10-14 and counter the forces blocking their access to care is smart development. However, the most comprehensive policy in Uganda relating to youth, the revised National Youth Policy, redefines youth as ages 15 to 35. This categorization neglects a large and highly vulnerable portion of the young people who could benefit from its provisions.

Very young adolescents have needs that are lost in general conversations of youth or children's issues. A youth-oriented approach does not start early enough to catch girls before they go off-track. Results from the AGI show many girls aged 10 to 14 already experience high levels of vulnerability. Interventions that start at age 15 begin too late to be considered effective preventive strategies against school dropout, child marriage, early childbearing, poor health, and continued poverty. While younger children are often reached through immunization programs and school registration, and older adolescents are the typical targets of peer education and youth center activities, young adolescents tend to fall through the cracks (Mensch et al. 1998; Bruce and Chong 2003). Girls ages 10-14 should be targeted with separate, stand-alone strategies to protect them from violations of their fundamental human rights and provide access to health, education, and other social services. 


\section{RECOMMENDATION 3}

\section{Collect additional data that can be disaggregated below the regional level, for younger adolescents aged 10 to 14, and for material and psychosocial support at the household level}

\begin{abstract}
The construction of the Adolescent Girls Multilevel Vulnerability Index has shown that there are several gaps in data on adolescent vulnerability. At the individual level, there are very few indicators available for girls aged 10 to 14 . New questions need to be developed and tested to better understand girls' vulnerabilities at these young ages and to inform a preventive approach to programming. At the household level, the participatory assessment highlighted the need for more data on support networks for adolescent girls. Lack of both material and psychosocial support from parents emerged as a vital component of adolescent vulnerability. At the community level, there is a need for more detailed data that can be further disaggregated to smaller, meaningful geographic areas below the regional levels. The construction of the community level indicators required extensive data manipulation and may not correspond to real community boundaries. More detailed data are critical for understanding community risk factors as well as urban vulnerability.
\end{abstract}

Suggestions for survey question topics have been added as Appendix II. The appendix should be used as a guidance regarding the types of questions that should be developed to accurately measure vulnerability among adolescent girls.

\section{FIGURE 50}

\section{CONNECTING SUBGROUPS OF GIRLS TO} COMMUNITY RESOURCES

Consider what is needed to repair the social contract:

Public-private partnerships hand in hand with girls

+ To ensure access to basic entitlements, services, and facilities

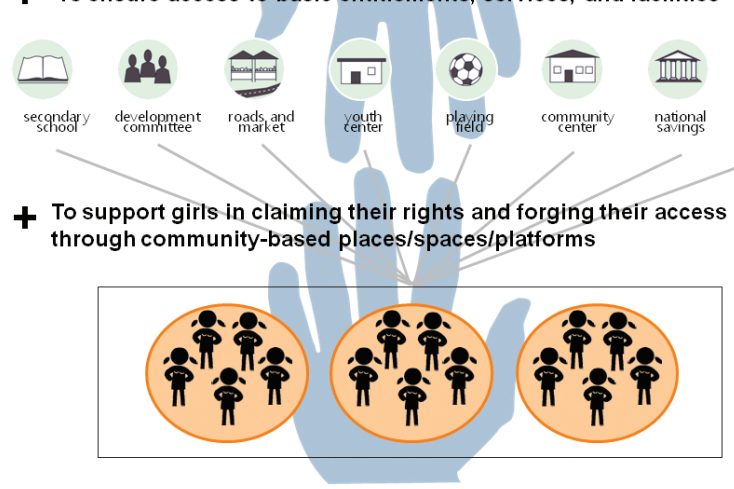

Source: Bruce 2011

\section{RECOMMENDATION 4}

Use data to locate investments and measure progress according to the internal diversity of adolescent populations in terms of age, gender, marital and schooling status, social status, economic class, living arrangements, and urban/rural residence

Increasing empirical evidence indicates that investing in the health, social, and economic well-being of the poorest girls in the most neglected locations will accelerate progress toward global development goals (Catino 2012). Policymakers must use evidence to design targeted strategies to connect isolated populations to resources and services that will prepare them for productive and protected futures (Figure 50). Adolescent girls have different needs depending on their age, whether they are in or out of school, married or unmarried, living in a rural or urban area, etc. They constitute a heterogeneous population and a "one size fits all" approach will not reach the most vulnerable. Policies should be grounded in data to attend to geographic and socioeconomic disparities and be specific about who exactly they are targeting.

Governments should implement the use of metrics to track the progress of adolescent girls in communities. Targets should be set and disaggregated for communities where indicators of girls' well-being are particularly poor and for specific subgroups with underlying social risk factors (e.g. girls who live apart from their parents and are not in school, girls who are married, girls who have migrated or are in domestic service, etc). Monitoring committees need to measure progress against these disaggregated benchmarks to determine whether interventions are reaching the populations they are designed to benefit.

\section{RECOMMENDATION 5}

Invest in replicable and scalable interventions in geographic areas with the highest concentrations of the girls at risk of the worst outcomes

The AGI can help to guide investment so that work is located where it is needed most. Initially, Karamoja, the West Nile and Western regions, and Kampala present opportunities to reach high concentrations of vulnerable girls with targeted allocation of scarce resources.

Girls aged 10-19 in Karamoja experience the highest rates of multilevel vulnerability in Uganda. This extreme vulnerability reflects prolonged violence, poverty, and widespread drought in this region, and requires investments tailored to a nomadic and pastoralist population. West Nile ranks second behind Karamoja in terms of multilevel vulner- 


\section{STRATEGIC INVESTMENT: THE RIGHT GIRLS AT THE RIGHT TIME}

Strategic policymaking to break the vicious cycle of intergenerational poverty, high fertility, and poor health means locating and investing in the poorest girls in the poorest communities. These are the most disadvantaged girls who suffer from human rights abuses, lack education and economic opportunity, are affected by HIV/AIDS, and have poor reproductive and maternal health outcomes. They are simultaneously the most disadvantaged girls, the girls most often missed by development and youth policy, and the population segments that would often benefit most from increased reproductive health knowledge, financial literacy, and opportunities to stay in school (Sewall-Menon et al. 2012).

"Investments in adolescents will have limited yield unless they are specifically targeted to subsets of adolescents, differentiated by age, gender, marital and schooling status, social status, economic class, living arrangements, and urban/rural residence" (Bruce and Chong 2003). There is no one prescription for reaching disadvantaged girls across different contextswhat works in one setting may not be appropriate in another. What is needed is, most often, not even consistent across different regions within one country. Governments must start by collecting and analyzing data disaggregated to the lowest possible administrative level for effective planning, and work through local structures for tailored intervention design.

ability, with over 85 percent of girls vulnerable at the individual and community levels, but has the fewest number of adolescent programs of all regions. Moreover, these programs largely fail to reach young, female adolescent populations. The estimated 155 programs in the West Nile region have the highest average percentage of male participants, and an average of 81 percent of program participants are over the age of 15 . In the Western region, home to 15 percent of Uganda's adolescent population, 71 percent of girls experience individual-level vulnerability. Nearly all of the programs found in the program scan for this region were co-ed, and, on average, dominated by male participants. There is a strong need for scalable girl-only programs to be designed in these areas to build social capital and increase educational and health outcomes. Investment in strategies to improve educational attainment and quality will be required to alleviate individual-level vulnerability, as rates are driven by indicators of educational deprivation. Kampala provides an example where further data disaggregation and research on how to address unique urban disparities is warranted.

\section{RECOMMENDATION 6}

\section{Create district-level committees to monitor and address adolescent girls issues}

While national coordination is important, experience shows that action must take place on a more local level to facilitate implementation and provide feedback on how policies play out on the ground. Establishing district-level committees mandated to oversee implementation of adolescent policies in their catchment area can help begin to "drill down" closer to community levels. For example, these committees could address cases of child marriage or girls not being able to return to school after childbirth, and serve as a monitoring group to feed information about successes and failures back up to the national-level committee.

\section{RECOMMENDATION 7}

\section{Strengthen child protections and address social norms and cultural values that drive irremediable rights violations and mistreatment of girls at the household and community levels}

As discussed throughout this report, a girl's environment largely shapes her opportunities. In Uganda-as in most other East and Southern African countries-traditional values draw girls out of social institutions such as school and thrust them prematurely into adult roles. The family is a highly valued social unit, and government is reluctant to overstep familial boundaries and intervene in affairs within the home. Family and community members view girls as women with sexual and domestic obligations upon entering puberty. At this juncture, girls return greater value by taking on domestic work or by marrying and relieving pressure on the household. Parents, guardians, and girls in poor households may view child marriage and early childbearing as a protective survival strategy and the only viable economic option. Adolescent girls are at risk of violence and abuse in their communities and in their relationships. As the AGI shows, the North, Eastern, and East Central regions of Uganda have high rates of adolescents ages 15 to 19 who are currently married, have ever been pregnant, and who have had high-risk sex.

These realities need to be addressed at the policy and programmatic level to sensitize communities to the dangers of practices such as child marriage, and the benefits of educating girls and providing them with skills to safely earn and manage their 
own resources. National responses to such social realities include maintaining reliable birth and marriage registration systems, issuing identification cards to everyone-especially girls-starting at early adolescence, and providing government incentives to families that keep girls in school and do not marry them off before the legal age. Similarly, a lot of work can and should be done through local bodies and traditional forums to shape attitudes and practices at the community and household levels. For example, existing village level structures such as savings and credit cooperatives can be engaged in educating girls and communities on their rights and including girls in financial activities.

\section{RECOMMENDATION 8}

\section{Prioritize interventions that improve educational quality to increase school retention and attainment}

AGI indicators at the individual and community levels have remained largely unchanged from 2006 to 2011, highlighting the need for improved policies and programs to address the issues captured therein. Education, in particular, stands out with indicators showing poor and variable outcomes across the country. Findings from the document review and in-depth interviews with policy stakeholders indicate that poor-quality curricula and instruction, over-crowding, lack of sufficient facilities and supplies, and teacher absenteeism are critical factors that must be addressed for educational outcomes to improve.

At the individual level for girls aged 10 to 14 , regions with the worst rankings have high levels of girls with no education or who are two years behind in school. Individual vulnerability for both girls ages 10-14 and 15-19 is largely shaped by girls failing to make the transition to secondary school. Karamoja shows the highest rates of vulnerability at the community level, and every community in this region is above the national mean for illiteracy in women 20 to 49 years. A focus on improving education with strategies tailored to the community and cultural context can improve both individual and community level outcomes. Investments can build on successes of programs such as Alternative Basic Education for Karamoja, a community-based program that accommodates the strict traditional values of the Karamojong people and adjusts schooling schedules and modalities according to young people's pastoral responsibilities (Ministry of Education, personal communication).

\section{RECOMMENDATION 9}

\section{Ensure that a strong program base exists that reaches vulnerable adolescent girls at ground level, puts assets directly in their hands, and creates an enabling environment in their communities}

Policies on paper alone, even with national and local monitoring bodies, are not sufficient to improve indicators reported earlier in the report. Without actual programs that increase girls' social, health and economic assets, words on paper will not generate needed change. Programs should directly strengthen girls' assets and create supportive environments within community institutions, (families, schools, churches and mosques, etc.) to improve their lives.

\section{BOX 8}

\section{EXAMPLES OF GIRL-FRIENDLY POLICY RESPONSES}

- Maintain a reliable system for birth and marriage registration, with specific outreach to poor or remote communities to promote access to vital records.

- Mandate that all adolescents be provided with an identification card to protect against rights violations-with special attention to supplying disadvantaged girls with proof of identify (national identity card, birth certificate, child health card, school enrollment card, etc.).

- Provide cash transfers and/or material incentives to families for keeping their daughters in school and delaying age at marriage.

- Provide incentives to villages that demonstrate increased female retention rates in schools or delayed age at marriage.

- Provide incentives to villages for creating safety plans to make community spaces safer for girls.

- Set school hours and times for service delivery such as contraceptive distribution and vocational training to accommodate girls' responsibilities and security needs.

- Collaborate with financial institutions to offer girl-friendly savings products and banking mechanisms.

- Eliminate barriers to school re-entry for pregnant girls, married girls, and adolescent mothers.

Selected points adapted from Girls Count: A Global Investment and Action Agenda, The Center for Global Development (Levine et al. 2009) and New Lessons: the Power of Educating Adolescent Girls, Population Council (Lloyd and Young 2009). 


\section{Program recommendations}

A common argument to counter the investments recommended in this report is that programs already exist at the community level for girls. On paper, coverage of "youth" programs extends to both males and females ages 10 to 30 and older. However, closer examination of programs and populations served makes it clear that the existing program base is not reaching vulnerable adolescent girls. Program coverage exercises carried out by the Population Council in over a half-dozen countries in sub-Saharan Africa show that the average participant profile is a male over the age of 18 . The vast majority of programs do not reach younger girls ages 10-14, or girls experiencing heightened vulnerability (out of school, married, young mothers, etc.) (Weiner 2007). The coverage exercise conducted in Uganda in 2011 and presented in this report provides an in-depth case study of how current "youth" programs are failing to reach vulnerable youth and even fewer are reaching vulnerable girls.

\section{Key characteristics of successful girls programs}

Before deciding on the content of an intervention, a program must have the proper structure to ensure participation of vulnerable girls. The following core building blocks are recommended for all adolescent girls programs regardless of their specific designations (i.e. HIV programs, livelihoods programs, etc.).

Safe place-A space in the community must be identified where girls can meet regularly. This should be the same place each time the program meets (weekly, daily, etc.). Girls are often socially isolated, whether they are living in rural areas or the most densely populated urban slum settings. As girls near puberty, their social world begins to contract and they are increasingly confined to the domestic sphere. Risks of harassment and/or violence and gendered social norms severely limit the number of places accessible to girls. As a result, available spaces for youth are generally more appropriate for their male age-mates. Therefore, a critical role that a girls program will play is to create space within a community that is considered safe and specific to girls' needs. These spaces can exist in a variety of structures-including, but not limited to, schools, churches and mosques, community halls, hair salons, and residence compounds. The space can be a general public space; in this case, it would be important for the community or structure owner to allow only girls to meet there on specific days. The geographic location of a safe space must also be considered. If girls have to pass through unsafe surrounding areas to reach program sites, it is not necessarily a suitable space.
Friends-Creating a space where a group of girls can meet regularly with peers and begin to trust and share with each other is a critical component of program structure. Opportunities for regular peer contact allow girls to build relationships and social networks, which are shown to be critical protective factors for girls as they progress through adolescence.

Mentors-A common characteristic of girls programs across various geographic settings is that groups and meetings are facilitated by female mentors. Mentors should be older than program participants so that they can serve as role models, but not so old that girls cannot identify with and relate to them. An ideal age range for mentors is 18 to 35. Mentors should also be from the same community as the girls. It is critical to select someone who will be available regularly to provide advice to the girls and be their resource in an emergency. This mentoring structure fills several purposes. It: 1) provides a source of support and a role model for the girls in the group-someone who they respect and admire and can call on for advice, 2) builds a cadre of young female leaders within the

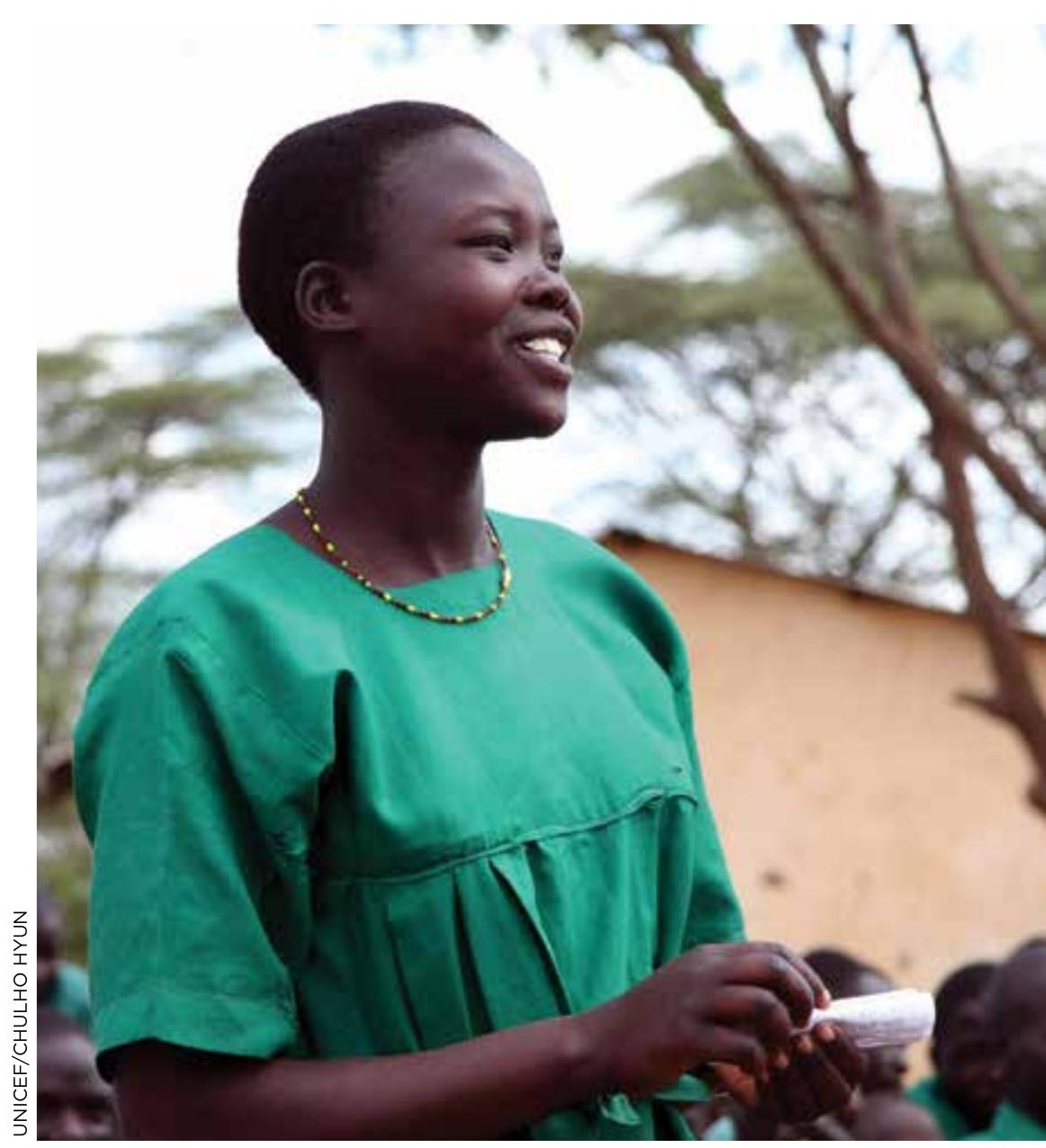

Successful girls programs must include a safe space in the community where girls can meet regularly with their peers and mentors. 
community who positively redefine the roles and expectations of adolescent girls, and 3) provides critical skill building and income generation for the mentors themselves (who are also program beneficiaries).

\section{Asset building for adolescent girls}

Once the structure of a program has been developed to ensure the participation of vulnerable girls, the content and focus of the program can be decided. Increasingly, building a diverse range of social, health, and economic assets for girls has proven successful in opening a range of health, life skills, and livelihoods opportunities.

An asset can be defined as a store of value that both increases opportunity and reduces vulnerability. For example, self-esteem is an asset. A girl can draw on her self-esteem to negotiate safer sex (reduce vulnerabilities) or to excel at a job interview (expand opportunities). Another example of an asset is savings. A girl can use her savings to pay a hospital bill in the event of a family illness instead of engaging in a risk behavior to obtain needed resources (reducing vulnerabilities). Savings can also be used to pay for a vocational training course (expand opportunities).

Using the asset building framework to design program content shifts the focus to a more preventive approach. The key question becomes "what do girls need?" as opposed to "what problems do girls have?" Often, the answers to what girls need will help them in a range of areas in their lives, as opposed to solving a single problem with a very narrow approach. Girls need social assets (friends, mentors, self-esteem, communication and leadership skills, strong social networks); health assets (knowledge on a wide range of health topics, access to health services, good health); and economic assets (financial literacy, savings, a productive skill) in order to address the integrated set of issues they face and navigate a safe, healthy, and productive transition to adulthood.

\section{Programming options}

Two programmatic approaches can expand opportunities available to adolescent girls at the community level. The first approach is to make changes to existing programs and institutions to allow for greater participation of adolescent girls. The second is the creation of new programs.

\section{Modification of existing programs}

Existing resources at the community level can be adjusted to incorporate girls programming elements and ensure that girls have access to the services to which they are entitled.
Schools-A number of interventions can be incorporated into the school setting, from direct policy implementation to program enrichment. First, stakeholders can identify existing education policies and work with school administration for their enforcement. This can include identifying girls who have dropped out of school and helping them to re-enroll, improving the physical safety of girls on school premises, and providing enrichment sessions for girls to help improve educational attainment. Given that schools are often one of the only physical spaces in which girls can meet, creating after-school clubs that are girl-only can provide regular safe spaces. Clubs can be run by the school, or by outside programs or community groups who use the physical space to hold sessions.

PROGRAM EXAMPLE

In response to a landmark court case that mandated Zambia's Ministry of Education to ensure that schools provide a safe environment for girls, the Population Council, as part of the Tisunge Ana Athu Akazi Coalition (TAAAC) led by Equality Now, worked with four partners to develop and evaluate a school-based program for adolescent girls in Lusaka. Implemented by the YWCA of Lusaka, Campaign for Female Education, Forum for African Women Educationalists of Zambia, and Planned Parenthood Association of Zambia, the program consists of weekly group meetings in the school setting where girls learn about and discuss sexual and gender-based violence (SGBV) rights and responses, HIV and sexual and reproductive health topics, financial education, and life skills. Groups are led by a combination of junior mentors (young women from the same school) and senior mentors (respected women in the community and teachers). The program has also engaged boys in the same schools, as well as provided training for guidance counselors on responding to sexual and gender based violence. Ultimately, this work aims to empower adolescent girls, sensitize boys, and strengthen the ability of school systems to prevent violence against girls.

Churches/mosques-Similar to schools, churches and mosques are public institutions that already engage youth and can provide a safe physical space in which girls can meet. Many religious institutions have "youth" groups that are a part of their community programming. It is possible to work with these religious institutions to a) create separate girls groups as part of their youth programming, b) examine their youth groups and make adjustments to ensure full and active participation of vulnerable adolescent girls, and c) use the church 
or mosque space for non-affiliated programming for girls when not used for other purposes.

Youth centers-Many communities have general youth programs or centers; however, it is likely that girls do not participate to the fullest extent in these settings. One change that can be made is to agree on certain days or hours when the center will be "girl-only" to provide a regular space and time each week when girls in the community can get together in a comfortable and welcoming environment. A second option is to conduct a coverage exercise (see Chapter 4) of youth centers to understand the profile of youth attending. Center staff must then commit to taking special steps to recruit vulnerable segments of adolescent girls to participate in ongoing and/or separate programs.

\section{PROGRAM EXAMPLE}

Ishraq, which means "sunrise" in Arabic, is a program for bringing marginalized rural girls into safe learning spaces. Ishraq seeks to improve the educational, health, and social opportunities for vulnerable girls in rural Upper Egypt. The program is tailored to respond to local needs for adolescent girls' education and health services, and is located in youth centers as a way of improving girls' access to public spaces and visibility in the community. At the start of Ishraq's implementation in each village, an agreement is reached with the youth center on the days and times girls will have access to the space. The centers create "girls corners" so that girls, their families, and the community feel comfortable with their attendance at this typically male public space. Ishraq's curriculum, while aiming to foster entry or re-entry into formal education, emphasizes literacy and life skills with special attention to reproductive health, civic engagement, livelihoods, and sports. Ishraq mobilizes the entire community to create an environment that is conducive to and accepting of social change.

Youth Councils-Many communities also have government-affiliated Youth Councils that are meant to represent the youth voice in the public sphere. Initiated in Uganda by the National Youth Council Act, youth representatives participate at all government levels. However, similar to gender bias found in youth center participation, equal participation of males and females on the Youth Councils is unlikely. Among female participants, it is even less likely that the most vulnerable populations of girls will be represented. Therefore, Youth Councils are another community institution appropriate for targeted intervention to ensure that vulnerable girls are given space and opportunity to participate. Membership can reach vulnerable segments perhaps through concerted implementation of affirmative action policies to recruit from disadvantaged and underserved regions and populations.

\section{Creation of new programs}

In many cases, stakeholders will need to design programs for adolescent girls from the ground up. Programmers should start with the three critical structural elements (a safe space, friends, and a mentor) and move through decisions on target population, recruitment strategies, content, community engagement, monitoring and evaluation, etc. For detailed guidelines on how to design girl-only programming, refer to Girl-Centered Program Design: A Toolkit to Develop, Strengthen and Expand Programs for Adolescent Girls (Austrian and Ghati 2010).

\section{PROGRAM EXAMPLE}

Biruh Tesfa (meaning "Bright Future" in Amharic) is a program for adolescent girls in urban slum areas of Ethiopia. The program is designed to assist out-of-school girls by creating safe spaces through which they can build a network of female peers and develop relationships with supportive adults.

Trained female mentors recruit girls through door-to-door household visits to identify eligible out-of-school girls ages 7-24. The household visit allows mentors to contact girls who may otherwise be missed, such as child domestic workers who are largely confined to the home. In addition, contact at the household level allows mentors to negotiate for girls' participation with gatekeepers such as employers of domestic servants and in-laws who often dictate how time is used. Once the girls are in groups, the program provides basic literacy, life skills, financial literacy and savings, and HIV/reproductive health education through clubs led by adult female mentors. Girls' clubs are held in meeting spaces donated by the kebele (local administration). Meeting times vary to accommodate the schedules of working girls.

As of 2012, over 35,000 out-of-school girls had participated in Biruh Tesfa groups in the poorest areas of 17 Ethiopian cities, including the capital, Addis Ababa. Biruh Tesfa girls are from very disadvantaged backgrounds: nearly half of the beneficiaries have lost at least one parent, and 1 in 7 participants have lost both parents. The project is one of the first of its kind to target child domestic workers. One-third of Biruh Tesfa beneficiaries are engaged in child domestic work, and one-third are daily manual laborers. 


\section{A note on targeted recruitment of vulnerable girls}

As shown throughout this report, adolescent girls are not a homogeneous population. They differ on many characteristics such as school-going and marital status, living arrangements, parenthood, and employment, each of which may expose them to a range of vulnerabilities. In the design of a girls program, special care must be taken to recruit the most vulnerable girls. If recruitment is not designed to attend to these differential categories, it is highly likely that those girls who are (relatively) better off-that is, in school, living with both their parents, connected to community leaders, teachers, etc.-will populate a program.

Door-to-door recruitment is an effective way to identify girls who are especially vulnerable but less likely to participate in programs (e.g. married girls, domestic workers, or disabled girls). These girls may not have social connections to make them aware of programs that exist, may not believe that a program is open to them, or may not be allowed to participate unless they are explicitly invited by staff members visiting their household (see program example of Biruh Tesfa above).

Another way to conduct targeted recruitment is by identifying geographic "hot spots." For example, AGI results show both within-country and between-country variation in levels of adolescent girl vulnerability. When faced with the decision of where to locate a program and direct resources, isolating geographic regions that are empirically most at risk can help to reach the most vulnerable girls and result in the greatest change in indicators.

\subsection{Investing in girls and the role of the AGI}

Investing in adolescents is a vital priority for Uganda and other countries in East and Southern Africa. Not only are adolescent girls a large and vulnerable group, but they play a crucial role in breaking the transmission of poverty between generations. Furthermore, rapid improvement in under-five mortality rates around the world makes reaching adolescent girls even more pressing to ensure that young people who survive childhood thrive into their second decade.

There is a history in development practice of the issues of greatest importance not receiving the greatest attention. Policy and program analyses carried out for the AGI project clearly show adolescent health and development to be one of these issues. A well-constructed index can play a crucial role in redirecting resources more equitably. The process of index construction brings together various stakeholders to conceptualize and analyze an issue, and the resulting index provides a tool for high-level advocacy, decisionmaking and resource allocation, and ongoing monitoring within and across countries.

The results of the Adolescent Girls Index and recommendations outlined in this report will play a critical role in increasing public attention to the needs of adolescent girls in Uganda. While the challenges facing adolescent girls in other parts of the world, as well as data availability, will vary, the importance of this population is constant. The AGI may not be directly replicable in different countries, but the underlying principles are applicable across settings and can be used to set priorities and hold decisionmakers accountable for delivering on the promises made to adolescent girls around the world.
PROGRAM EXAMPLE

In the Amhara region of Ethiopia, rates of child marriage are among the highest in the world. Half of all girls in Amhara are married before their fifteenth birthday. As a response, the Population Council developed and implemented the Berhane Hewan program to reduce child marriage among unmarried girls and improve health outcomes for married girls in Amhara. The program promotes functional literacy, life skills, reproductive health education, and opportunities for saving money. Economic incentives are provided to encourage families to allow their daughters to participate in girls groups that meet five days per week and to remain in school. Married girls meet once a week to obtain much-needed health information, peer interaction, and social support.

After two years of implementation, Council researchers carried out an impact evaluation among adolescent girls in the pilot site and comparable girls in a control site. The evaluation found that significantly fewer girls in the experimental area had been married during early adolescence (ages 10-14) compared to girls of similar age in the control site. Among married girls, those living in the project site were nearly three times more likely to use family planning methods (Erulkar and Muthengi 2009) 


\section{REFERENCES}

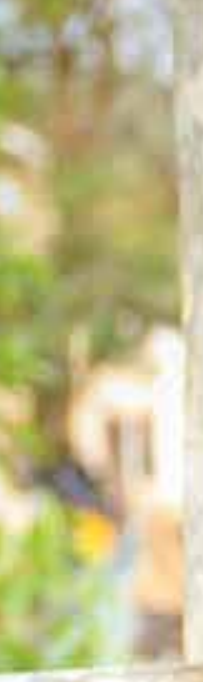


Agot, K., Stoep, A. V., Tracy, M., et al. (2010). "Widow inheritance and HIV prevalence in Bondo District, Kenya: Baseline results from a prospective cohort study." PloS One 5(11) e14028. doi:10.1371/journal. pone.0014028.

Akwara, P. A., Noubary, B., Lim Ah Ken, P., et al. (2010). "Who is the vulnerable child? Using survey data to identify children at risk in the era of HIV and AIDS." AIDS Care 22(9): 1066-1085

Alkire, S. and Foster, J. (2011). "Understandings and misunderstandings of multidimensional poverty measurement." The Oxford Poverty and Human Development Initiative (OPHI). <http://www.ophi.org uk/understandings-and-misunderstandings-ofmultidimensional-poverty-measurement/>.

Alkire, S., Conconi A., and Roche, J. M. (2013). "Multidimensional Poverty Index 2013: Brief Methodological Note and Results" Oxford Poverty and Human Development Initiative, Oxford University. <http://ophi.qeh ox.ac.uk>

Ashford, L. (2007). Africa's Youthful Population: Risk or Opportunity? Washington, DC: Population Reference Bureau. <http://www.prb.org/Publications/ PolicyBriefs/AfricasYouthfulPopulation.aspx>.

Austrian, K. (2012). Girls' Leadership and Mentoring. New York: Population Council and UN Adolescent Girls Task Force. <http://www.popcouncil.org/pdfs/ 2012PGY_GirlsFirst_Leadership.pdf>

Austrian, K. and Ghati, D. (2010). Girl-Centered Program Design: A Toolkit to Develop, Strengthen and Expand Programs for Adolescent Girls. New York: Population Council.

Balarajan, Y., Ramakrishnan, U., Özaltin, et al. (2011) "Anaemia in low-income and middle-income countries." The Lancet 378(9809): 2123-2135.

Bandura, A. (1977). "Self-efficacy: toward a unifying theory of behavioral change." Psychological Review 84(2): 191.

Bandura, R. (2008). "A Survey of Composite Indices Measuring Country Performance: 2008 Update." UNDP, Office of Development Studies. <http://www. undp.org/developmentstudies/docs/indices_2008_ bandura.pdf>.

Ben-Arieh, A. (2000). "Beyond welfare: measuring and monitoring the state of children-new trends and domains." Social Indicators Research 52(3): 235-257.

(2006). "Is the study of the 'State of our Children' changing? Re-visiting after 5 years." Children and Youth Services Review 28(7): 799-811.

(2008). "The child indicators movement: Past, present, and future." Child Indicators Research 1(1): 3-16.

Black, M. (1996). Children First: The Story of UNICEF, Past and Present. Oxford, UK: Oxford University Press.

Bloom, D. E., and Canning, D. (2000). "The health and wealth of nations." Science 287(5456): 1207-1209.

Blum, R. W. (1998). "Healthy youth development as a model for youth health promotion: A review." The Journal of Adolescent Health 22(5): 368-375.

Bongaarts, J. (1994). "Population policy options in the developing world.” Science 263(5148): 771-776.
(2012). "UNFPA Population Council Decomposition Population Growth (version 2.0.2) [Microsoft Excel]. New York: Population Council.

Bongaarts, J., and Bulatao, R. A. (1999). "Completing the demographic transition." Population and Development Review 25(3): 515-529.

Bowers, E. P., Li, Y., Kiely, M. et al. (2010). "The five Cs model of positive youth development: A Longitudinal analysis of confirmatory factor structure and measurement invariance." Journal of Youth and Adolescence 39(7): 720-735

Bronfenbrenner, U. (1979). The Ecology of Human Development: Experiments by Nature and Design. Cambridge, MA: Harvard University Press.

Bronfenbrenner, U. (1977). "Toward an experimental ecology of human development." American Psychologist 32(7): 513-531.

Bruce, J. (2007a). "Reaching the girls left behind: Targeting adolescent programming for equity, social inclusion, health, and poverty alleviation." Presented at Commonwealth Women's Affairs Ministers' Meeting, Uganda. <http://www.popcouncil.org/pdfs/ Bruce2007_Commonwealth_FullText.pdf $>$.

(2007b). "Girls left behind: Redirecting HIV interventions toward the most vulnerable." Promoting Healthy, Safe, and Productive Transitions to Adulthood, Brief 23. New York: Population Council. <http://www.popcouncil.org/pdfs/TABriefs/ PGY_Brief23_GirlsLeftBehind.pdf $>$.

. (2011). "Scaling for change: Strategic investment in the poorest girls in the poorest communities." Presented at the Clinton Global Initiative, New York, 20-22 September.

Bruce, J., and Bongaarts, J. (2009). "The new population challenge." In A Pivotal Moment: Population, Justice, and the Environmental Challenge, (ed.) L. Mazur. Washington, DC: Island Press.

Bruce, J., and Chong, E. (2003). The Diverse Universe of Adolescents, and the Girls and Boys Left Behind: A Note on Research, Program, and Policy Priorities. New York: UN Millennium Project.

Bruce, J., Haberland, E., Chong, E., Grant, M., and Joyce, A. (2006). "The girls left behind: The failed reach of current schooling, child health, youthserving, and livelihoods programs for girls living in the path of HIV." Policy Paper. New York: Population Council.

Burt, M., Zweig, J., and Roman, J. (2001). "Modeling the payoffs of interventions to reduce adolescent vulnerability." In Adolescent Risk and Vulnerability: Concepts and Measurement. Washington, DC: National Research Council, Board on Children, Youth, and Families, Institute of Medicine.

Catino, J. (2012). "The health of vulnerable adolescent girls: A strategic investment for double return." A Girls First! Publication, New York: Population Council and UN Adolescent Girls Task Force.

Center for Reproductive Rights. (2011). "10 key points about Uganda's laws and policies on termination of pregnancy." <http://reproductiverights.org/sites/ crr.civicactions.net/files/documents/WEB_pub fac_uganda_11.28.11.pdf>. 
Center for the Study of International Cooperation in Education. (n.d.). "Prospects, challenges and policy options of Ethiopian education system towards the achievement of EFA goals." <http://home. hiroshima-u.ac.jp/cice/e-forum/paper67.pdf>.

Chambers, R. (1989). "Editorial introduction: Vulnerability, coping and policy." IDS Bulletin 20(2): 1-7.

Cicchetti, D. and Rogosch, F. A. (1996). "Equifinality and multifinality in developmental psychopathology." Development and Psychopathology 8(4): 597-600.

Clark, S. and Hamplová, D. (2013). "Single motherhood and child mortality in sub-Saharan Africa: A life course perspective." Demography epub. doi: 10.1007/s13524-013-0220-6.

Cleland, J., Ndugwa, R., and Zulu, E. (2010). "Family planning in sub-Saharan Africa: Progress or stagnation?” Bulletin of the World Health Organization 89: 137-143.

Coenjaerts, C., Ernst, C., Fortuny, M., Rei, D., and Pilgrim, M. (2009). "Youth employment." In Promoting ProPoor Growth Employment. Paris: OECD. <http://www. oecd.org/dataoecd/27/4/43280339.pdf>.

Demokratie and Dialog E.V. (2013). "Overview of national youth policies." <http://www.youthpolicy.org/ nationalyouthpolicies/>

DeVellis, R. F. (1991). Scale Development: Theory and Applications (Second edition) (Vol. 26). Newbury Park, CA: Sage Publications.

Dodge, K. A. and Pettit, G. S. (2003). "A biopsychosocial model of the development of chronic conduct problems in adolescence." Developmental Psychology 39(2): 349.

Drewnowski, J. (1966). Social and Economic Factors in Development: Introductory Considerations on Their Meaning, Measurement, and Interdependence. New York: United Nations Research Institute for Social Development.

Drewnowski, J. and Scott, W. (1966). "The level of living index." New York: United Nations Research Institute for Social Development. <http://books.google.com/ books?id=_cyZQAAACAAJ>.

Earls, F. and Carlson, M. (2001). "The social ecology of child health and wellbeing." Annual Review of Public Health 22(1): 143-166.

Engel, G. (1977). "The need for a new medical model: A challenge for biomedicine." Science 196(4286): 129-136.

Erulkar, A. and Matheka, J. (2007). "Adolescents in the Kibera slums of Nairobi, Kenya." Nairobi: Population Council.

Erulkar, A. and Muthengi, E. (2009). "Evaluation of Berhane Hewan: A program to delay child marriage in rural Ethiopia." International Perspectives on Sexual and Reproductive Health 35(1): 6-14.

Erulkar, A. S., Tekle-Ab, M., Simie, N., and Gulema, T. (2004). "Adolescent life in low income and slum areas of Addis Ababa, Ethiopia." New York: Population Council.

Ethiopian Embassy. (1993). "National Policy on Women (2)." <http://www.ethioembassy.org.uk/fact\%20file/ a-z/women-1.htm>.
Ethiopian Ministry of Health. (2006). "National Reproductive Health Strategy." <http://phe-ethiopia.org/ admin/uploads/attachment-161-National_RH_ strat\%5B1\%5D.pdf>.

Federal Negarit Gazetta of FDRE. (2000). "Ethiopian Revised Family Code." <http://www.scribd.com/ doc/28793467/Ethiopian-Revised-Family-Code>.

Fischhoff, B., Nightingale, E. O., and lannotta, J. G. (2001). Adolescent Risk and Vulnerability: Concepts and Measurement. Washington, DC: The National Academies Press.

Forsyth, B., Horwitz, S., Leventhal, J., Bruger, J., and Leaf, P. (1996). "The Child Vulnerability Scale: An instrument to measure parental perceptions of child vulnerability." Journal of Pediatric Psychology 21(1): 89-101.

Forum for Women in Democracy. (2010). Budget Decisions on Gender: A Gender Budget Analysis of Key Ministerial Policy Statement and Budgets FY 2010/11. Kampala, Uganda.

Glick, P. and Sahn, D. E. (2000). "Schooling of girls and boys in a West African country: The effects of parental education, income, and household structure." Economics of Education Review 19(1): 63-87.

Gordon, D., Nandy, S., Pantazis, C., et al. (2003). "The Distribution of Child Poverty in the Developing World." Centre for International Poverty Research, University of Bristol. <www.nscb.gov.ph/poverty/TCPovStat/ reading.../ChildPov_UNICEF.pdf $>$.

Gore, F. M., Bloem, P. J., Patton, G. C., et al. (2011). "Globa burden of disease in young people aged 10-24 years: A systematic analysis." The Lancet $377(9783)$ : 2093-2102.

Government of the FDRE. (1993). "Ethiopia Labour Code." <http://www.ilo.org/dyn/natlex/docs/WEBTEXT/31977/64870/E93ETH10.htm>.

Government of the FDRE. (2004). "The Criminal Code of the Federal Democratic Republic of Ethiopia." <http://www.ilo.org/dyn/natlex/docs/ELECTRONIC/ 70993/75092/F1429731028/ETH70993.pdf>.

Guttmacher Institute. (2013). "Unintended pregnancy and abortion in Uganda." In Brief. <http://www. guttmacher.org/pubs/IB-Unintended-PregnancyUganda.html>.

Hagen-Zanker, J. and McCord, A. (2010). Financing social protection in the light of international spending targets: A public sector spending review. Overseas Development Institute. <http://www.odi.org.uk/ resources/docs/6309.pdf>.

Hallman, K. (2004). "Socioeconomic disadvantage and unsafe sexual behaviors among young women and men in South Africa." Policy Research Division Working Paper No. 190. New York: Population Council.

(2005). "Gendered socioeconomic conditions and HIV risk behaviours among young people in South Africa." African Journal of AIDS Research 41(1): 37-50.

Hallman, K. and Diers, J. (2004). "Social isolation and economic vulnerability: Adolescent HIV and pregnancy risk factors." Paper presented at the Annual Meeting of the Population Association of America, Boston, MA, 1-3 April. 
Hallman, K., Govender, K., Mbatha, E., Pattman, R., Bhana, D., Walsh, J. (2007). "Social capital, socioeconomic aspirations, and HIV risk behaviors among poor South African youth." Paper presented at the Third South African AIDS Conference, Durban, South Africa, 6 June.

Hobbs, F. and Lippman, L. (1990). Children's Wellbeing: An International Comparison. US Dept. of Commerce, Bureau of the Census.

ICAP. (1998). "Drinking age limits.” International Center for Alcohol Policies. <http://www.icap.org/table/ minimumagelimitsworldwide>

Immigration and Refugee Board of Canada. (2004). "Uganda: Prevalence of forced marriage in Uganda and the availability of state protection (2000-2004)." <http://www.unhcr.org/refworld/topic,45a5fb512, 45a608be2,42df61b42f,0,,,UGA.html>

International Youth Foundation. (2011). "Navigating challenges, charting hope: A cross-sector situational analysis on youth in Uganda". Baltimore, MD: IYF. <http://www.iyfnet.org/sites/default/files/YouthMap_ Uganda_Exec_Version\%20.pdf>

Jordan, T. E. (1993). "Estimating the quality of life for children around the world: NICQL'92." Social Indicators Research 30(1): 17-38.

Kalibala, S., Schenk, K. D., Weiss, D. C., and Elson, L. (2012). "Examining dimensions of vulnerability among children in Uganda." Psychology, Health \& Medicine: 7(13): 295-310.

Knox, A., Duvvury, N., and Milici, N. (2007). "Connecting rights to reality: A progressive framework of core legal protections for women's property rights." Washington, DC: ICRW.

Kogan, L. S. and Jenkins, S. (1974). "Indicators of child health and welfare: Development of the DIPOV index." Center for Social Research, Graduate Center, City University of New York; distributed by Columbia University Press.

Land, K. C., Lamb, V. L., and Mustillo, S. K. (2001). "Child and youth wellbeing in the United States, 1975-1998: Some findings from a new index." Social Indicators Research 56(3): 241-318.

Lerner, R. M., Eye, A., Lerner, J. V., Lewin-Bizan, S., and Bowers, E. P. (2010). "Introduction-The meaning and measurement of thriving: A view of the issues." Journal of Youth and Adolescence 39(7): 707-719.

Levine, R., Lloyd, C., Greene, M., and Grown, C. (2009). Girls Count: A Global Investment and Action Agenda. Washington, DC: The Center for Global Development.

Lippman, L. H. (2007). "Indicators and indices of child wellbeing: A brief American history." Social Indicators Research 83(1): 39-53.

Lloyd, C. (2006). "Schooling and adolescent reproductive behavior in developing countries." New York: Millennium Development Project. <www.unmillenniumproject.org/documents/CBLloyd-final.pdf>.

Lloyd, C. B. and Young, J. (2009). New Lessons: The Power of Educating Adolescent Girls: A Girls Count Report on Adolescent Girls. New York: Population Council.

Lustig, N. (2011). "Multidimensional indices of achievements and poverty: What do we gain and what do we lose?" SSRN eLibrary. <http://papers.ssrn.com/ sol3/papers.cfm?abstract_id=1910099\#>.

Marshall, W. A. and Tanner, J. M. (1969). "Variations in pattern of pubertal changes in girls." Archives of Disease in Childhood 44(235): 291 -303.

(1970). "Variations in the pattern of pubertal changes in boys." Archives of Disease in Childhood 45(239): $13-23$.

McGillivray, M. (1991). "The human development index: Yet another redundant composite development indicator?" World Development 19(10): 1461-1468.

McGranahan, D. V., Richard-Proust, C., Sovani, N. V., and Subramanian, M. (1972). Contents and Measurement of Socio-economic Development. New York: UNRISD.

MEASURE Evaluation. (2009). Child Status Index. <http:// www.cpc.unc.edu/measure/tools/child-health/ child-status-index>. Accessed 10 August 2011

Melchiorre, A. (2004). "At what age?...Are school children employed, married and taken to court?" Right to Education Project. < http://www.unicef.org/tdad/ atwhatage04.pdf>.

Mensch, B., Bruce, J., and Greene, M. (1998). The Uncharted Passage: Girls' Adolescence in the Developing World. New York: Population Council.

Mensch, B., Singh, S., and Casterline, J. (2005). "Trends in the timing of first marriage among men and women in the developing world." PGY Working Paper No. 202. New York: Population Council.

Ministry of Education [Kenya]. (2007a). "Republic of Kenya Ministry of Education Strategic Plan 20082012." <http://www.education.go.ke/Documents. aspx?doc $\mid \mathrm{D}=1650>$.

Ministry of Education [Uganda]. (2007b). "Education sector national implementation framework, 20082010." Lusaka. <http://planipolis.iiep.unesco.org/ upload/Zambia/Zambia_NIS.pdf>.

Ministry of Education [Zambia]. (1996). "Educating our future." <http://www.ibe.unesco.org/International/ ICE/natrap/Zambia.pdf>.

Ministry of Education and Sports [Rwanda]. (n.d.). Girls' Education Strategic Plan 2008-2012. Retrieved from http://www.rwandagirlsinitiative.org/app/webroot/ browser/files/GGA/MinEdGirlEdStratPlan.pdf

Ministry of Education and Sports [Uganda]. (2008b). "Revised education sector strategic plan, 20072015." Kampala, Uganda. <http://www.education. go.ug/files/downloads/Revised\%20Education\%20 Sector\%20strategic\%20plan\%202007-2015(1).pdf>.

Ministry of Finance, Planning and Economic Development [Uganda]. (2008). "National population policy for social transformation and sustainable development." Population Secretariat: Kampala. <http:// www.hsph.harvard.edu/population/policies/uganda. pop.08.pdf>.

(2010). "National population policy action plan (2011-2015)." Population Secretariat: Kampala. <http://www.popsec.org/publications_19_ 220494683.pdf>.

(2011). "Annual economic performance report 2010/11." Population Secretariat: Kampala. <http:// www.finance.go.ug/index.php/about-mofped/ ministry-structure.html>. 
Ministry of Finance, Planning and Economic Development, DCFU Bank, Stanbic Bank, and Centenary Bank (n.d.). The Youth Venture Capital Fund (Entrepreneurship Project). <http://www.finance.go.ug/ dmdocuments/The\%20Youth\%2OVenture\%20 Capital\%20Fund.pdf>

Ministry of Gender and Family Promotion [Rwanda] (2011). "Strategic plan for the integrated child rights policy in Rwanda." <http://www.unicef.org/rwanda/ RWA_resources_icrpstratplan.pdf $>$.

Ministry of Gender, Labour and Social Development [Uganda]. (1999). "National action plan on women." Directorate of Gender: Kampala.

. (2001). "Uganda national youth policy.” Kampala.

. (2004). "National orphans and other vulnerable children policy.” Kampala. <http://www.unicef.org/ uganda/National_OVC_Policy.pdf $>$.

(2007a). "National policy on HIV/AIDS and the world of work." Kampala. <http://www.mglsd.go.ug/ wp-content/uploads/2011/O4/NATIONAL.pdf>.

. (2007b). "The Uganda gender policy.” Kampala, Uganda.

(2010). "National strategic programme plan of interventions for orphans and other vulnerable children 2011/12-2015/16." Kampala. <http://www.unicef.org/ uganda/Final_Printed_OVC_Strategic_Plan_ Uganda_-NSPPI_2.pdf>

. (2012). "Draft Uganda National Youth Policy (revised).” Kampala, Uganda.

Ministry of Health [Uganda]. (2001a). "Policy for reduction of mother-to-child HIV transmission in Uganda." <http://www.youth-policy.com/Policies/Uganda Policy for the Reduction of Maternal to Child Transmission.pdf>.

(2001b). "The national policy guidelines and service standards for reproductive health services." Reproductive Health Division: Kampala. <http://www. youth-policy.com/Policies/Uganda National Policy Guidelines and Service Standards for Reproductive Health Services.pdf>.

(2004). "National adolescent health policy for Uganda." <http://www.youth-policy.com/Policies/ UGAyouthpol2004.pdf>.

(2005). "Uganda national policy guidelines for HIV counseling and testing." Retrieved from <http:// www.who.int/hiv/pub/guidelines/uganda_art.pdf $>$.

(2010). "Health sector strategic plan III 2010/112014/15." <http://www.health.go.ug/docs/HSSP_ III_2010.pdf $>$.

Ministry of Labor and Social Affairs [Ethiopia]. (2005). "Federal Democratic Republic of Ethiopia country response to the questionnaire on violence against children." <http://www2.ohchr.org/english/bodies/ CRC/docs/study/responses/Ethiopia.pdf>

Ministry of Sports, Youth, and Child Development [Zambia]. (2006). "Zambia National Child Policy." <http://www.parliament.gov.zm/index.php? option=com_docman\&task=doc_view\&gid=842>.

Miringoff, M. (1990). "Monitoring of social wellbeing of the nation." Public Welfare 48(4): 34
Montgomery, M. R. (2009). "Urban poverty and health in developing countries." Population Bulletin 64(2). Washington, DC: Population Reference Bureau.

Moore, A. M., Awusabo-Asare, K., Madise, N., et al. (2007). "Coerced first sex among adolescent girls in subSaharan Africa: Prevalence and context." African Journal of Reproductive Health 11(3): 62-82.

Morris, M. D. (1980). "The Physical Quality of Life Index (PQLI).” Development Digest 18(1): 95-109.

Mugisha, F. (2006). "School enrollment among urban nonslum, slum and rural children in Kenya: Is the urban advantage eroding?" International Journal of Educational Development 26(5): 471-482.

Muhwezi, D. (2003). "Gender sensitive educational policy and practice: A Uganda case study." Background paper prepared for the Education for All Global Monitoring Report 2003/4. Kampala.

National Assembly [Uganda]. (2010). "Report of the fifth committee on sport, youth, and child affairs for the fifth session of the tenth national assembly appointed on 22 September 2010." Lusaka, Uganda. $<$ http://www.parliament.gov.zm/index.php? option=com_docman\&task=doc_view\&gid=842>.

National Planning Authority [Uganda]. (2010). "National development plan (2010/11-2014/15).” Kampala. <http://planipolis.iiep.unesco.org/upload/Uganda/ Uganda_NDP_April_2010.pdf>

National Youth Council [Uganda]. (2006). "Uganda Country Report on National Youth Consultation Meeting." <http://213.55.79.31/adf/adfv/docs/UgandanCountry Report.pdf>.

Nishimura, M., Ogawa, K., Sifuna, D., et al. (2009). "A comparative analysis of Universal Primary Education policy in Ghana, Kenya, Malawi, and Uganda." Journal of International Cooperation in Education 12(1): 143-158.

O'Hare, W. P. and Bramstedt, N. L. (2003). "Assessing the KIDS COUNT composite index." A Kids Count Working Paper. Baltimore, MD: Annie E. Casey Foundation.

Obare, F., Birungi, H., and Kavuma, L. (2011). "Barriers to sexual and reproductive health programming for adolescents living with HIV in Uganda." Population Research and Policy Review 30: 151-163.

OECD. (2008). Handbook on Constructing Composite Indicators: Methodology and User Guide. OECD Publishing. <http://composite-indicators.jrc.ec. europa.eu/Document/Handbook_FINAL.pdf>.

OECD Development Centre. (n.d.). Social Institutions and Gender Index, Uganda. <http://genderindex.org/ country/uganda\#_ftnref26>.

Parliament of the Republic of Uganda. (2009). "Bill No. 19: Marriage and Divorce Bill." <http://www.parliament. go.ug/new/images/stories/bills/Marriage_Divorce_ bill_2009_1.pdf>.

Population Council. (2009). Adolescent Girls Programming and Capacity Building Workshop: Workshop Report. New York: Population Council. <http:// www.popcouncil.org/pdfs/PGYO9_AdolWkshop Nairobi08.pdf>

Powell, J. (2010). "Karamoja: A literature review.” London: Saferworld. <http://dspace.cigilibrary.org/jspui/ bitstream/123456789/28769/1/Karamoja\%20A\%20 literature\%20review.pdf?1>. 
Prasad, N. (2005). Research Proposal Construction of a Social Policy Index (SPI). Geneva: UNRISD.

Pullum, T., Johnson, K., Land, K., and Nyberg, B. (2011). "Using survey data to target programs for highly vulnerable children in Ethiopia." Paper presented at the Third International Conference of the International Society for Child Indicators, York, U.K.

Raj, A., Saggurti, N., Balaiah, D., and Silverman, J. G. (2009). "Prevalence of child marriage and its effect on fertility and fertility-control outcomes of young women in India: A cross-sectional, observational study." The Lancet 373(9678): 1883-1889.

Raworth, K. and Stewart, D. (2003). "Critiques of the Human Development Index: a review." In Readings in Human Development, S. Fukuda-Parr and A.K. Shiva-Kumar (eds.), New York: Oxford University Press, pp. 164-176.

Reproductive Health Division, Ministry of Health [Uganda]. (2004). "National adolescent health policy for Uganda." <http://www.youth-policy.com/Policies/ UGAyouthpol2004.pdf>

Republic of Kenya. (2006). "Sexual offences act." <http:// www.gender.go.ke/index.php/Gender-Mainstreaming/View-category.html>.

(2002). "The Children Act." Nairobi. <http://www kenyalaw.org/Downloads/GreyBook/12.\%20The\%20 Children's\%20Act\%20Act.pdf>.

Republic of Rwanda. (2003). "Constitution of the Republic of Rwanda." <http://www.rwandahope.com/ constitution.pdf $>$.

Republic of Uganda. (1973). "Customary marriage (registration) act." Kampala. <http://www.ulii.org/ug/ legislation/consolidated-act/248>.

(1993). "National youth council act." Kampala. $<$ http://www.ulii.org/ug/legislation/consolidatedact/319>.

(1998). "The land act." <http://www.ulii.org/ug/ legislation/consolidated-act/227>.

(2006). "Employment act.” Kampala. <http:// www.publicservice.go.ug/public/Employment\%20 Act\%202006.pdf>.

(2007a). "Children act." Kampala. <www. ugandaembassy.com/The_Children_Act.pdf $>$.

(2007b). "Penal code (amendment) act, 2007." Kampala. <http://www.ulii.org/content/penal-codeamendment-act-2007>.

(2008). "Acts supplement: The Education (preprimary, primary, and post-primary) Act, 2008 Uganda Gazette No. 44(C1)." Entebbe. <http:// planipolis.iiep.unesco.org/upload/Uganda/Uganda_ EducationAct.pdf>.

(2010). "National youth council (amendment) act." Kampala. <http://www.ulii.org/content/nationalyouth-council-amendment-act $>$.

Republic of Zambia. (1991). "Constitution of Zambia act." <http://unpan1.un.org/intradoc/groups/public/ documents/cafrad/unpan004847.pdf>.

(1996). "The juveniles act." < Zambian Laws Database at http://zamlaws.zambia.co.zm/laws_view. php?chapter $=53>$.
Right to Education Project. (2012). "Right to education country factsheet: Zambia." <http://www.right-toeducation.org/sites/r2e.gn.apc.org/files/Right_to_ education_country_factsheet_Zambia_October_ 2012_O.pdf>.

Rwanda Public Policy Observatory. (2011). "Legal and policy framework for gender equality and the empowerment of women in Rwanda." <http://www. ipar-rwanda.org/index.php?option $=$ com docman\&task $=$ doc_details\&gid $=32 \& \mid$ temid $=>$.

Sameroff, A. J. and Chandler, M. J. (1975). "Reproductive risk and the continuum of caretaking casualty." Review of Child Development Research 4: 187-244.

Sen, A. (1979). "Issues in the measurement of poverty." Scandinavian Journal of Economics 81(2): 285-307.

(1987). Commodities and Capabilities. New Delhi: Oxford University Press.

Sewall-Menon, Bruce, J., Austrian, K., Brown, R., et al. (2012). "The cost of reaching the most disadvantaged girls: Programmatic evidence from Egypt, Ethiopia, Guatemala, Kenya, South Africa, and Uganda." New York: Population Council.

Shisana, O. and Simbayi, L. C. (eds.). (2002). Nelson Mandela/HSRC Study of HIV/AIDS: South African National HIV Prevalence, Behavioural Risks and Mass Media: Household Survey 2002: Executive Summary. HSRC Press.

Stewart, F. and Deneulin, S. (2002). "Amartya Sen's contribution to development thinking." Studies in Comparative International Development 37(2): 61-70.

Temin, M. and Levine, R. (2009). "Start with a girl-A New agenda for global health." Washington, DC: Center for Global Development. <http://www.cgdev.org/ files/1422899_file_Start_with_a_Girl_FINAL.pdf >.

Uganda Aids Commission (UAC). (2007). "Moving toward universal access: National HIV \& AIDS strategic plan 2007/8-2011/12." Republic of Uganda. <http://www.ilo.org/wcmsp5/groups/public/---ed_ protect/---protrav/---ilo_aids/documents/ legaldocument/wcms_125553.pdf>

Uganda Bureau of Statistics. (2012). "Population." $<$ http://www.ubos.org/?st=pagerelations $2 \& i d=$ 17\&p=related\%20pages\%202:Population>.

Uganda Youth Development Link. (2011). "Commercial sexual exploitation of children in Uganda: A critical review of efforts to address CSEC 2005-2011." <http:// www.uydel.org/downloads/CSEC in Uganda 2011 UYDEL booklet -23-08-2011pdf-20111206-115302.pdf>.

United Nations. (2011). "Concluding observations of the Committee on the Elimination of Discrimination against Women: Ethiopia." <http://www2.ohchr.org/ english/bodies/cedaw/docs/co/CEDAW-C-ETHcO-7.pdf>.

UNDP. (1990). Human Development Report 1990. New York: Oxford University Press. <http://hdr.undp.org/ en/media/hdr_1990_en_front.pdf $>$.

(2013). Human Development Report 2013-The Rise of the South: Human Progress in a Diverse World. New York: UNDP. < http://hdr.undp.org/en/media/ HDR_2013_EN_complete.pdf>. 
UNESCO. (2012). Education for All Global Monitoring Report 2012: Youth and Skills: Putting Education to Work. Paris, France: UNESCO. <http://unesdoc. unesco.org/images/0021/002180/218003e.pdf>.

UNESCO-IBE. (2010). World Data on Education: Uganda. $7^{\text {th }}$ Edition. <http://www.ibe.unesco.org/ fileadmin/user_upload/Publications/WDE/2010/ pdf-versions/Uganda.pdf>.

UNICEF. (2005). Early Marriage: A Harmful Traditional Practice (Statistical Exploration). New York: UNICEF.

(2011). The State of the World's Children 2011: Adolescence. New York: UNICEF.

(2012). Progress for Children: A Report Card on Adolescents (No. 10). New York: UNICEF. <http:// www.unicef.org/publications/index_62280.html>.

(2013a). The State of the World's Children 2013. New York: UNICEF. <http://www.unicef.org/ sowc2013>

(2013b). "Water, sanitation and hygiene: Water supply." Webpage. New York: UNICEF. <http://www. unicef.org/wash/index_watersecurity.html>.

UNICEF Innocenti. (2010). The Dynamics of Social Change: Toward the Abandonment of Female Genital Mutilation/Cutting in Five African Countries. Florence, Italy: UNICEF Innocenti Research Center. <http://www.childinfo.org/files/fgm_insight_eng. $p d f>$.

UNICEF and Tanzania National Bureau of Statistics. (2009). Tanzania: Study on Child Poverty and Disparities. UNICEF and Tanzania National Bureau of Statistics. <https://sites.google.com/site/tanzaniastudyonchildpoverty/>.

United Nations, Department of Economic and Social Affairs. (2011). World Population Prospects 2010. New York: United Nations Publications.

USAID. (2012). HIV/AIDS Health Profile: Sub-Saharan Africa. USAID. <http://www.usaid.gov/our_work/ global_health/aids/Countries/africa/hiv_summary_ africa.pdf>
Viner, R. M., Coffey, C., Mathers, C., Bloem, et al. (2011). "50-year mortality trends in children and young people: A study of 50 low-income, middle-income, and high-income countries." The Lancet 377(9772): 1162-1174.

Von Struensee, S.V. (2004). "The Domestic Relations Bill in Uganda: Potentially addressing polygamy, bride price, cohabitation, marital rape, widow inheritance, and female genital mutilation." <http://dx.doi.org/ 10.2139/ssrn.623501>.

Weiner, A. (2007). "Assessing the equity in youth programs." Promoting Safe, Healthy and Productive Transitions to Adulthood, Brief No. 28. New York: Population Council.

World Bank. (2013). "World development indicators 2013: GDP per capita, PPP (current international \$)." Webpage. Washington, DC: World Bank. <http:// data.worldbank.org/data-catalog/worlddevelopment-indicators $>$.

(2011). "World development indicators: Prevalence of HIV, total (\% of population ages 15-49)." Webpage. Washington, DC: World Bank. <http:// data.worldbank.org/indicator/SH.DYN.AIDS.ZS.>

World Health Organization (WHO). (2009). Global Health Risks: Mortality and Burden of Disease Attributable to Selected Major Risks. Geneva: WHO. <http://www.who.int/healthinfo/global_burden_ disease/GlobalHealthRisks_report_full.pdf>.

Young Leaders Think Tank. (2011). “Employment policies for Uganda: Young leaders perspectives." Konrad-Adenauer-Stiftung: Kampala. <http://www.kas.de/wf/doc/kas_29797-1522-2-30. pdf?111221152359>

Zambia Gender in Development Division. (2008). "National action plan on gender-based violence." <http://countryoffice.unfpa.org/zambia/drive/ GBV-NAP_2008-2013_FINAL.pdf>. 



\section{(0) APPENDICES}

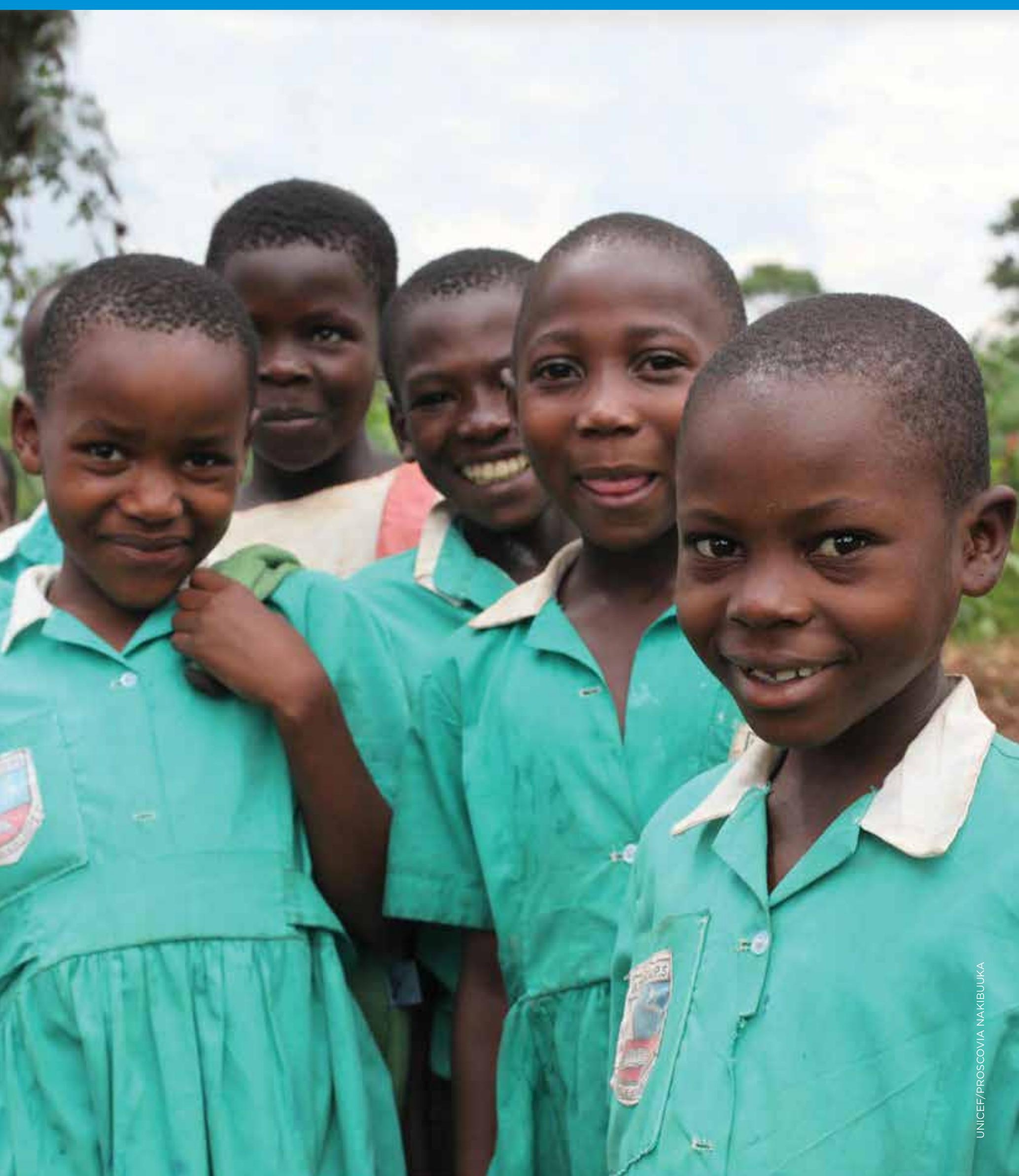




\section{Appendix 1: Participatory assessment}

\begin{abstract}
A participatory assessment was added to the report to validate the indicators included in the index. The aims of the participatory assessment were to consult adolescent girls about the issues most important to them, understand the challenges and risks girls face in their lives, and to validate the index and report findings.
\end{abstract}

\section{Methods}

The Population Council conducted nine discussion sessions with adolescent girls across six regions in Uganda. Based on resource and time constraints, discussion groups were organized through existing youth programs. Both in-school and out-of-school girls were recruited for the groups as well as those who do and do not participate in youth programs. This was done to ensure inclusion of more vulnerable populations rather than only the more accessible and most-served.

Each discussion group consisted of 6-10 girls with a total of 68 girls. All girls were between the ages of 15 and 26 . One group was conducted with younger girls but was not included due to ethical considerations. Groups were organized separately for girls in- and out-of-school when possible but,

\begin{tabular}{|c|c|c|}
\hline \multicolumn{3}{|l|}{ TABLE A1 } \\
\hline \multicolumn{3}{|c|}{$\begin{array}{l}\text { LOCATION, NUMBER AND TYPE OF EACH } \\
\text { DISCUSSION GROUP }\end{array}$} \\
\hline LOCATION & $\begin{array}{r}\text { NUMBER } \\
\text { OF GROUPS }\end{array}$ & TYPE OF GIRLS \\
\hline Jinja & 1 & Mix of in- and out-of-school \\
\hline Mbale & 1 & Mix of in- and out-of-school \\
\hline Mubende & 1 & Mix of in- and out-of-school \\
\hline Fort Portal & 2 & $\begin{array}{l}\text { Mix of in- and out- } \\
\text { of-school (1) } \\
\text { Non-program (1) }\end{array}$ \\
\hline Gulu & 2 & $\begin{array}{l}\text { Mix of in- and out- } \\
\text { of-school (1) } \\
\text { Non-program (1) }\end{array}$ \\
\hline Arua & 2 & $\begin{array}{l}\text { In-school only (1): } \\
\text { Out-of-school only (1) }\end{array}$ \\
\hline
\end{tabular}

due to time constraints, were often mixed. Mixed groups were predominantly comprised of out-ofschool girls. Out-of-school girls appeared to feel comfortable participating and sharing their stories in mixed groups. Each session lasted approximately 60 minutes. Informed consent was collected from all participants. Data was anonymous from the moment of collection. Participants were not paid for involvement in the study, but a collective gift was given to each club.

Researchers conducted the first group in Jinja and then split up, with one researcher traveling to the North and another to the East and West. Two Ugandan facilitators were trained to help moderate each session. Research assistants were recruited through the Community Development Research Network (CDRN). The research assistants served as translators when possible. If the research assistants did not know the local language, the girls club mentor or program assistant was asked to assist.

The groups were organized through the network of BRAC Empowerment and Livelihoods for Adolescents (ELA) clubs. ELA is a large-scale youth program with 1,285 clubs across Uganda reaching 47,000 girls. Together with the BRAC initiative in Karamoja, BRAC programs in Uganda reach more than 50,000 girls. ELA members consist of girls ranging in age from 13 to 21 (sometimes younger) with a mix of experiences in schooling, marital status, and single motherhood. Each club includes approximately 35 members. Clubs are operational from 2:00-6:00 pm everyday except Sunday. Each club is led by an adolescent leader or "mentor" who is selected and trained by BRAC. The mentor conducts trainings in the clubs and empowers girls to share the information with others. The clubs provide safe social spaces for girls to gather and receive information on life skills, financial literacy/ livelihoods, and entrepreneurship; sexual and reproductive health education; and leadership training. Several clubs offer microfinance loans. BRAC recently completed a randomized controlled trial of the life skills component of the clubs.

During the groups, girls were asked to tell stories about the lives of girls in their communities. Researchers instructed participants to "think of a girl's life as a river, running from when she is 10 years old 
all the way up to when she will be 24." Researchers then placed cards on the ground representing ages 10 to $24: 10,12,14$, etc. They asked "What happens along that river? Tell us about the life of girls like you from ages 10 to 24." Although girls were told to tell stories broadly about "girls in their community," most girls told their stories in the first person.

Following each story, issues were identified and written on note cards. Girls then discussed the age at which each issue was common and placed the cards on the ground at that age. Probing or general questions were asked regarding the following, if not mentioned: the perspectives of girls not in the program, HIV, the influence of older women in the community, positive influences, and ways of overcoming challenges.

\begin{abstract}
It all happened when I lost my parents at the age of 12 years. From that time I became the household head, I started taking care of my siblings and it was hard, so I had to enter into a relationship hoping to get some help from my boyfriend. But unfortunately I got pregnant. When my boyfriend heard all about the pregnancy he left me and that was around 14 years old. When I was 16 years old I got another pregnancy, still when the boyfriend knew that I was pregnant he also left me. I am not married yet. So I was only left with no option for my life but to do casual work and that's how I get money for a living. Taking care of the children is difficult. I survive by doing garden work, etc. I use this to feed my family. There is nothing good that has ever happened in my life.
\end{abstract}

-ELA MEMBER, JINJA

\section{Results}

\section{Individual level}

Girls frequently began their stories with an example of a break or instability in the household and family structure, such as a parent's death, divorce, or moving from home to live with a relative. This instability was often the catalyst for multiple subsequent indicators of vulnerability at the individual level. While not an inherently "negative" characteristic, living apart from one or both parents was commonly linked to impacts such as school dropout, entry into work or male-female relationships, pregnancy, and marriage. Girls frequently reported dropping out of school to support themselves, their siblings, or their children-generally at age 10 to 12 when girls are at the primary fifth grade level. Because of household resource shortages correlating with parental absence, girls were often forced to prioritize entry into work over school attendance, whether doing casual work for food, selling small goods, or engaging in risky or exploitative employment.

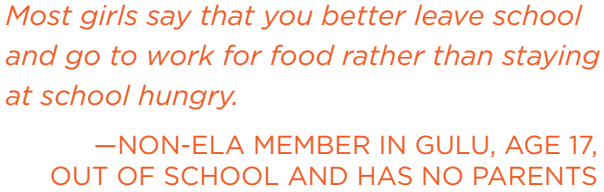

Relationships were often described as an escape mechanism and support strategy ("survival sex"). Girls reported wanting a boyfriend, pregnancy, and marriage for the perceived support the relationship and provider would bring. We overwhelmingly heard of "boyfriends leaving" after pregnancy or girls being mistreated by the husband they had hoped would support them. Some girls included wanted pregnancies in their description of seeking out a relationship to receive monetary, material, and emotional support, while other pregnancies described were unintended consequences of these strategic relationships. HIV was mentioned often in the context of girls engaging in sex with older men for financial support. There seems to be a negatively reinforcing cycle around girls seeking out relationships for survival, suffering negative outcomes such as abuse or neglect, and then looking for another boyfriend, husband, or pregnancy after the preceding relationship's end. Despite encountering the same outcomes again and again, these girls too often do not hold enough social capital to allow them to seek alternatives to risky relationships and childbearing.

Most of the individual-level issues that girls discussed are captured in the index's individual-level indicators. However, there is no indicator available across all DHS and MICS surveys for work, and the indicator for individual experience of violence is not available for all countries included in the index.

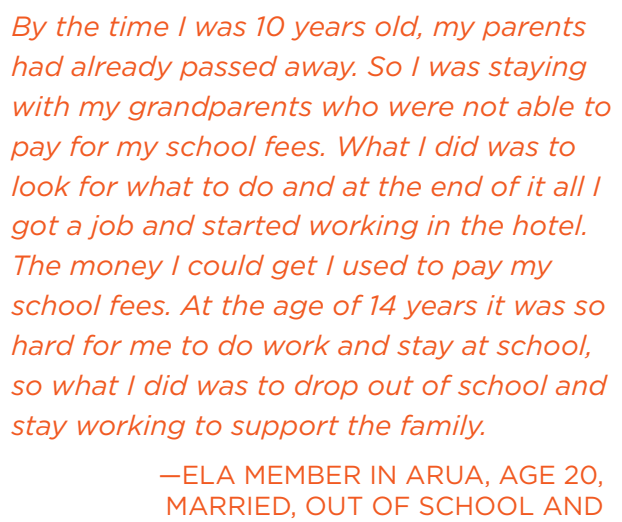

\section{Household level}

At the household level, each girl talked about the importance of support from parents and relatives. For the vast majority, this was in the context of receiving minimal or insufficient support from caretakers and family members. The household was often a primary stressor in girls' stories of their "life journey." Neglect and abuse (both emotional and physical) by immediate family members and 


\section{Age clustering}

As issue cards were placed along the timeline at the age when experiences were common, clustering of issues became apparent. The frequency and age of the top issues is recorded in the table below (Table A2). School dropout was mentioned 35 times out of a total of about 36 stories. Early pregnan$c y$, relationships, marriage and first sex were all mentioned over ten times. The highest frequencies occurred between the ages of 12 to 16 years old. School dropout was mentioned 13 times around the age of 16 .

The graph below depicts the total frequency of all issues within an age group (Figure A1). Issues peak at age 16 and then begin to drop off. Issues arise well in advance of and start to cluster by age 12 .

Figure A2 shows a timeline of three different issues in relation to each other: school dropout, pregnancy and marriage. School dropout and pregnancy both peak around the age of 16 and are likely related to one another. Marriage peaks a little later at the age of 18 .

Based on all of the discussion groups, adolescent girls are the most vulnerable between the ages of 12 and 16 (Figure A3), with issues consolidating in early adolescence. First sex and relationships were most common at the age of 14 . These patterns indicate the need for early intervention as a preventive approach targeting vulnerability by age 12 .

\section{TABLE A2}

\section{FREQUENCY OF THE TOP NINE ISSUES, BY AGE GROUP, ALL GROUPS}

\begin{tabular}{|c|c|c|c|c|c|c|c|c|}
\hline ISSUE & 10 OR YOUNGER & 12 & 14 & 16 & 18 & 20 & 22 & TOTAL \\
\hline School dropout* & 4 & 9 & 8 & 13 & 1 & & & 35 \\
\hline Pregnancy & & 1 & 7 & 10 & 1 & 1 & & 20 \\
\hline Relationship (girl-boy) & & 1 & 10 & 2 & 1 & & & 14 \\
\hline Marriage & & 1 & 2 & 3 & 5 & 1 & & 12 \\
\hline First sex & & 4 & 6 & 1 & & & & 11 \\
\hline Violence or abuse & 3 & 1 & 1 & 4 & & & & 9 \\
\hline No support from parents & 3 & 1 & 1 & 2 & & & & 7 \\
\hline Forced to leave home & & 2 & 1 & 2 & & 2 & & 7 \\
\hline Paid/Casual work & 3 & & & 4 & & & & 7 \\
\hline
\end{tabular}

*School fees was grouped with school dropout.

Source: Author's calculations, based on Uganda participatory assessment.

Note: Values greater than 10 are shown in orange, 7-10 are shown in blue, 4-6 are shown in green.

\section{FIGURE A1}

FREQUENCY OF ALL ISSUES, BY AGE GROUP, ALL GROUPS

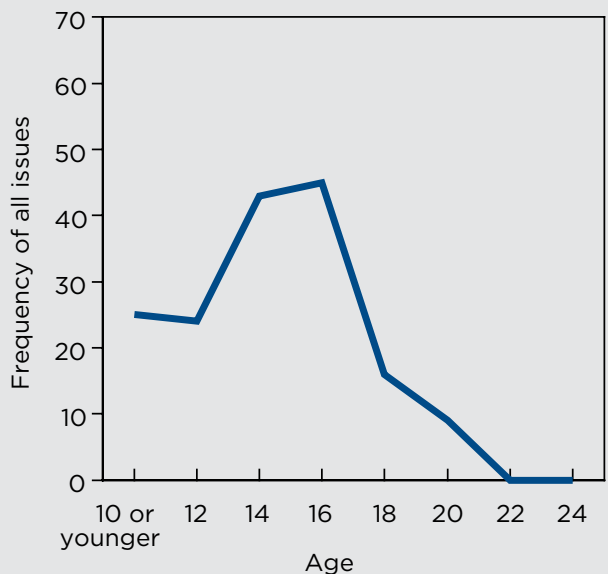

Source: Author's calculations, based on Uganda participatory assessment.

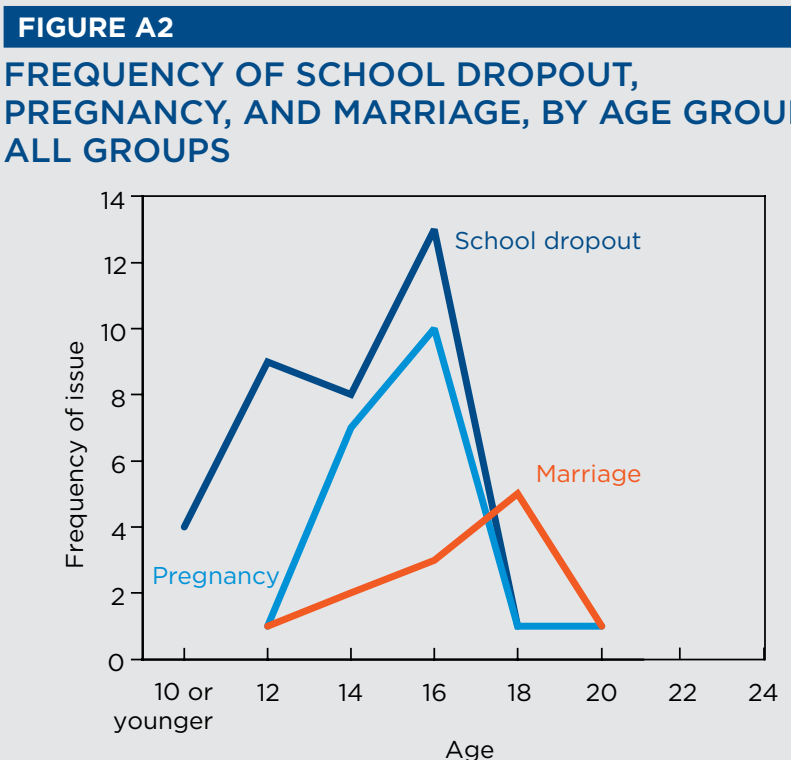

Source: Author's calculations, based on Uganda participatory assessment. 


\section{Group differences}

As previously noted, discussion groups were carried out separately with girls who were participating in the ELA clubs (members) and those who were not (non-members). While logistical constraints limited the ability to speak separately with in-school and out-of-school girls, to the extent possible researchers attempted to speak separately with and draw comparisons between these two subgroups of girls.

There were no substantial differences between the responses given by ELA members and girls not participating in the ELA clubs. However, this is believed to be an artifact of the research design, as ELA non-members were selected to participate in the discussion groups by the coordinator and mentors of the BRAC clubs. Therefore, it is likely that girls selected were those with more social connections and not the most isolated or excluded in the community. This reinforces the importance of considering these findings illustrative rather than representative of the populations involved in the participatory assessment.

In the discussion group with only in-school girls, responses were markedly different than the majority of the discussion groups (that were largely comprised of out-of-school girls given the time of day when the groups were conducted). In-school girls used a different narrative approach to discussing their "life journey"-telling their stories in the third person as opposed to detailing their own experience with vulnerability and risk. Also, girls in the in-school group more often discussed positive parental influences-such as parents encouraging girls to go to school-which was counter to the tone of the discussion of household parental/caretaker dynamics in the largely out-of-school groups.

In discussions on community influence, in-school girls again gave different answers than out-ofschool girls. In-school girls were aware of the vulnerability points and deficits common in their community, but often spoke of negative outcomes happening to other girls as opposed to personal experiences. As one participant stated, "Most girls in our community are not in school so when we come together, talk, get advice from the elder, we go back in our communities and tell their parents to take the children to school because most parents do not support their children with education." Interestingly, the in-school group was the only session during which discussion of the influence of older women in the community was largely reported to be positive. Girls reported that older women provide advice and support for them to stay in school, delay sex until marriage, and protect themselves in relationships. According to one participant, "In our community we normally have youth meetings where older women come to us and give us advice and also encourage us to continue school". This protective dynamic was not reported in the other discussion groups.

\footnotetext{
I am happy because I am still staying with

my parents, they are taking good care of me,

they give me whatever I need, they are not mistreating me and they always encourage me that I should continue with my studies, that I will get married when I am ready to.
}

FREQUENCY OF THE TOP NINE ISSUES BY AGE GROUP, ALL GROUPS

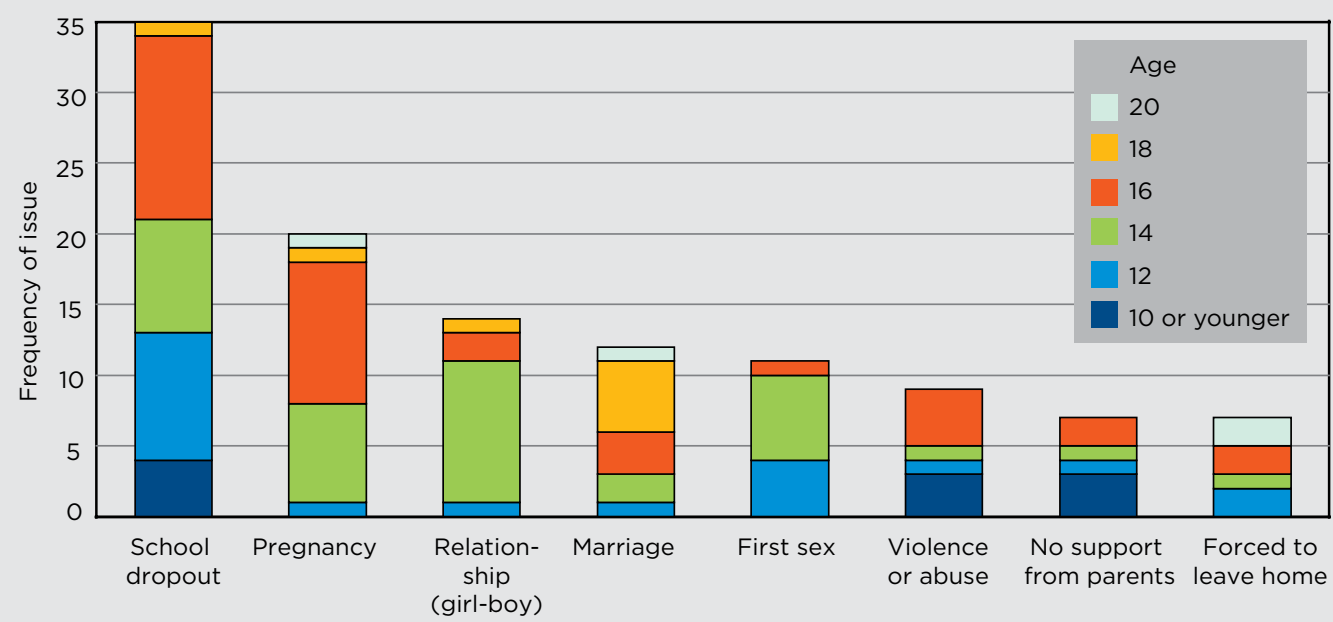

Source: Author's calculations, based on Uganda participatory assessment. 
Lingering effects of conflict were detected in discussion groups in the North. In Gulu, girls reported having lost their parents to rebel fighting and abductions at very young ages ("it happened at 7 years"). One participant indicated that "Most children were abducted at that [young] age because rebels wanted those who would easily listen to their instructions, whom they can easily scare, who will not easily recall their homes in case they escaped."

Most groups discussed prevalence of and risk factors for HIV. However, the level of discussion varied between groups in different regions. In some areas-Mbale, for example-HIV was a common topic of discussion that girls volunteered freely. In others, however, girls spoke about the epidemic only when prompted with probing questions. In all groups, HIV was reported to be a concern in the community and in the girls' lives, but with varying levels of intensity.

\section{Positive influences}

A positive youth development approach can be highly beneficial for policy and programming to improve the lives of adolescent girls around the world. Due to limitations in the data available for index construction, the index takes a deficits approach to conceptualizing vulnerability. However, the research team wanted to explore and draw out the positive aspects of the lives of the girls in discussion groups. Group facilitators asked what participants liked about being a girl; what they liked about their lives, families, and communities; etc.

ELA members often used this time to talk about how much they enjoyed and benefited from participation in the clubs. Girls frequently discussed the protective power of the group environment. They indicated that they liked gathering together and having a place to meet and talk with other girls. They reported increased access to information to be a primary benefit of group membership. Girls in the club are able to obtain important information about sexual and reproductive health, education, etc. ELA members value the advice received from peers and mentors and education received on health and livelihoods. In particular, they value the microfinance component of the program and the information and support the club affords them to help delay pregnancy.

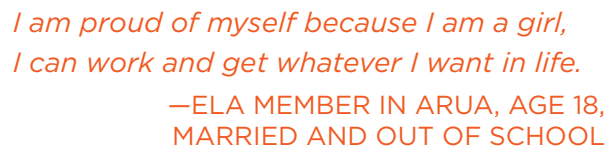

Our community values and respects young girls like us and that make us feel proud. -ELA MEMBER IN MBALE

\author{
BRAC provides us with microfinance loans \\ which enable us to start up our own busi- \\ nesses and this has economically empow- \\ ered us to become independent. \\ -ELA MEMBER IN MBALE
}

\section{Conclusions}

Index conceptualization was validated at the individual and community levels. At the individual level, indicators capture the common themes of living apart from parents, school dropout, marriage, pregnancy, and risky sexual behaviors. However, there is no indicator available across all DHS and MICS surveys for work, and the indicator for individual experience of violence is not available for all countries included in the index. The largest gap at the individual level is the lack of indicators available for girls ages 10 to 14. Age clustering showed that most issues happen between the ages of 14 to 16 and become common as early as 12 . These patterns in early age groups reinforce the need for a preventive approach and the development of indicators that monitor the situation of girls in this age group. There is currently little information across countries about what makes girls vulnerable at these young ages.

At the community level, girls almost universally mentioned the influence of the attitudes and behaviors of older women. Women in the older cohort seem to perpetuate negative attitudes and social norms about allowing girls to build their own protective assets. The participatory assessment validated the importance of the community-level indicators used in the index.

Gaps were identified at the household level. Girls mentioned the importance of support from parents and relatives in almost every story. Girls that had more positive stories also had more support from family members. This finding highlights the importance of developing indicators to measure economic and psychosocial support within the household. 


\section{Appendix II: Suggestions for additional survey topics}

The adolescent girls index project has repeatedly shown that there are wide gaps in DHS and MICS surveys regarding questions that are relevant to adolescent girls across the age spectrum. In order to accurately understand adolescent girls, additional questions or an adolescent module should be added to these surveys. The topics below are based on examples from adolescent surveys or findings from the participatory assessment in Appendix I. The following list should serve as guidance on the types of questions that should be added to current surveys. This list is illustrative, not comprehensive.

\section{Household structure}

- Detailed household relationship coding

\section{Support}

- Number of friends or close personal relationships

- Relationship with first person you would reach out to for help

- Quality of relationship between the adolescent and the mother/father in the household

- Scale of parents' levels of supportiveness

- Advice from mother/father

- Material support from mother/father

- Emotional support from mother/father

- Role models-who are role models, their characteristics, male or female

- Conflicts with mother/father

- Topics discussed with mother/father such as aspirations, goals, personal life, friends, religion, schoolwork

- Ever forced to leave home

- Ever felt pressure to work to support oneself or family

- Moved away from home for employment

- Types of support from older women in the community
- Role models who are older women in the community

- Parents live in or outside of the home

- Frequency of interactions with parents

- Excessive work, chores or responsibilities at home

- Balance of school work and responsibilities at home

\section{Laws and regulations}

- Knowledge of legal age at marriage

- Safe spaces to go in community

\section{Additional reproductive/sexual health topics}

- Age at first date or start of romantic relationship

- Frequency of going out or dating

- Concurrent partnerships

- Age of partner

- Have you been pregnant or had a child

- Financial support from partner

- Single partner or married to father of child 


\section{Appendix III: Forms}

\section{PROGRAM SCAN FORM}

\begin{tabular}{|c|c|c|c|c|c|c|c|c|}
\hline \multicolumn{2}{|c|}{ Level 1 DISTRICT 1} & \multicolumn{2}{|c|}{ Select One } & \multicolumn{3}{|r|}{ Select All } & \multirow[b]{2}{*}{ Contact } & \multirow[b]{2}{*}{ Phone } \\
\hline \# & Program Name & Type & Who & $\begin{array}{l}\text { Min } \\
\text { Age }\end{array}$ & $\begin{array}{l}\text { Max } \\
\text { Age }\end{array}$ & Topic & & \\
\hline 1 & PROGRAM 3 & $G(F) N$ & С B (G) & 12 & 24 & HIV N RH Life LH (SOO & JIM Q. & 07000003 \\
\hline 2 & PROGRAM 4 & $G F(C) N$ & (C) $B$ G & 10 & 12 & HIV $(\mathrm{N} R$ Life LH S O & SUSAN E. & 07000004 \\
\hline 3 & PROGRAM 5 & (G) $\mathrm{FC} \mathrm{N}$ & C B (G) & 15 & 18 & HIV N RH Life LH S O & TIM R. & 07000005 \\
\hline 4 & PROGRAM 6 & $G \quad F \quad C N$ & (C) $B$ G & 10 & 24 & HIV N RH Life LH S O & GREG P. & 07000006 \\
\hline 5 & & $G \quad F \quad N$ & $C B G$ & & & HIV $N$ RH Life LH $S O$ & & \\
\hline 6 & & G F C N & $C B G$ & & & HIV $N$ RH Life LH $S O$ & & \\
\hline 7 & & G F C N & $C B G$ & & & HIV $N$ RH Life LH $S \quad O$ & & \\
\hline 8 & & $G \quad F \quad N$ & $C B G$ & & & HIV $N$ RH Life LH $S \quad O$ & & \\
\hline 9 & & G F C N & $C B G$ & & & HIV $N$ RH Life LH $S \quad O$ & & \\
\hline 10 & & G F C N & $C B \quad G$ & & & HIV $N$ RH Life LH S O & & \\
\hline 11 & & $G F C N$ & $C B G$ & & & HIV $N$ RH Life LH S O & & \\
\hline 12 & & G F C N & $C B G$ & & & HIV N RH Life LH S O & & \\
\hline 13 & & G F C N & $C B G$ & & & HIV $N$ RH Life LH $S \quad O$ & & \\
\hline 14 & & G F C N & $C B G$ & & & HIV N RH Life LH S O & & \\
\hline 15 & & G F C N & $C B G$ & & & HIV $N$ RH Life LH $S \quad O$ & & \\
\hline 16 & & G F C N & $C B G$ & & & HIV $N$ RH Life LH $S \quad O$ & & \\
\hline 17 & & G F C N & $C B \mathrm{~B}$ & & & HIV N RH Life LH S O & & \\
\hline 18 & & G F C N & $C B G$ & & & HIV $N$ RH Life LH $S \quad O$ & & \\
\hline 19 & & G F C N & $C B G$ & & & HIV $N$ RH Life LH $S \quad O$ & & \\
\hline 20 & & G F C N & $C B G$ & & & HIV $N$ RH Life LH $S \quad O$ & & \\
\hline & & $G=G o v ' t$ & $C=$ Co-ed & & & $N=$ Nutrition & & \\
\hline & & $\mathrm{F}=$ Faith & $\mathrm{B}=$ Boys & & & $\mathrm{RH}=$ Reproductive health & & \\
\hline & & $\mathrm{C}=\mathrm{CBO}$ & $\mathrm{G}=$ Girls & & & LH=Livelihoods & & \\
\hline & & $\mathrm{N}=\mathrm{NGO}$ & & & & $\mathrm{S}=$ Sports & & \\
\hline & & & & & & $\mathrm{O}=$ Other & & \\
\hline
\end{tabular}




\section{SUBCOUNTY PROGRAM SURVEY}

\section{Program Name}

Contact Name
How many young people attend this program on a regular basis?

How many of these are boys?

How many of these boys are younger than 10 ?

How many of these boys are 10 to 14 ?

How many of these boys are 15 to 19 ?

How many of these boys are older than 19?

How many of these are girls?

How many of these girls are younger than 10 ?

How many of these girls are 10 to 14 ?

How many of these girls are 15 to 19 ?

How many of these girls are older than 19 ?

How many of the boys/girls are ever married?

How many of the boys/girls are out of school?

How many of the boys/girls have had children?

What is the farthest that any of your regular attendees walks to reach your program (in minutes)?

What types of activities does your program offer? (select all)

$$
\begin{aligned}
& \text { _ HIV/AIDS } \\
& \text { Nutrition } \\
& \text { Reproductive health } \\
& \text { Life skills }
\end{aligned}
$$

Subcounty

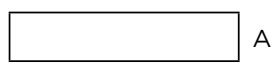

$B+G=A$
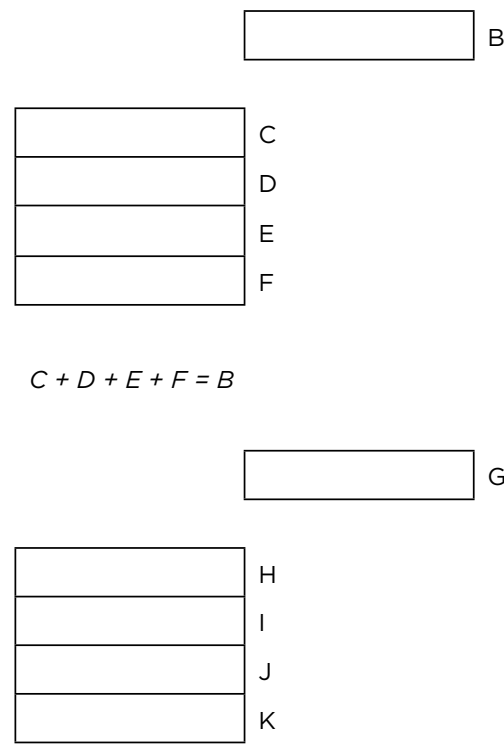

$$
H+I+J+K=G
$$

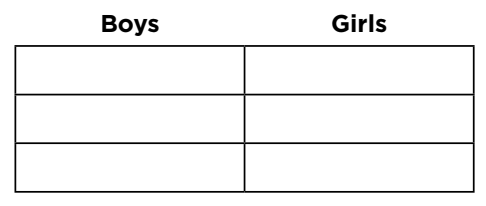

How many older adults assist with the program, including you?

\begin{tabular}{r|l|l|}
\multicolumn{1}{c}{ Men } & \multicolumn{1}{c}{ Women } \\
\cline { 2 - 3 } Older than 30 & & \\
\cline { 2 - 3 } & & \\
\cline { 2 - 3 } & &
\end{tabular}

What type of program is this? Government NGO $\mathrm{CBO}$ Faith-based 


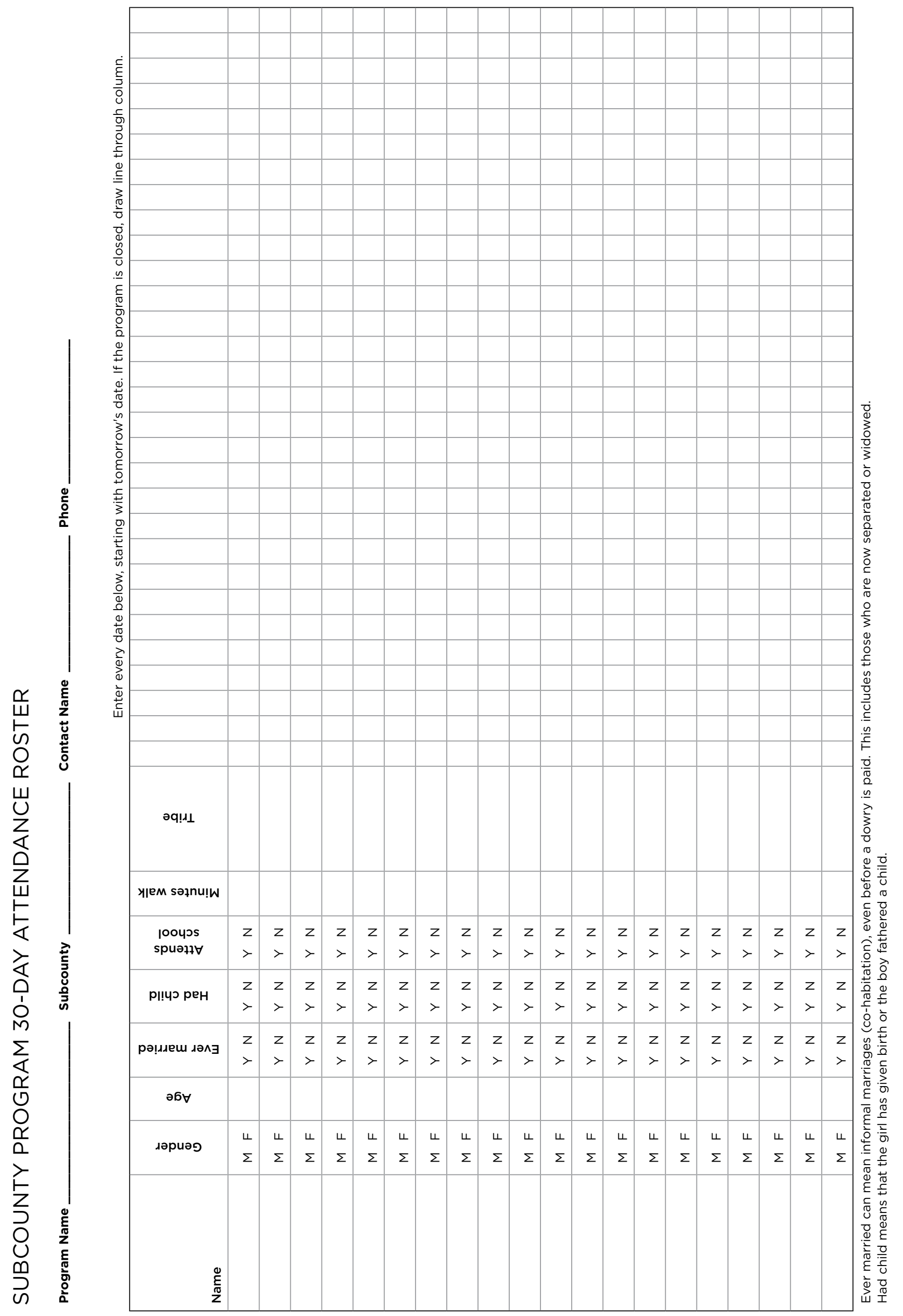




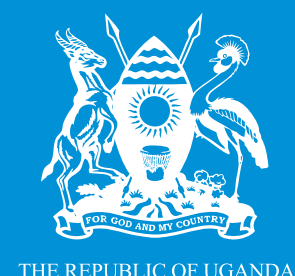

Ministry of Gender, Labour and Social Development

Plot 2, Simbamanyo House

PO Box 7136 George Street

Kampala, Uganda

\section{(1) Population Council}

One Dag Hammarskjold Plaza

New York, NY 10017 USA

www.popcouncil.org

\section{unicef}

UNICEF Uganda

Plot 9, George Street

Kampala, Uganda 